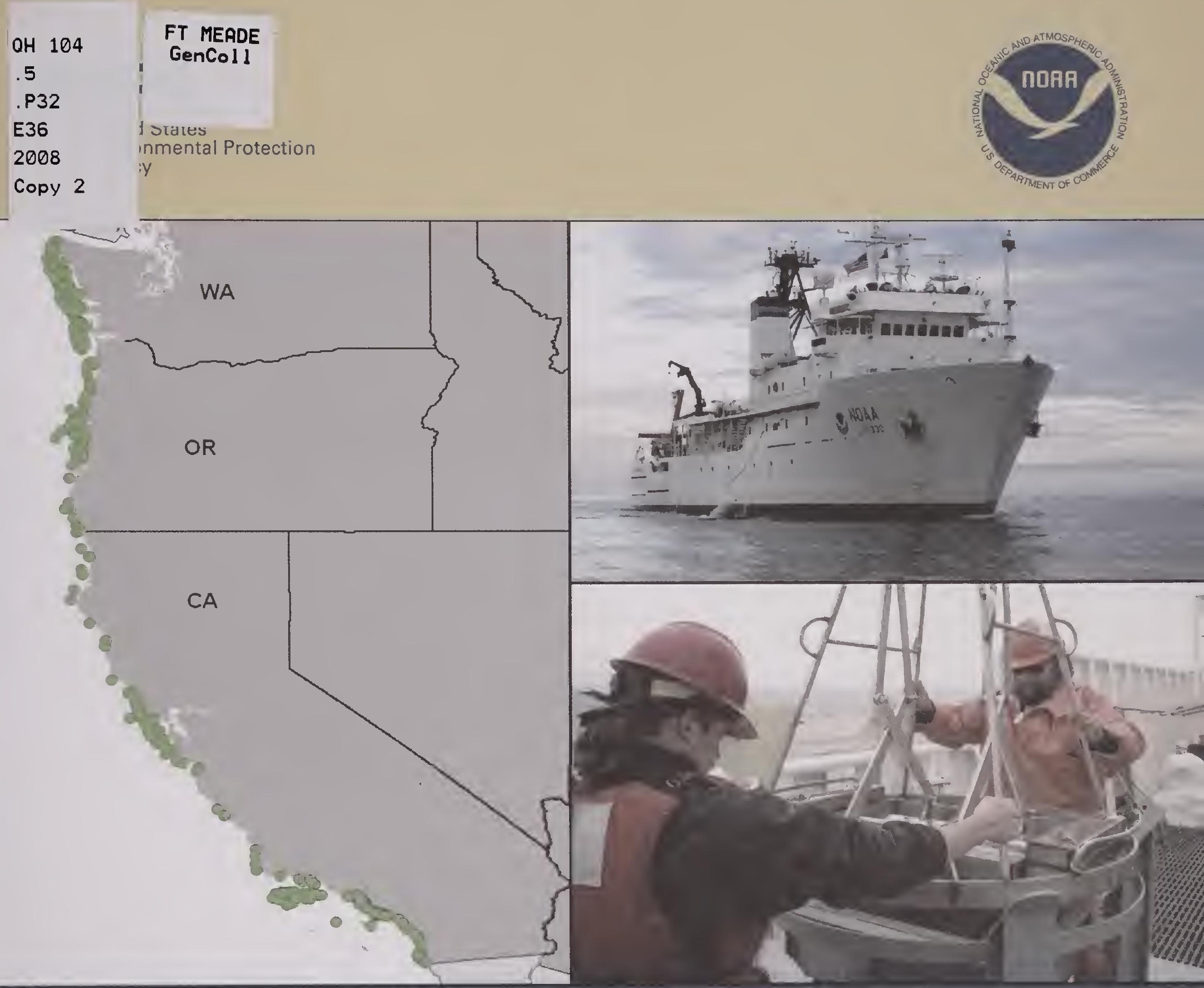

\title{
Ecological Condition of Coastal Ocean Waters along the U.S. Western Continental Shelf: 2003
}


8 


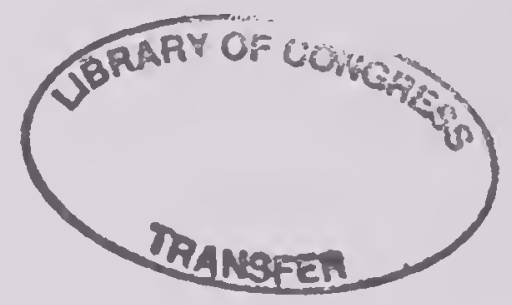

\title{
Ecological Condition of Coastal Ocean Waters along the U.S. Western Continental Shelf: 2003
}

\author{
September 2008
}

\section{Prepared By}

Walter G. Nelson ${ }^{1}$, Jeffrey L. Hyland ${ }^{2}$, Henry Lee $I^{1}$, Cynthia L. Cooksey ${ }^{2}$, Janet O. Lamberson ${ }^{1}$, Faith A. Cole ${ }^{1}$, Patrick J. Clinton ${ }^{1}$

Author Affiliations

${ }^{1}$ Western Ecology Division

National Health and Environmental Effects Research Laboratory

U.S. Environmental Protection Agency

Newport OR 97365

${ }^{2}$ Center for Coastal Environmental Health and Biomolecular Research

National Oceanic and Atmospheric Administration

219 Fort Johnson Road

Charleston, South Carolina 29412-9110 


\section{Preface}

This document provides an assessment of the status of ecological condition in coastal-ocean waters along the U.S. continental shelf, from the Strait of Juan de Fuca, WA to the Mexican border, based on sampling conducted in June 2003. The project was a large collaborative effort by the U.S. Environmental Protection Agency (EPA), the National Oceanic and Atmospheric Administration (NOAA), and West Coast States. It also represents one of a series of assessments conducted under the Western regional component of EPA's National Coastal Assessment (NCA-West). The NCA is the coastal component of the nationwide Environmental Monitoring and Assessment Program (EMAP). The NCA-West program is administered through the EPA and implemented through partnerships with a variety of federal and state agencies, universities, and the private sector. The 2003 west-coast shelf assessment involved the participation and collaboration of EPA, NOAA, Washington Department of Ecology, Oregon Department of Environmental Quality, and the Southern California Coastal Water Research Project (SCCWRP), with additional contributions from personnel of Alaska Department of Environmental Conservation, and Moss Landing Marine Laboratories.

\section{The appropriate citation for this report is:}

W.G. Nelson, J.L. Hyland, H. Lee II, C.L. Cooksey, J.O. Lamberson, F.A. Cole, and P.J. Clinton. 2008. Ecological Condition of Coastal Ocean Waters along the U.S. Western Continental Shelf: 2003. EPA 620/R-08/001, U.S. EPA, Office of Research and Development, National Health and Environmental Effects Research Laboratory, Western Ecology Division, Newport OR, 97365; and NOAA Technical Memorandum NOS NCCOS 79, NOAA National Ocean Service, Charleston, SC 29412-9110. 137 p.

\section{Disclaimer}

This document has been subjected to review by the National Health and Environmental Effects Research Laboratory of EPA and the National Ocean Service of NOAA and approved for publication. Approval does not signify that the contents reflect the official views of these agencies, nor does mention of trade names or commercial products constitute endorsement or recommendation for use. 


\section{Acknowledgments}

The information in this document has been funded wholly or in part by EPA under Cooperative Agreements with the State of Washington Department of Ecology (CR 827869 ), Oregon Department of Environmental Quality (CR 87840 ), and SCCWRP (CR 827870 ) and an Inter-Agency Agreement with the National Marine Fisheries Service (DW 13938780). Additionally, cooperative efforts with the NOAA National Ocean Service were conducted under a General Collaborative Agreement (NOS \#MOA2005-003/6764, EPA \#PW139221956-01-0).

This study involved the participation of numerous representatives from a variety of federal, state, local, academic, and private institutions. Many individuals within EPA made important contributions to the study. Critical guidance and vision in establishing the overall NCA-West program was provided by Kevin Summers of Gulf Ecology Division. Tony Olsen of Western Ecology Division (WED), with technical support from staff of Computer Science Corporation, provided the sampling designs utilized for various aspects of the study. Lorraine Edmond of Region 10 and Terrence Fleming of the Region 9 Offices of EPA ably served as the regional liaisons with the state participants. Robert Ozretich of WED performed a detailed review of the database contents used for this analysis, and we additionally thank him for his extensive quality assurance review of this document.

A major portion of the study area was sampled from the NOAA ship MCARTHUR II on Cruise AR-03-01-NC, which consisted of three legs encompassing the period from June 1-26, 2003. All members of the three field crews (see list below) are commended for their high level of technical expertise, teamwork and dedication to getting the required sampling completed. In particular, the dedication of the Chief Scientists for each of the three legs is greatly appreciated. These were Sarah Wilson formerly with Washington Department of Ecology (Leg 1), Larry Caton with Oregon Department of Environmental Quality (Leg 2), and Rusty Fairey with Moss Landing Marine Laboratories (Leg 3). Special appreciation also is extended to the officers and crew of the NOAA ship McARTHUR II for the superb job performed.

Sarah Wilson also was especially helpful in obtaining published and unpublished data on the location of cable crossings, hard bottom areas, and other hazards to the safe and successful conduct of field sampling. Dr. Chris Goldfinger of Oregon State University and Dr. Gary Greene of Moss Landing Marine Laboratories kindly supplied unpublished bottom type data that was of assistance in preparation of the maps for determining sample locations.

Personnel of the Fisheries Resource Analysis and Monitoring (FRAM) Division of the Northwest Fisheries Science Center (NWFSC) of NOAA collected fish specimens as part of their western ground-fish surveys at stations that coincided with the NCA-WEST sampling area. These specimens supplemented the pool of samples available for tissue-contaminant analysis performed subsequently by EPA and state partners. 
Appreciation is extended particularly to the following NWFSC individuals for their assistance: Tonya Ramsey, Dan Kamikawa, Erica Fruh, Eric Eisenhardt, Keith Bosley, Victor Simon, Chad Keith, Chante Davis, Keri York, Josie Thompson, Jennifer Gilden, Jennie Flammang, Stacey Miller, lan Stewart, Vanessa Tuttle, Jim Benante, Roger Clark, John Harms, Beth Horness, Lisa Lysak, Jennifer Menkel.

Data coverage throughout the Southern California Bight portion of the study area (Pt. Conception, CA to the Mexican border) was made possible through coordination with a companion assessment conducted by SCCWRP during the same general timeframe using similar methods and indicators. Dr. Steven Weisberg, Director of SCCWRP, was the principal liaison for coordination with the Bight '03 study. Additional assistance with coordination of sampling and data submission was provided by Ken Schiff, Larry Cooper, and Shelly Moore of SCCWRP.

Editorial assistance with the document was provided by Jimmie Cheney and Karen Ebert. The report cover was produced with the assistance of Brian Garges of the Graphics Department of the National Health and Environmental Effects Research Laboratory (NHEERL). Technical reviews of this report were provided by Steven Gittings and Len Balthis with NOAA and by Valerie Partridge with Washington Department of Ecology. 
The members of the scientific crews for the EMAP 2003 survey of ecological conditions of the western U.S. continental shelf are listed below and their contributions to this study are gratefully acknowledged. An * indicates the Chief Scientist on the particular cruise leg.

\begin{tabular}{|c|c|c|}
\hline Cruise Leg & Name & Affiliation \\
\hline \multirow[t]{14}{*}{ Leg 1 - Washington } & \multicolumn{2}{|c|}{ June 1 - June 7, 2003} \\
\hline & Sarah Wilson* & WA Dept. of Ecology \\
\hline & Julia Bos & WA Dept. of Ecology \\
\hline & Ed Bowlby & Olympic Coast National Marine Sanctuary \\
\hline & Jon Buzitis & NOAA/National Marine Fisheries Service \\
\hline & Larry Caton & OR Dept. of Environmental Quality \\
\hline & Ken Dzinbal & WA Dept. of Ecology \\
\hline & Steve Hale & Environmental Protection Agency \\
\hline & Shera Hickman & AK Dept. of Environmental Conservation \\
\hline & Jeff Hyland & NOAA/National Ocean Service \\
\hline & Noel Larson & WA Dept. of Ecology \\
\hline & Valerie Partridge & WA Dept. of Ecology \\
\hline & Dave Terpening & Environmental Protection Agency \\
\hline & Doc Thompson & Environmental Protection Agency \\
\hline \multirow{13}{*}{ Leg 2 - Oregon } & \multicolumn{2}{|c|}{ June 8 - June 15,2003} \\
\hline & Larry Caton ${ }^{\star}$ & OR Dept. of Environmental Quality \\
\hline & Aaron Borisenko & OR Dept. of Environmental Quality \\
\hline & Greg Coffeen & OR Dept. of Environmental Quality \\
\hline & Cindy Cooksey & NOAA/National Ocean Service \\
\hline & Rusty Fairey & Moss Landing Marine Lab \\
\hline & Won Kim & OR Dept. of Environmental Quality \\
\hline & Peter Leinenbach & Environmental Protection Agency \\
\hline & Greg McMurray & OR Dept. of Environmental Quality \\
\hline & Sarah Miller & OR Dept. of Environmental Quality \\
\hline & Greg Pettit & OR Dept. of Environmental Quality \\
\hline & Steve Rumrill & South Slough Estuarine Reserve \\
\hline & Andy Schaedel & OR Dept. of Environmental Quality \\
\hline \multirow[t]{12}{*}{ Leg 3 - California } & \multicolumn{2}{|c|}{ June 18 - June 26, 2003} \\
\hline & Rusty Fairey* & Moss Landing Marine Lab \\
\hline & JD Dubick & NOAA/National Ocean Service \\
\hline & Lorraine Edmond & Environmental Protection Agency \\
\hline & Laura Gabanski & Environmental Protection Agency \\
\hline & Matt Huber & Moss Landing Marine Lab \\
\hline & Tom Kimball & Moss Landing Marine Lab \\
\hline & Sara Lowe & San Francisco Estuary Institute \\
\hline & Mark Pranger & Moss Landing Marine Lab \\
\hline & Bruce Thompson & San Francisco Estuary Institute \\
\hline & Tamara Vos & Moss Landing Marine Lab \\
\hline & Susan Wainwright & NOAA Teacher at Sea Program (vo \\
\hline
\end{tabular}





\section{Table of Contents}

Preface ii

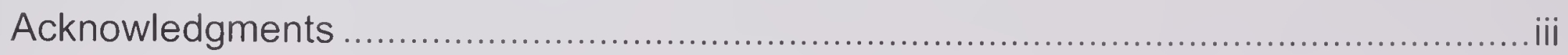

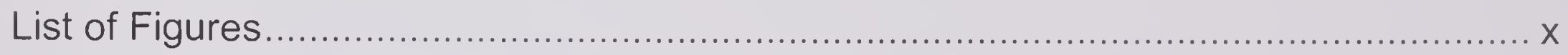

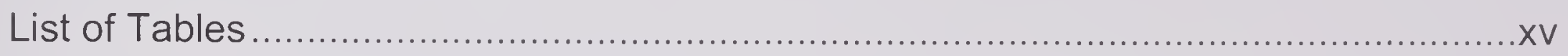

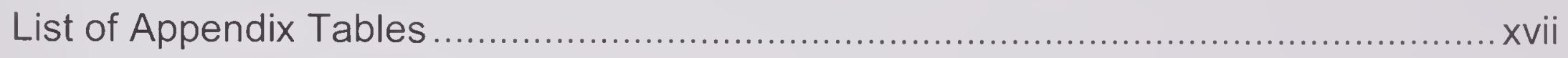

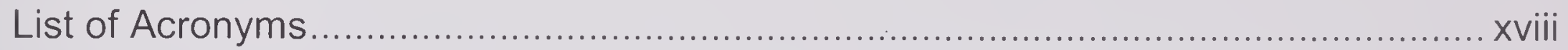

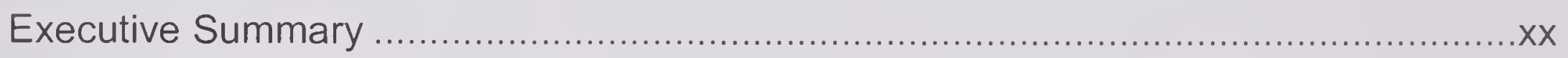

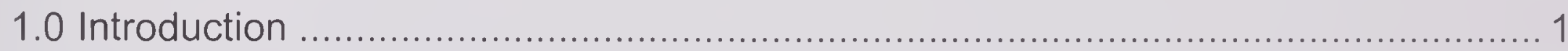

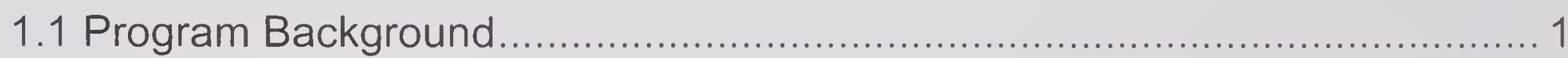

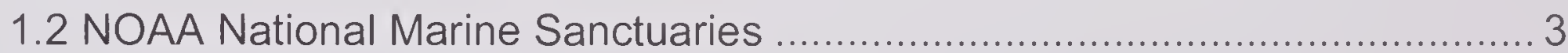

1.3 Southern California Bight 2003 Regional Monitoring Program .................... 4

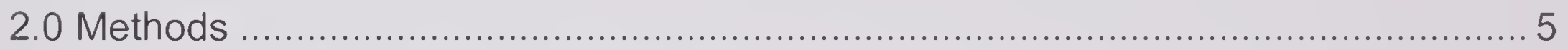

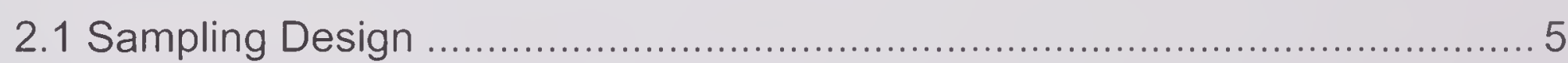

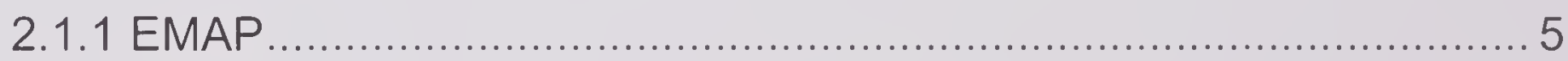

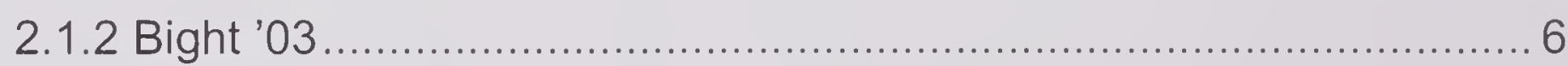

2.1.3 FRAM Groundfish Survey ...................................................... 7

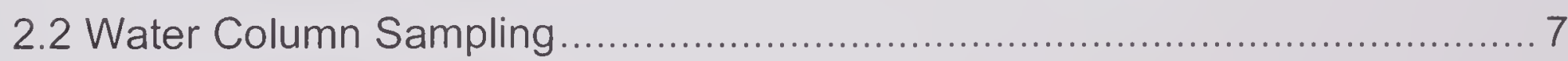

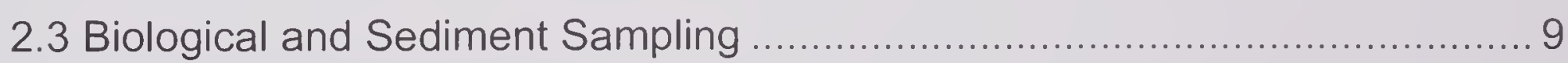

2.3.1 Sediment Pollutant and Nutrient Analysis ................................... 9

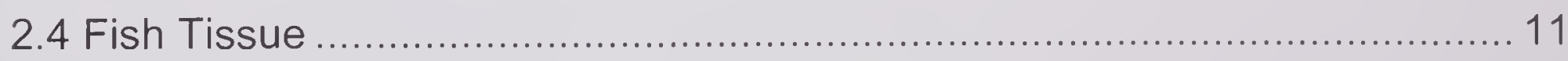

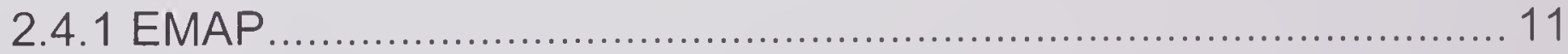

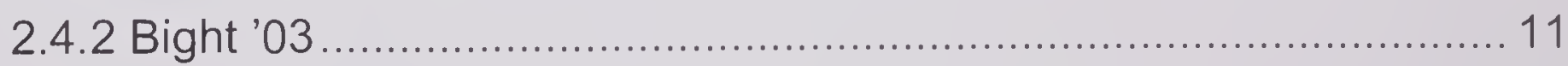


2.4.3 FRAM Groundfish Survey ................................................. 12

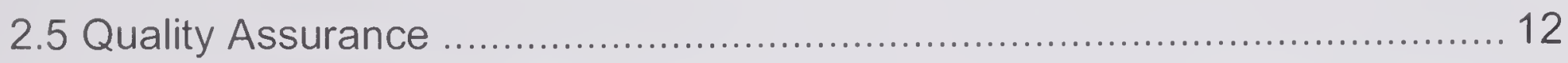

2.5.1 Quality Assurance/ Quality Control of Chemical Analyses............ 12

2.5.2 Metals in Sediments............................................................. 13

2.5.3 Organics in Sediments ......................................................... 14

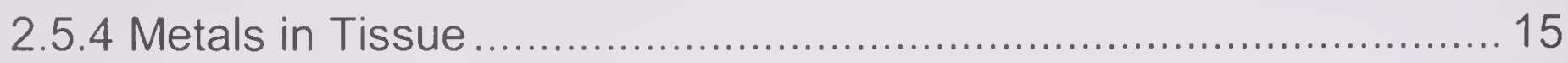

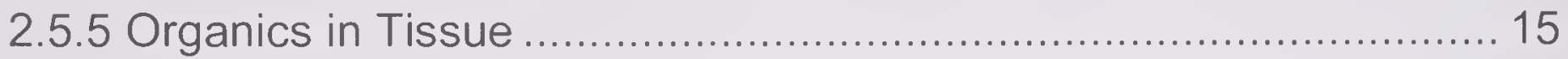

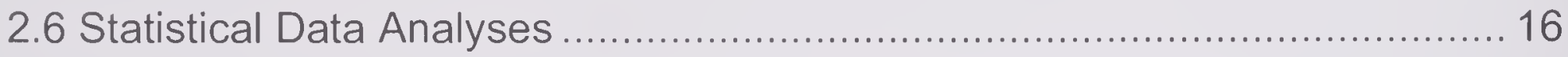

2.7 Sampling, Data Integration and Data Quality Issues ............................. 17

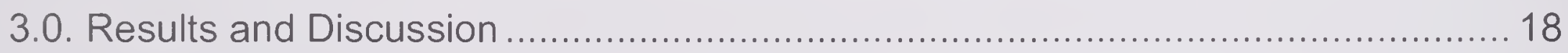

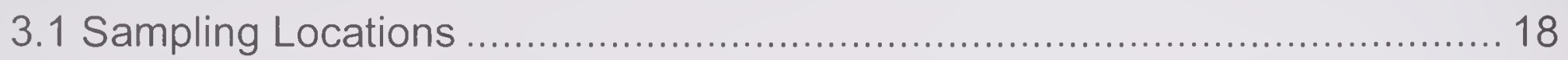

3.2 Water Column Characteristics ............................................................ 30

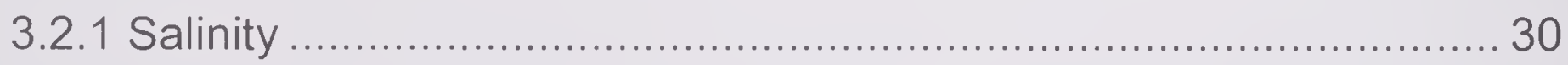

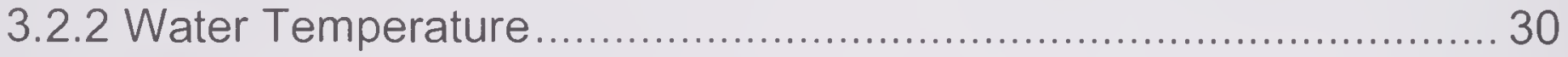

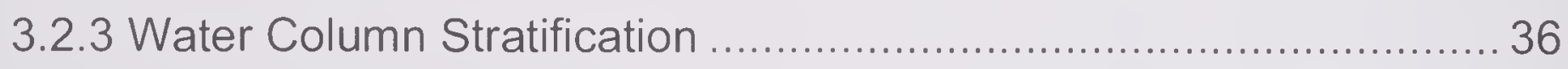

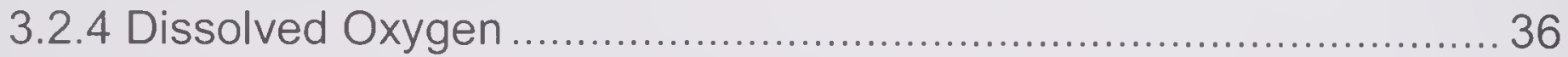

3.2.5 Total Suspended Solids ........................................................ 42

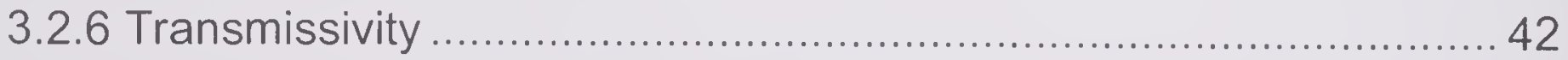

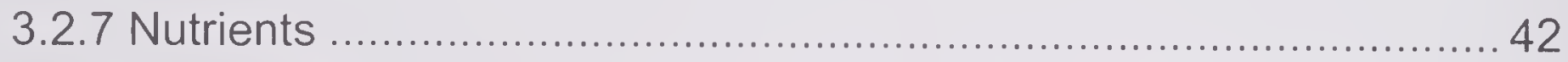

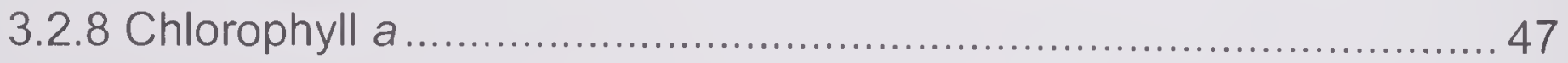

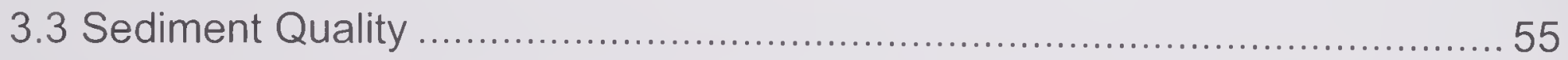

3.3.1 Sediment Composition: Grain Size and TOC ............................. 55 
3.3.2 Sediment Contaminants: Metals and Organics 62

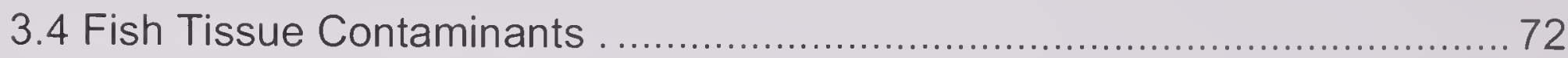

3.4.1 EMAP/NCA-West Survey ........................................................ 72

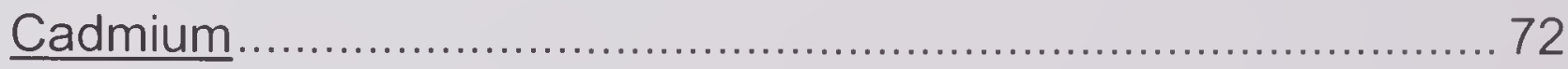

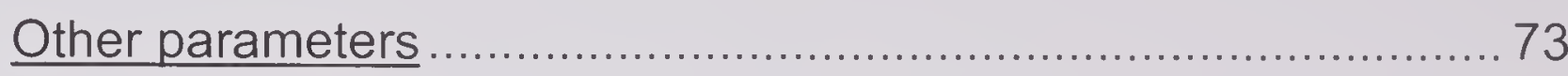

3.4.2 FRAM Groundfish Survey ................................................... 77

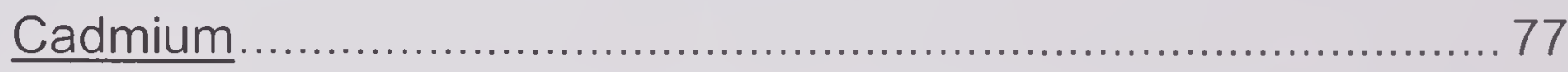

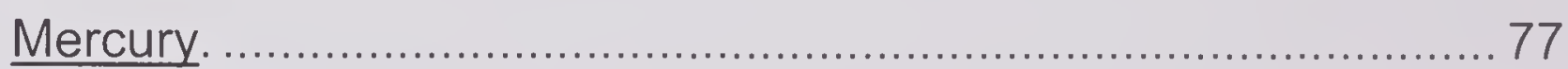

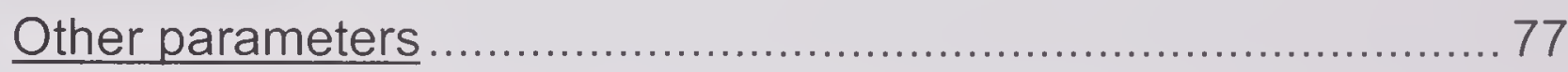

3.5 Status of Benthic Communities............................................................. 79

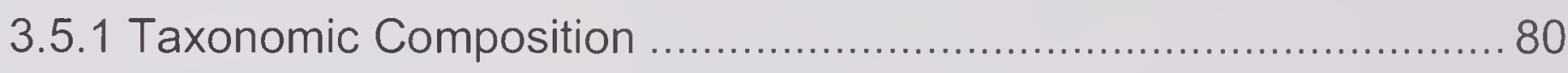

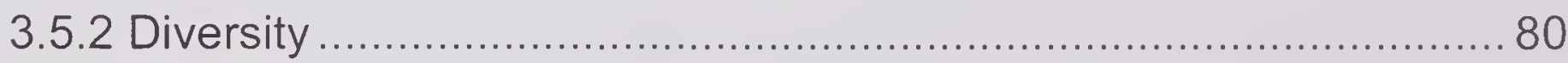

3.5.3 Abundance and Dominant Taxa ............................................... 94

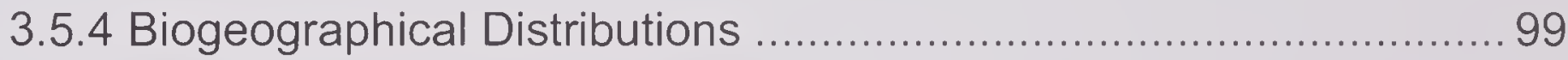

3.5.5 Nonindigenous Species ....................................................... 106

3.5.6 Potential Linkage to Stressor Impacts.................................... 107

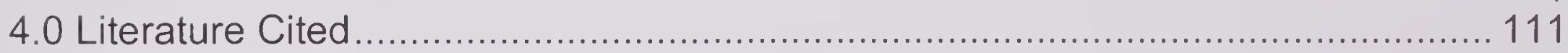

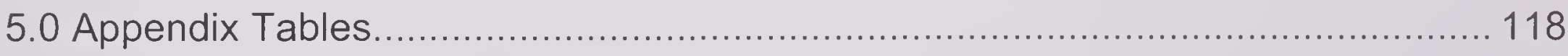




\section{List of Figures}

Figure 2.2.1. CTD and Niskin bottle rosette sampler on the deck of the NOAA Ship MCARTHUR II.

Figure 2.3.1. Close up view of double Van Veen grab sampler used for bottom sampling.

Figure 2.4.1. Hook-and-line fishing for fish tissue sampling aboard the NOAA Ship MCARTHUR II.

Figure 3.1.1. Distribution of sampling stations for the NCA 2003 West Coast Shelf Assessment.

Figure 3.1.2. Distribution of sampling stations for the NCA 2003 West Coast Shelf Assessment along the continental shelf of Washington.

Figure 3.1.3. Distribution of sampling stations for the NCA 2003 West Coast Shelf Assessment along the continental shelf of Oregon.

Figure 3.1.4. Distribution of sampling stations for the NCA 2003 West Coast Shelf Assessment along the continental shelf of California north of Pt. Conception.

Figure 3.1.5. Distribution of sampling stations for the NCA 2003 West Coast Shelf Assessment along the continental shelf of California south of Pt. Conception within the Southern California Bight.

Figure 3.1.6. Distribution of sampling stations for the 2003 FRAM Groundfish Survey from which fish tissue samples were collected for analysis by NCA.

Figure 3.1.7. Distribution of sampling stations for the 2003 FRAM Groundfish Survey along the continental shelf of Washington, from which fish tissue samples were collected for analysis by NCA.

Figure 3.1.8. Distribution of sampling stations for the 2003 FRAM Groundfish Survey along the continental shelf of Oregon, from which fish tissue samples were collected for analysis by NCA.

Figure 3.1.9. Distribution of sampling stations for the 2003 FRAM Groundfish Survey along the continental shelf of northern California, from which fish tissue samples were collected for analysis by NCA. 
Figure 3.1.10. Percent area (and $95 \% \mathrm{Cl}$ ) of West Coast Shelf sampling area vs. depth.

Figure 3.2.1. Distribution of surface salinity values for the West Coast Shelf sampling area, June 2003.

Figure 3.2.2. Mean +1 SD surface salinity compared among (A) all, California, Oregon and Washington sample locations, and (B) California NMS, California non-NMS, Olympic Coast NMS, and Washington-Oregon non-NMS sample locations.

Figure 3.2.3. Mean +1 SD bottom salinity compared among (A) all, California, Oregon and Washington sample locations, and (B) California NMS, California non-NMS, Olympic Coast NMS, and Washington-Oregon non-NMS sample locations.

Figure 3.2.4. Mean +1 SD surface temperature compared among (A) all, California, Oregon and Washington sample locations, and (B) California NMS, California non-NMS, Olympic Coast NMS, and Washington-Oregon non-NMS sample locations. . .............. 34

Figure 3.2.5. Mean +1 SD bottom temperature compared among (A) all, California, Oregon and Washington sample locations, and (B) California NMS, California non-NMS, Olympic Coast NMS, and Washington-Oregon non-NMS sample locations. ...

Figure 3.2.6. Mean $+1 \mathrm{SD}$ water column stratification index $\left(\Delta \sigma_{t}\right)$ compared among $(\mathrm{A})$ all, California, Oregon and Washington sample locations, and (B) California NMS, California non-NMS, Olympic Coast NMS, and Washington-Oregon non-NMS sample locations.

Figure 3.2.7. Bakun upwelling index for $36^{\circ} \mathrm{N}$ latitude for the West Coast in June 2003.

Figure 3.2.8. Mean +1 SD surface dissolved oxygen compared among (A) all, California, Oregon and Washington sample locations, and (B) California NMS, California non-NMS, Olympic Coast NMS, and Washington-Oregon non-NMS sample locations. .

Figure 3.2.9. Distribution of bottom dissolved oxygen concentration values for the West Coast Shelf sampling area, June 2003.

Figure 3.2.10. Mean +1 SD bottom dissolved oxygen compared among (A) all, California, Oregon and Washington sample locations, and (B) California NMS, California non-NMS, Olympic Coast NMS, and Washington-Oregon non-NMS sample locations. . 
Figure 3.2.11. Mean +1 SD surface Total Suspended Solids compared among (A) all, California, and Washington sample locations, and (B) California NMS, California nonNMS, Olympic Coast NMS, and Washington non-NMS sample locations.

Figure 3.2.12. Mean $+1 \mathrm{SD}$ surface transmissivity compared among (A) all, California, Oregon and Washington sample locations, and (B) California NMS, California non-NMS, Olympic Coast NMS, and Washington-Oregon non-NMS sample locations. 44

Figure 3.2.13. Mean +1 SD bottom transmissivity compared among (A) all, California, Oregon and Washington sample locations, and (B) California NMS, California non-NMS, Olympic Coast NMS, and Washington-Oregon non-NMS sample locations. 45

Figure 3.2.14. Mean $+1 \mathrm{SD}$ surface nitrate + nitrite compared among (A) all, California, Oregon and Washington sample locations, and (B) California NMS, California non-NMS, Olympic Coast NMS, and Washington-Oregon non-NMS sample locations.

Figure 3.2.15. Mean +1 SD surface ammonium compared among (A) all, California, Oregon and Washington sample locations, and (B) California NMS, California non-NMS, Olympic Coast NMS, and Washington-Oregon non-NMS sample locations.

Figure 3.2.16. Mean $+1 \mathrm{SD}$ surface dissolved inorganic nitrogen compared among (A) all, California, Oregon and Washington sample locations, and (B) California NMS, California non-NMS, Olympic Coast NMS, and Washington-Oregon non-NMS sample locations.

Figure 3.2.17. Mean +1 SD surface orthophosphate compared among (A) all, California, Oregon and Washington sample locations, and (B) California NMS, California non-NMS, Olympic Coast NMS, and Washington-Oregon non-NMS sample locations. .

Figure 3.2.18. Mean +1 SD N/P ratio in surface waters compared among $(A)$ all, California, Oregon and Washington sample locations, and (B) California NMS, California non-NMS, Olympic Coast NMS, and Washington-Oregon non-NMS sample locations. .

Figure 3.2.19. Mean $+1 \mathrm{SD}$ surface silicate concentration compared among (A) all, California, Oregon and Washington sample locations, and (B) California NMS, California non-NMS, Olympic Coast NMS, and Washington-Oregon non-NMS sample locations. .

Figure 3.2.20. Mean +1 SD surface chlorophyll a concentration compared among (A) all, California, Oregon and Washington sample locations, and (B) California NMS, California non-NMS, Olympic Coast NMS, and Washington-Oregon non-NMS sample locations. 
Figure 3.3.1. Percent area (and 95\% confidence interval) of overall West Coast Shelf sampling area vs. sediment percent fines (silt/clay).

Figure 3.3.2. Comparison of sediment percent silt/clay (mean + 1 SD) by (A) West Coast vs. individual states and (B) National Marine Sanctuary (NMS) vs. non-NMS stations.

Figure 3.3.4. Comparison of sediment percent Total Organic Carbon (TOC, mean +1 SD) by (A) West Coast vs. individual states and (B) National Marine Sanctuary (NMS) vs. non-NMS stations.

Figure 3.3.5. Comparison of the spatial extent of sediment contamination by (A) West Coast vs. individual states and (B) National Marine Sanctuary (NMS) vs. non-NMS stations.

Figure 3.3.6. Distribution of Total DDT concentrations in sediments along the SCB relative to $\mathrm{ERL}$ and $\mathrm{ERM}$ guidelines.

Figure 3.3.7. Distribution of 4,4'-DDE concentrations in sediments along the SCB relative to $E R L$ and $E R M$ guidelines.

Figure 3.3.8. Distribution of mercury concentrations in sediments along the continental shelf of California relative to ERL and ERM guidelines.

Figure 3.3.9. Distribution of 2-methylnaphthalene concentrations in sediments along the SCB relative to ERL and ERM guidelines. 70

Figure 3.3.10. Distribution of chromium concentrations in sediments along the western U.S. continental shelf relative to ERL and ERM guidelines.

Figure 3.4.1. Tissue vs. sediment concentration of cadmium at corresponding stations from the EMAP/NCA-West 2003 shelf survey including samples from Washington, Oregon and California.

Figure 3.5.1. Comparison of percent faunal composition by abundance among (A) all, California, Oregon, and Washington sample locations, and (B) California NMS, California non-NMS, Olympic Coast NMS, and Washington-Oregon non-NMS sample locations

Figure 3.5.2. Comparison of percent faunal composition by taxa among (A) all, California, Oregon, and Washington sample locations, and (B) California NMS, California non-NMS, Olympic Coast NMS, and Washington-Oregon non-NMS sample locations. 
Figure 3.5.3. Comparison of benthic species richness (mean $+1 \mathrm{SD}$ ) among (A) all, California, Oregon, and Washington sample locations, and (B) California NMS, California non-NMS, Olympic Coast NMS, and Washington-Oregon non-NMS sample locations.

Figure 3.5.4. Percent area (and 95\% confidence interval) of overall West Coast Shelf sampling area vs. benthic species richness (\# taxa/0.1- $\mathrm{m}^{-2} \mathrm{grab}$ ).

Figure 3.5.5. Map illustrating the distribution of benthic species richness (\# taxa per $0.1-\mathrm{m}^{2} \mathrm{grab}$ ) throughout the West Coast region.

Figure 3.5.6. Comparison of benthic species diversity $\left(H^{\prime}\right.$, mean $\left.+1 S D\right)$ among (A) all, California, Oregon, and Washington sample locations, and (B) California NMS, California non-NMS, Olympic Coast NMS, and Washington-Oregon non-NMS sample locations.

Figure 3.5.7. Percent area (and 95\% confidence interval) of overall West Coast Shelf sampling area vs. Shannon-Wiener $\left(\mathrm{H}^{\prime}\right)$ diversity index.

Figure 3.5.8. Comparison of benthic density (mean $+1 \mathrm{SD}$ ) among (A) all, California, Oregon, and Washington sample locations, and (B) California NMS, California nonNMS, Olympic Coast NMS, and Washington-Oregon non-NMS sample locations.

Figure 3.5.9. Percent area (and 95\% confidence interval) of overall West Coast Shelf sampling area vs. benthic abundance (number of individuals $/ \mathrm{m}^{2}$ ).

Figure 3.5.10. Marine ecoregions bordering the Pacific Coast of the United States from Southern California through the Aleutian Islands. 104

Figure 3.5.11. Latitudinal pattern of abundance of the polychaete Magelona longicornis. 105

Figure 3.5.12. Latitudinal pattern of abundance of the bivalve Axinopsida serricata. 105 Figure 3.5.13. Latitudinal pattern of abundance of the ophiuroid Amphiodia urtica. .. 106 Figure 3.5.14. Latitudinal pattern of abundance of the decapod Pinnixa occidentalis. . 


\section{List of Tables}

Table 2.2.1. Equipment used for hydrographic profile measurements.

Table 2.3.1. Compounds analyzed in sediments and fish tissues in the West Coast Shelf Assessment.

Table 3.3.1. Comparison of sediment physical characteristics and chemical contaminant concentrations for (A) West Coast vs. individual states and (B) National Marine Sanctuaries (NMS) vs. non-NMS.

Table 3.3.2. ERM and ERL guidance values in sediments (Long et al. 1995).....

Table 3.3.3. Comparison of the \% area of sediments with chemical contaminants in excess of corresponding ERL and ERM sediment quality guidelines.

Table 3.3.4 Comparison of the number of stations with chemical contaminants in excess of corresponding ERL and ERM sediment quality guideline values. ........................6 66

Table 3.4.1. Risk-based EPA advisory guidelines for recreational fishers. 74

Table 3.4.2. Comparison by state of the concentrations of metals $(\mu \mathrm{g} / \mathrm{g}$ wet weight) and organic compounds ( $\mathrm{ng} / \mathrm{g}$ wet weight) measured in fish tissue composites from fish collected in the 2003 EMAP/NCA-West).

Table 3.4.3. Comparison by NMS vs. non-sanctuary status of the concentrations of metals ( $\mu \mathrm{g} / \mathrm{g}$ wet weight) and organic compounds (ng/g wet weight) measured in fishtissue composites from fish collected in the 2003 EMAP/NCA-West survey).

Table 3.4.4. Concentrations of metals ( $\mu \mathrm{g} / \mathrm{g}$ wet weight) and organic compounds $(\mathrm{ng} / \mathrm{g}$ wet weight) measured in tissue composites of fish collected from 60 stations in the 2003 FRAM survey.

Table 3.4.5. Ratios of concentrations of measured parameters in fillets vs. remains of fish in flatfish collected in Washington for the FRAM survey.

Table 3.5.1. Summary of major taxonomic groups for the west-coast shelf region wide.

Table 3.5.2. Comparison of the proportion of taxa within major taxonomic groups on the shelf vs. West Coast estuaries.

Table 3.5.3. Comparison of the number of taxa, $\mathrm{H}^{\prime}$ diversity $\left(\log _{2}\right)$, and densities $\left(\mathrm{m}^{-2}\right)$ of benthic infaunal assemblages on the shelf vs. West Coast estuaries. 
Table 3.5.4. Fifty most abundant benthic taxa in the West Coast shelf survey regionwide.

Table 3.5.5. Comparison of dominant (10 most abundant) taxa among (A) all, California, Oregon, and Washington sample locations, and (B) California NMS, California nonNMS, Olympic Coast NMS, and Washington-Oregon non-NMS sample locations....... 98

Table 3.5.6. Nonindigenous species from the shelf survey................................. 108 


\section{List of Appendix Tables}

Appendix Table 1. Sampling coordinates for the 2003 West Coast Shelf Assessment.

Appendix Table 2. Sampling coordinates for the 2003 FRAM Groundfish Survey stations from which fish were analyzed for tissue contaminants by EPA.

Appendix Table 3a. Summary for Washington data of performance with regard to QC criteria for analysis of reference materials, matrix spike recoveries, and relative percent difference or coefficient of variation (RPD, CV ) of replicates.

Appendix Table 3b. Summary for Oregon data of performance with regard to QC criteria for analysis of reference materials, matrix spike recoveries, and relative percent difference or coefficient of variation (RPD, CV ) of replicates.

Appendix Table 3c. Summary for California data of performance with regard to QC criteria for analysis of reference materials, matrix spike recoveries, and relative percent difference or coefficient of variation (RPD, CV ) of replicates.

Appendix Table 4. Summary by station of key benthic variables and corresponding sediment and water-quality indicators.

Appendix Table 5. Biogeographic distributions of the 39 most abundant benthic taxa identified to species in the West Coast shelf survey. 


\section{List of Acronyms}

CBNMS

CDF

CINMS

CTD

CRM

CV

CWA

DO

EAM

EMAP

EPA

ERL

ERM

FRAM

GAO

GFNMS

GIS

GPS

GRTS

IEA

LCM

MBNMS

MDL

MOA

MOU

NCA

NCA-West

NCCOS

NMFS

NMS

NMAO

NOAA

NOS

N/P

NWFSC

OCNMS

ORD

$P A H$

PAR

$P C B$

QA/QC

$\mathrm{RL}$

RPD
Cordell Bank National Marine Sanctuary

Cumulative distribution function

Channel Islands National Marine Sanctuary

Conductivity-Temperature-Depth

Certified Reference Material

Coefficient of Variation

Clean Water Act

Dissolved Oxygen Concentration

Ecosystem Approach to Management

Environmental Monitoring and Assessment Program

U.S. Environmental Protection Agency

Effects Range Low

Effects Range Median

Fishery Resource Analysis and Monitoring

U. S. General Accounting Office

Gulf of Farallones National Marine Sanctuary

Geographic Information System

Global Positioning System

Generalized Random Tessellation Stratified

Integrated Ecosystem Assessment

Laboratory Control Material

Monterey Bay National Marine Sanctuary

Method Detection Limit

Memorandum of Agreement

Memorandum of Understanding

National Coastal Assessment

National Coastal Assessment - Western regional component

National Centers for Coastal Ocean Science

National Marine Fisheries Service

National Marine Sanctuary

NOAA Marine and Aircraft Operation

National Oceanic and Atmospheric Administration

NOAA National Ocean Service

Nitrogen to Phosphorus

Northwest Fisheries Science Center

Olympic Coast National Marine Sanctuary

EPA Office of Research and Development

Polycyclic Aromatic Hydrocarbons

Photosynthetically Active Radiation

Polychlorinated Biphenyls

Quality Assurance/Quality Control

Reporting Limit

Relative Percent Difference 
SCB

SCCWRP

SRM

$S D$

SQG

TOC

TSS

WED
Southern California Bight

Southern California Water Resources Research Project

Standard Reference Material

Standard Deviation

Sediment Quality Guideline

Total Organic Carbon

Total Suspended Solids

Western Ecology Division 


\section{Executive Summary}

The western National Coastal Assessment (NCA-West) program of EPA, in conjunction with the NOAA National Ocean Service (NOS), conducted an assessment of the status of ecological condition of soft sediment habitats and overlying waters along the western U.S. continental shelf, between the target depths of 30 and $120 \mathrm{~m}$, during June 2003. NCA-West and NOAA/NOS partnered with the West Coast states (Washington (WA), Oregon (OR), and California (CA)), and the Southern California Coastal Water Research Project (SCCWRP) Bight '03 program to conduct the survey. A total of 257 stations were sampled from Cape Flattery, WA to the Mexican border using standard methods and indicators applied in previous coastal NCA projects. A key study feature was the incorporation of a stratified-random sampling design with stations stratified by state and National Marine Sanctuary (NMS) status. Each of the three states was represented by at least 50 random stations. There also were a total of 84 random stations located within NOAA's five NMSs along the West Coast including the Olympic Coast NMS (OCNMS), Cordell Bank NMS (CBNMS), Gulf of Farallones NMS (GFNMS), Monterey Bay NMS (MBNMS), and Channel Islands NMS (CINMS). Collection of flatfish via hook-and-line for fish-tissue contaminant analysis was successful at 50 EMAP/NCA-West stations. Through a collaboration developed with the FRAM Division of the Northwest Fisheries Science Center, fish from an additional 63 stations in the same region and depth range were also analyzed for fish-tissue contaminants.

Bottom depth throughout the region ranged from $28 \mathrm{~m}$ to $125 \mathrm{~m}$ for most stations. Two slightly deeper stations from the Southern California Bight (SCB) $(131,134 \mathrm{~m})$ were included in the data set. About $44 \%$ of the survey area had sediments composed of sands (<20\% silt-clay), about $47 \%$ was composed of intermediate muddy sands (20$80 \%$ silt-clay), and about $9 \%$ was composed of muds (> $80 \%$ silt-clay). The majority of the survey area (97\%) had relatively low percent total organic carbon (TOC) levels of $<2 \%$, while a small portion $(<1 \%$ ) had high TOC levels $(>5 \%)$, in a range potentially harmful to benthic fauna.

Salinity of surface waters for $92 \%$ of the survey area were $>31$ psu, with most stations $<31$ psu associated with the Columbia River plume. Bottom salinities ranged only between 31.6 and 34.4 psu. There was virtually no difference in mean bottom salinities among states or between NMS and non-NMS stations. Temperatures of surface water (range $8.5-19.9^{\circ} \mathrm{C}$ ) and bottom water (range $5.8-14.7^{\circ} \mathrm{C}$ ) averaged several degrees higher in CA in comparison to WA and OR. The $\Delta \sigma_{t}$ index of watercolumn stratification indicated that about $31 \%$ of the survey area had strong vertical stratification of the water column. The index was greatest for waters off WA and lowest for CA waters.

Only about $2.6 \%$ of the survey area had surface dissolved oxygen (DO) concentrations $\leq 4.8 \mathrm{mg} / \mathrm{L}$, and there were no values below the lower threshold (2.3 $\mathrm{mg} / \mathrm{L}$ ) considered harmful to the survival and growth of marine animals. Surface DO 
concentrations were higher in WA and OR waters than in CA, and higher in the OC NMS than in the CA sanctuaries. An estimated $94.3 \%$ of the area had bottom-water DO concentrations $\leq 4.8 \mathrm{mg} / \mathrm{L}$ and $6.6 \%$ had concentrations $\leq 2.3 \mathrm{mg} / \mathrm{L}$. The high prevalence of DO from 2.3 to $4.8 \mathrm{mg} / \mathrm{L}$ ( $85 \%$ of survey area) is believed to be associated with the upwelling of naturally low DO water across the West Coast shelf.

Mean TSS and transmissivity in surface waters (excluding OR due to sample problems) were slightly higher and lower, respectively, for stations in WA than for those in CA. There was little difference in mean TSS or transmissivity between NMS and nonNMS locations. Mean transmissivity in bottom waters, though higher in comparison to surface waters, showed little difference among geographic regions or between NMS and non-NMS locations.

Concentrations of nitrate + nitrite, ammonium, total dissolved inorganic nitrogen (DIN) and orthophosphate $(P)$ in surface waters tended to be highest in CA compared to WA and OR, and higher in the CA NMS stations compared to CA non-sanctuary stations. Measurements of silicate in surface waters were limited to WA and CA (exclusive of the SCB) and showed that concentrations were similar between the two states and approximately twice as high in CA sanctuaries compared to OCNMS or nonsanctuary locations in either state. The elevated nutrient concentrations observed at CA NMS stations are consistent with the presence of strong upwelling at these sites at the time of sampling. Approximately $93 \%$ of the area had DIN/P values $\leq 16$, indicative of nitrogen limitation. Mean DIN/P ratios were similar among the three states, although the mean for the OCNMS was less than half that of the CA sanctuaries or nonsanctuary locations. Concentrations of chlorophyll $a$ in surface waters ranged from 0 to $28 \mu \mathrm{g} \mathrm{L}^{-1}$, with $50 \%$ of the area having values $<3.9 \mu \mathrm{g} \mathrm{L}^{-1}$ and $10 \%$ having values $>$ $14.5 \mu \mathrm{g} \mathrm{L}^{-1}$. The mean concentration of chlorophyll a for CA was less than half that of WA and OR locations, and concentrations were lowest in non-sanctuary sites in CA and highest at the OCNMS.

Shelf sediments throughout the survey area were relatively uncontaminated with the exception of a group of stations within the SCB. Overall, about $99 \%$ of the total survey area was rated in good condition $(<5$ chemicals measured above corresponding effect range low (ERL) concentrations). Only the pesticides 4,4'-DDE and total DDT exceeded corresponding effect range-median (ERM) values, all at stations in CA near Los Angeles. Ten other contaminants including seven metals ( $\mathrm{As}, \mathrm{Cd}, \mathrm{Cr}, \mathrm{Cu}, \mathrm{Hg}, \mathrm{Ag}$, $\mathrm{Zn}), 2$-methylnaphthalene, low molecular weight PAHs, and total PCBs exceeded corresponding ERLs. The most prevalent in terms of area were chromium (31\%), arsenic $(8 \%)$, 2-methylnaphthalene $(6 \%)$, cadmium $(5 \%)$, and mercury $(4 \%)$. The chromium contamination may be related to natural background sources common to the region. The 2-methylnaphthalene exceedances were conspicuously grouped around the CINMS. The mercury exceedances were all at non-sanctuary sites in CA, particularly in the Los Angeles area. 
Concentrations of cadmium in fish tissues exceeded the lower end of EPA's noncancer, human-health-risk range at nine of 50 EMAP/NCA-West and nine of 60 FRAM groundfish-survey stations, including a total of seven NMS stations in CA and two in the OCNMS. The human-health guidelines for all other contaminants were only exceeded for total PCBs at one station located in WA near the mouth of the Columbia River.

Benthic species richness was relatively high in these offshore assemblages, ranging from 19 to 190 taxa per $0.1-\mathrm{m}^{2}$ grab and averaging 79 taxa/grab. The high species richness was reflected over large areas of the shelf and was nearly three times greater than levels observed in estuarine samples along the West Coast (e.g NCA-West estuarine mean of 26 taxa/grab). Mean species richness was highest off CA (94 taxa/ grab) and lower in OR and WA (55 and 56 taxa/grab, respectively). Mean species richness was very similar between sanctuary vs. non-sanctuary stations for both the CA and OR/WA regions. Mean diversity index $\mathrm{H}^{\prime}$ was highest in CA (5.36) and lowest in WA (4.27). There were no major differences in mean $\mathrm{H}^{\prime}$ between sanctuary vs. nonsanctuary stations for both the CA and OR/WA regions.

A total of 1,482 taxa $(1,108$ to species) and 99,135 individuals were identified region-wide. Polychaetes, crustaceans and molluscs were the dominant taxa, both by percent abundance $(59 \%, 17 \%, 12 \%$ respectively) and percent species $(44 \%, 25 \%$, $17 \%$, respectively). There were no major differences in the percent composition of benthic communities among states or between NMSs and corresponding non-sanctuary sites. Densities averaged 3,788 $\mathrm{m}^{-2}$, about $30 \%$ of the average density for West Coast estuaries. Mean density of benthic fauna in the present offshore survey, averaged by state, was highest in CA $\left(4,351 \mathrm{~m}^{-2}\right)$ and lowest in OR $\left(2,310 \mathrm{~m}^{-2}\right)$. Mean densities were slightly higher at NMS stations vs. non-sanctuary stations for both the CA and OR/WA regions.

The 10 most abundant taxa were the polychaetes Mediomastus spp., Magelona longicornis, Spiophanes berkeleyorum, Spiophanes bombyx, Spiophanes duplex, and Prionospio jubata; the bivalve Axinopsida serricata, the ophiuroid Amphiodia urtica, the decapod Pinnixa occidentalis, and the ostracod Euphilomedes carcharodonta. Mediomastus spp. and $A$. serricata were the two most abundant taxa overall. Although many of these taxa have broad geographic distributions throughout the region, the same species were not ranked among the 10 most abundant taxa consistently across states. The closest similarities among states were between OR and WA. At least half of the 10 most abundant taxa in NMSs were also dominant in corresponding nonsanctuary waters.

Many of the abundant benthic species have wide latitudinal distributions along the West Coast shelf, with some species ranging from southern CA into the Gulf of Alaska or even the Aleutians. Of the 39 taxa on the list of 50 most abundant taxa that could be identified to species level, $85 \%$ have been reported at least once from estuaries of CA, OR, or WA exclusive of Puget Sound. Such broad latitudinal and estuarine distributions are suggestive of wide habitat tolerances. 
Thirteen $(1.2 \%)$ of the 1,108 identified species are nonindigenous, with another 121 species classified as cryptogenic (of uncertain origin), and 208 species unclassified with respect to potential invasiveness. Despite uncertainties of classification, the number and densities of nonindigenous species appear to be much lower on the shelf than in the estuarine ecosystems of the Pacific Coast. Spionid polychaetes and the ampharetid polychaete Anobothrus gracilis were a major component of the nonindigenous species collected on the shelf.

NOAA's five NMSs along the West Coast of the U.S. appeared to be in good ecological condition, based on the measured indicators, with no evidence of major anthropogenic impacts or unusual environmental qualities compared to nearby nonsanctuary waters. Benthic communities in sanctuaries resembled those in corresponding non-sanctuary waters, with similarly high levels of species richness and diversity and low incidence of nonindigenous species. Most oceanographic features were also similar between sanctuary and non-sanctuary locations. Exceptions (e.g., higher concentrations of some nutrients in sanctuaries along the CA coast) appeared to be attributable to natural upwelling events in the area at the time of sampling. In addition, sediments within the sanctuaries were relatively uncontaminated, with none of the samples having any measured chemical in excess of ERM values. The ERL value for chromium was exceeded in sediments at the OCNMS, but at a much lower percentage of stations (four of 30) compared to WA and OR non-sanctuary areas (31 of 70 stations). ERL values were exceeded for arsenic, cadmium, chromium, 2methylnaphthalene, low molecular weight PAHs, total DDT, and 4,4'-DDE at multiple sites within the CINMS. However, cases where total DDT, 4,4'-DDE, and chromium exceeded the ERL values were notably less prevalent at CINMS than in non-sanctuary waters of CA. In contrast, 2-methylnaphthalene above the ERL was much more prevalent in sediments at the CINMS compared to non-sanctuary waters off the coast of $\mathrm{CA}$. While there are natural background sources of PAHs from oil seeps throughout the $\mathrm{SCB}$, this does not explain the higher incidence of 2-methylnaphthalene contamination around CINMS. Two stations in CINMS also had levels of TOC (>5\%) potentially harmful to benthic fauna, though none of these sites exhibited symptoms of impaired benthic condition.

This study showed no major evidence of extensive biological impacts linked to measured stressors. There were only two stations, both in CA, where low numbers of benthic species, diversity, or total faunal abundance co-occurred with high sediment contamination or low DO in bottom water. Such general lack of concordance suggests that these offshore waters are currently in good condition, with the lower-end values of the various biological attributes representing parts of a normal reference range controlled by natural factors. Results of multiple linear regression, performed using full model procedures to test for effects of combined abiotic environmental factors, suggested that latitude and depth had significant influences on benthic variables regionwide. Latitude had a significant inverse influence on all three of the above benthic variables, i.e. with values increasing as latitude decreased $(p<0.01)$, while depth had a 
significant direct influence on diversity $(p<0.001)$ and inverse effect on density ( $p$ $<0.01$ ). None of these variables varied significantly in relation to sediment $\%$ fines (at $p<0.1$ ), although in general there was a tendency for muddier sediments (higher $\%$ fines) to have lower species richness and diversity and higher densities than coarser sediments.

Alternatively, it is possible that for some of these sites the lower values of benthic variables reflect symptoms of disturbance induced by other unmeasured stressors. The indicators in this study included measures of stressors (e.g., chemical contaminants, eutrophication) that are often associated with adverse biological impacts in shallower estuarine and inland ecosystems. However, there may be other sources of humaninduced stress in these offshore systems (e.g., bottom trawling) that pose greater risks to ambient living resources and which have not been captured. Future monitoring efforts in these offshore areas should include indicators of such alternative sources of disturbance. 


\subsection{Introduction}

\subsection{Program Background}

The U.S. Environmental Protection Agency (EPA) and the National Oceanic and Atmospheric Administration (NOAA) both perform a broad range of research and monitoring activities to assess the status and potential effects of human activities on the health of coastal ecosystems and to promote the use of this information in protecting and restoring the Nation's coastal resources. Authority to conduct such work is provided through several legislative mandates including the Clean Water Act (CWA) of 1977 (33 U.S.C. §§ 1251 et seq.), National Coastal Monitoring Act (Title V of the Marine Protection, Research, and Sanctuaries Act, 33 U.S.C. $\S \S 2801-2805)$, and the National Marine Sanctuary Act of 2000. Where possible the two agencies have sought to coordinate related activities through partnerships with states and other institutions to prevent duplications of effort and bring together complementary resources to fulfill common research and management goals. Accordingly, in summer 2003, NOAA, EPA, and partnering West Coast states - Washington (WA), Oregon (OR), and California (CA) - combined efforts to conduct a joint survey of ecological condition of aquatic resources in near-coastal waters along the U.S. western continental shelf using multiple indicators of ecological condition. The study is an expansion of EPA's Environmental Monitoring and Assessment Program (EMAP) and subsequent National Coastal Assessment (NCA), which seek to assess condition of the Nation's environmental resources within a variety of coastal and terrestrial resource categories. The coastal component of EMAP/NCA on the West Coast of the U.S. began in 1999 with a focus in estuaries (see Nelson et al. 2004, 2005; Hayslip et al. 2006; Wilson and Partridge 2007; U.S. EPA 2001, 2004, 2006). The current assessment, based on sampling conducted in summer 2003, extends this work to near-coastal shelf waters (depths of 30-120 m) from the Canadian to Mexican borders (see Figures 3.1.1 - 3.1.9 below).

A focus of the study was on the collection and analysis of water, sediment, and biological samples using standard methods and indicators applied in previous coastal EMAP/NCA projects (U.S. EPA 2001, 2004; Nelson et al. 2004). A key feature was the incorporation of a stratified-random sampling design, with stations (257 total) stratified by State and National Marine Sanctuary (NMS) status. Each of the three states (WA, Oregon, California) was represented by at least 50 random stations. There also were a total of 84 random stations included within NOAA's five NMSs along the West Coast. The probabilistic sampling design provided a basis for making unbiased statistical estimates of the spatial extent of ecological condition relative to various measured indicators and corresponding thresholds of concern. These included standard EMAP/NCA ecological indicators of water quality, sediment quality, and biological condition (benthic fauna and fish).

Assessments of status relative to these various indicators are presented in the present report on a region-wide basis, by State, and by NMS vs. non-sanctuary status. The state-level information will be of value to EPA and the States in their efforts to meet 
requirements under the CWA to report on the condition of each state's aquatic resources. The information on the status of NMS resources, which has been derived from standard monitoring methods and indicators that allow comparisons to the surrounding regional ecosystem and across other sanctuaries as a system, helps to fulfill the needs of system-wide monitoring strategies for the NMS Program (NMSP 2004) as well as related directives under the NMS Reauthorization Act of 2000. Moreover, because the protocols and indicators are consistent with those used in previous EMAP/NCA estuarine surveys, comparisons also can be made between conditions in offshore waters and those observed in neighboring estuarine habitats, thus providing a more holistic account of ecological conditions and processes throughout the inshore and offshore resources of the region. Such information should provide valuable input for future National Coastal Condition Reports, which historically have focused on estuaries (U.S. EPA 2001, 2004).

Lastly, results of this study should provide support to evolving interests within the U.S. and other parts of the world to move toward an ecosystem approach to management (EAM) of coastal resources (Murawski 2007; Marine Ecosystems and Management 2007). Integrated Ecosystem Assessments (IEAs) have been identified as an important component of an EAM strategy (Murawski and Menashes 2007, Levin et al. 2008). An IEA is a synthesis and quantitative analysis of information on relevant natural and socio-economic factors in relation to specified ecosystem management goals (Levin et al. 2008). Initial steps in the IEA process include the assessment of baseline conditions defining the status of the system as well as the assessment of stressor impacts and their links to source drivers and pressures. Results of the present study will be available to support such initial steps in the development of an IEA for the California Current Large Marine Ecosystem. While the focus of the present study is on indicators of ecological condition, limited socio-economic indicators have been included as well (e.g., fish contaminant levels, water clarity, marine debris), which can be used to help address some common human-dimension questions, such as "Are the fish safe to eat?" or "Is the water clean enough to swim in?"

This assessment was made possible through the cooperation of numerous organizations. The project was funded principally by EPA (Office of Research and Development, ORD) and co-managed through a Memorandum of Agreement (MOA) by staff from EPAJORD and the NOAA National Ocean Service's (NOS) National Centers for Coastal Ocean Science (NCCOS). NOAA's Office of Marine and Aviation Operations provided three weeks of ship time on the NOAA Ship McARTHUR II, which supported the primary sampling effort conducted in June 2003 from the Strait of Juan de Fuca in Washington south to Pt. Conception, CA. The Northwest Fisheries Science Center (NWFSC), under NOAA's National Marine Fisheries Service (NMFS), provided field support and analysis of fish pathologies through a cooperative agreement with EPA. The NWFSC also supplemented the collection of fish samples for contaminant and pathology analysis through coordination of sampling conducted by their Fishery Resource Analysis and Monitoring (FRAM) Division at stations falling within the appropriate depth range during their annual west-coast groundfish surveys. State 
partners included Washington Department of Ecology, Oregon Department of Environmental Quality, and the Southern California Water Resources Research Project (SCCWRP). Additional field support was provided by scientists from the three State partners, EPA Region 10, EPA ORD, the Alaska Department of Environmental Conservation, and South Slough Estuarine Research Reserve.

The intent of the study design was to include continental shelf waters all along the West Coast of the U.S., from the Strait of Juan de Fuca in Washington to the Mexican border. The coordination of two separate survey efforts was necessary in order to cover such a large area. The first was the above-mentioned June 2003 cruise conducted from the NOAA Ship MCARTHUR II, which covered sampling from the Strait of Juan de Fuca south to Pt. Conception, CA. This effort was coordinated with a companion assessment conducted by SCCWRP during the same general time-frame, in the area between Pt. Conception and the Mexican border, known as the Southern California Bight (SCB). The Bight '03 assessment was conducted using a similar probabilistic sampling design and most of the same condition indicators (Allen et al. 2007, Bay et al. 2005, Ranasinghe et al. 2007, Schiff et al. 2006), and thus the data could be integrated with data from the more northern stations to provide an overall assessment of condition throughout the western U.S. continental shelf.

\subsection{NOAA National Marine Sanctuaries}

There are currently four NMSs along the coast of California, one off the coast of Washington, and none off the coast of Oregon. All of the West Coast NMSs represent areas particularly rich in a diverse array of marine life, including marine mammals, seabirds, fishes, invertebrates and plants. The Channel Islands NMS off the coast of California is the oldest, established in 1980, and covers an area of 4,294 km² surrounding the islands of Anacapa, Santa Cruz, Santa Rosa, San Miguel and Santa Barbara out to six nautical miles offshore around each of the five islands. The Gulf of the Farallones NMS $\left(3,237 \mathrm{~km}^{2}\right)$ and Cordell Bank NMS $\left(1347 \mathrm{~km}^{2}\right)$ are adjacent to each other and located along the central California coast off San Francisco. The Gulf of the Farallones NMS was established in 1981 and includes the Farallon Islands National Wildlife Refuge. Cordell Bank NMS, established in 1989, includes Cordell Bank seamount whose summit lies only 37 meters below the surface. The Monterey Bay NMS is the most recently established NMS in California (1992), and is also the largest on the West Coast. It extends from Rocky Point in Marin County to Cambria in San Luis Obispo County, a shoreline length of $444 \mathrm{~km}$ and encompasses $13,784 \mathrm{~km}^{2}$ of ocean.

To the north, the Olympic Coast NMS was established in 1994 and protects about $8,570 \mathrm{~km}^{2}$ of the Pacific Ocean between Cape Flattery and the mouth of the Copalis River, a distance of about $217 \mathrm{~km}$. Some $105 \mathrm{~km}$ of the sanctuary's coastline borders the Olympic National Park, while the Flattery Rocks, Quillayute Needles, and Copalis Rock National Wildlife Refuges are within the sanctuary boundaries. Maps of each of the West Coast NMS may be found at: http://sanctuaries.noaa.gov/pgallery/atlasmaps/welcome.html. 


\subsection{Southern California Bight 2003 Regional Monitoring Program}

In response to the need for an integrated assessment of the condition of the southern California coastal ocean, SCCWRP brought together 58 organizations in the summer of 2003 to conduct a comprehensive assessment of the ecological condition of the SCB. This study, known as Bight'03, was the third regional-scale assessment of the SCB by SCCWRP, following earlier related efforts in 1994 and 1998. There also have been older studies of the benthic fauna of shelf, slope, and basin habitats throughout the SCB conducted by other investigators (Jones 1969, Fauchald and Jones 1978). The spatial extent of the SCCWRP-related regional assessments ranged from $\mathrm{Pt}$. Conception in the north to the Mexican border. During the 2003 effort, sampling was extended to include estuaries and continental slope and basin areas down to a depth of $1,000 \mathrm{~m}$. Bight'03 included three components: Coastal Ecology, Shoreline Microbiology and Water Quality. Shoreline microbiology was not a part of the scope of the EMAP study. The Water Quality component of Bight'03 (Nezlin et al. 2007) was focused on examination of the effects of storm water runoff on the SCB. Sampling did not fall within the EMAP index period and was designed to address a different set of research questions, and thus data collected under this component could not be integrated with the EMAP assessment. However, water quality data from some stations within the SCB were collected by SCCWRP under a cooperative agreement with EPA. The Coastal Ecology Component of Bight'03 assessed sediment contaminants and the effect of these contaminants on biota in the SCB, and analyzed a set of contaminants that were virtually the same as those assessed in the EMAP program (Ranasinghe et al. 2007). 


\subsection{Methods}

Methods for the 2003 survey of condition of the continental shelf of the West Coast were in general the same as those developed for the EPA National Coastal Assessment (Nelson et al. 2004), with modifications to reflect the generally deeper nature of the resource being assessed.

Sampling for a major portion of the survey area (Strait of Juan de Fuca, WA, to Point Conception, CA) was conducted on NOAA Ship McARTHUR II Cruise AR-03-01NC, June 1-26, 2003 (Cooksey 2003). The cruise consisted of three legs: Leg 1 along the Washington coast (Seattle to Astoria, OR, June 1-8); Leg 2 along the Oregon coast (Astoria, OR to Eureka, CA, June 8-16); and Leg 3 along the California coast, from the Oregon border to Pt. Conception (Eureka, CA to Pt. Conception and back to San Francisco, CA, June 18-26). Samples were collected from the deck of the McARTHUR II during around-the-clock operations.

At each station, samples were obtained for characterization of: 1) community structure and composition of benthic macroinfauna (fauna retained on a 1.0-mm sieve); 2) concentration of chemical contaminants in sediments (metals, pesticides, PCBs, PAHs); 3) general habitat conditions (water depth, dissolved oxygen, conductivity, temperature, chlorophyll a, light transmittance, water-column nutrients, $\%$ silt-clay versus sand content of sediment, organic-carbon content of sediment); and 4) condition of selected demersal fish species caught by hook-and-line (contaminant body burdens and visual evidence of pathological disorders).

\subsection{Sampling Design}

\subsubsection{EMAP}

A major target to be assessed was the soft-sediment benthic resources and overlying water quality of the continental shelf, in the depth range between 30 and 120 $\mathrm{m}$, from the Strait of Juan de Fuca in Washington to the Mexican border. Given the high cost of research ship time and the desire to insure that attempts at sampling rocky bottoms were minimized, considerable effort was taken to develop a GIS data layer of only soft sediment habitat. No comprehensive bottom type map of the continental shelf of West Coast existed at the time of this study, although data were provided by several individuals at research institutions that were developing such maps under NOAA funding. An attempt was also made to obtain the general locations of commercial submarine cable crossings, and these zones, along with high activity shipping channels and other restricted access regions were omitted from the GIS layer defining the target resource area.

The study utilized a stratified random sampling design, known as a Generalized Random Tessellation Stratified (GRTS) survey design. The EMAP/NCA sampling effort consisted of a total of 150 stations that were distributed across the sampling area, partitioned in several ways. Each of the three states received 50 stations. In 
Washington, the 50 stations were partitioned into 30 stations randomly selected within the Olympic Coast NMS (OCNMS), and 20 stations in the remainder of the shelf waters. Similarly, in California, the 50 stations were partitioned into two groups consisting of 30 stations randomly selected within the combined area of the Cordell Bank, Gulf of Farallones, Monterey Bay, and Channel Islands NMSs, and 20 stations selected in nonsanctuary waters of California north of Pt. Conception.

Each sampling region is termed a multi-density category. For each multi-density category (Appendix Table 1), geographic coordinates for the number of primary target stations listed above were determined during the study design process. Additionally, each multi-density category had an equal number of alternate sampling locations selected in case a primary site should have to be rejected due to safety concerns or the presence of rocky bottom. Because of the severe logistic constraint of the number of ship days available, when a primary station was abandoned, the nearest alternate station within the multi-density category was selected and sampling was attempted.

After completion of the field survey, additional adjustments to the frame area definitions were made. For the present report, the principal adjustment was to exclude the area of the continental shelf within the Strait of Juan de Fuca from inclusion in the resource definition. This decision was made because all bottom samples attempted at multiple stations found rocky instead of soft bottom, indicating that the region may not fit the target resource definition of soft sediment shelf habitat. Thus, weighting factors used in data analysis reflect the removal of this sample area.

\subsubsection{Bight'03}

Data coverage throughout the SCB portion of the study area (Pt. Conception, CA to the Mexican border) was made possible through coordination with a companion assessment, the Bight'03 study conducted by SCCWRP. The basic sampling design of the Bight'03 study was the same as that used for the EMAP survey. Sampling sites were selected in a stratified random fashion in 12 multi-density categories that represented distinct regions of interest within the SCB using a Generalized Random Tessellation Stratified (GRTS) design (Ranasinghe et al. 2007). There was overlap with the target depth zone sampled by EMAP for two Bight'03 multi-density categories. Given the identical design approaches, data from Bight'03 for these two categories could be merged with EMAP data into a single statistical analysis for the West Coast shelf. Geographic coordinates for the Bight'03 stations which were included with the EMAP stations in the present analysis are provided in Appendix 1. Inspection of depth information was used to confirm that Bight'03 stations actually fell within the target depth range of the EMAP study, and some stations included in a multi-density category in the Bight'03 study were excluded from inclusion with the EMAP data. A total of 30 stations within the Channel Islands NMS and 43 stations along the mainland shelf fell with the EMAP target depth zone of 30-120 m. The list of water column parameters measured varied considerably among these stations and rarely comprised the full list of parameters measured by the EMAP study. 


\subsubsection{FRAM Groundfish Survey}

Samples from the West Coast Groundfish Surveys conducted by the Fisheries Resource Analysis and Monitoring (FRAM) Division of the Northwest Fisheries Science Center (NWFSC) of NOAA were used to supplement the pool of samples available for tissue-contaminant body-burden analysis. FRAM surveys began in 1998 and by 2003 had adopted a probability-based sampling design. However the design could not be readily integrated into that used by EMAP/NCA. The FRAM groundfish-survey area included depths from 30 fathoms $(55 \mathrm{~m})$ to 700 fathoms $(1287 \mathrm{~m})$ and was partitioned by International North Pacific Fishing Commission zones. Therefore, a GIS coverage of groundfish-survey sample locations was created, and the EMAP/NCA sample frame defining the region between 30 and $120 \mathrm{~m}$ was overlaid on this GIS data layer. A target sample number of 50 groundfish sites per state was established. In Oregon and Washington, only 28 and 21 stations, respectively, met the EMAP/NCA depth criterion, and thus all available sites were selected. In California, a subset of 50 sites was randomly selected from the list of 78 sites within the depth range. Fish from 63 sites were initially selected for contaminant analysis, but data from three of these sites were subsequently excluded from data analysis because the sites were greater than $120 \mathrm{~m}$ in depth. Sites from which fish were analyzed for contaminants are shown in Figs. 3.1.63.1.9 and are listed in Appendix Table 2.

\subsection{Water Column Sampling}

Vertical water-column profiles of conductivity, temperature, chlorophyll a concentration, transmissivity, dissolved oxygen, and depth were obtained with a SeaBird Electronics Conductivity-Temperature-Depth (CTD) data sonde unit with additional sensors (Table 2.2.1). The unit was a SBE 9Plus with an 11Plus deck unit to provide real-time data supplied by the NOAA Ship McARTHUR II. Supplemental sensors were supplied by Washington DOE. The unit was also equipped with 12 Niskin water sample bottles to acquire discrete water samples at three designated water depths: $0.5 \mathrm{~m}$ below sea surface, mid-water column, and near the seabed (Figure 2.2.1). In practice, the near-surface samples were collected from just below the surface to a depth of $5.3 \mathrm{~m}$. Continuous profiles of conductivity, temperature, dissolved oxygen, chlorophyll a (fluorometer), transmissivity, and depth were recorded during the descent and ascent of the unit. Discrete water samples were processed for nutrients, total suspended solids (TSS), and chlorophyll a. For nutrients and chlorophyll a, only surface values are reported since this is the region of the water column most likely to be affected by anthropogenic influences. For temperature, salinity, dissolved oxygen, transmissivity and TSS, only surface and bottom values are reported, since these values typically provide the maximum range of values within a station. Data for all three depths for all variables are included in the study database and are available on request from the authors.

In the assessment of estuarine waters in the NCA program, light availability in the water column was evaluated using either Secchi depth or water column 
photosynthetically available radiation (PAR) measured with PAR sensors. For the Western NCA, the vertical profile PAR data were used to calculate an estimate of the percent transmittance of incident PAR at a reference depth of $1 \mathrm{~m}$ (Nelson et al. 2005). In the present study, a transmissometer attached to the CTD was used to measure in situ light attenuation. The instrument measured the percentage of light that reached a receiver with a narrow field of view at $25 \mathrm{~cm}$ from a light source generating a narrow beam. Transmissivity and percent transmittance of PAR are not directly comparable measurements.

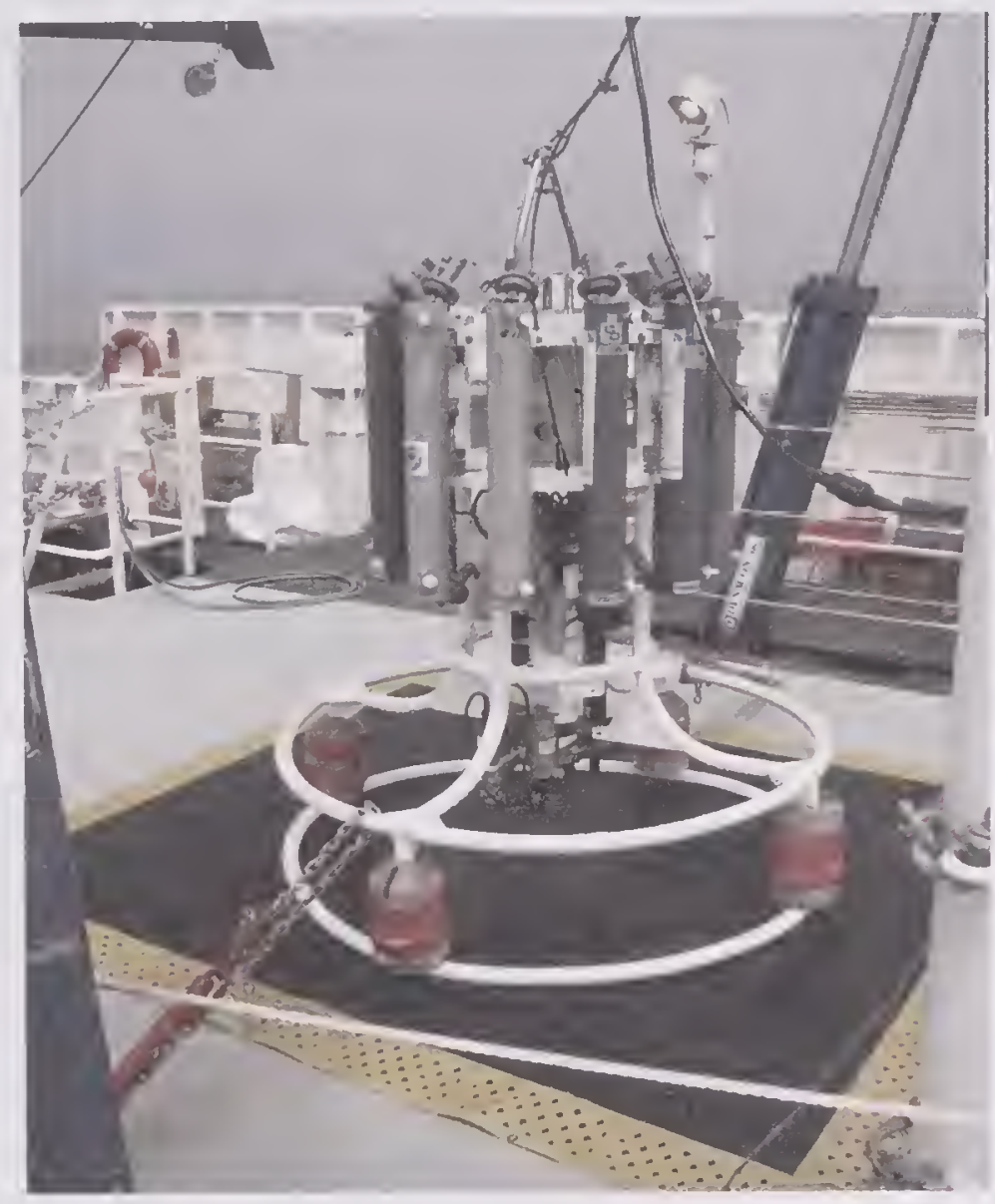

Figure 2.2.1. CTD and Niskin bottle rosette sampler on the deck of the NOAA Ship MCARTHUR II.

The CTD was lowered into the water until it was completely submerged and held just below the surface for three minutes, allowing the water pump to purge any air in the system. The unit was then returned to the sea surface to begin the profile, and lowered slowly to the bottom at approximately $0.8 \mathrm{~m} \mathrm{~s}^{-1}$, held near the seabed for one minute, and then recovered at a similar velocity. To prevent the equipment from hitting the seabed due to wave motion, the maximum depth to which the CTD was lowered was generally about 3-8 $\mathrm{m}$ above the bottom. 
Table 2.2.1. Equipment used for hydrographic profile measurements.

\begin{tabular}{|l|l|}
\hline \multicolumn{1}{|c|}{ Parameter } & \multicolumn{1}{c|}{ CTD or Sensor } \\
\hline Salinity & $\begin{array}{l}\text { Sea-Bird Electronics SBE 9Plus } \\
\text { Derived from conductivity (CTD) }\end{array}$ \\
\hline Temperature & Sea-Bird Electronics SBE 9Plus \\
\hline Dissolved oxygen & Sea-Bird Electronics SBE-43 sensor \\
\hline Chlorophyll-a fluorescence & WET Labs WETStar fluorometer \\
\hline Transmissivity & WET Labs C-Star transmissometer \\
\hline
\end{tabular}

\subsection{Biological and Sediment Sampling}

Sediment sampling was undertaken using a custom-designed Van Veen grab (Figure 2.3.1). The sampling device is composed of two $0.1-\mathrm{m}^{2}$ samplers, joined together in a single frame. The unit was 60 inches high, 42 inches in diameter and weighed 450 pounds with its full complement of four, 50-pound, stainless-steel weights. Sample material obtained by the grabs was used for analysis of macroinfaunal communities, concentration of sediment contaminants, \% silt-clay, and organic-carbon content. Three grab samples were required at the majority of stations to acquire adequate sediment (approximately $2 \mathrm{~L}$ ) for both benthic infauna (one grab) and chemistry sample processing. A grab sample was deemed successful when the grab unit was $>75 \%$ full (with no major slumping). The benthic samples were sieved onboard through 1.0-mm (WA and OR stations), or through nested 0.5- $\mathrm{mm}$ and 1.0-mm screens (CA stations), and preserved in 10\% buffered formalin. Fauna from California stations retained in the $0.5-1.0 \mathrm{~mm}$ sieve fraction were processed as part of a supplemental study and are not considered in this report. Thus all benthic data reported here pertain to the $>1.0-\mathrm{mm}$ fraction.

\subsubsection{Sediment Pollutant and Tissue Analysis}

Sediments and fish tissues were analyzed for a suite of organic pollutants and metals (Table 2.3.1) using analytical methods from the NOAA NS\&T Program (Lauenstein and Cantillo 1993) or described in the EMAP Laboratory Methods Manual (U.S. EPA 1994). For all three states, 15 metals were analyzed in sediments and 13 metals were analyzed in whole-body fish tissues. Antimony and manganese were analyzed in tissue samples from California and Washington. A total of 21 PCB congeners (PCBs), DDT and its primary metabolites, 14 chlorinated pesticides, and 23 polynuclear aromatic hydrocarbons (PAHs) were analyzed in sediments from all three states (Table 2.3.1). The same suite of chlorinated compounds was analyzed in fish tissue except that hexachlorobenzene was not analyzed in samples from California. PAHs were measured in tissues from California and Washington and are not reported here. Total organic carbon and percent fines of the sediment were analyzed in samples from all sites. 
Table 2.3.1. Compounds analyzed in sediments and fish tissues in the West Coast Shelf Assessment. All compounds were analyzed in all three states in both sediment and fish with the exceptions that PAHs, antimony and manganese were analyzed in fish tissues only in California and Washington, and hexachlorobenzene was not analyzed in fish tissues in California.

\begin{tabular}{|c|c|c|c|}
\hline $\begin{array}{l}\text { Polycyclic Aromatic } \\
\text { Hydrocarbons } \\
\text { (PAHs) }\end{array}$ & $\begin{array}{c}\text { PCB Congeners } \\
\text { (Congener Number and } \\
\text { Compound) }\end{array}$ & $\begin{array}{l}\text { DDT and Other } \\
\text { Chlorinated } \\
\text { Pesticides }\end{array}$ & $\begin{array}{c}\text { Metals and } \\
\text { Misc. }\end{array}$ \\
\hline $\begin{array}{l}\text { Low Molecular Weight } \\
\text { PAHs } \\
\text { 1-methylnaphthalene } \\
\text { 1-methylphenanthrene } \\
\text { 2-methylnaphthalene } \\
\text { 2,6-dimethylnaphthalene } \\
\text { 2,3,5-trimethylnaphthalene } \\
\text { Acenaphthene } \\
\text { Acenaphthylene } \\
\text { Anthracene } \\
\text { Biphenyl } \\
\text { Dibenzothiophene } \\
\text { Fluorene } \\
\text { Naphthalene } \\
\text { Phenanthrene } \\
\\
\text { High Molecular Weight } \\
\text { PAHs } \\
\text { Benz(a)anthracene } \\
\text { Benzo(a)pyrene } \\
\text { Benzo(b)fluoranthene } \\
\text { Benzo(k)fluoranthene } \\
\text { Benzo(g,h,i)perylene } \\
\text { Chrysene } \\
\text { Dibenz(a,h)anthracene } \\
\text { Fluoranthene } \\
\text { Indeno(1,2,3-c,d)pyrene } \\
\text { Pyrene }\end{array}$ & 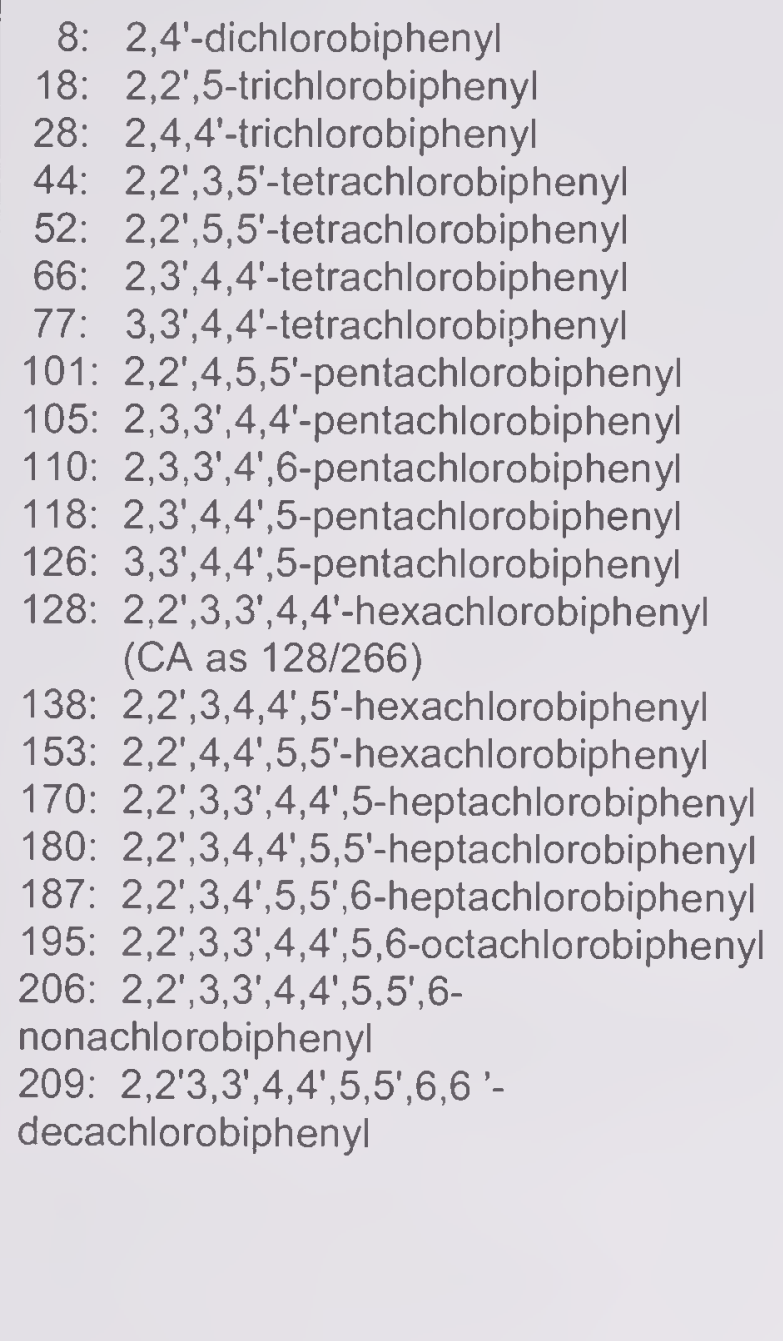 & $\begin{array}{l}\text { DDTs } \\
2,4^{\prime}-\text { DDD } \\
4,4^{\prime}-\mathrm{DDD} \\
2,4^{\prime}-\mathrm{DDE} \\
4,4^{\prime}-\mathrm{DDE} \\
2,4^{-}-\mathrm{DDT} \\
4,4^{\prime}-\mathrm{DDT} \\
\\
\text { Cyclopentadienes } \\
\text { Aldrin } \\
\text { Dieldrin } \\
\text { Endrin } \\
\text { Chlordanes } \\
\text { Alpha-Chlordane } \\
\text { Heptachlor } \\
\text { Heptachlor Epoxide } \\
\text { Trans-Nonachlor } \\
\text { Others } \\
\text { Endosulfan I } \\
\text { Endosulfan II } \\
\text { Endosulfan Sulfate } \\
\text { Hexachlorobenzene } \\
\text { Lindane (gamma-BHC) } \\
\text { Mirex } \\
\text { Toxaphene }\end{array}$ & $\begin{array}{l}\text { Metals } \\
\text { Aluminum } \\
\text { Antimony } \\
\text { Arsenic } \\
\text { Cadmium } \\
\text { Chromium } \\
\text { Copper } \\
\text { Iron } \\
\text { Lead } \\
\text { Manganese } \\
\text { Mercury } \\
\text { Nickel } \\
\text { Selenium } \\
\text { Silver } \\
\text { Tin } \\
\text { Zinc } \\
\\
\text { Miscellaneous } \\
\text { Total Organic } \\
\text { Carbon } \\
\text { Percent Fines }\end{array}$ \\
\hline
\end{tabular}




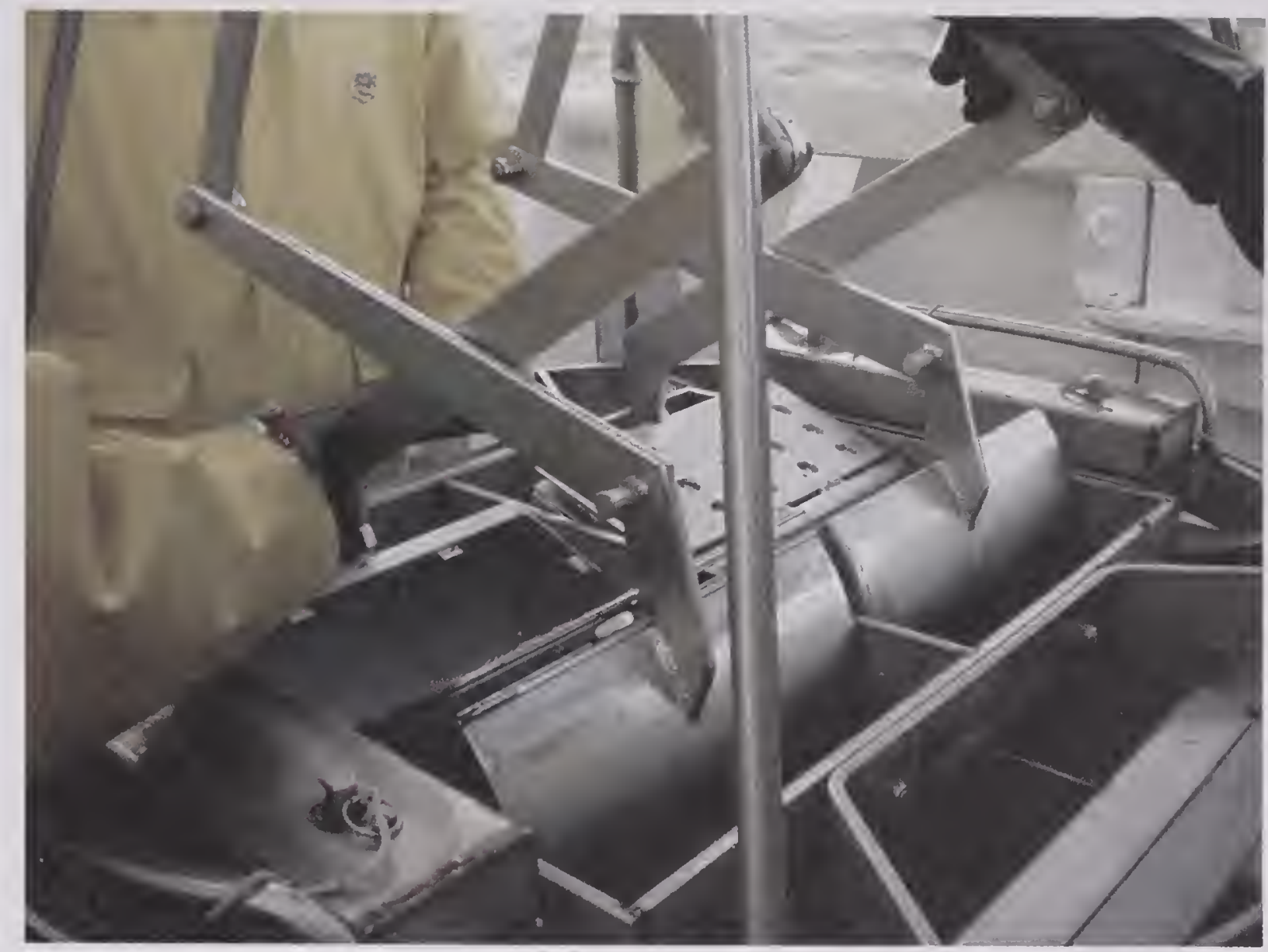

Figure 2.3.1. Close-up view of double Van Veen grab sampler used for bottom sampling.

\subsection{Fish Tissue}

\subsubsection{EMAP}

The NOAA Ship McARTHUR II had only recently entered service and was not yet fitted out to conduct trawl operations at the time of the EMAP/NCA Assessment. Instead, hook-and-line fishing methods (Figure 2.4.1) were used in an effort to capture bottom fish for inspection of external pathologies and for subsequent analysis of chemical contaminants in tissues of selected species. Any captured fish were identified and inspected for gross external pathologies. Selected species, primarily the Pacific sanddab (Citharichthys sordidus), also were frozen for subsequent chemical contaminant body-burden analysis. Water depths less than $80 \mathrm{~m}$ were generally fished quite easily with hook-and-line. Fishing at night, in high currents and in deeper water depths was difficult and was often unproductive. In particular, during the California leg of the cruise, high winds and seas physically hindered the ability to keep fishing gear on the bottom at many stations.

\subsubsection{Bight'03}

While a variety of fish studies were conducted as part of Bight'03 (Allan et al. 2007), there were no collections of benthic fish species for tissue contaminant analysis. 


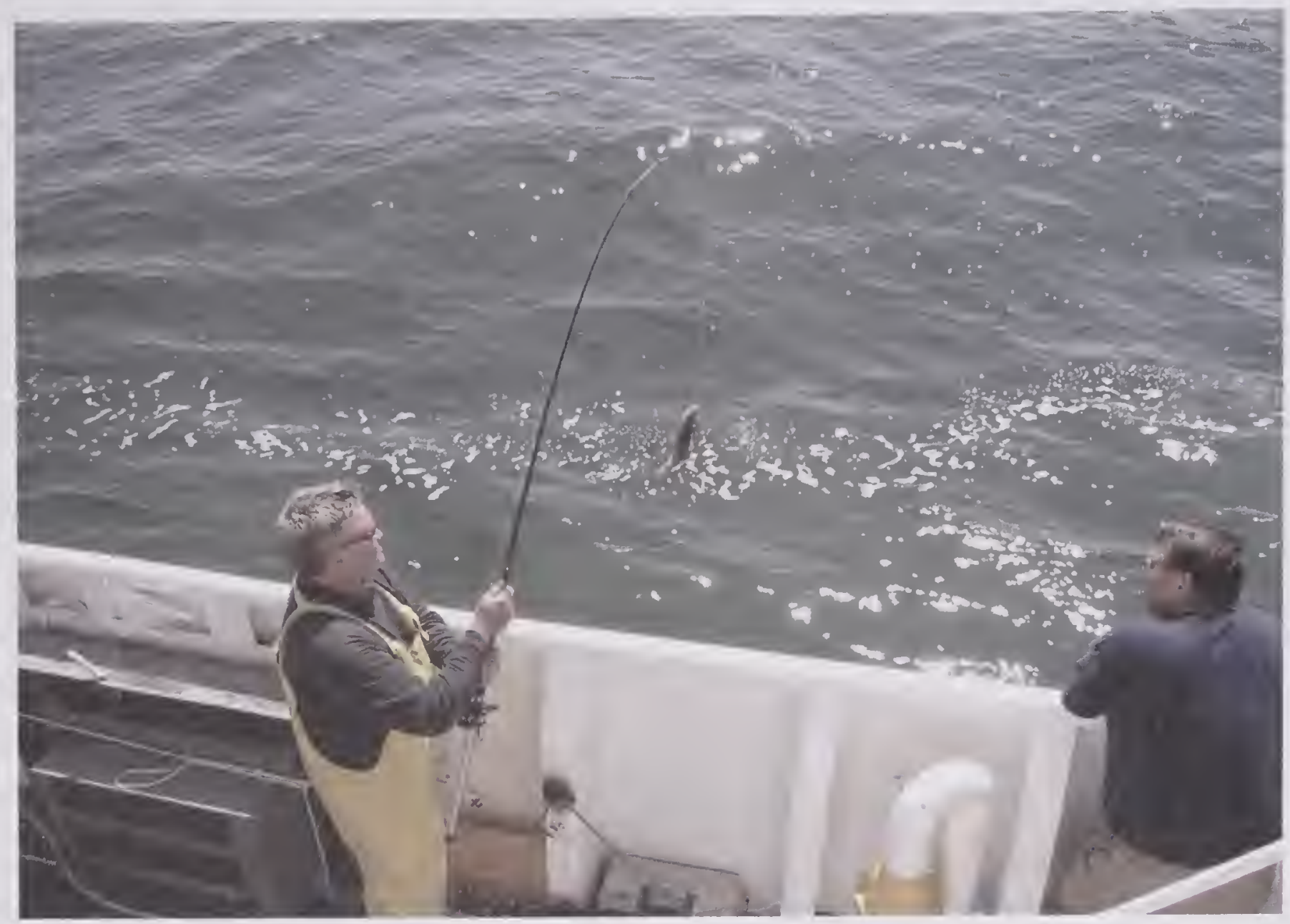

Figure 2.4.1. Hook-and-line fishing for fish tissue sampling aboard the NOAA ship MCARTHUR II.

\subsubsection{FRAM Groundfish Survey}

At the FRAM sites, bottom trawl operations were conducted by commercial fishing vessels chartered by NOAA. GPS and net-mounted sensors recorded time series of position, depth, temperature, and net dimension readings during trawling and other environmental observations were collected manually. At the conclusion of each trawl operation, species composition, fish sex, length, weight and other observations were gathered either manually or by various electronic equipment. Fish were frozen on board and transferred to EPA or state partners for analysis of fish-tissue contaminants.

\subsection{Quality Assurance}

\subsubsection{Quality Assurance/ Quality Control of Chemical Analyses}

The quality assurance/quality control (QA/QC) program for the NCA-West program is defined by the "Environmental Monitoring and Assessment Program (EMAP): National Coastal Assessment Quality Assurance Project Plan 2001-2004" (U.S. EPA 2001). A performance-based approach is used which, depending upon the compound, includes: 1) continuous laboratory evaluation through the use of Certified Reference Materials (CRMs), Laboratory Control Materials (LCMs), or Standard Reference Material (SRM); 2) laboratory spiked sample matrices; 3) laboratory reagent 
blanks; 4) calibration standards; 5) analytical surrogates; and 6) laboratory and field replicates. The objective of this performance-based approach is to assist the laboratories in meeting desired Data Quality Objectives (DQOs) as defined in the EMAP Quality Assurance Project Plan (U.S. EPA 2001).

A measure of whether the analytical procedure is sufficient to detect the analytes at environmental levels of concern is the Method Detection Limits (MDLs). Approved laboratories were expected to perform in general agreement with the target MDLs presented for NCA analytes (Table A7-2 in U.S. EPA 2001). Because of analytical uncertainties close to the MDL, there is greater confidence with concentrations above the Reporting Limit (RL), which is the concentration of a substance in a matrix that can be reliably quantified during routine laboratory operations. Typically, RLs are 3-5 times the MDL. In these analyses, concentrations between the MDL and the RL were included in the calculation of the means or cumulative distribution functions (CDFs), while values below the MDL were set to zero.

One measure of accuracy of the analytical procedure is the "relative accuracy," which is based on computing the percent deviation of the laboratory's value from the true or "accepted" values in CRMs, LCMs, or SRMs. The requirements for PAHs, PCBs, and pesticides are that the "Lab's value should be within $\pm 30 \%$ of true value on average for all analytes, not to exceed $\pm 35 \%$ of true value for more than $30 \%$ of individual analytes" (U.S. EPA 2001). For metals and other inorganic compounds, the laboratory's value for each analyte should be within $\pm 20 \%$ of the true value of the CRM, LCM, or SRM. Another measure of accuracy is the percent recovery from matrix spikes. High percent recoveries in matrix spikes indicate that the analytical method and instruments can adequately quantify the analyte but do not evaluate the ability of the analytical procedure to extract the compound from natural tissue or sediment matrices. Measures of precision are the "relative percent differences" (RPD) or coefficient of variation (CV) of replicate samples, with the objective that the RPD or CV should be $<30 \%$.

A post-analysis assessment of the success of the analytical laboratories in meeting NCA QA/QC requirements was conducted by the QA manager of the Western Ecology Division. The percent recovery from certified/standard materials, recovery from matrix spikes, and the average RPD for non-zero sample replicates and matrix spikes are given in Appendix Tables $3 a-3 c$ and summarized here.

\subsubsection{Metals in Sediments}

The recommended MDL (Table A7-2 in U.S. EPA, 2001) varies by metal, ranging from $0.01 \mu \mathrm{g} / \mathrm{g}$ for mercury to $1500 \mu \mathrm{g} / \mathrm{g}$ for aluminum. The MDLs for metals in sediment were met by each state with the following exceptions. Oregon had a MDL for antimony of $0.3 \mu \mathrm{g} / \mathrm{g}$ versus the recommended detection limit of $0.2 \mu \mathrm{g} / \mathrm{g}$. Washington had a MDL for selenium of $0.84 \mu \mathrm{g} / \mathrm{g}$ versus the recommended detection limit of 0.1 $\mu \mathrm{g} / \mathrm{g}$. Oregon had a MDL for tin of $0.5 \mu \mathrm{g} / \mathrm{g}$ versus the recommended detection limit of 
$0.1 \mu \mathrm{g} / \mathrm{g}$. Washington had a high MDL for tin $(20 \mu \mathrm{g} / \mathrm{g})$ however due to the method of calculating the MDL for this compound the RL $(0.2 \mu \mathrm{g} / \mathrm{g})$ was lower than the MDL and close to the recommended detection level of $0.1 \mu \mathrm{g} / \mathrm{g}$.

California and Oregon met all the DQOs for the average deviation for all sediment metals, deviations for the individual metals, and for precision. California had a low accuracy for silver while Oregon had a low accuracy for tin. Washington met the precision and the matrix spike recovery DQOs for all metals. However, the average deviation for the 15 metals in Washington was $29.8 \%$, exceeding the DQO of an average of $20 \%$ for metals. Failure to meet this DQO was due to the high deviance $(>90 \%)$ for arsenic, selenium, and tin, and values for these metals should be interpreted cautiously for samples from Washington.

\subsubsection{Organics in Sediments}

The recommended MDLs (Table A7-2 in U.S. EPA, 2001) are $10 \mathrm{ng} / \mathrm{g}$ for PAHs and $1 \mathrm{ng} / \mathrm{g}$ for PCBs, DDTs, and chlorinated pesticides. All three states met the MDL requirements for all the organic compounds with the exception of toxaphene in California which had a MDL of $10 \mathrm{ng} / \mathrm{g}$. With the exception of PCBs for one of two standards used by Washington, all three states met the DQOs for recovery from matrix spikes and for precision for all the organic compounds.

In terms of accuracy, California met the DQOs that the average deviation for all PCBs was within $\pm 30 \%$ of the average value within the standard reference material as well as that $70 \%$ of the individual PCB congeners were measured within $\pm 35 \%$ of the true values. Washington failed to meet the recommended average deviation from reference materials of $<30 \%$ for PCBs. The major factor driving this failure was PCB congener 105 which had a percent deviation of $192 \%$. When all the PCB congeners are considered, $83 \%$ of the individual congeners were within $\pm 35 \%$ of true values. Oregon accuracy for PCBs was not as high as the other two states, with an average difference between the reported PCB values and the certified values of $115 \%$ or $71 \%$ if PCB 170 is excluded. Only three of the 19 PCB congeners were within $\pm 35 \%$ of true value in the standards even though recoveries were high in the matrix spikes. In analyzing the sediment PCB data, the Oregon data should be interpreted cautiously as should the PCB 105 data from Washington.

Both California and Oregon met the accuracy DQOs for sediment DDTs, though Oregon had poor accuracy with 2,4'-DDE. In Washington, all three of the DDTs measured in the standard reference material exceeded the value in the standard by $>50 \%$. In analyzing the sediment DDT data, the Washington values should be interpreted cautiously

The standard reference materials used by the three states did not contain most of the non-DDT pesticides, so that it was necessary to use the recoveries in the matrix spikes as a measure of accuracy. In California, all the recoveries from the spiked matrix 
was within $2-12 \%$ of the true value while in Oregon 10 of the 12 non-DDT pesticides were within $\pm 35 \%$ of the value in the spiked matrix. Accuracy was not as good in Washington with 7 of the 12 pesticides within $\pm 35 \%$ of the spiked value. Because recoveries from a spiked matrix is not as rigorous an evaluation of accuracy as those derived from natural matrices, small differences in concentrations should not be over interpreted.

California met the accuracy DQOs for sediment PAHs. In Oregon, the average percent deviation from the true value for PAHs was $40 \%$ compared to the DQO of $30 \%$. Eight of the $20 \mathrm{PAHs}$ measured in the reference material deviated from the true values by $>35 \%$, though only benzo(b)fluoranthene and dibenz(a,h)anthracene showed deviations $>50 \%$. Washington also failed to meet the overall standard, with an average percent deviation for all PAHs of $44 \%$. Nine of the $23 \mathrm{PAHs}$ measured in Washington deviated by $>35 \%$ from the true value, with 6 of these compounds deviating by $>50 \%$ (2,3,5-trimethylnaphthalene, 2,6-dimethylnaphthalene, acenaphthylene, benzo(k)fluoranthene, dibenz(a,h)anthracene, dibenzothiophene). The PAH data should be interpreted with consideration that Oregon and Washington did not achieve the average overall DQOs for PAHs and, in particular, data for compounds deviating by $>50 \%$ should be interpreted cautiously.

\subsubsection{Metals in Tissue}

The recommended MDL (Table A7-2 in U.S. EPA, 2001) in tissue varies by metal, ranging from $0.01 \mu \mathrm{g} / \mathrm{g}$ for mercury to $50 \mu \mathrm{g} / \mathrm{g}$ for iron and zinc. All three states met the MDL recommendations for metals in tissue with the following exceptions: at $0.015 \mu \mathrm{g} / \mathrm{g}$, Oregon's MDL for mercury was slightly higher than the recommended detection of $0.01 \mathrm{\mu g} / \mathrm{g}$. Both Oregon and Washington exceeded the recommended MDL for tin of $0.05 \mu \mathrm{g} / \mathrm{g}$ with detection limits of $0.15 \mu \mathrm{g} / \mathrm{g}$ and $0.2-0.22 \mu \mathrm{g} / \mathrm{g}$ respectively. All three states met the requirement for precision. Oregon and Washington met the DQO that recovery of metals from matrix spikes should be in the range of $50 \%-120 \%$ of the spiked concentration. However, California did not conduct any matrix spikes with tissues. In terms of accuracy, all three states met the average and individual DQOs, though the Washington standard reference material contained only 7 of the 13 metals.

\subsubsection{Organics in Tissue}

The recommended MDLs (Table A7-2 in U.S. EPA, 2001) in tissue are $2.0 \mathrm{ng} / \mathrm{g}$ for both PCBs and the chlorinated pesticides. All three states met the MDL recommendations for organics in tissues with the following exceptions: Oregon had a MDL of $20 \mathrm{ng} / \mathrm{g}$ for endosulfan I, endosulfan II, and endosulfan sulfate. Oregon had a MDL of $200 \mathrm{ng} / \mathrm{g}$ for toxaphene while California had a detection limit of $10 \mathrm{ng} / \mathrm{g}$. Oregon had a detection limit of $10 \mathrm{ng} / \mathrm{g}$ for endrin. All three states met the requirement for precision that the average RPD or CV for PCBs and pesticides in replicate samples be $<30 \%$. Oregon and Washington met the DQO that recovery of PCBs and pesticides from matrix spikes should be in the range of $50 \%-120 \%$ of the spiked concentration. 
However, California did not conduct any matrix spikes with tissues.

In terms of accuracy, California met the DQOs that the average deviation for all PCBs was within $\pm 30 \%$ of the average value within the standard material as well as that $70 \%$ of the individual PCB congeners were measured within $\pm 35 \%$ of true value. Both Washington and Oregon failed the DQO that the average deviation for the PCBs should be within $\pm 30 \%$ of the average value in the standard. Additionally, only 3 of the 17 PCB congeners measured in Oregon and none of the 10 congeners measured in Washington were within $\pm 35 \%$ of the value in the standard. Because of this low accuracy when assessed with standard reference materials, the tissue PCB data from Oregon and Washington need to be interpreted cautiously.

In both California and Oregon, the average percent deviation of the four DDTs measured in the reference material was less than or equal to the DQO of $30 \%$. However, the value for 4,4'-DDE in Oregon differed from the reference material by $>50 \%$. In comparison, all four of the DDTs measured in Washington deviated from the standard reference material by $\geq 63 \%$. Because of the low accuracy when assessed with standard reference materials, the tissue DDT data from Washington and the Oregon 4,4'-DDE values should be interpreted cautiously.

California analyzed only two of the 14 non-DDT pesticides in the standard reference material and did not conduct matrix spikes with tissues as an alternate demonstration of recovery. Accuracy for the compounds measured in the reference material (dieldrin and trans-nonachlor) was good; however without values for the other pesticides it is not possible to assess the overall accuracy for the non-DDT pesticides in California. Washington and Oregon measured most of the non-DDT pesticides in either their reference material and/or in a spiked matrix. Average deviation for the pesticides in both states failed the DQO and deviations for most individual pesticides were $>35 \%$ from the reference material or the spiked matrix. Because of the uncertain accuracy in the California tissue values and the low accuracy in Oregon and Washington, the tissue values for the non-DDT pesticides should be used cautiously.

\subsection{Statistical Data Analyses}

The use of a probability-based sampling design allows the development of estimates of the extent of area, with 95\% confidence intervals, of the West Coast Shelf resource $(30-120 \mathrm{~m})$ corresponding to any specified value of the measured indicator. Analysis of indicator data was conducted by calculation of cumulative distribution functions (CDFs), an analysis approach that has been used extensively in other EMAP/NCA coastal studies (Summers et al. 1993, Strobel et al. 1995, Hyland et al. 1996, U.S. EPA 2004, 2006). A detailed discussion of methods for calculation of the CDFs used in EMAP analyses is provided in Diaz-Ramos et al. (1996). Results of the CDF analysis are presented in the present report primarily as the values of an indicator which correspond to given percentiles of the cumulative distribution. Where known 
thresholds of concern exist, e.g. dissolved oxygen concentration $<2.3 \mathrm{mg} / \mathrm{L}$, percentiles are reported for such values. Where thresholds of concern have not been developed, e.g., the benthic variables, indicator values that represent common reporting values for frequency distributions (e.g., the median, $90^{\text {th }}$ percentile, upper and lower quartiles), are presented. Data presented graphically in this report are primarily in the form of CDFs, pie charts, and simple bar graphs representing the mean +1 standard deviation of the indicator values.

\subsection{Sampling, Data Integration, and Data Quality Issues}

The initial effort to develop a sampling frame representing only soft-sediment areas of the West Coast was generally a success, and a limited number of stations within the EMAP cruise effort had to be abandoned as a result of encountering rocky bottom. Primarily this occurred in the Strait of Juan de Fuca (Section 2.1 above), and the frame definition was adjusted a posteriori to remove this area. There were two additional stations abandoned on the Washington shelf, no stations were abandoned on the Oregon shelf, and two stations were abandoned on the California shelf as a result of encountering rocky bottom. All abandoned stations were replaced with alternate stations from the initial sampling design.

During the Oregon leg of the EMAP cruise, there were malfunctions of the CTD sensors which affected data for temperature, salinity, depth, and dissolved oxygen at numerous stations on the Oregon shelf. Questionable data due to equipment malfunction were flagged in the database and removed from data analyses. All Oregon Total Suspended Solids (TSS) data were flagged as questionable and removed from analyses. Filters for TSS appear to have been inadequately washed to remove salt crystals.

While the Bight ' 03 and NCA-West/EMAP studies were both designed as probability-based surveys, and the initial presumption was that data could be easily merged, the studies were executed and managed separately, and some data integration and compatibility issues arose as a result. For example, water-column nutrient samples were not collected at all Bight '03 stations within the target depth range for the NCAWest/EMAP survey. For those samples collected, only nitrate and nitrite were analyzed, whereas the NCA-West/EMAP samples were analyzed for nitrate, nitrite and ammonium, and thus the studies were not directly comparable for total dissolved nitrogen. Tissue contaminant samples of demersal fishes were generally not collected under the Bight '03 program. In the case of some multi-density categories, the Bight '03 program was unable to sample the target number of primary stations called for in the sample design, and no alternate stations were occupied. Thus the multi-density category weights for the data analysis were adjusted based on the actual number of stations occupied. 


\subsection{Results and Discussion}

Presentation of results for individual indicators utilizes cumulative distribution functions (CDFs) representing the percentage area of the sample frame associated with given values of the indicator. In the case of some parameters, estimates of the percentage of shelf area above or below published benchmark values of the indicator are also presented. For example, estimates are made of the percentage of area having sediment contaminants in excess of corresponding Effects Range Median (ERM) or Effects Range Low (ERL) sediment quality guideline values of Long et al. (1995) where such values are available (see Section 3.2.2). In other cases where there are no relevant benchmarks available from the literature, common statistical percentiles (e.g., $50^{\text {th }}, 90^{\text {th }}$, upper and lower quartiles) are used to assist in the interpretation of spatial patterns.

\subsection{Sampling Locations}

A total of 146 stations from Cape Flattery, WA, to Pt. Conception, CA were successfully sampled as part of Cruise AR-03-01-NC (Figures 3.1.1-3.1.5, Appendix Table 1). Data from one additional station off Santa Catalina Island that was a part of the NCA continental shelf assessment design were also provided by SCCWRP. An additional three stations within the NCA that were within the Channel Islands could not be sampled because of rocky bottom and were abandoned. Data from fifty stations were obtained within Washington waters. Data from fifty stations were also obtained within Oregon waters, although a sample for sediment infauna was not obtained at Station OR03-0010. Data from forty-seven stations were obtained in California waters (46 north of Pt. Conception and one off Santa Catalina Island). Although there was some evidence of washing of the sediments from the infaunal sample at Station CA030140, the data were included in the analyses. Of those 147 stations, 57 occurred within National Marine Sanctuary (NMS) boundaries, including 30 in the Olympic Coast NMS, 12 in the Gulf of Farallones NMS, 14 in Monterey Bay NMS, and one in Cordell Bank NMS.

A total of 110 additional stations were successfully sampled for some or all of the NCA parameters within the target depth range by participants in the Bight ' 03 survey. These stations were located within the Channel Islands NMS (27 stations) and throughout the SCB (83 stations, Figures 3.1.5). The 83 stations were distributed in five multi-density categories that were part of the Bight ' 03 survey design, with sample numbers per category ranging from 6 to 29 (Appendix Table 1). Rocky bottom was prevalent in the Channel Islands NMS and many stations in the original sampling design could not be sampled.

Fish from a total of 91 stations within Washington, Oregon, and California waters (Fig. 3.1.6 - 3.1.9) were collected for EPA for fish tissue contaminants as part of NOAA's FRAM Groundfish survey. Due to resource limitations, samples from 63 stations were actually analyzed, while three of these stations were excluded when they 
were found to have been sampled outside the target depth range (Appendix Table 2).

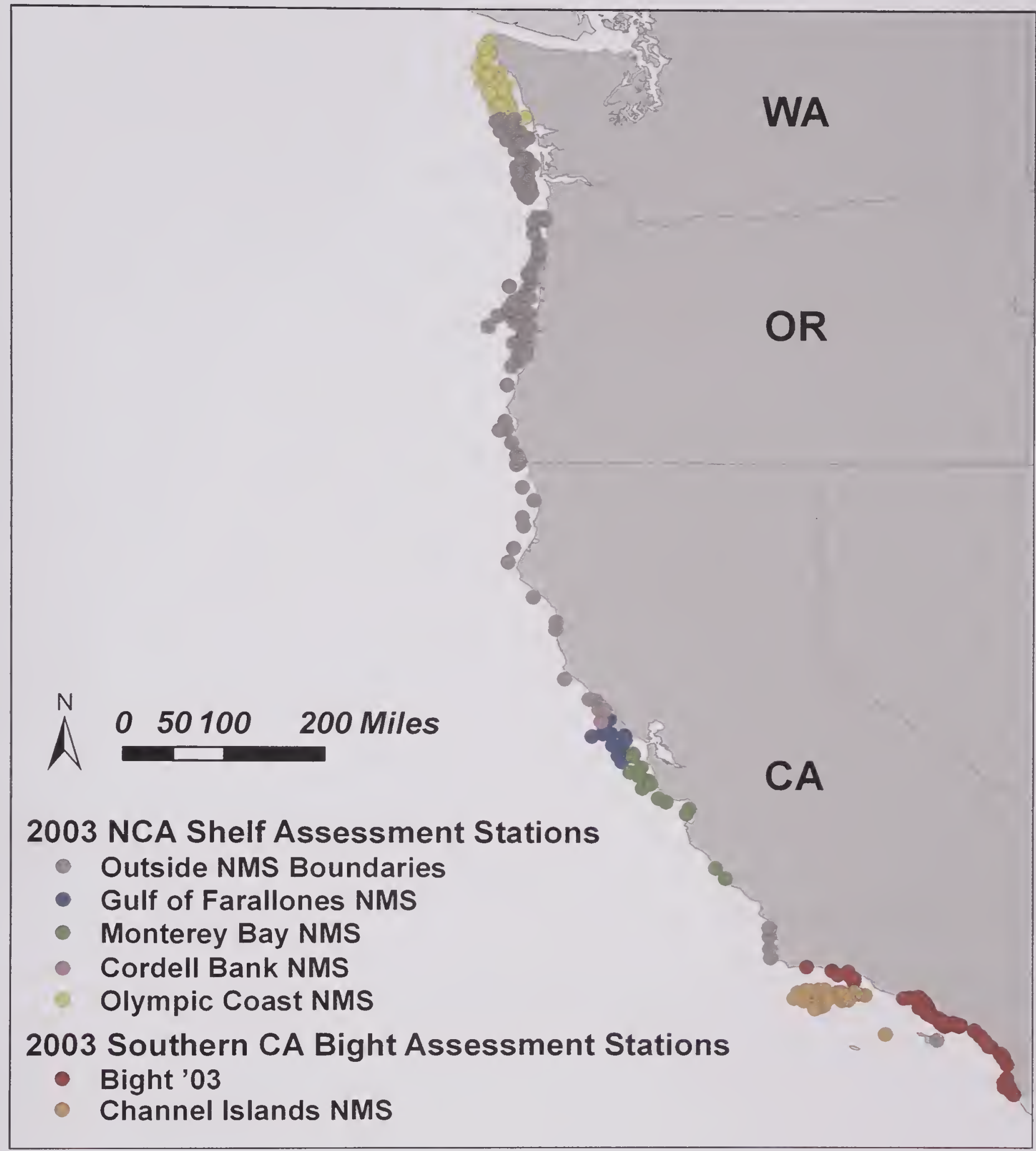

Figure 3.1.1. Distribution of sampling stations for the NCA 2003 West Coast Shelf Assessment. Data from stations sampled as part of the Bight '03 program that were within the target depth range were included in the NCA analyses. All stations within the Channel Islands were sampled by participants in the Bight ' 03 program. 


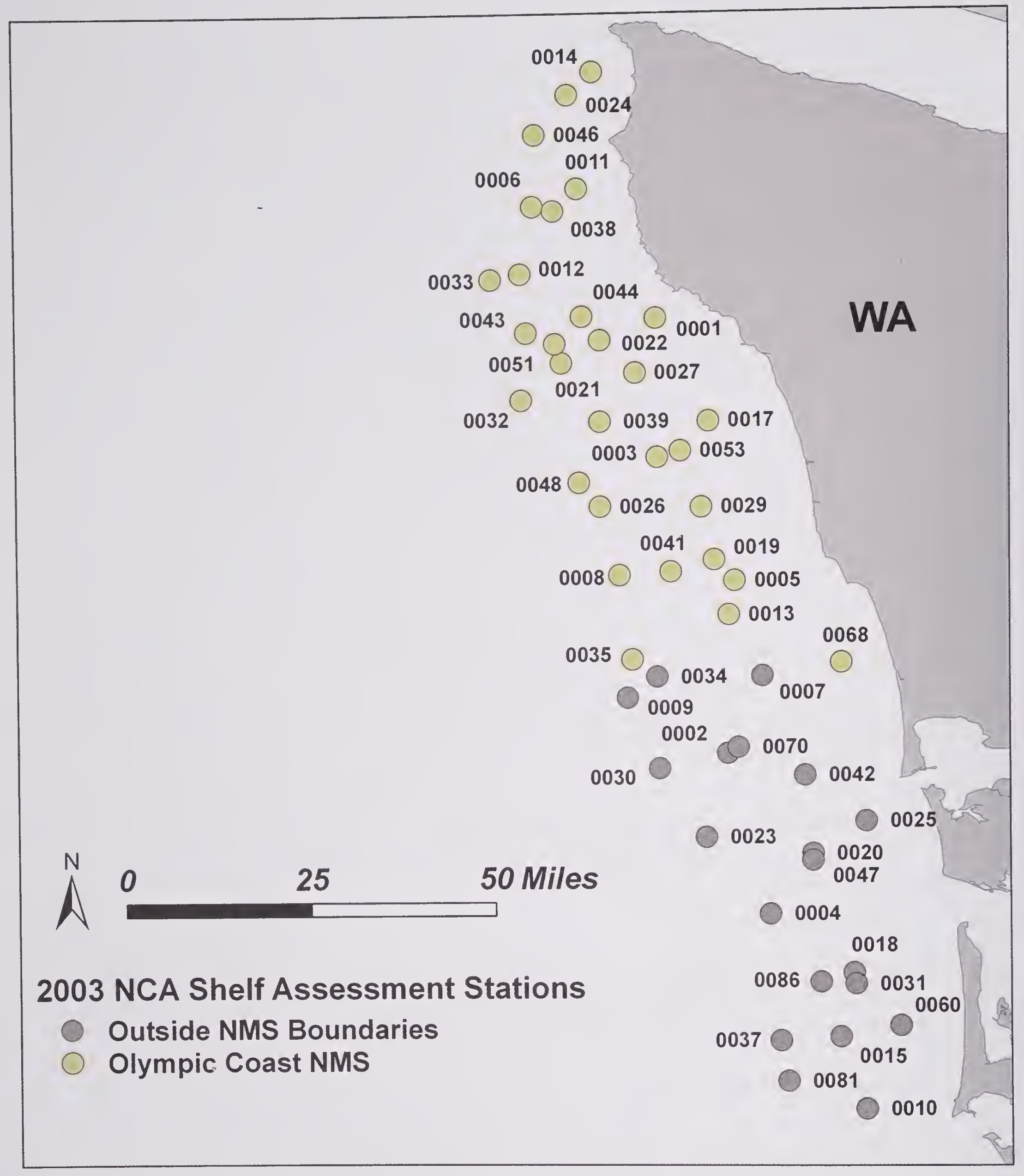

Figure 3.1.2. Distribution of sampling stations for the NCA 2003 West Coast Shelf Assessment along the continental shelf of Washington, showing stations within or outside of the Olympic Coast NMS. Numbers are the last 4 digits of the EMAP Station ID (Appendix Table 1). 


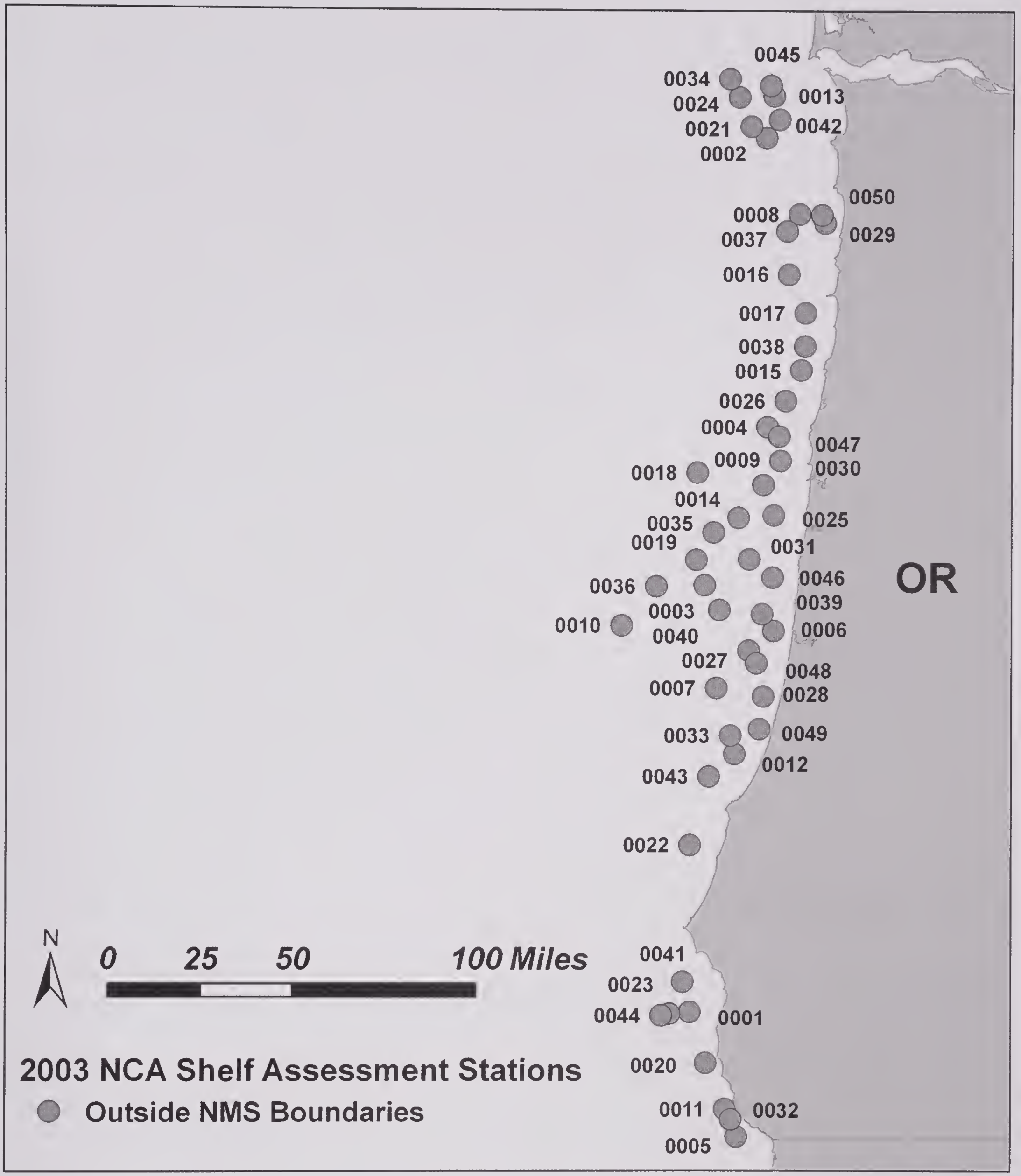

Figure 3.1.3. Distribution of sampling stations for the NCA 2003 West Coast Shelf Assessment along the continental shelf of Oregon. Numbers are the last 4 digits of the EMAP Station ID (Appendix Table 1). 


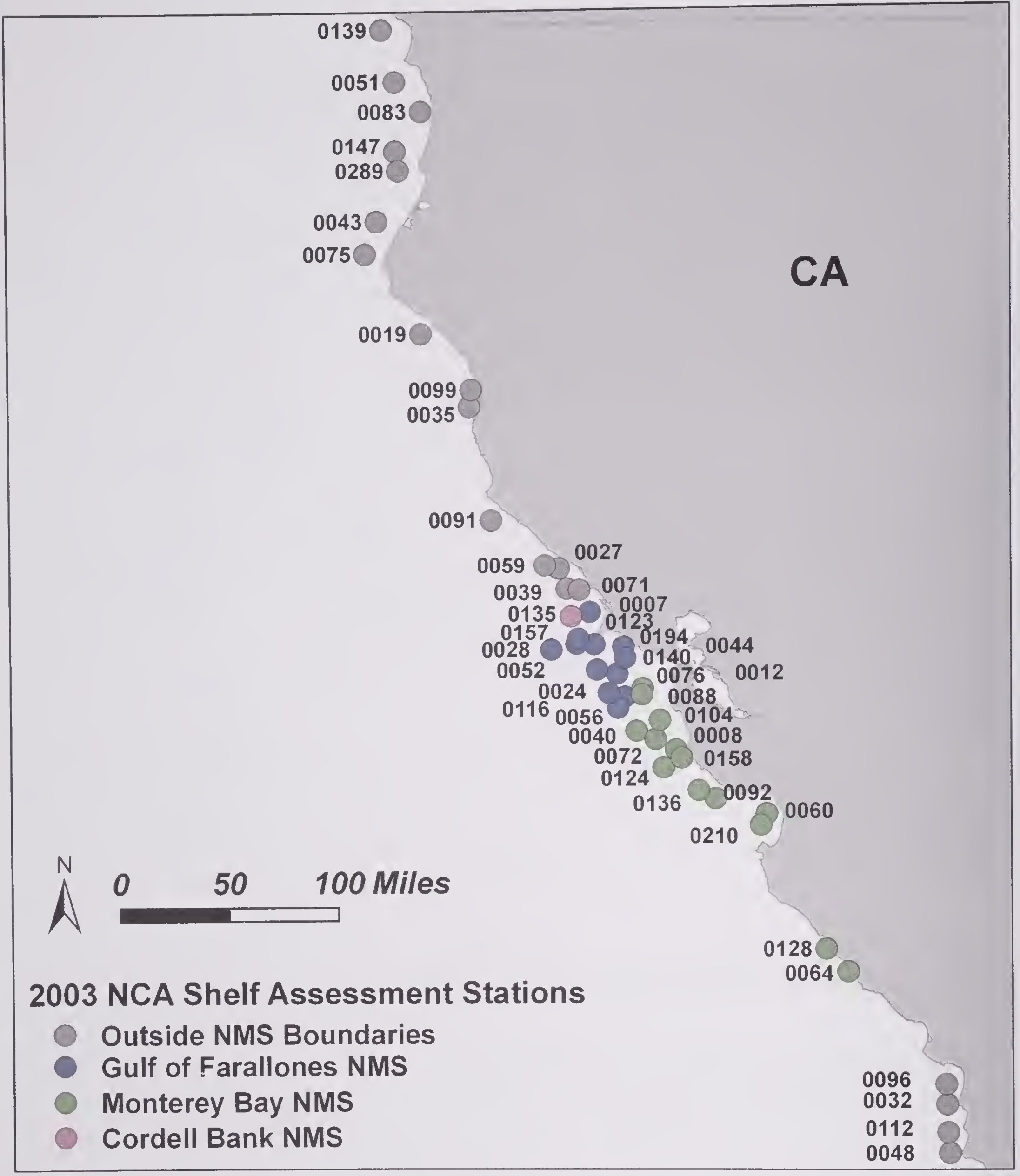

Figure 3.1.4. Distribution of sampling stations for the NCA 2003 West Coast Shelf Assessment along the continental shelf of California north of Pt. Conception. The region includes three NMS. Numbers are the last 4 digits of the EMAP Station ID (Appendix Table 1). 
$\frac{4}{\frac{5}{0}}$

荥

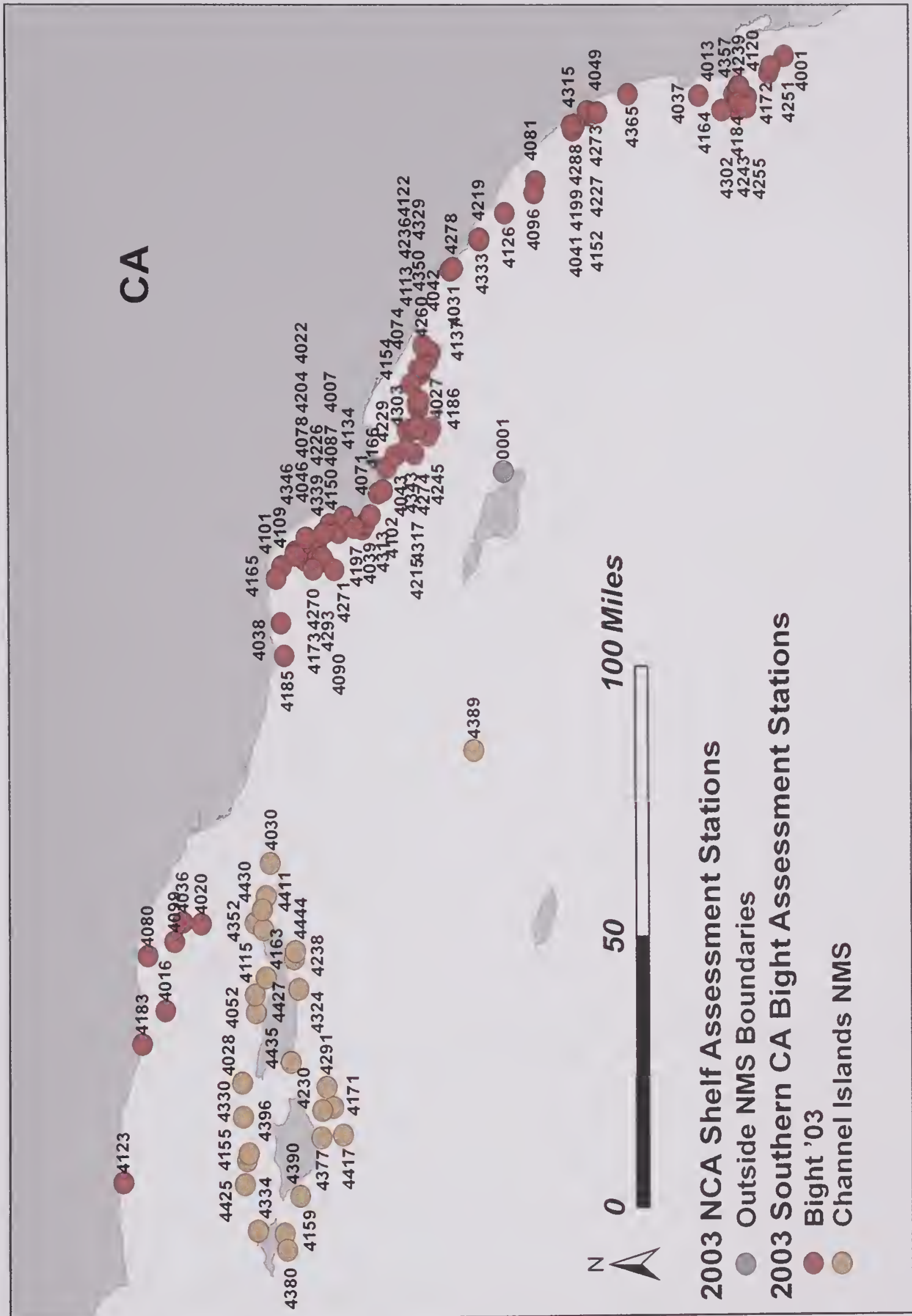

言旁

0 음

$\stackrel{\oplus}{\mp}$

은

음

它 峁

क ज

क व

क है

禹立

प)

ज芹

舫

ก .

U든

क

उ

응 둔

它声

๖ํ

$\stackrel{\oplus}{=}$

은

क

응 둥

훈 응

ด

등

它施

论证远

을 을

을 을

○

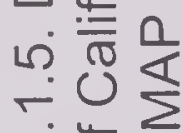

लं

产 


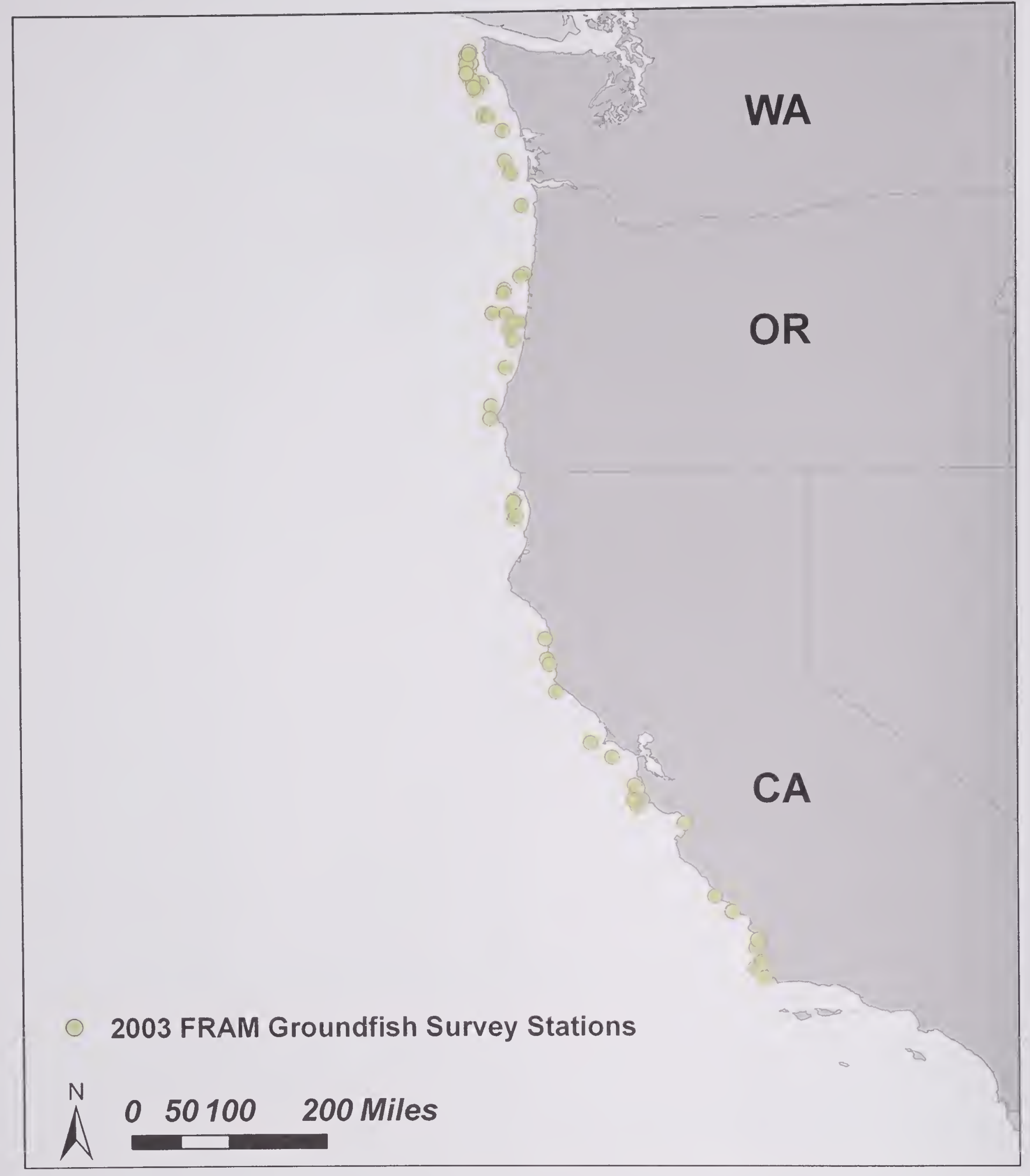

Figure 3.1.6. Distribution of sampling stations for the 2003 FRAM Groundfish Survey from which fish tissue samples were collected for analysis by NCA. 


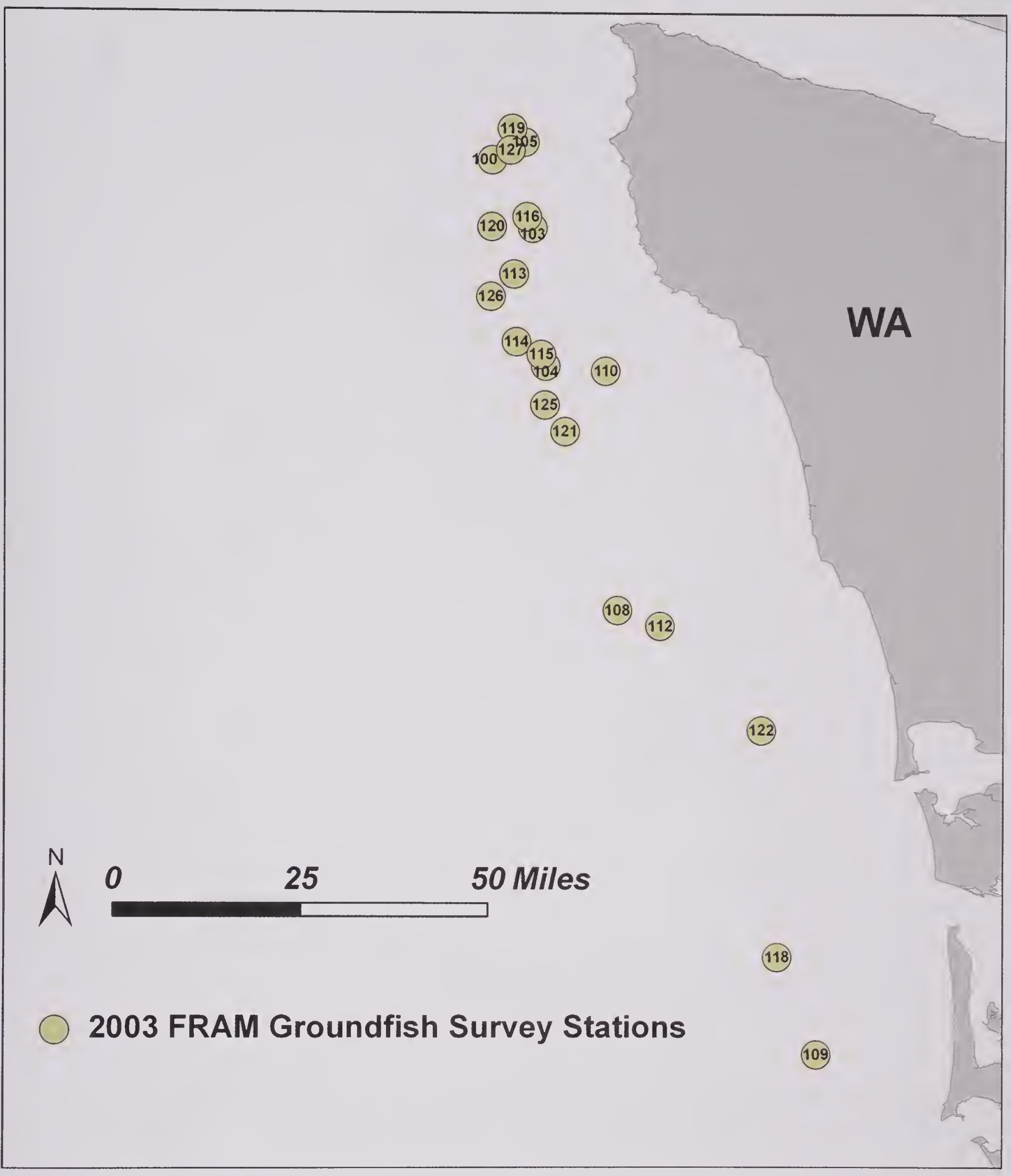

Figure 3.1.7. Distribution of sampling stations for the 2003 FRAM Groundfish Survey along the continental shelf of Washington, from which fish tissue samples were collected for analysis by NCA. Numbers are the last 3 digits of the EMAP Station ID (Appendix Table 2). 


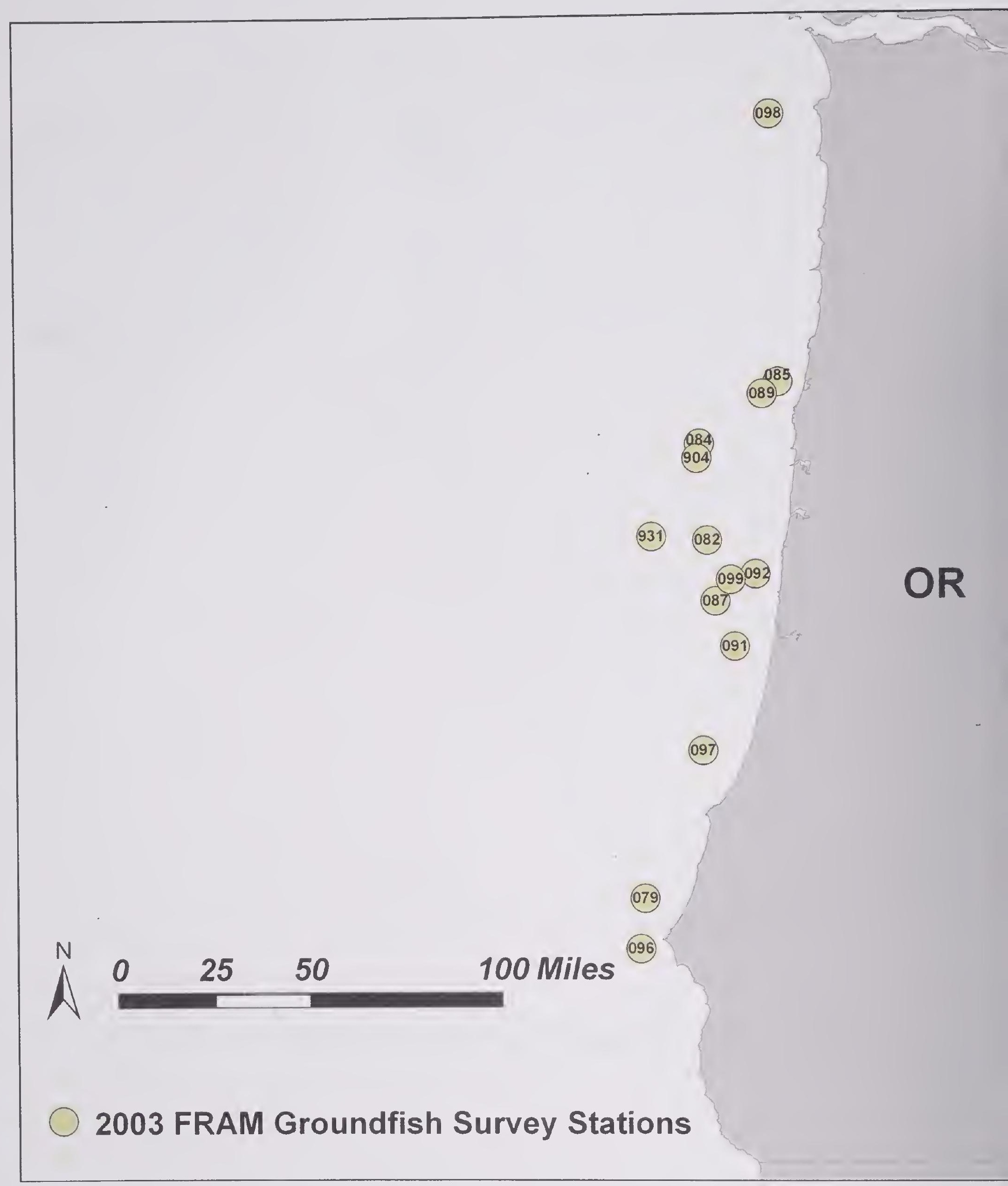

Figure 3.1.8. Distribution of sampling stations for the 2003 FRAM Groundfish Survey along the continental shelf of Oregon, from which fish tissue samples were collected for analysis by NCA. Numbers are the last 3 digits of the EMAP Station ID (Appendix Table 2). 


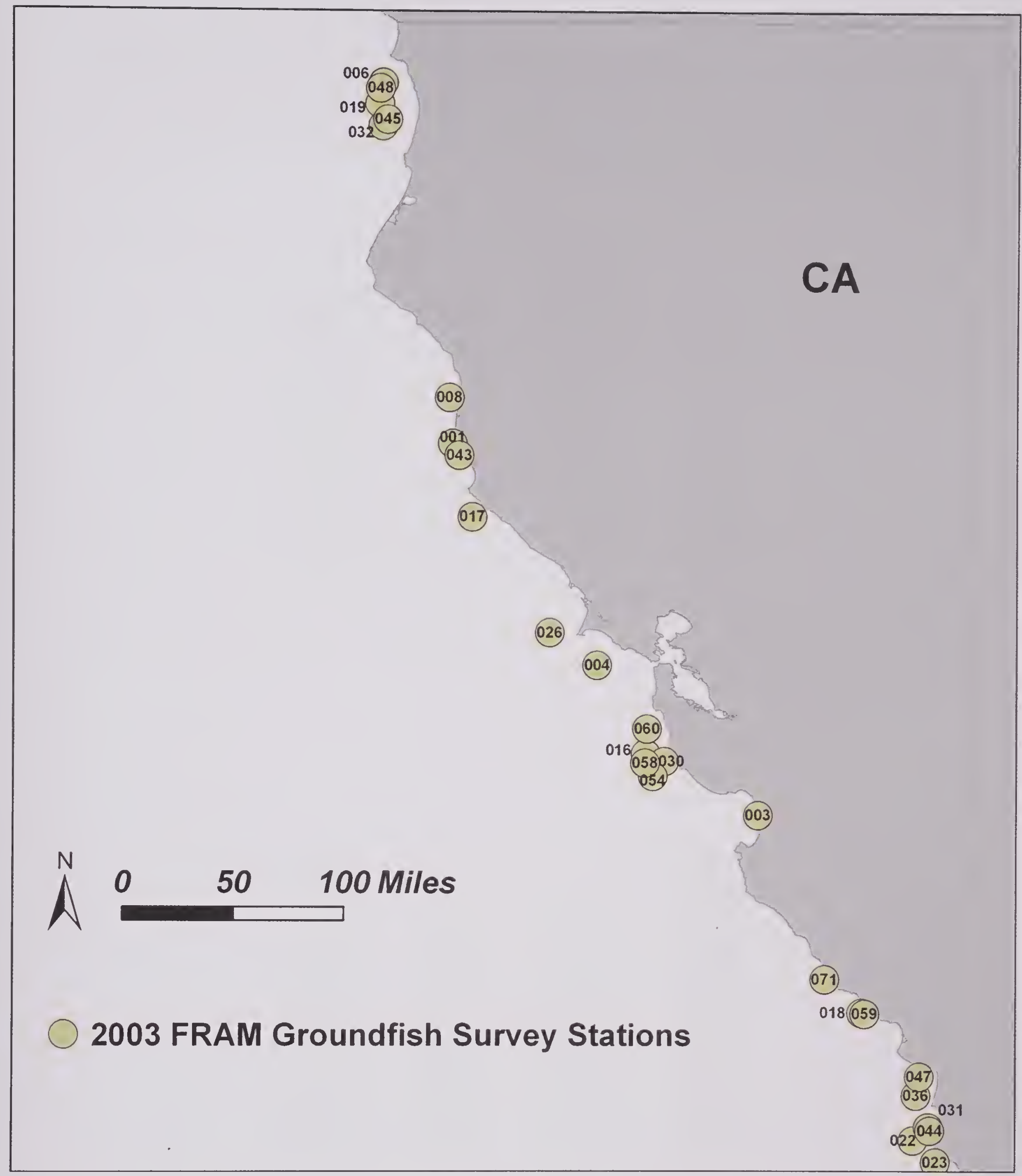

Figure 3.1.9. Distribution of sampling stations for the 2003 FRAM Groundfish Survey along the continental shelf of northern California, from which fish tissue samples were collected for analysis by NCA. Numbers are the last 3 digits of the EMAP Station ID (Appendix Table 2). 
Bottom depth for the 257 stations sampled in waters of the West Coast shelf ranged from $28 \mathrm{~m}$ to $138 \mathrm{~m}$. Four stations, all from the SCB sampled as part of the Bight ' 03 study, exceeded the target frame depth of $120 \mathrm{~m}$ but were included in the analyses in order to obtain adequate sample numbers from some multi-density categories. The mean depth of the waters of the West Coast shelf sampled was $72.6 \mathrm{~m}$ (Figure 3.1.10).

A variety of bottom types was encountered among the various stations. Along the Pacific coastline of Washington, the seabed was mostly fine sand, with a higher incidence of silt and clay in water depths greater than $60 \mathrm{~m}$. Five stations in Washington could not be sampled due to the presence of hard bottom and thus were replaced with alternate sites from the sampling design. Three stations in the Strait of Juan de Fuca could not be sampled because they fell in an area of seabed composed of coarse gravel, cobbles and rock fragments. These stations were replaced with reserve sites along the Pacific coastline, outside the Strait of Juan de Fuca, and near the mouth of the Columbia River. Along the Oregon coastline, fine sand was also the most common bottom type encountered. The sediment collected during the California leg of the cruise was highly variable and included both fine sands and silty sediments. The highest percentages of fine sediments were found at California stations. Two stations along the California coastline had to be abandoned due to rocky conditions and were replaced with alternate stations. Further details on sediment composition are presented in Section 3.3.1 below. 

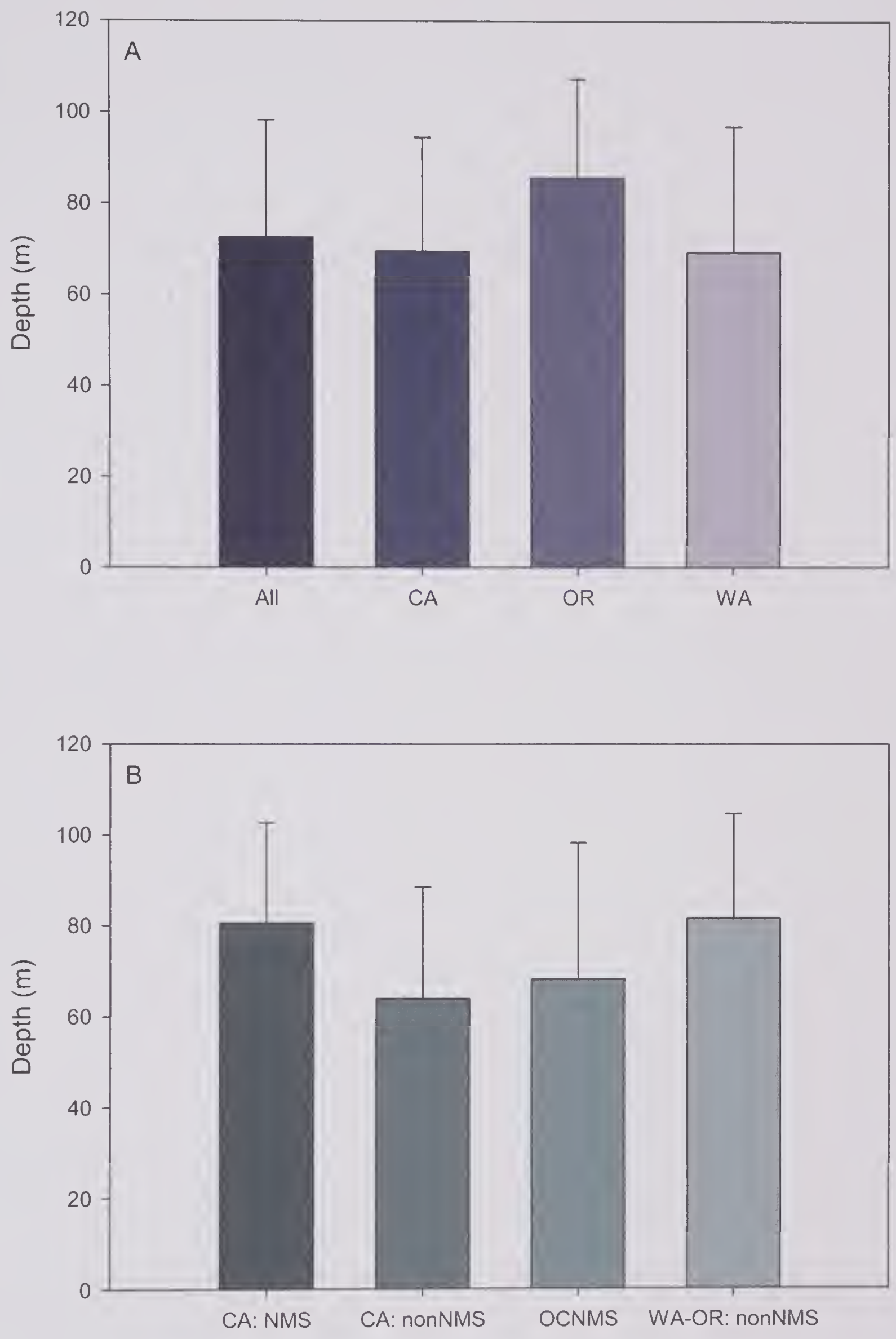

Figure 3.1.10. Mean +1 SD station depths compared among (A) all, California, Oregon, and Washington sample locations, and (B) California NMS, California non-NMS, Olympic Coast NMS, and Washington-Oregon nonNMS sample locations. 


\subsection{Water Column Characteristics}

\subsubsection{Salinity}

Salinity in the surface waters of the West Coast shelf for the 140 stations for which data were obtained ranged from 21.2 to $34.0 \mathrm{psu}$. The $50^{\text {th }}$ percentile of area had a surface salinity of $33.3 \mathrm{psu}$, while the $90^{\text {th }}$ percentile had a salinity of 33.9 psu. An estimated $8 \%$ of area had a surface salinity of $\leq 31$ psu. The majority of stations with surface salinity $\leq 31$ psu were located off the mouth of the Columbia River or farther south along the Oregon coast, presumably within the plume from the Columbia River (Figure 3.2.1). Surface salinity was generally less than 33 psu to the north of Cape Blanco, Oregon, and greater than 33 psu to the south of Cape Blanco (Figure 3.2.1). Reflecting this pattern, mean surface salinities were slightly lower in Washington and Oregon than California (Figure 3.2.2 A), and slightly lower in the OCNMS as compared to the CA NMSs (Figure 3.2.2 B).

Bottom salinity ranged only between 31.6 and 34.4 psu for the 164 stations for which data were obtained. The $50^{\text {th }}$ percentile of area had a bottom salinity of $33.9 \mathrm{psu}$, while the $90^{\text {th }}$ percentile had a salinity of $34.0 \mathrm{psu}$. An estimated $3.3 \%$ of the area of the shelf surveyed had a bottom salinity of $<33$ psu, represented by seven stations all located within the northern region of the Washington shelf. There was virtually no difference in the mean bottom salinity among states or between NMS and non-NMS stations (Figure 3.2.3).

\subsubsection{Water Temperature}

Temperature in the surface water of the West Coast shelf for the 140 stations for which data were obtained ranged from $8.5^{\circ} \mathrm{C}$ to $19.9^{\circ} \mathrm{C}$. The $50^{\text {th }}$ percentile of area had a surface-water temperature of $11.9^{\circ} \mathrm{C}$, while the $90^{\text {th }}$ percentile had a surface water temperature of $13.5^{\circ} \mathrm{C}$. Mean surface-water temperatures were similar between Washington and Oregon, while the California average was several ${ }^{\circ} \mathrm{C}$ higher (Figure 3.2.4 A). Highest mean surface temperatures were observed in the CA non-NMS stations. The CA NMS stations were similar to the OCNMS (Figure 3.2.4 B), reflecting the fact that most measurements were obtained from the NMS off the central California coast, while temperature data were missing from the Channel Islands NMS.

Temperature in the bottom water of the West Coast shelf for the 164 stations for which data were obtained ranged from $5.8^{\circ} \mathrm{C}$ to $14.7^{\circ} \mathrm{C}$. The $50^{\text {th }}$ percentile of area had a bottom-water temperature of $7.8^{\circ} \mathrm{C}$, while the $90^{\text {th }}$ percentile had a bottom water temperature of $9.7^{\circ} \mathrm{C}$. Bottom-water temperatures for stations on the California coast were generally warmer by several ${ }^{\circ} \mathrm{C}$ than those from Oregon and Washington (Figure 3.2.5 A). The bottom-water temperatures for the CA NMS stations were slightly higher than the OCNMS (Figure $3.2 .5 \mathrm{~B}$ ) and probably would be much higher if temperature data from the 
Channel Islands NMS were available to include in the CA NMS average.

California non-NMS locations had the highest mean bottom-water temperature, resulting from the facts that many of the measurements were obtained within the Southern California Bight and that temperature data for NMSs in California were from more northerly locations exclusive of the Channel Islands NMS.

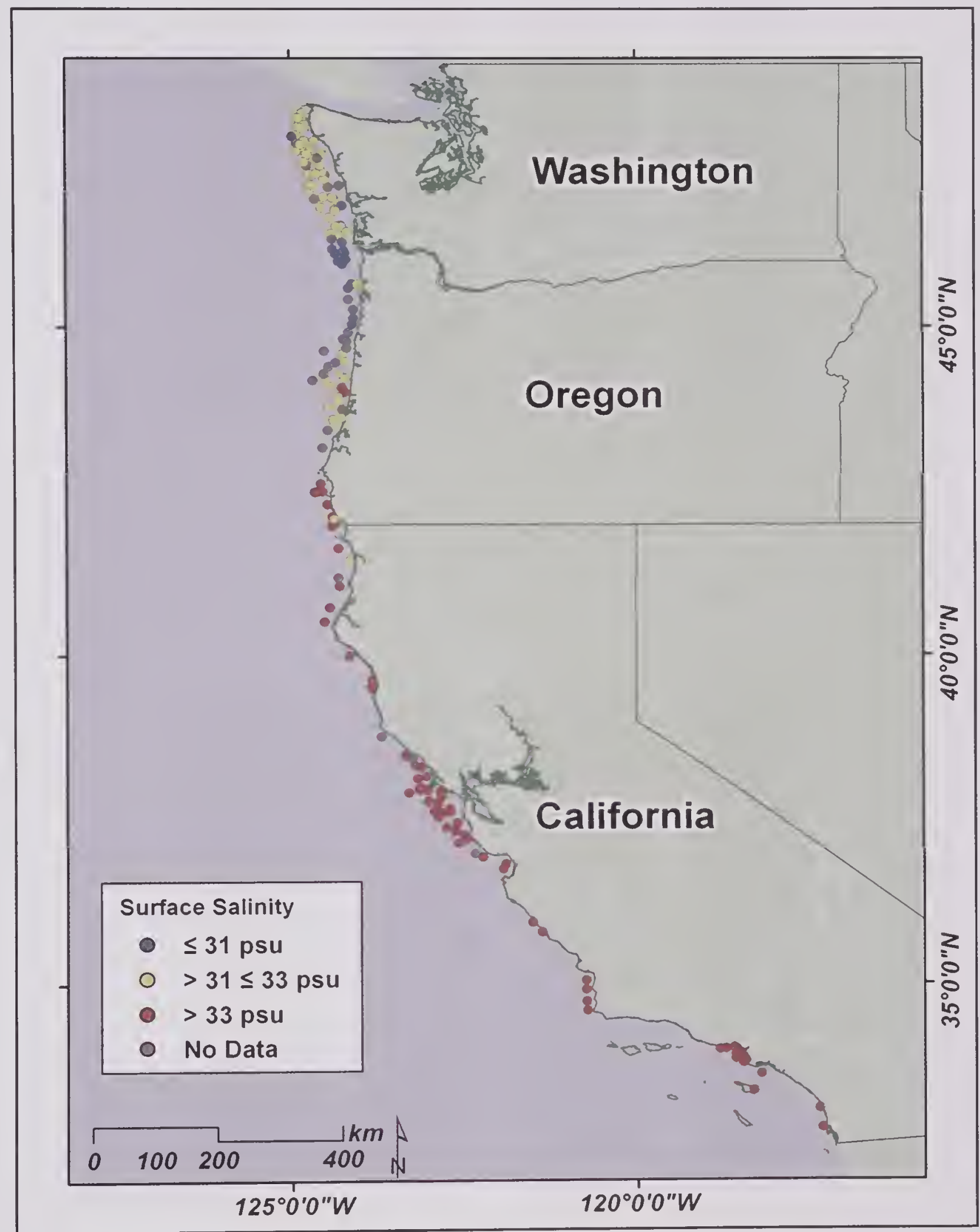

Figure 3.2.1. Distribution of surface salinity values for the West Coast Shelf sampling area, June 2003. 

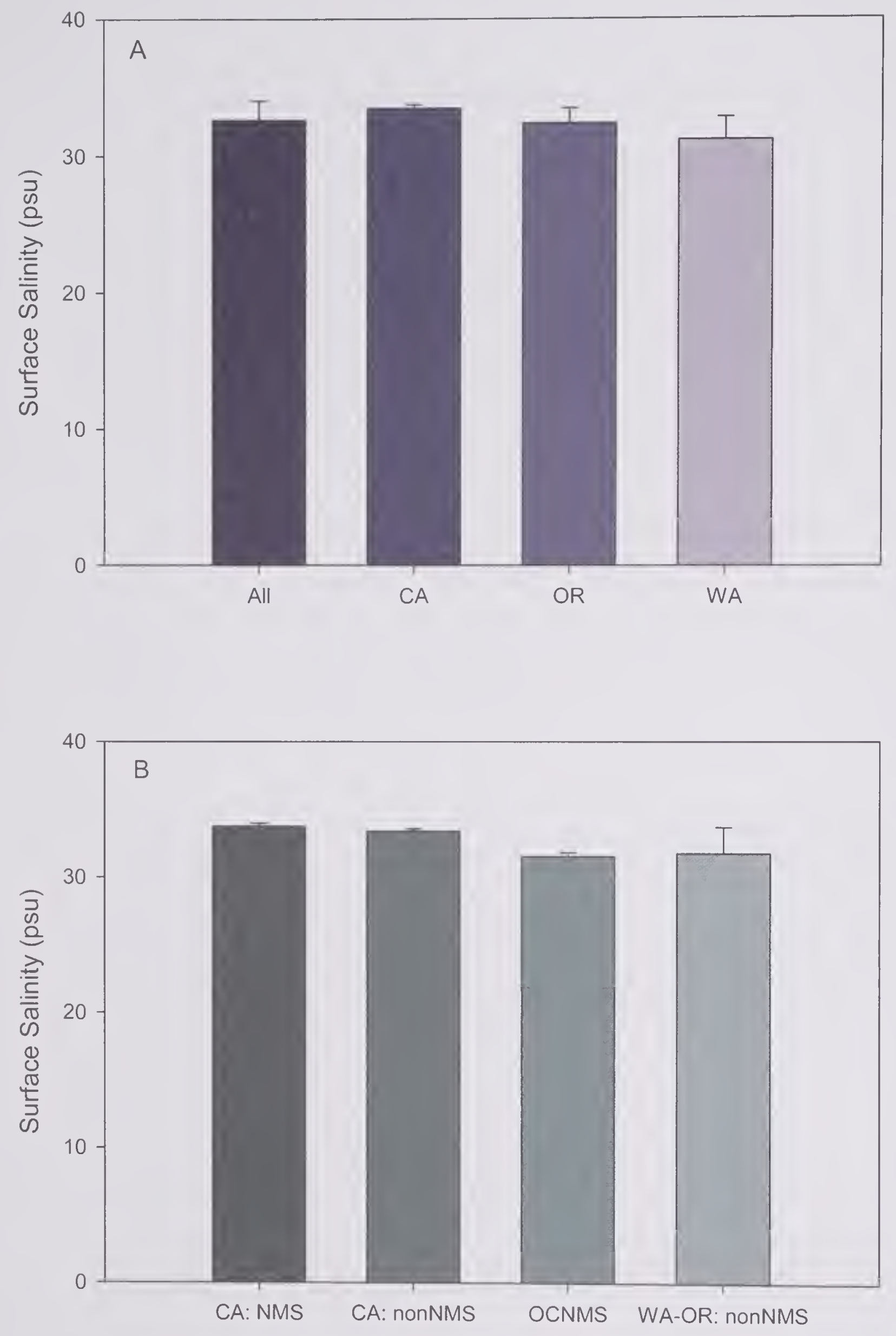

Figure 3.2.2. Mean +1 SD surface salinity compared among (A) all, California, Oregon, and Washington sample locations, and (B) California NMS, California non-NMS, Olympic Coast NMS, and Washington-Oregon nonNMS sample locations. 

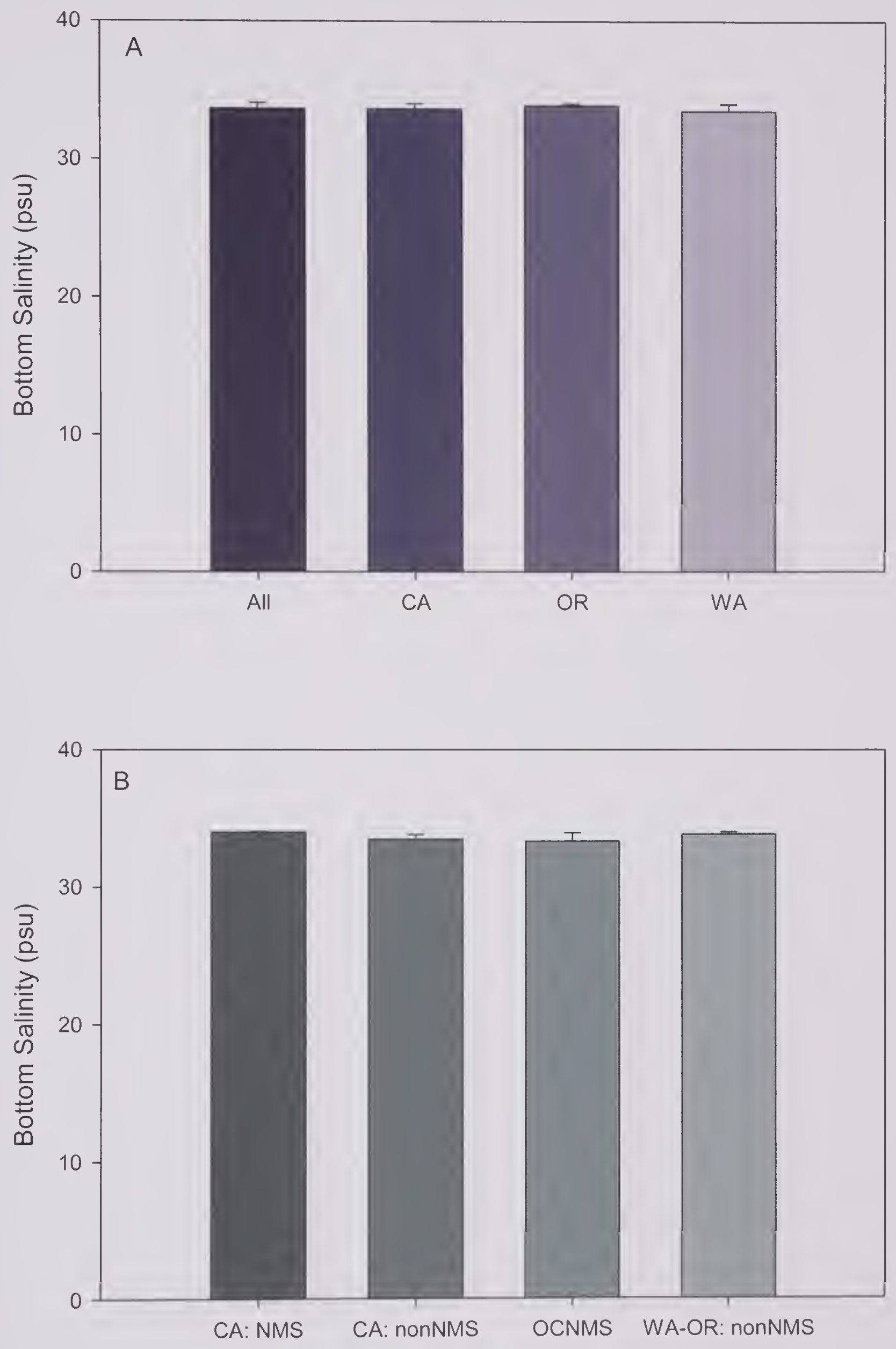

Figure 3.2.3. Mean +1 SD bottom salinity compared among (A) all, California, Oregon, and Washington sample locations, and (B) California NMS, California non-NMS, Olympic Coast NMS, and Washington-Oregon nonNMS sample locations. 

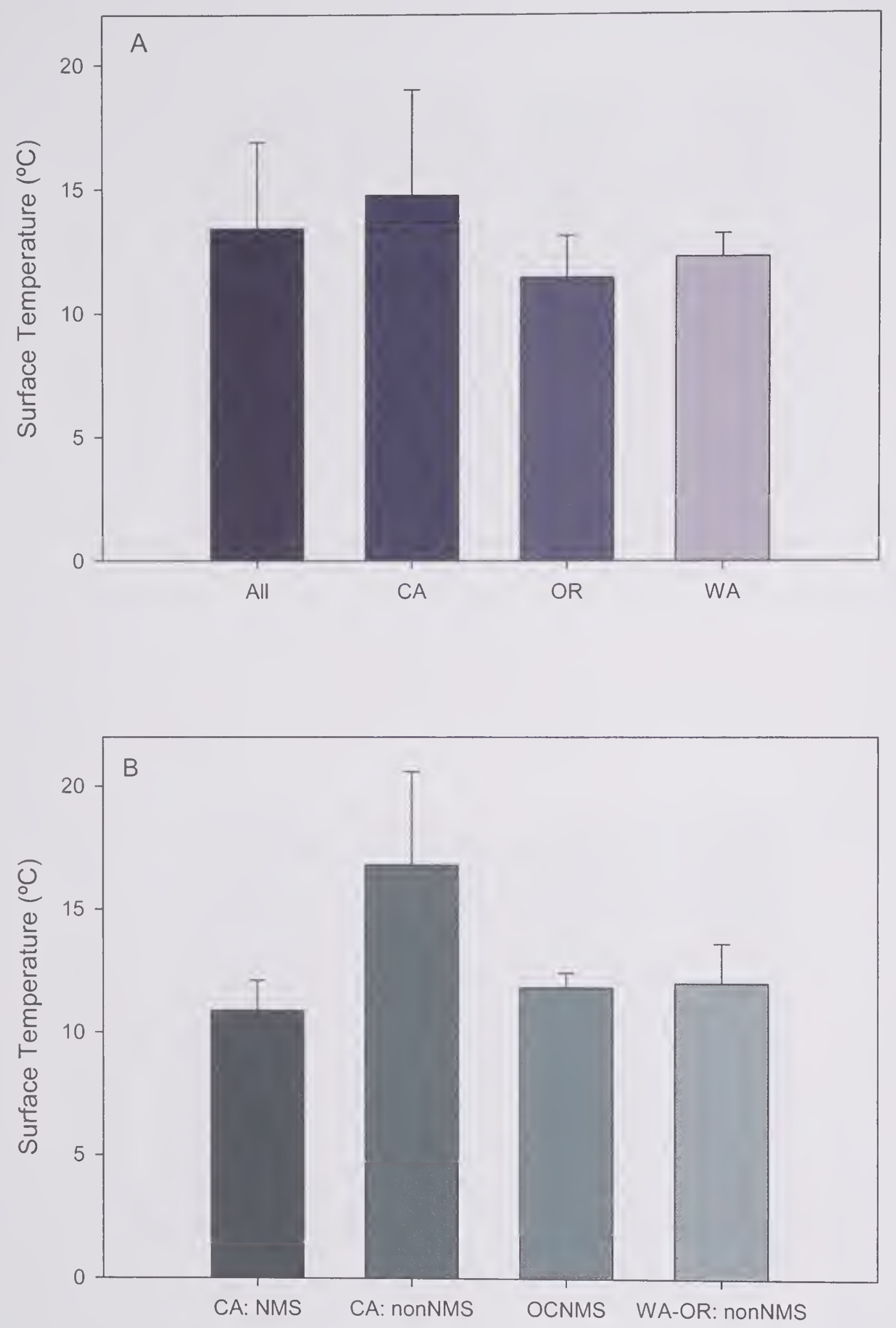

Figure 3.2.4. Mean +1 SD surface temperature compared among (A) all, California, Oregon, and Washington sample locations, and (B) California NMS, California non-NMS, Olympic Coast NMS, and Washington-Oregon non-NMS sample locations. 

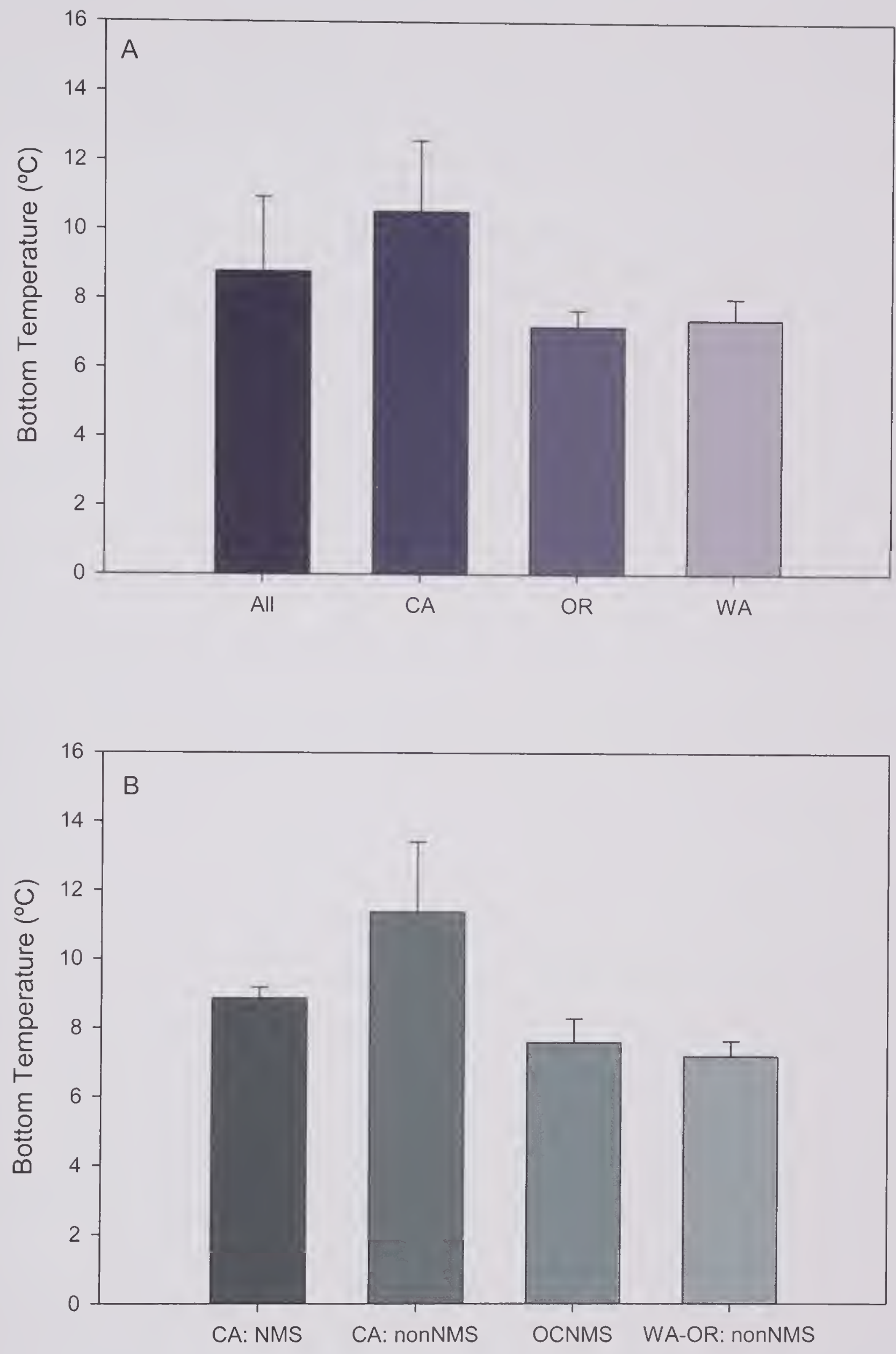

Figure 3.2.5. Mean $+1 \mathrm{SD}$ bottom temperature compared among (A) all, California, Oregon, and Washington sample locations, and (B) California NMS, California non-NMS, Olympic Coast NMS, and Washington-Oregon non-NMS sample locations. 


\subsubsection{Water-Column Stratification}

As an indicator of water-column stratification, an index of the variation between surface and bottom water densities was calculated from temperature and salinity data. The index $\left(\Delta \sigma_{t}\right)$ is the difference between the computed bottom and surface $\sigma_{t}$ values, where $\sigma_{t}$ is the density of a parcel of water with a given salinity and temperature relative to atmospheric pressure.

The $\Delta \sigma_{t}$ index for the 140 stations from waters of the West Coast shelf for which data were available ranged from 0.9 to 10.6 . Approximately $30.5 \%$ of the area of waters of the West Coast shelf had $\Delta \sigma_{t}$ index values greater than 2 , indicating strong vertical stratification of the water column. The mean stratification index was greatest for waters off Washington and least for California waters (Figure 3.2.6). The mean stratification index was lowest for the CA NMS locations and less than half the mean for the CA non-NMS stations. During the sampling of the central California coast where three of the CA NMS are located, extremely high winds were encountered, and it is likely that wind induced upwelling greatly reduced water-column stratification in this region. The Bakun upwelling index reflects the intensity of large-scale, wind-induced coastal upwelling based on estimates of offshore Ekman transport driven by geostrophic wind stress. Index values for $36^{\circ} \mathrm{N}$ latitude for the West Coast in June 2003 (source:

http://www.pfeg.noaa.gov/products/PFEL/modeled/indices/upwelling/NA/upwell menu_NA.html) showed that the peak upwelling period for the month occurred in the period June 17-24, exactly at the time when the CA NMS stations were being sampled (Figure 3.2.7).

\subsubsection{Dissolved Oxygen}

The range of dissolved oxygen (DO) concentrations in the surface waters of the West Coast shelf (data available for 140 stations) was $4.1 \mathrm{mg} / \mathrm{L}$ to 13.3 $\mathrm{mg} / \mathrm{L}$. U.S. EPA (2000a) proposed that a DO value below $2.3 \mathrm{mg} / \mathrm{L}$ is harmful to the survival and growth of marine animals based on data from the Virginian biogeographic province. A DO value of $>4.8 \mathrm{mg} / \mathrm{L}$ is considered the chronic protective value for growth, i.e. the ceiling above which DO conditions should support both survival and growth of most marine species. Values between 2.3 and $4.8 \mathrm{mg} / \mathrm{L}$ are potentially harmful to larval recruitment, depending on duration. Only approximately $2.6 \%$ of the area of waters of the West Coast shelf had surface DO concentrations $\leq 4.8 \mathrm{mg} / \mathrm{L}$. The $50^{\text {th }}$ percentile of area had a surface-water DO concentration of $9.8 \mathrm{mg} / \mathrm{L}$. Surface DO concentrations were higher in Washington and Oregon waters than in California and higher in the OC NMS than in the CA NMSs (Figure 3.2.8).

Bottom-water DO concentrations region-wide ranged from 2.1 to $8.3 \mathrm{mg} / \mathrm{L}$ across the 140 stations with acceptable DO data. Unfortunately, an instrument 

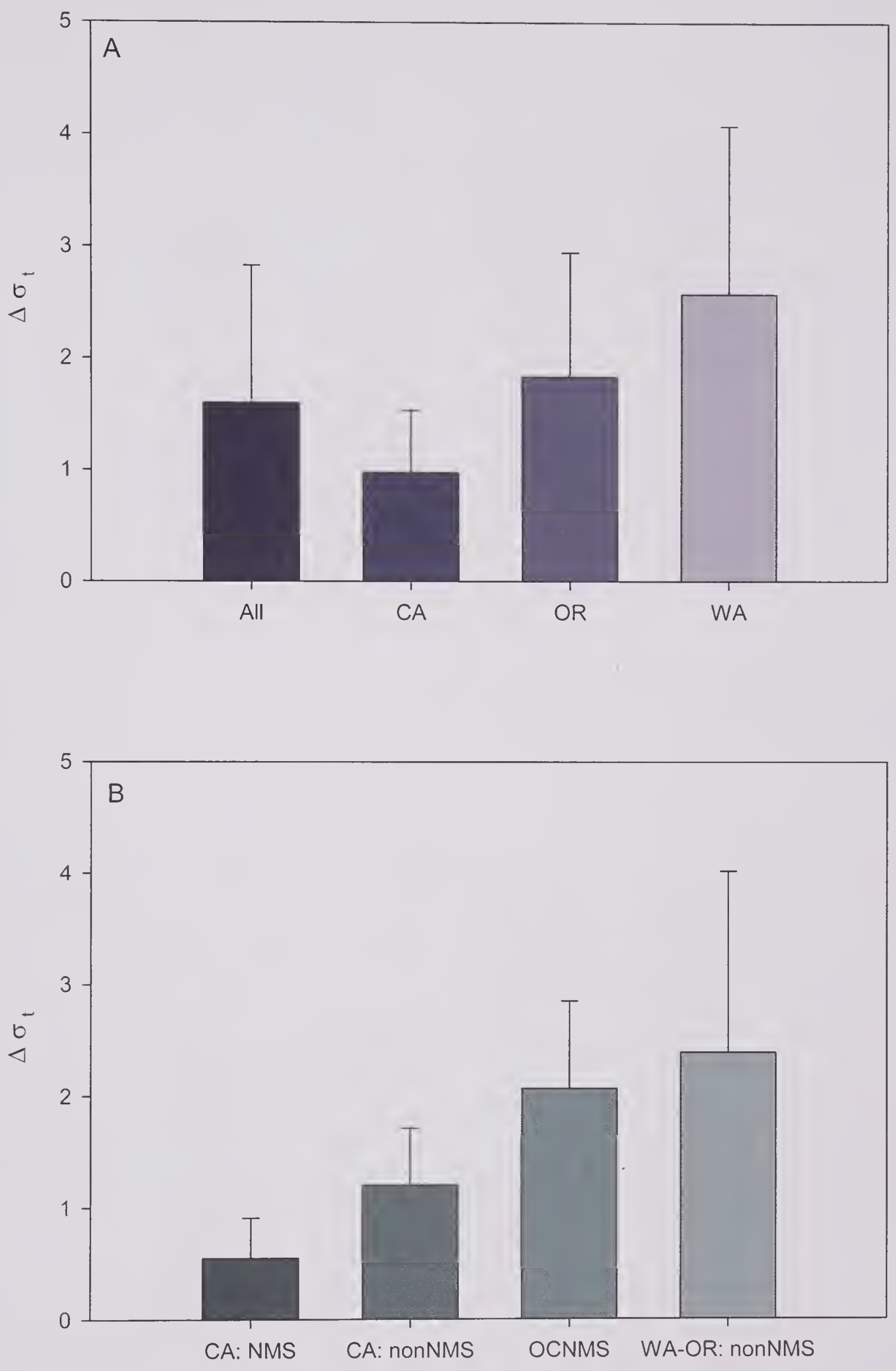

Figure 3.2.6. Mean $+1 \mathrm{SD}$ water-column stratification index $\left(\Delta \sigma_{t}\right)$ compared among $(A)$ all, California, Oregon, and Washington sample locations, and (B) California NMS, California non-NMS, Olympic Coast NMS, and Washington-Oregon non-NMS sample locations. 


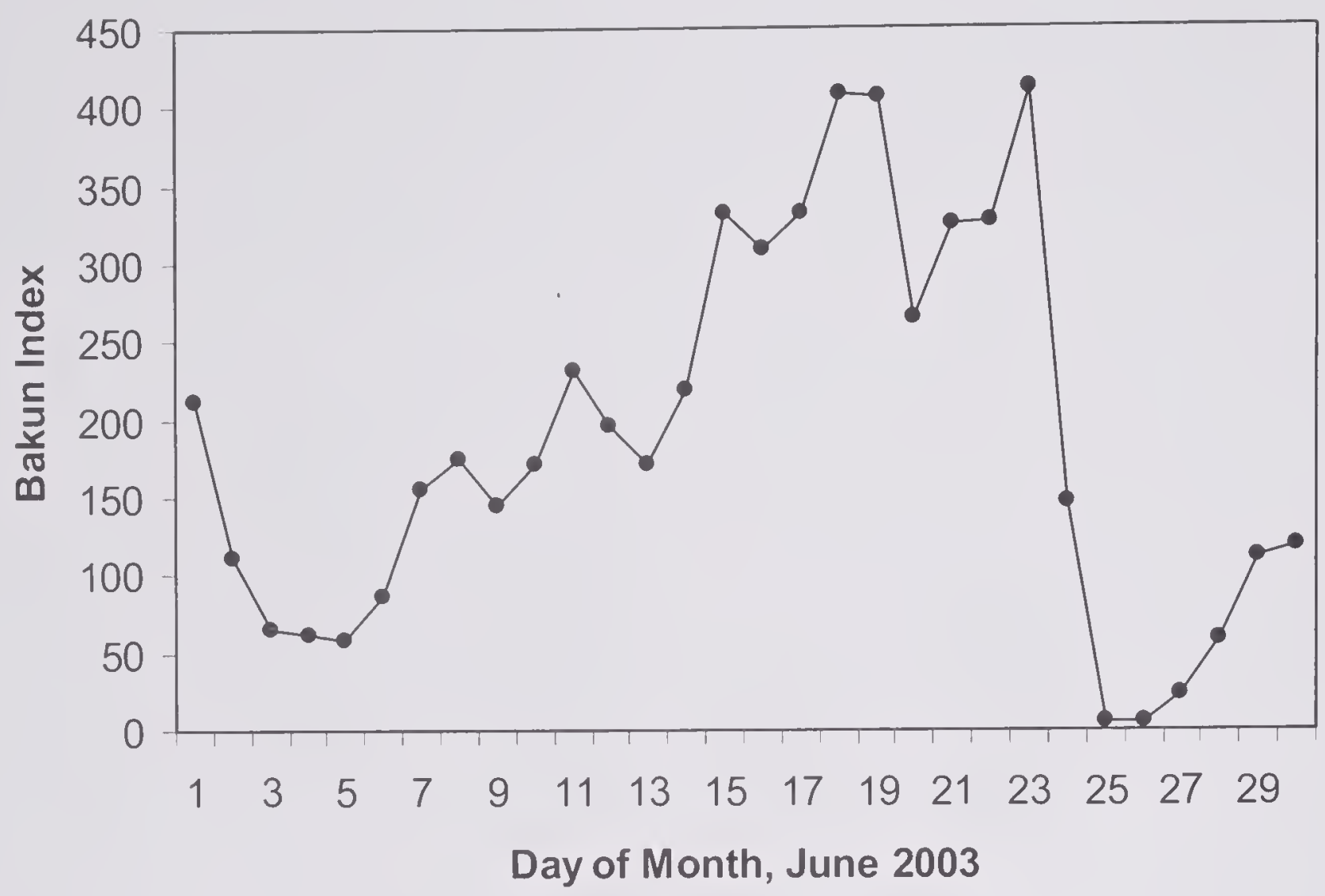

Figure 3.2.7. Bakun upwelling index for $36^{\circ} \mathrm{N}$ latitude for the West Coast in June 2003.

cable problem resulted in a failure to collect DO data from many stations along the north and central Oregon coast. An estimated $94.3 \%$ of the shelf area had a bottom-water DO concentration $\leq 4.8 \mathrm{mg} / \mathrm{L}$ and $6.6 \%$ of the area $(6$ of the 140 stations where DO data were available) had a bottom-water DO concentration $\leq$ $2.3 \mathrm{mg} / \mathrm{L}$. There was no geographic concentration of stations with bottom-water $\mathrm{DO}$ in this $\leq 2.3 \mathrm{mg} / \mathrm{L}$ range (Figure 3.2.9). Stations with bottom-water $\mathrm{DO} \geq 4.8$ $\mathrm{mg} / \mathrm{L}$ were concentrated at the extreme southern and northern ends of the survey region. Mean bottom-water DO concentrations were lower at Oregon stations than for Washington and California locations (Figure 3.2.10 A). Mean bottom DO was lower at the CA NMS stations than at the CA non-NMS stations, presumably resulting from the strong upwelling occurring during the sampling period that moved deeper low-DO water into the area (Figure 3.2.10 B).

Hypoxia on the continental shelf of the West Coast appears to be associated with upwelling conditions in the region, while severe hypoxic events in inshore shelf areas $(<70 \mathrm{~m})$ may be associated with changes in cross-shelf current patterns (Grantham et al. 2004). It appears that the frequency of shelf hypoxia has increased in recent years, and that shelf anoxia has now been observed at inner-shelf stations within $2 \mathrm{~km}$ of the surf zone (Chan et al. 2008). 

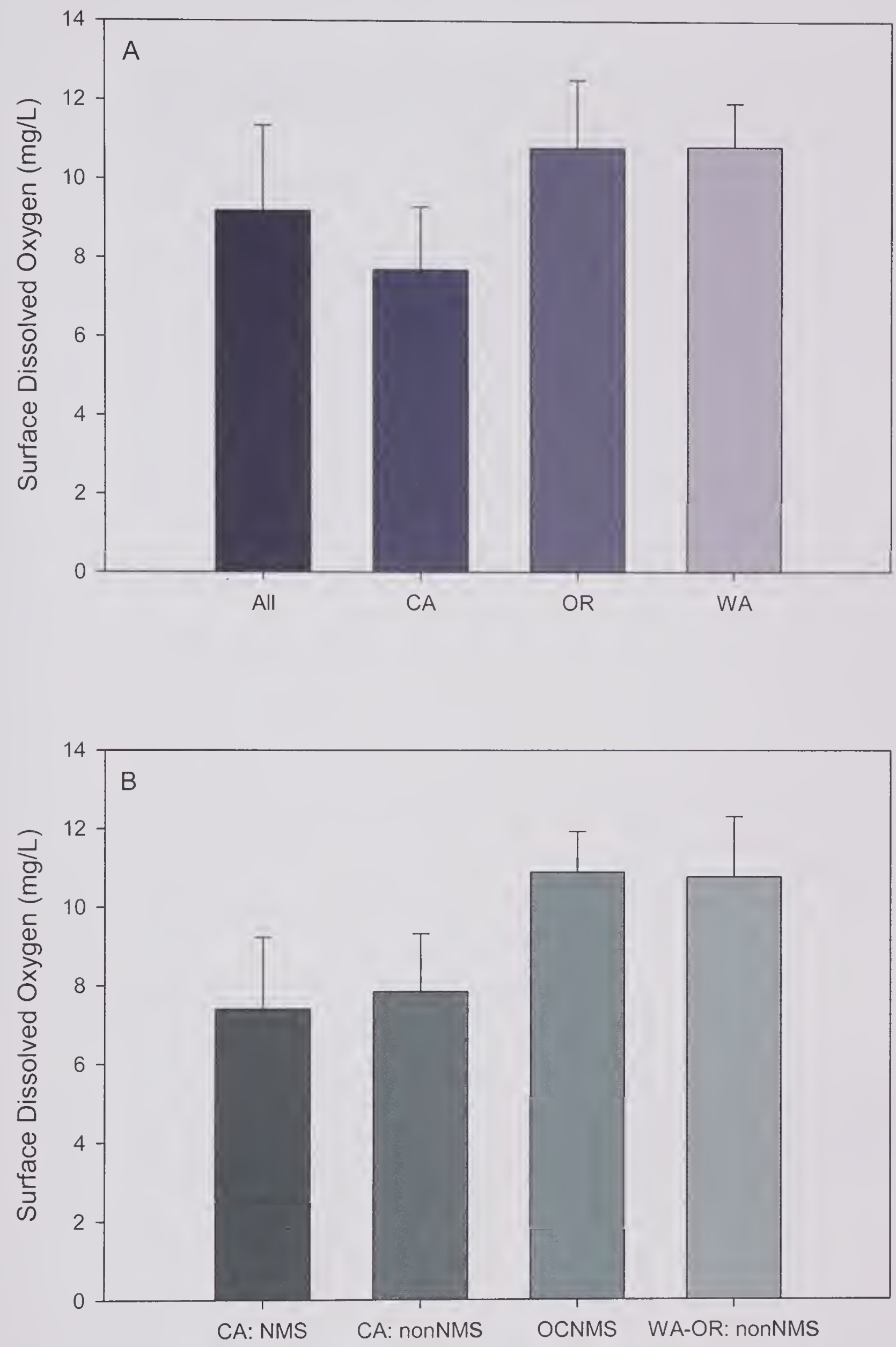

Figure 3.2.8. Mean +1 SD surface dissolved oxygen compared among (A) all, California, Oregon, and Washington sample locations, and (B) California NMS, California non-NMS, Olympic Coast NMS, and Washington-Oregon non-NMS sample locations. 


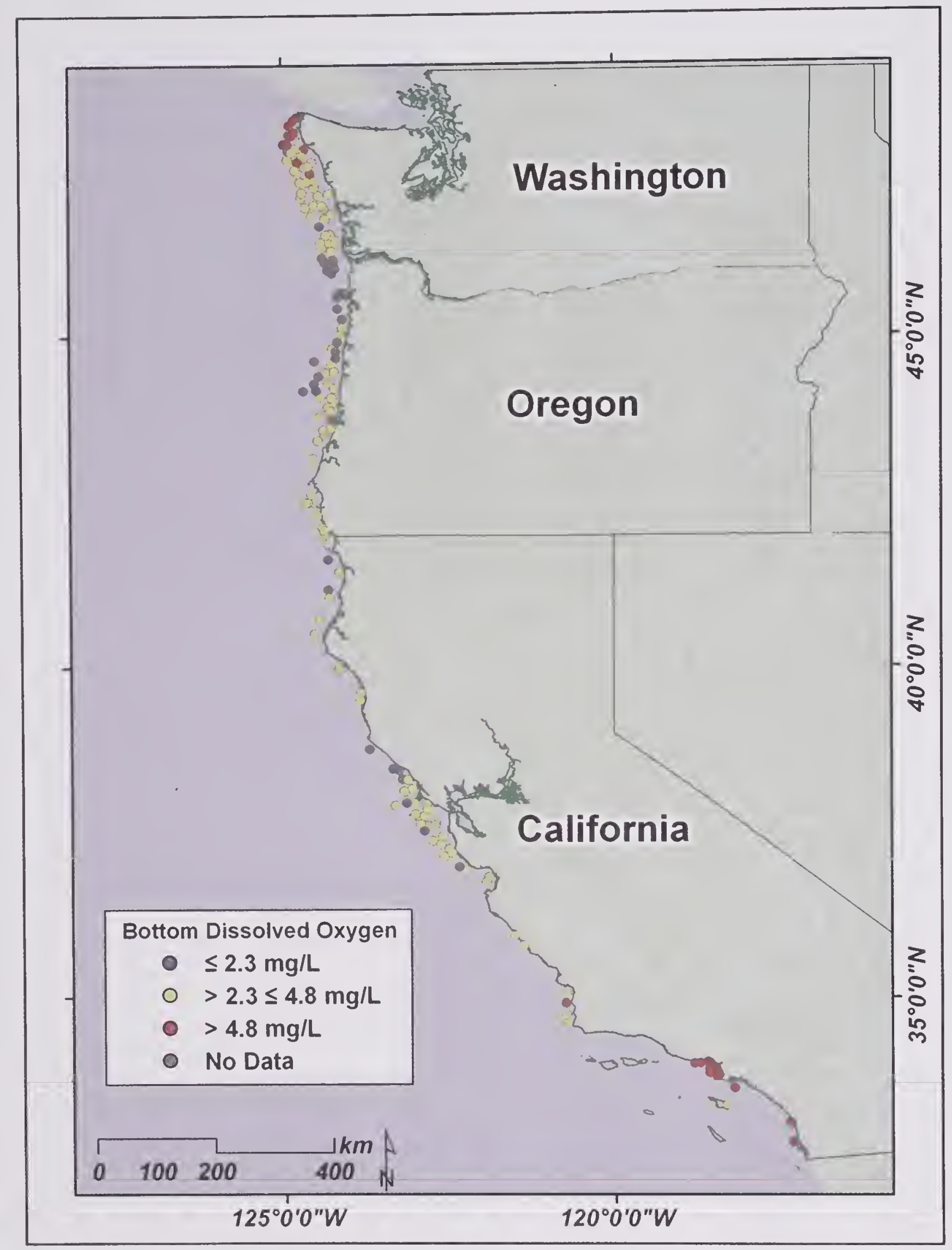

Figure 3.2.9. Distribution of bottom dissolved oxygen concentration values for the West Coast Shelf sampling area, June 2003. 

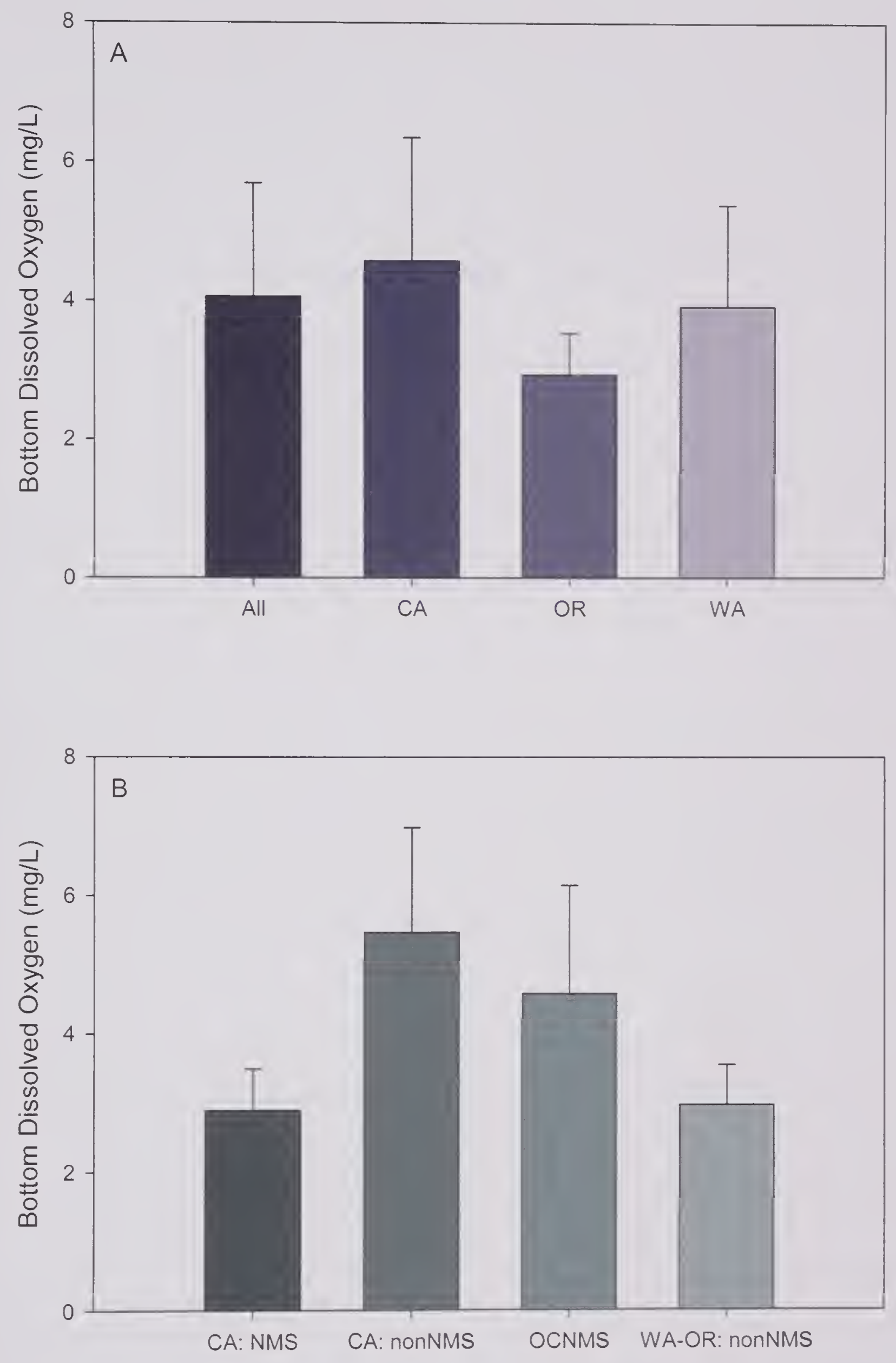

Figure 3.2.10. Mean $+1 \mathrm{SD}$ bottom dissolved oxygen compared among (A) all, California, Oregon, and Washington sample locations, and (B) California NMS, California non-NMS, Olympic Coast NMS, and Washington-Oregon non-NMS sample locations. 


\subsubsection{Total Suspended Solids}

The surface values for Total Suspended Solids (TSS) in waters of the West Coast shelf ranged from 0 to $10 \mathrm{mg} / \mathrm{L}$ for the 137 stations with data. Because the TSS samples from Oregon were not properly processed, these data were not included in the present analysis. The $50^{\text {th }}$ percentile of the survey area had a TSS concentration of $4.0 \mathrm{mg} / \mathrm{L}$, and the $90^{\text {th }}$ percentile of area corresponded to a TSS concentration of $7.4 \mathrm{mg} / \mathrm{L}$. Mean TSS in surface waters was slightly higher for stations in Washington than for those in California (Figure 3.2.11A). There was little difference in mean TSS between NMS and non-NMS locations (Figure 3.2.11B).

\subsubsection{Transmissivity}

Transmissivity in the surface waters of the West Coast shelf ranged from $13.7 \%$ to $98.9 \%$ across the 140 stations with acceptable data. The $50^{\text {th }}$ percentile of the survey area had transmissivity of $74.3 \%$, and the $90^{\text {th }}$ percentile of area had a transmissivity of $86.8 \%$. Mean transmissivity in surface waters was higher for stations in California than for those in Oregon and Washington and showed little difference between stations inside vs. outside NMSs (Figure 3.2.12).

Transmissivity in the bottom waters of the West Coast shelf ranged from $5.0 \%$ to $95.2 \%$ across the 175 stations with acceptable data. The $50^{\text {th }}$ percentile of the survey area had transmissivity of $85.6 \%$ and the $90^{\text {th }}$ percentile of area had a transmissivity of $91.6 \%$. Mean transmissivity in bottom waters showed little difference among geographic regions or between NMS and non-NMS locations Figure 3.2.13). Across the West Coast shelf, bottom waters had relatively higher mean transmissivity than surface waters (Figures 3.2.12; 3.2.13).

\subsubsection{Nutrients}

The surface-water concentration of nitrate + nitrite in waters of the West Coast shelf ranged from 0 to $546.6 \mu \mathrm{g} / \mathrm{L}$ at the 188 stations with data. The $50^{\text {th }}$ percentile of area of the surface waters of the West Coast shelf sampled had a nitrate + nitrite concentration of $26.2 \mu \mathrm{g} / \mathrm{L}$, with the $90^{\text {th }}$ percentile of area characterized by a nitrate + nitrite concentration of $354 \mu \mathrm{g} / \mathrm{L}$. The mean value of nitrate + nitrite concentration in surface waters was highest in California as compared to Washington and Oregon and three times higher in the CA NMS stations as compared to the CA non-NMS stations (Figure 3.2.14). The elevated nitrate + nitrite observed at the CA NMS stations is consistent with the presence of strong upwelling at these sites at the time of sampling. 

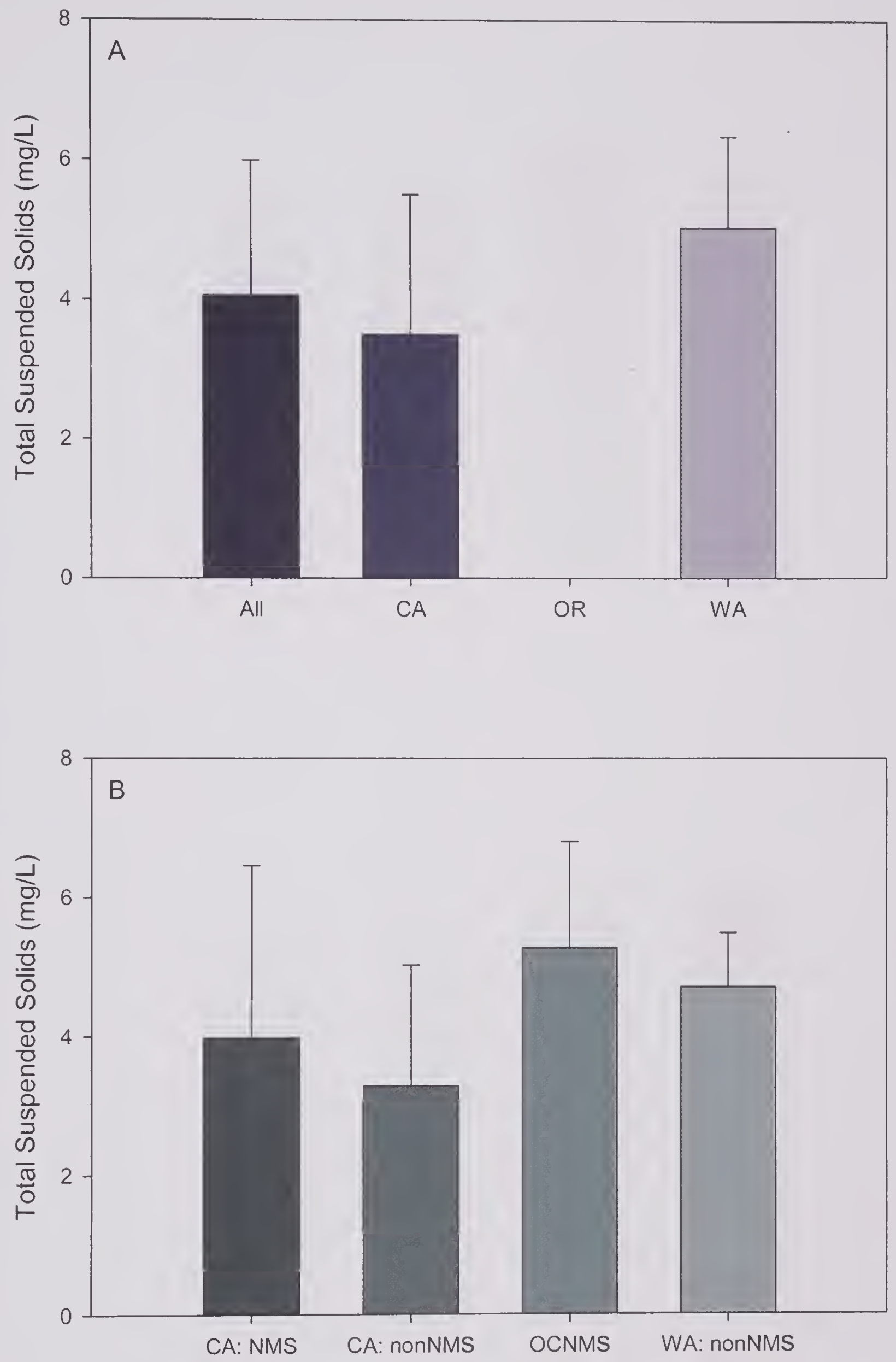

Figure 3.2.11. Mean +1 SD surface Total Suspended Solids compared among (A) all, California, and Washington sample locations, and (B) California NMS, California non-NMS, Olympic Coast NMS, and Washington nonNMS sample locations. Oregon data was not acceptable. 

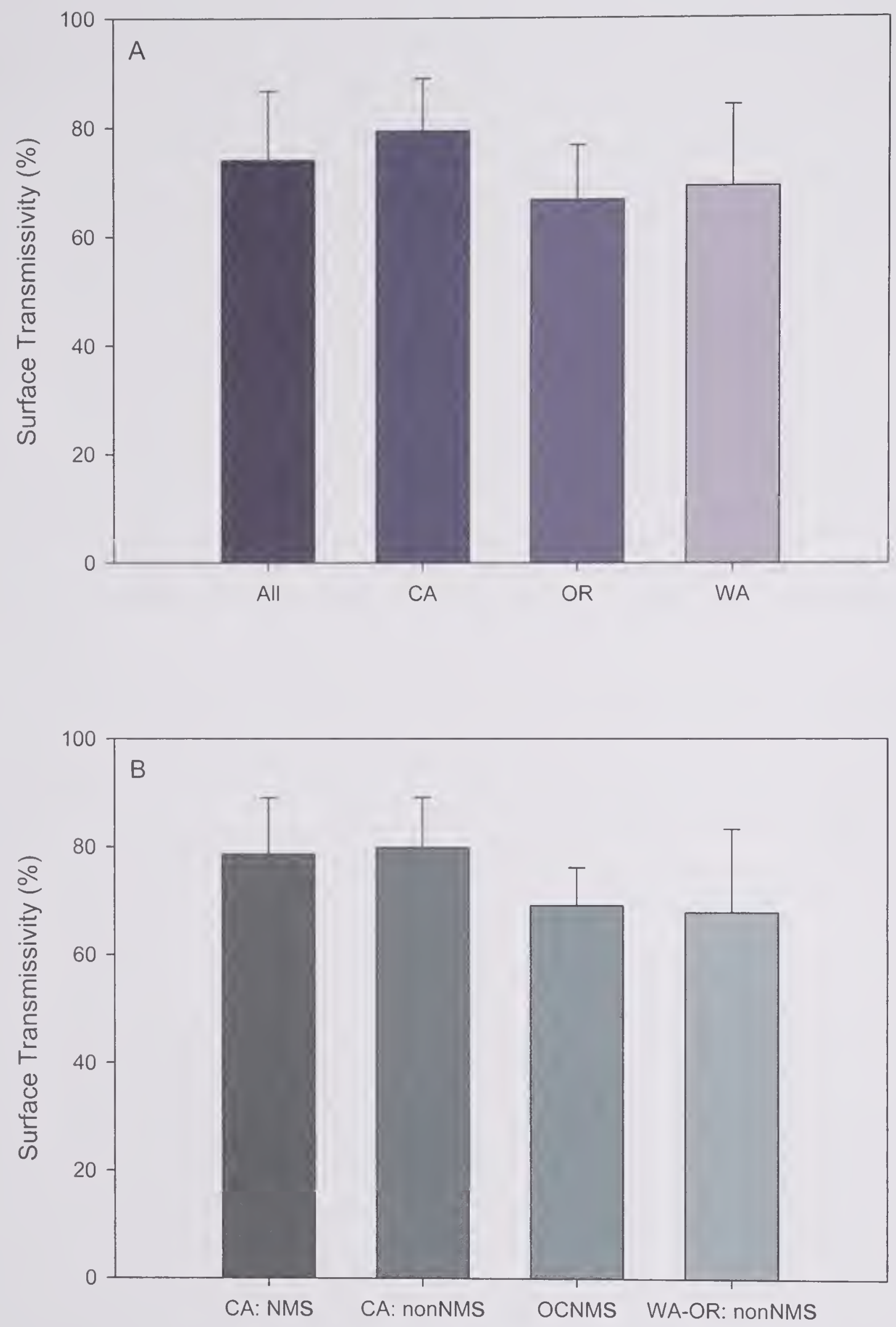

Figure 3.2.12. Mean $+1 \mathrm{SD}$ surface transmissivity compared among (A) all, California, Oregon, and Washington sample locations, and (B) California NMS, California non-NMS, Olympic Coast NMS, and Washington-Oregon non-NMS sample locations. 

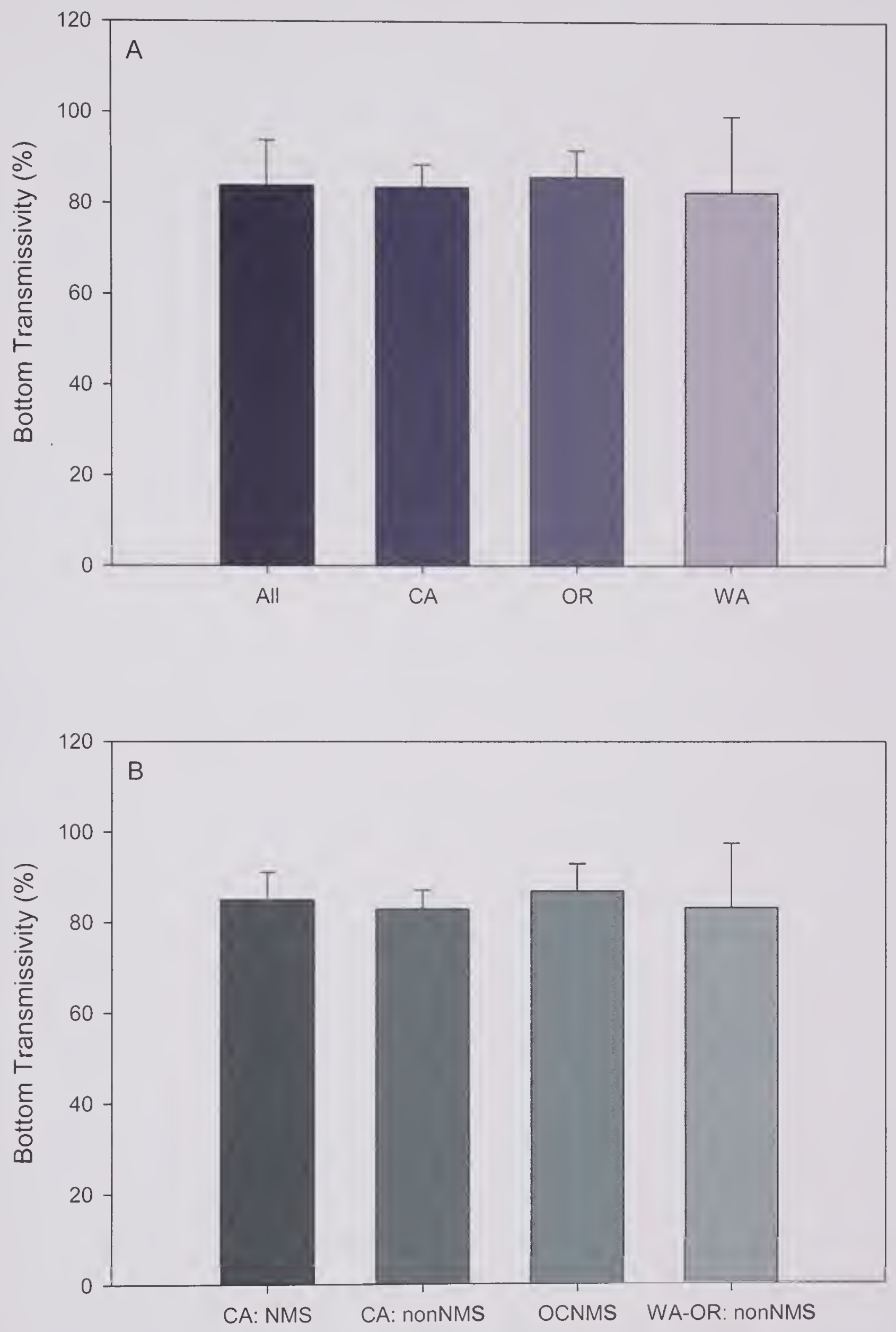

Figure 3.2.13. Mean $+1 \mathrm{SD}$ bottom transmissivity compared among $(A)$ all, California, Oregon, and Washington sample locations, and (B) California NMS, California non-NMS, Olympic Coast NMS, and Washington-Oregon non-NMS sample locations. 
The surface-water concentration of ammonium in waters of the West Coast shelf, exclusive of the waters of the SCB for which ammonium was not analyzed, ranged from 0 to $50 \mu \mathrm{g} / \mathrm{L}$ at the 146 stations for which data were available. The $50^{\text {th }}$ percentile of area of the surface waters of the West Coast shelf sampled had an ammonium concentration of $2.2 \mu \mathrm{g} / \mathrm{L}$, with the $90^{\text {th }}$ percentile of total area characterized by an ammonium concentration of 21.4 $\mu \mathrm{g} / \mathrm{L}$. The mean value of ammonium in surface waters was highest in California and Oregon and lowest in Washington, with the lowest mean concentration of ammonium being found from stations sampled in the OCNMS (Figure 3.2.15).

The surface-water concentration of total dissolved inorganic nitrogen (DIN: nitrogen as nitrate + nitrite + ammonium) in waters of the West Coast shelf, exclusive of the waters of the SCB for which ammonium was not analyzed, ranged from 0.1 to $596.7 \mu \mathrm{g} / \mathrm{L}$ for the 146 stations with data. The $50^{\text {th }}$ percentile of area of the surface waters of the West Coast shelf sampled had a DIN concentration of $47.4 \mu \mathrm{g} / \mathrm{L}$, with the $90^{\text {th }}$ percentile of total area characterized by a DIN concentration of $367 \mu \mathrm{g} / \mathrm{L}$. The mean value of DIN concentration in surface waters was highest in California as compared to Washington and Oregon (Figure 3.2.16 A). DIN concentration for the CA NMSs was slightly higher than for the CA non-NMS stations, but the difference was much smaller than was the case for nitrate + nitrite only (Figure 3.2.16 B).

The surface-water concentration of orthophosphate in waters of the West Coast shelf ranged from 0 to $80.1 \mu \mathrm{g} / \mathrm{L}$ for the 188 stations with data. The $50^{\text {th }}$ percentile of area of the surface waters of the West Coast shelf sampled had an orthophosphate concentration of $11.4 \mu \mathrm{g} / \mathrm{L}$, with the $90^{\text {th }}$ percentile of total estuarine area characterized by a concentration of $61 \mu \mathrm{g} / \mathrm{L}$. The mean value of orthophosphate concentration in surface waters was higher in California than in Washington and Oregon, where values were similar (Figure 3.2.17 A). Mean orthophosphate concentration in surface waters of the CA NMSs was more than three times greater than the mean value for the OCNMS and the non-NMS areas of the shelf (Figure 3.2.17 B). The elevated orthophosphate values are again consistent with the occurrence of upwelling during sampling of the CA NMS stations.

The ratio of total dissolved inorganic nitrogen (nitrogen as nitrate + nitrite + ammonium) concentration to total orthophosphate concentration was calculated as an indicator of which nutrient may be controlling primary production. A ratio above 16 is generally considered indicative of phosphorus limitation, and a ratio below 16 is considered indicative of nitrogen limitation (Geider and La Roche 2002). The N/P ratio ranged from 7.9 to 24.0 , across the 146 stations in waters of the West Coast shelf where sufficient measurements were collected to compute the ratio. Approximately $93 \%$ of area of the West Coast shelf had N/P values $\leq 16$. The $50^{\text {th }}$ percentile of area of the waters of the West Coast shelf sampled had a ratio of 12.8 , while the $90^{\text {th }}$ percentile of area had a ratio of 14.6 . The mean N/P values were similar for the three states, while that for the OCNMS 
was less than half that of the CA NMS and non-NMS areas (Figure 3.2.18). Examination of the Bakun upwelling index at $48^{\circ} \mathrm{N}$ shows that there was downwelling occurring in the region of the OCNMS just prior to the sampling at this location, and only weak upwelling occurring during the sampling period.

Silicate concentrations of water samples were analyzed by the states of Washington and California (exclusive of the SCB), but not Oregon. Therefore there were only 97 sample sites with silicate data available. The surface-water concentration of silicate in waters of the West Coast shelf within Washington and California ranged from 0 to $2040.5 \mu \mathrm{g} / \mathrm{L}$. The $50^{\text {th }}$ percentile of area of the waters of the West Coast shelf sampled had a silicate concentration of $307 \mu \mathrm{g} / \mathrm{L}$, with the $90^{\text {th }}$ percentile of area characterized by a concentration of $973 \mu \mathrm{g} / \mathrm{L}$. The mean silicate concentration for surface waters was similar between Washington and California locations, while the mean silicate concentration for the CA NMSs was approximately twice that of the OCNMS and the non-NMS locations (Figure 3.2.19). These results are again consistent with the spatial patterns of upwelling on the shelf during the sampling period.

\subsubsection{Chlorophyll a}

The surface-water concentration of chlorophyll a for the 187 stations sampled in waters of the West Coast shelf ranged from 0 to $28 \mu \mathrm{g} / \mathrm{L}$ (Figure 3.2.20). The $50^{\text {th }}$ percentile of area of the waters of the West Coast shelf sampled had a chlorophyll a concentration of $3.9 \mu \mathrm{g} / \mathrm{L}$, while the $90^{\text {th }}$ percentile had a chlorophyll a concentration of $14.5 \mu \mathrm{g} / \mathrm{L}$. The mean chlorophyll a concentration for surface waters in California was less than half that of locations in Washington and Oregon locations (Figure 3.2.20 A). The lowest mean chlorophyll a concentration was for the CA non-NMS locations, while the mean for the CA NMS locations was approximately $60 \%$ of that found in the OCNMS (Figure 3.2.20 B). 

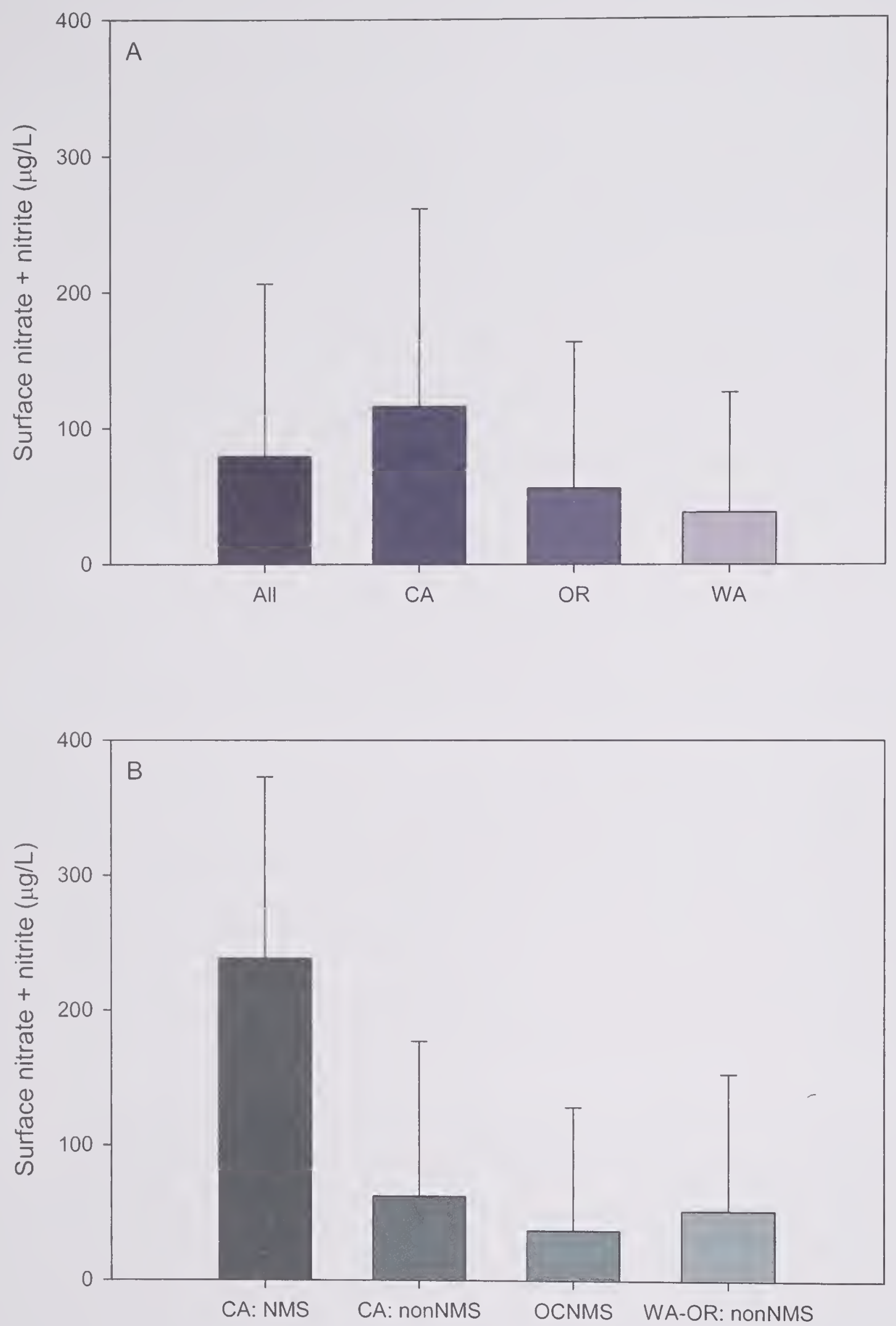

Figure 3.2.14. Mean $+1 \mathrm{SD}$ surface nitrate + nitrite compared among (A) all, California, Oregon, and Washington sample locations, and (B) California NMS, California non-NMS, Olympic Coast NMS, and Washington-Oregon non-NMS sample locations. 

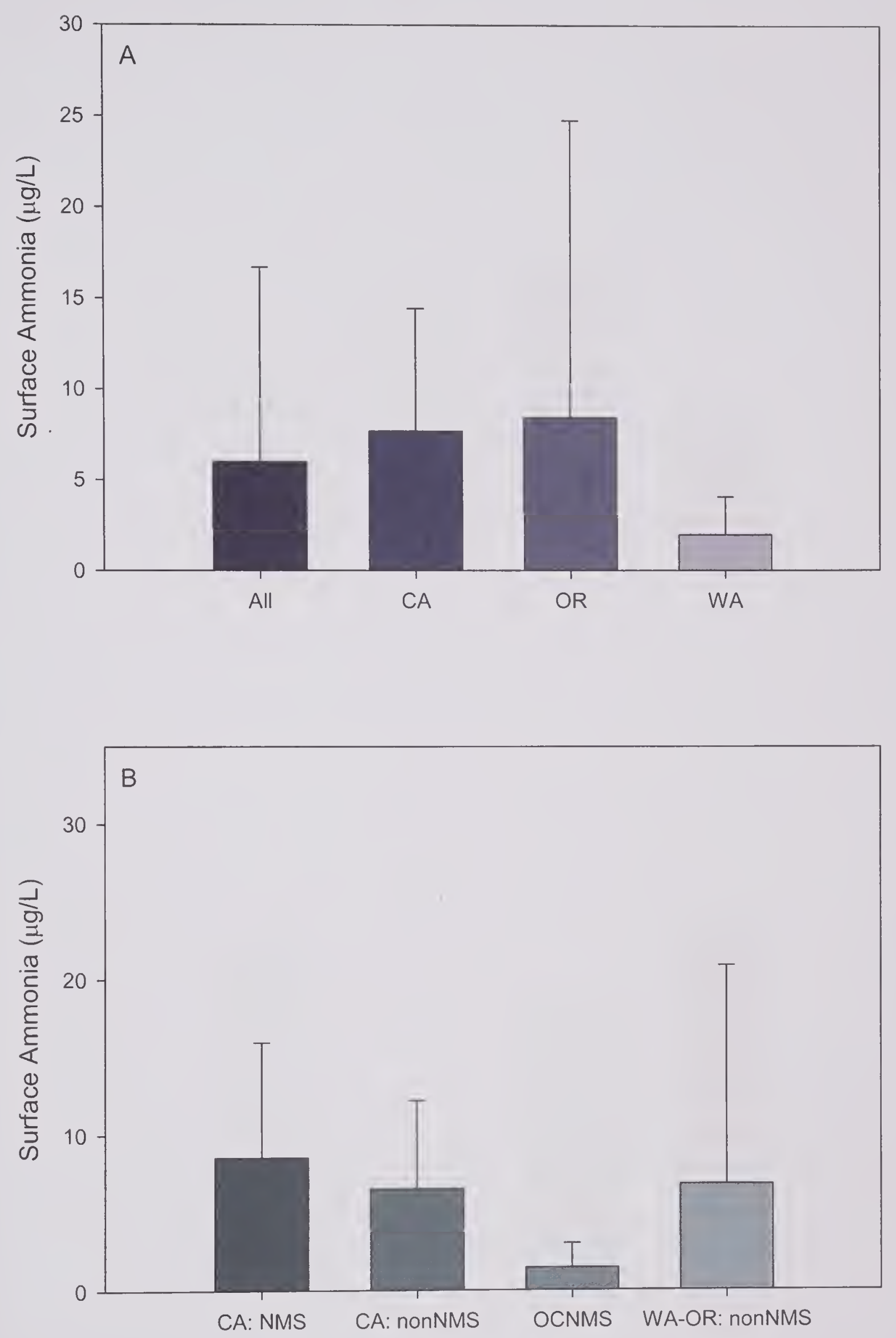

Figure 3.2.15. Mean +1 SD surface ammonium compared among (A) all,

California, Oregon, and Washington sample locations, and (B) California NMS, California non-NMS, Olympic Coast NMS, and Washington-Oregon non-NMS sample locations. SCB stations not included due to lack of ammonium data. 

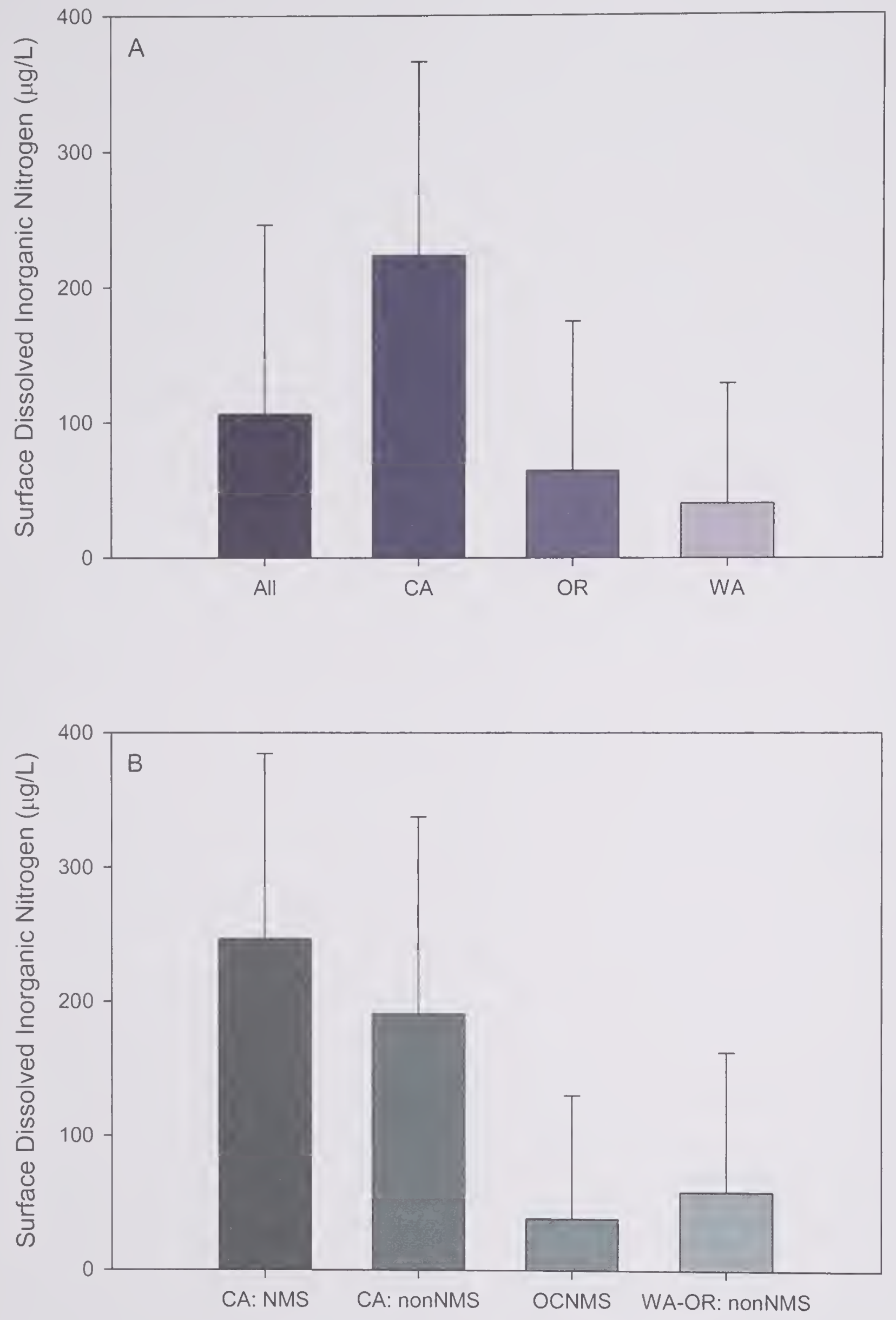

Figure 3.2.16. Mean +1 SD surface dissolved inorganic nitrogen compared among $(A)$ all, California, Oregon, and Washington sample locations, and (B) California NMS, California non-NMS, Olympic Coast NMS, and Washington-Oregon non-NMS sample locations. California Bight stations not included due to lack of ammonium data. 

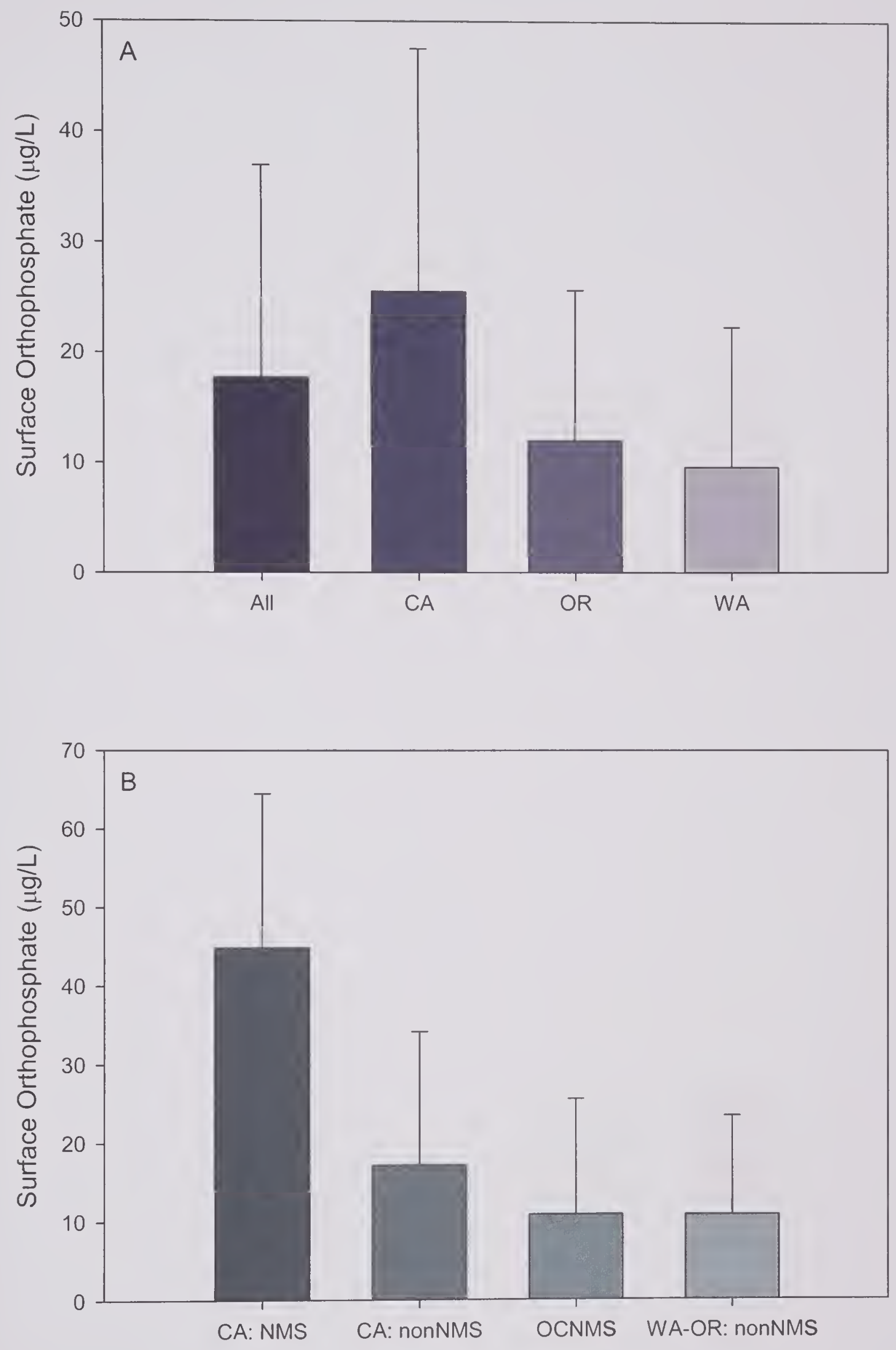

Figure 3.2.17. Mean +1 SD surface orthophosphate compared among (A) all, California, Oregon, and Washington sample locations, and (B) California NMS, California non-NMS, Olympic Coast NMS, and Washington-Oregon non-NMS sample locations. 

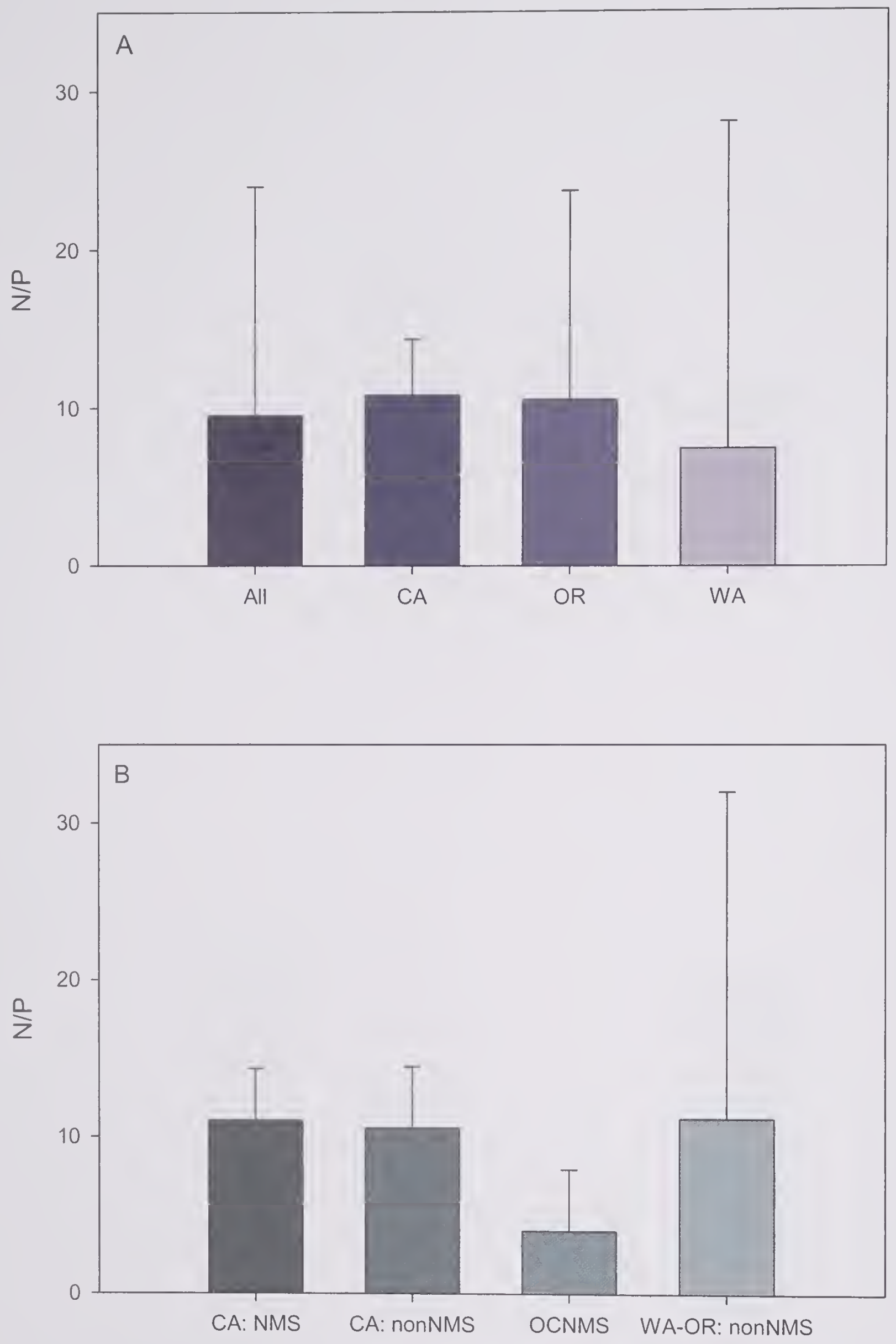

Figure 3.2.18. Mean $+1 \mathrm{SD} N / \mathrm{P}$ ratio in surface waters compared among $(A)$ all, California, Oregon, and Washington sample locations, and (B) California NMS, California non-NMS, Olympic Coast NMS, and Washington-Oregon non-NMS sample locations. California Bight stations not included due to lack of ammonium data. 

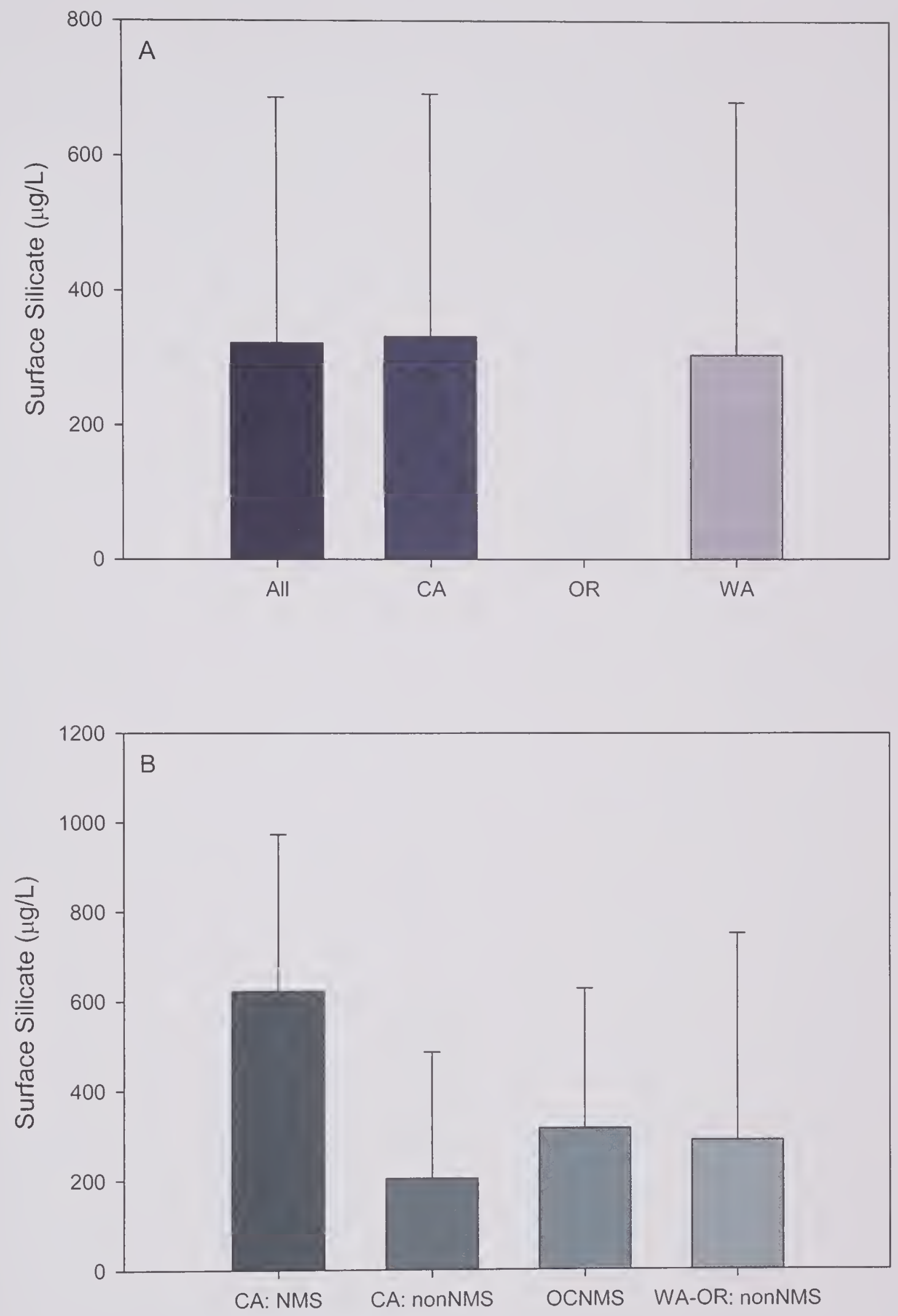

Figure 3.2.19. Mean +1 SD surface silicate concentration compared among (A) all, California, and Washington sample locations, and (B) California NMS, California non-NMS, Olympic Coast NMS, and Washington non-NMS sample locations. Silicate was not measured at stations in Oregon or in the SCB (see text). 

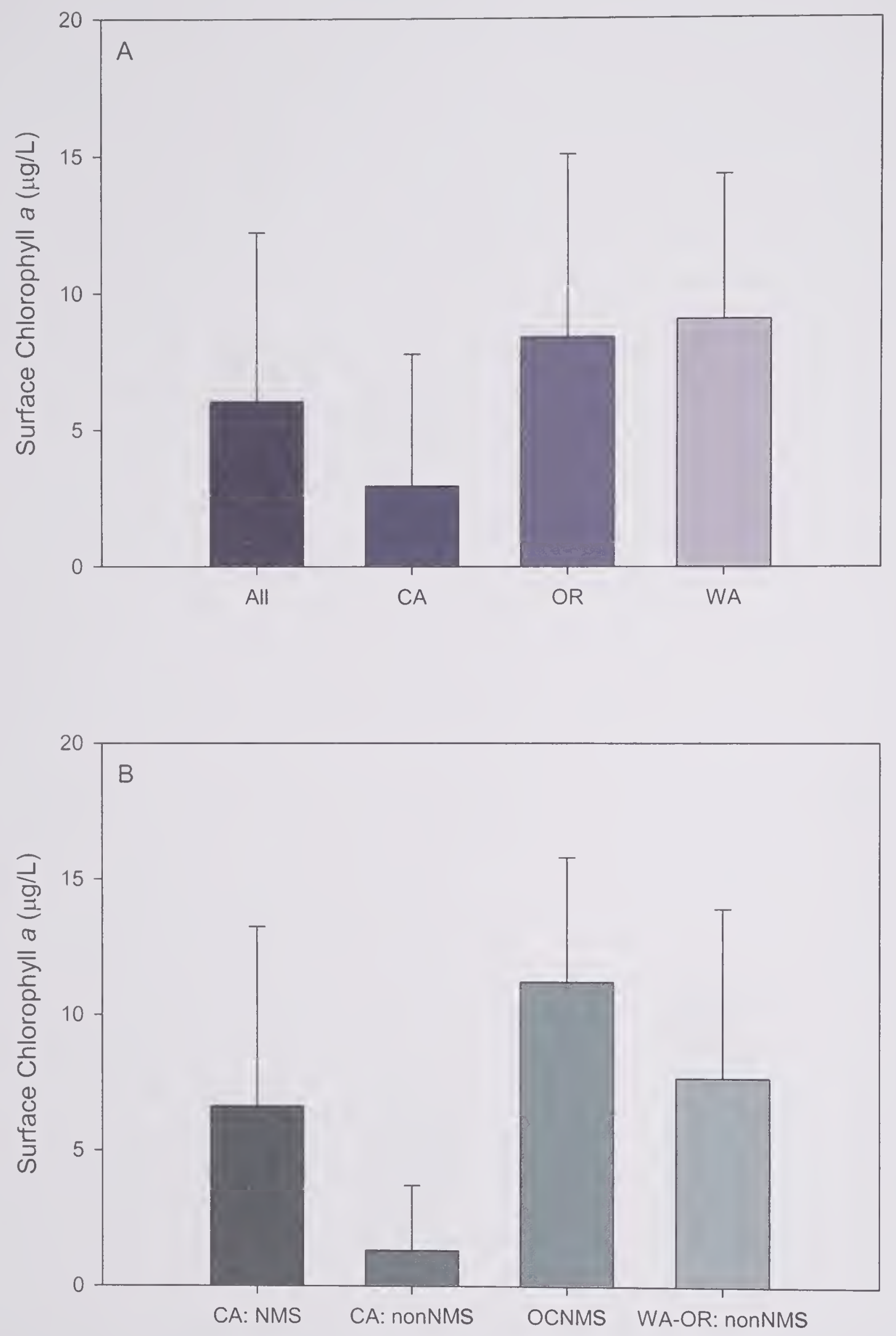

Figure 3.2.20. Mean +1 SD surface chlorophyll a concentration compared among (A) all, California, Oregon, and Washington sample locations, and (B) California NMS, California non-NMS, Olympic Coast NMS, and Washington-Oregon non-NMS sample locations. 


\subsection{Sediment Quality}

Table 3.3.1 provides a summary of the means and ranges of sediment physical characteristics and chemical contaminant concentrations for all West Coast stations combined as well as by individual states (CA, Oregon, Washington) and National Marine Sanctuary (NMS) vs. non-sanctuary status. The latter comparison includes California sanctuaries (Channel Islands NMS, Monterrey Bay NMS, Gulf of the Farallones NMS, and Cordell Bank NMS) vs. non-sanctuary stations in California and stations in the Olympic Coast NMS (OCNMS) vs. non-sanctuary stations in Oregon and Washington. Appendix 4 also provides a breakdown of this information by individual station. Sedimentquality data were available at 257 stations throughout the region for chemical contaminant variables, 255 stations for sediment grain size, and 256 stations for TOC.

\subsubsection{Sediment Composition: Grain Size and TOC}

The percentage of silt-clay in sediments ranged from $0.5 \%$ to $98.7 \%$ region-wide (Table 3.3.1, Fig. 3.3.1). Approximately $44 \%$ of the overall survey area had sediments composed of sands ( $<20 \%$ silt-clay), $47 \%$ was composed of intermediate muddy sands (20-80\% silt-clay), and $9 \%$ was composed of muds (> $80 \%$ silt-clay). All mud sediments ( $>80 \%$ silt-clay) occurred in California. The majority of California sediments consisted of intermediate muddy sands, while Oregon and Washington were dominated by sands (Fig. 3.3.2).

Percent total organic carbon (TOC) in sediments exhibited a wide range $(0.0 \%$ to $7.6 \%)$ throughout the region (Table 3.3.1, Fig. 3.3.3). The majority of the survey area (97\%) had relatively low TOC levels of $<2 \%$, while a small portion $(<1 \%)$, consisting of two sites in California, had high TOC levels $(>5 \%$; Fig. 3.3.4). About $2 \%$ of the survey area (represented by 10 sites) had intermediate levels of TOC (2-5\%). In comparison, estuarine habitats along the U.S. West Coast have high levels of TOC in similarly limited areas $(<1 \%)$ and intermediate levels of TOC over slightly broader areas $(11 \%$ of the estuarine area) (U.S. EPA 2004). The upper and lower thresholds of $2 \%$ and $5 \%$ used here for evaluating the biological significance of sediment TOC content are adopted from earlier EPA National Coastal Condition Reports (e.g., U.S. EPA 2004). Hyland et al. (2005) also identified TOC concentrations $>3.6 \%(36 \mathrm{mg} / \mathrm{g})$ as an upper range associated with a high risk of degraded benthic condition from multiple coastal areas around the world. The portion of the present survey area with TOC in excess of this slightly more conservative cut point also was relatively small $(<1 \%)$ and limited to California. The three sites in California with sediment TOC content in excess of either upper threshold $(3.6 \%$ or $5 \%)$ were in the Channel Islands NMS (CINMS) (Fig. 3.3.4, Appendix 4). The cause of the elevated TOC at these sites is unknown at this time. 


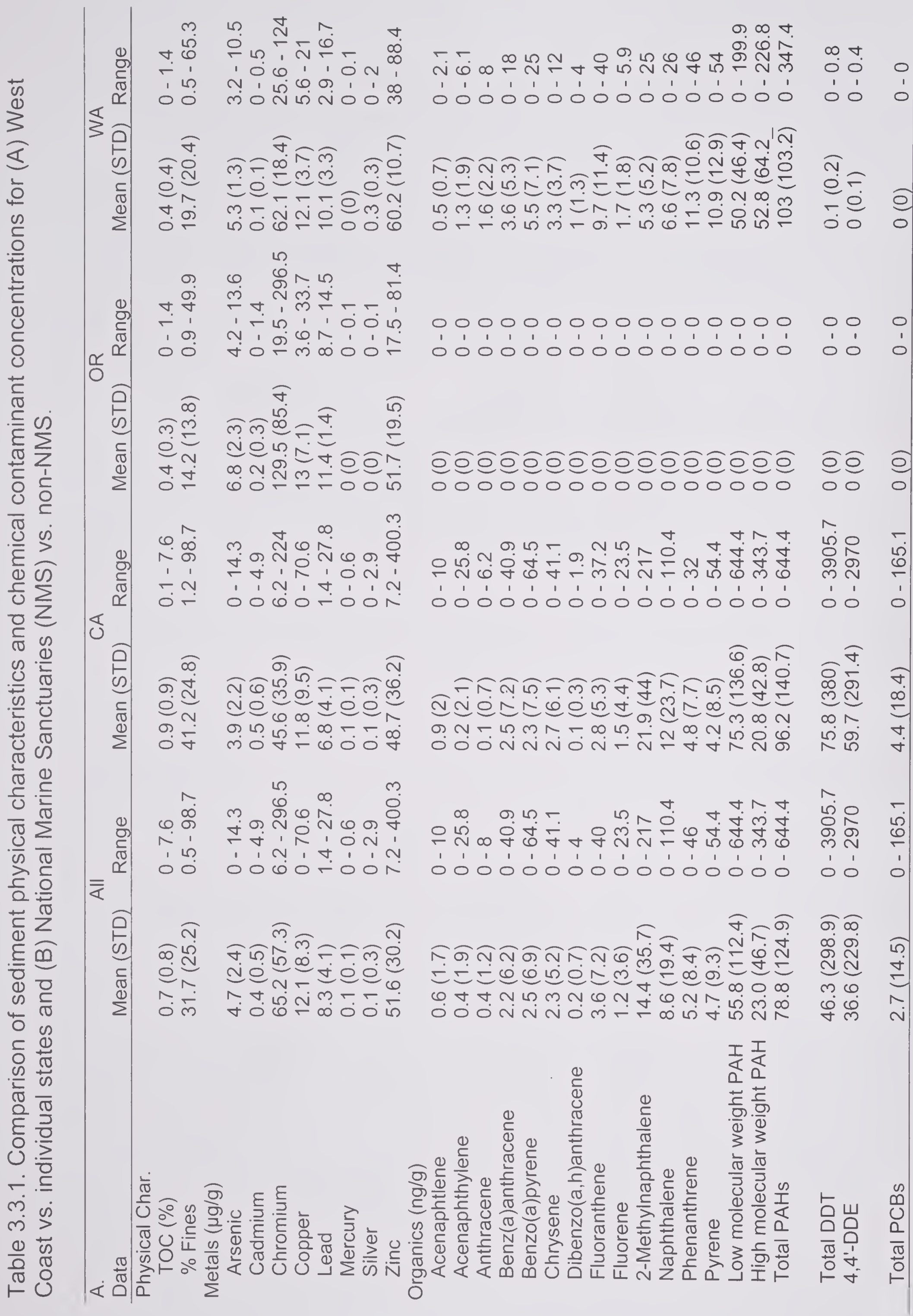




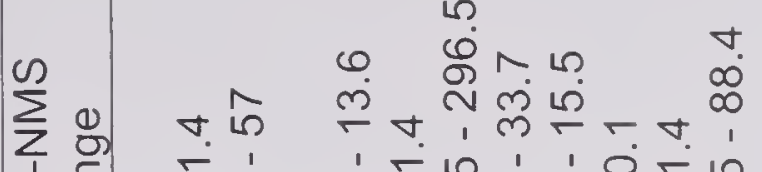

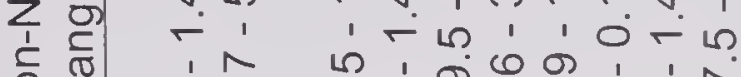

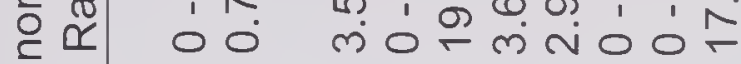
テं

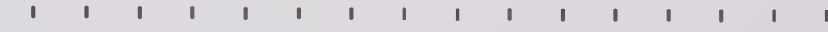

这品 क

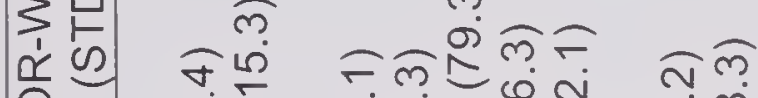
vie-

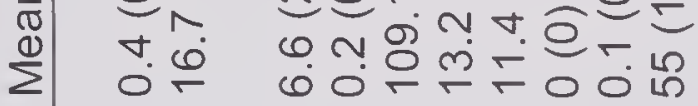

0000000000000000

$\infty$

$\begin{array}{lll}1 & 0 & 0 \\ 0 & 0 & 0\end{array}$

00

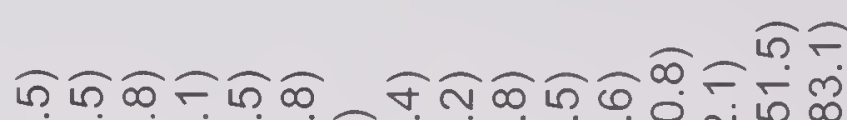

近-

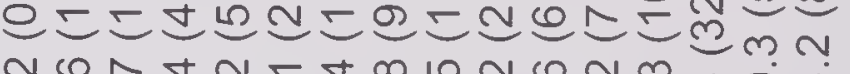

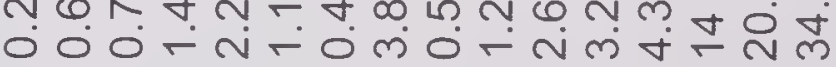

Fૅ

อ்

ก

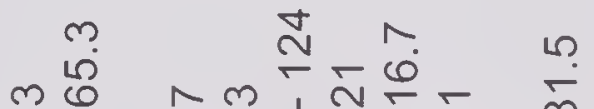

ग) m

- ம

$1,1,1,1,1,1,1,1,0$

000000000000000 -

$m \stackrel{2}{2}$

000

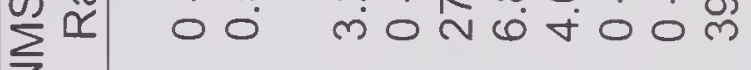

บิำ

ले

m.

กิ

bo

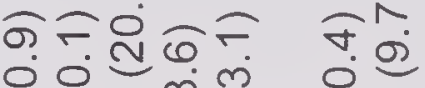

อำ

宁

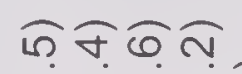

กิริติ

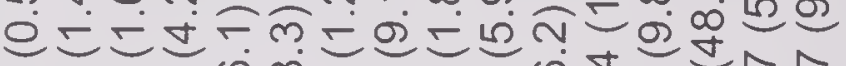

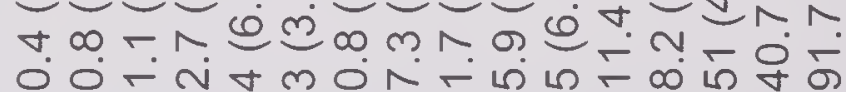

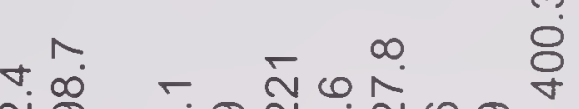

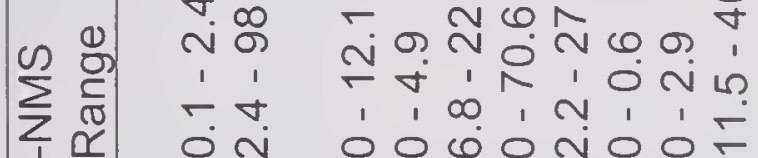

$0_{0}$

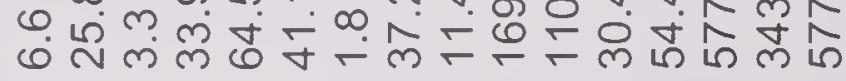

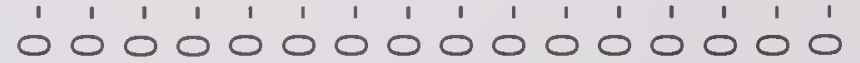

응

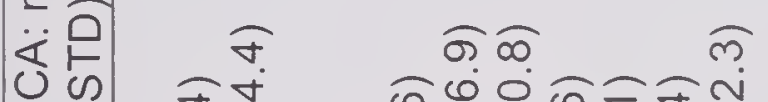

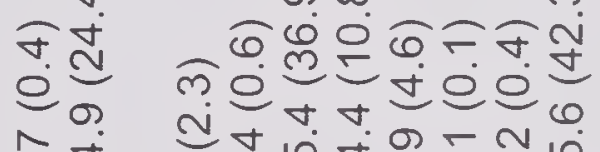

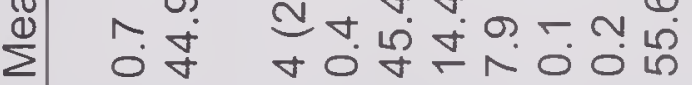

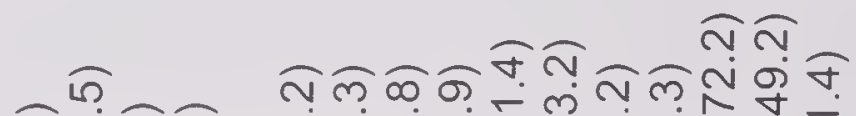

Eญ

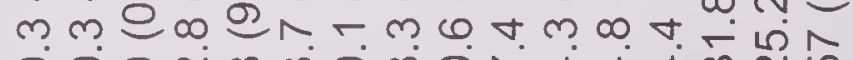

00

100

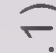

อิ

000

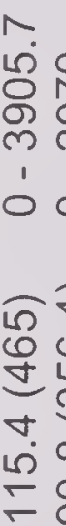

เి

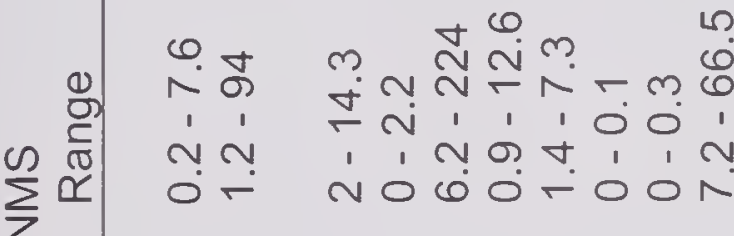

o n n

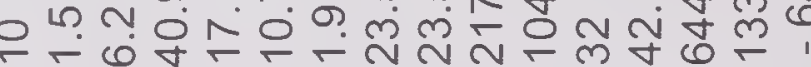

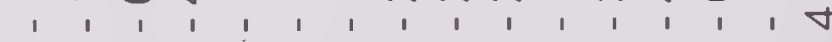
$000000000000000 \%$

क

这吕

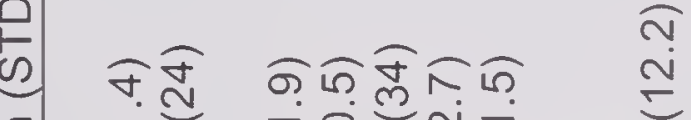

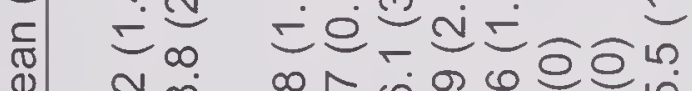

$\sum \stackrel{\infty}{\sim} \stackrel{\infty}{\sim}$

mं

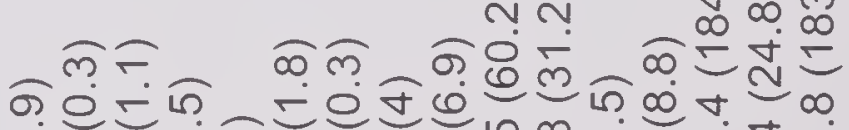

eEn

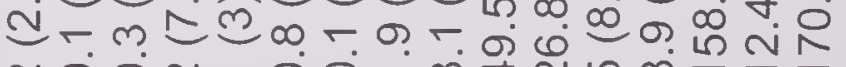

6.6

iं

000

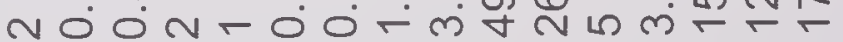

m

$\frac{I}{\frac{1}{4}}$

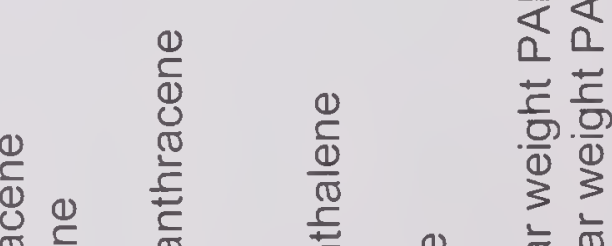

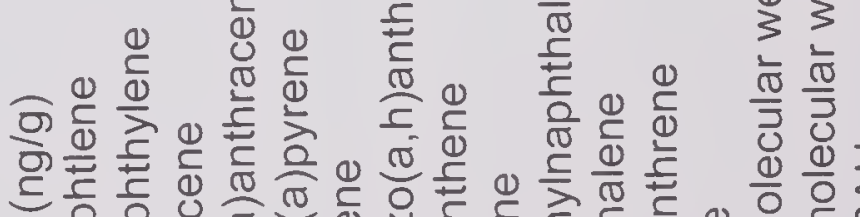

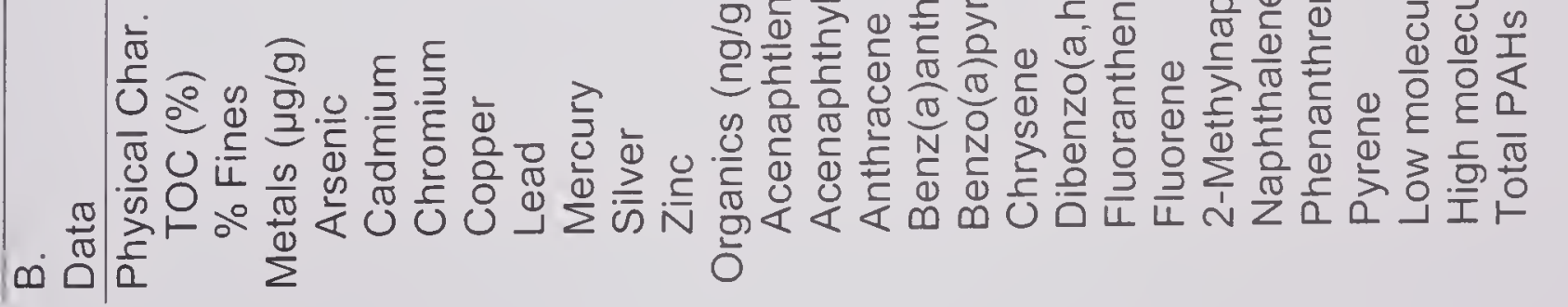

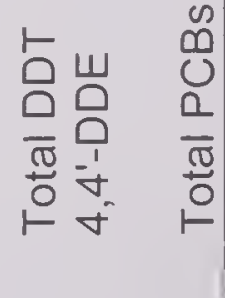




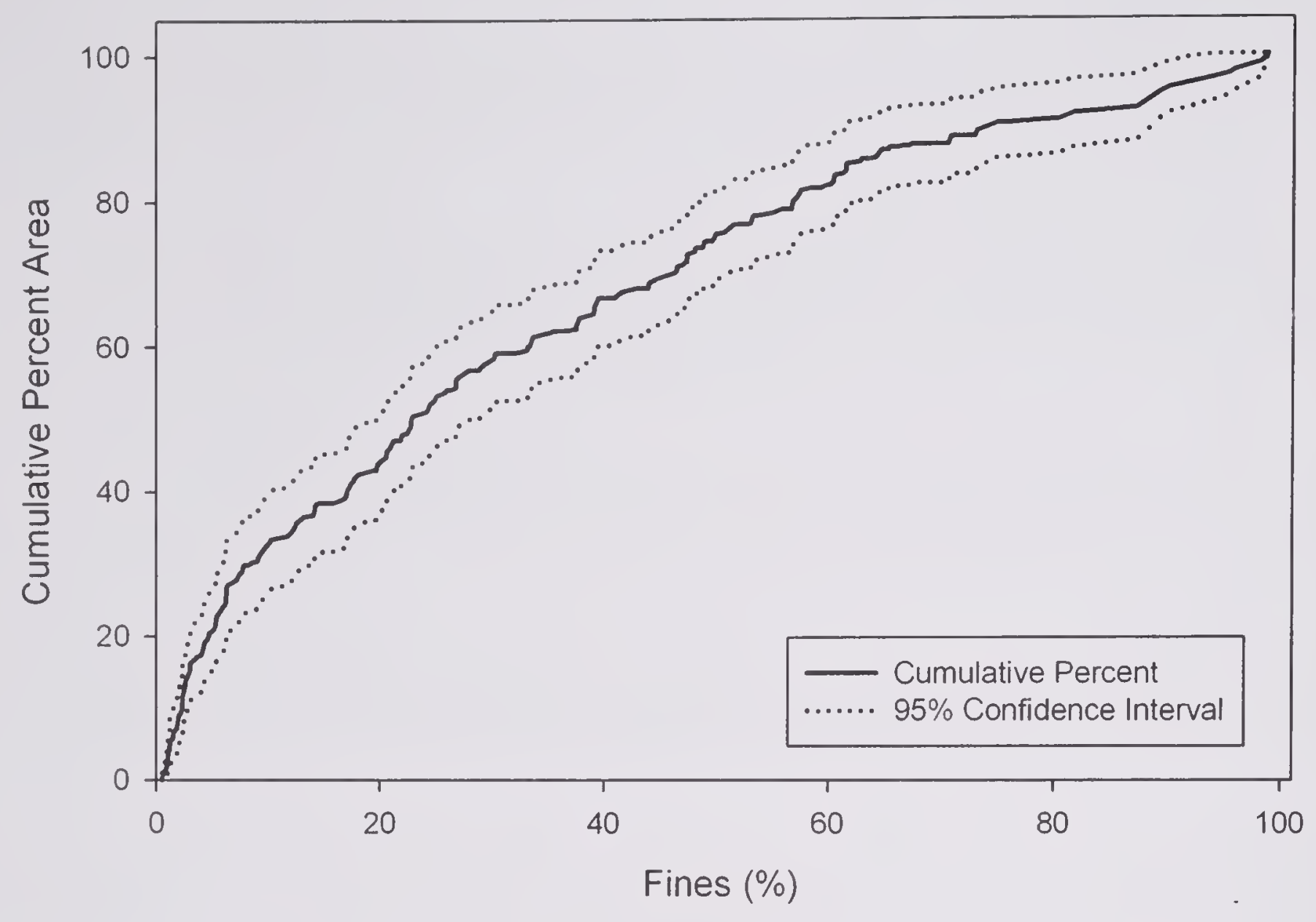

Figure 3.3.1. Percent area (and 95\% confidence interval) of overall West Coast Shelf sampling area vs. sediment percent fines (silt/clay). 

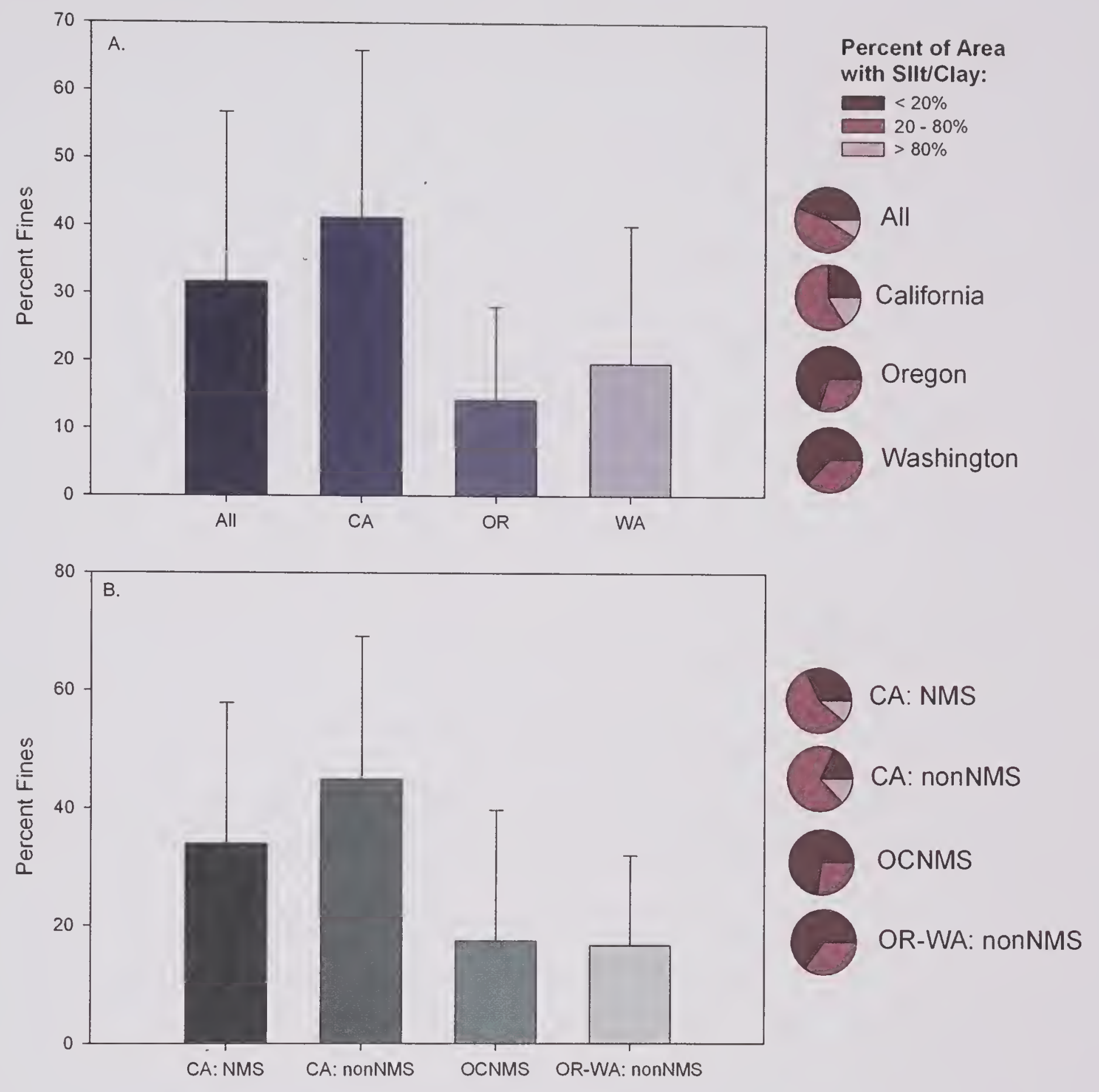

Figure 3.3.2. Comparison of sediment percent silt/clay (mean $+1 \mathrm{SD}$ ) by (A) West Coast vs. individual states and (B) National Marine Sanctuary (NMS) vs. non-NMS stations. 


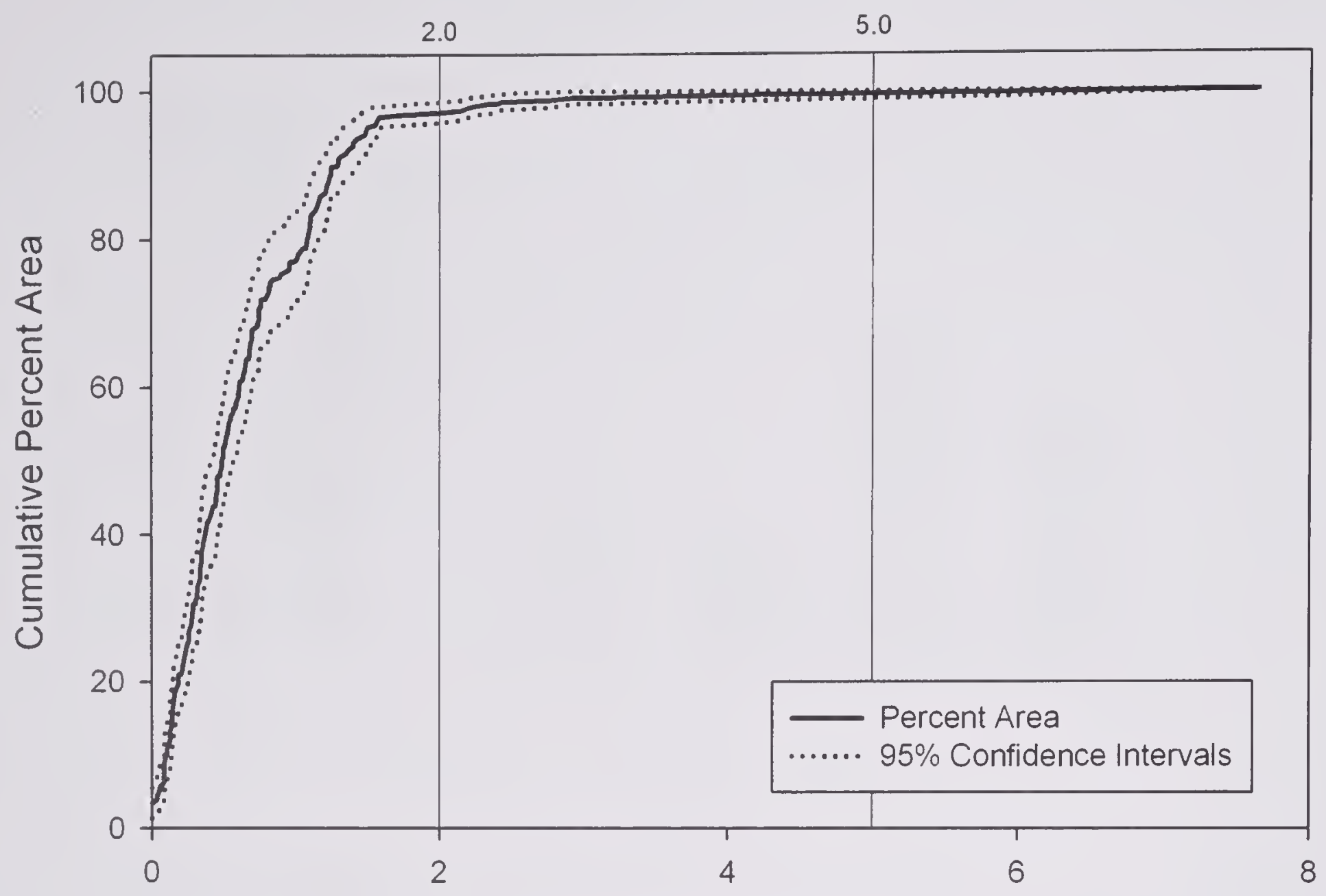

Total Organic Carbon (\%)

Figure 3.3.3. Percent area (and $95 \%$ confidence interval) of overall West Coast Shelf sampling area vs. sediment percent Total Organic Carbon (TOC).

60 

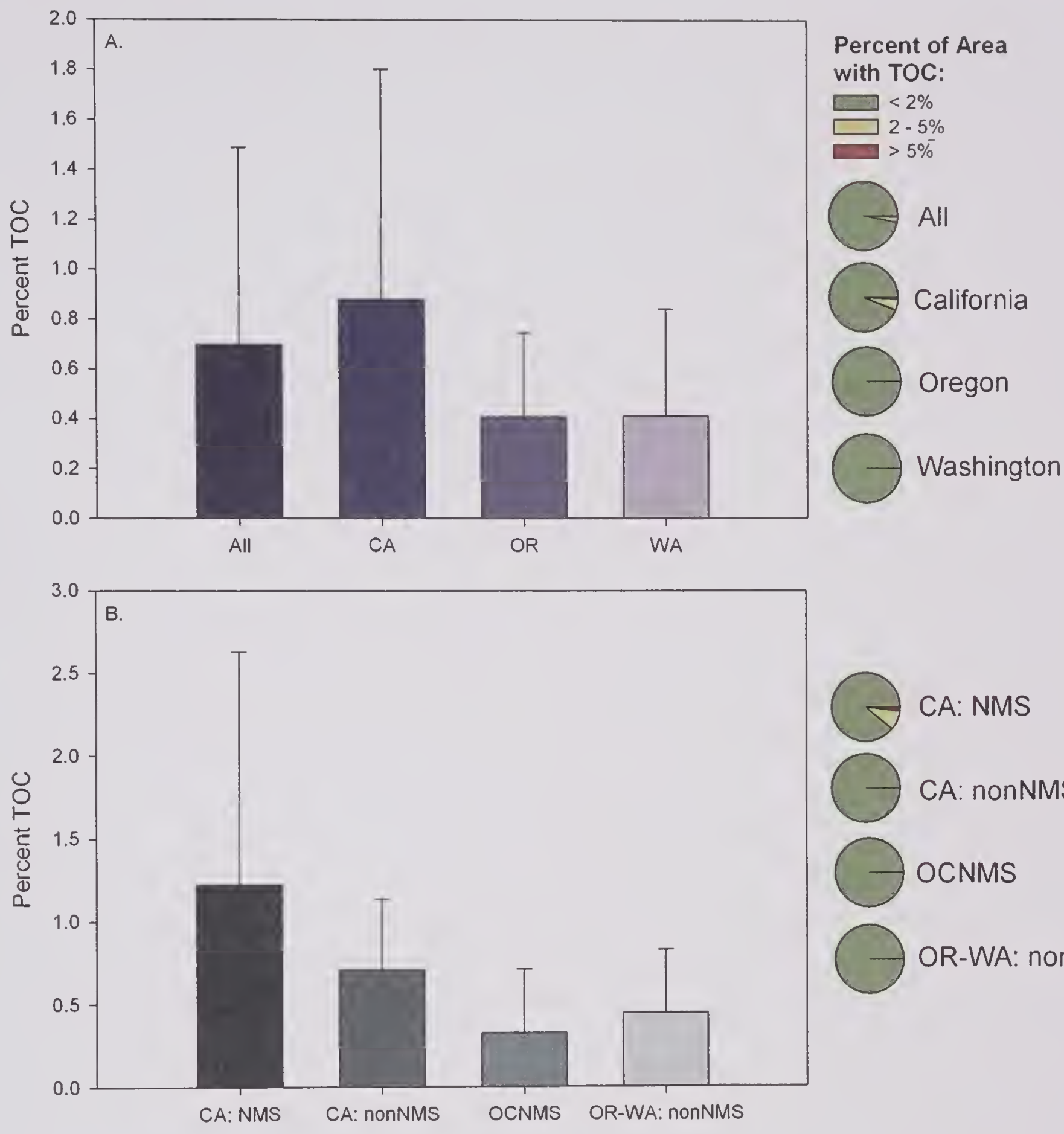

CA: NMS

CA: nonNMS

OCNMS

OR-WA: nONNMS

Figure 3.3.4. Comparison of sediment percent Total Organic Carbon (TOC, mean $+1 \mathrm{SD}$ ) by (A) West Coast vs. individual states and (B) National Marine Sanctuary (NMS) vs. non-NMS stations. 


\subsubsection{Sediment Contaminants: Metals and Organics}

Effects Range-Low (ERL) and Effects Range-Median (ERM) sediment quality guideline (SQGs) values from Long et al. (1995) were used to help in interpreting the biological significance of observed chemical contaminant levels in sediments. ERL values are lower-threshold bioeffect limits, below which adverse effects of the contaminants on sediment-dwelling organisms are not expected to occur. In contrast, ERM values represent mid-range concentrations of chemicals above which adverse effects are more likely to occur. A list of 28 chemicals, or chemical groups, for which ERL and ERM guidelines have been developed is provided in Table 3.3.2 along with the corresponding SQG values (from Long et al. 1995). Nickel was excluded from the present assessment because the SQG values have a low reliability for West Coast conditions, where naturally high crustal concentrations of the metal exist (Long et al. 1995, Long et al. 2000). Lauenstein et al. (2000) also found historical background concentrations of nickel in sediment cores along the West Coast in a range of 35-70 $\mu \mathrm{g} / \mathrm{g}$, which bracket the nickel ERM value of $51.6 \mu \mathrm{g} / \mathrm{g}$. Any site with one or more chemicals (other than nickel) that exceeded corresponding ERM values was rated as having poor sediment quality, any site with five or more chemicals between corresponding ERL and ERM values was rated as fair, and any site that had less than five ERLs exceeded and no ERMs exceeded was rated as good (sensu U.S. EPA 2004).

Sediments throughout the shelf survey area were relatively uncontaminated except for a group of stations in the SCB. Overall, about $99 \%$ of the total survey area (represented by 230 stations) had a rating of good, $<1 \%$ (represented by seven stations) had fair conditions with $\geq 5$ chemicals in excess of ERL values, and $<1 \%$ (represented by 22 stations) had poor conditions with $\geq$ 1 chemical in excess of the higher-threshold ERM values (Fig. 3.3.5). The pesticides 4,4'-DDE and total DDT were the only two contaminants that exceeded corresponding ERM values (Tables 3.3.3, 3.3.4). The ERM for total DDT was exceeded at 17 stations (representing $<1 \%$ of the overall survey area) and the ERM for 4,4'-DDE was exceeded at 22 stations (representing $<1 \%$ of the overall survey area). All of these sites were in California near Los Angeles. Total DDT and 4,4'-DDE were found in excess of the lower-threshold ERL values at 41 and 31 stations respectively, all of which again were in California, mostly in the Los Angeles area (Tables 3.3.3, 3.3.4; Figs. 3.3.6, 3.3.7).

Ten other contaminants, including seven metals (As, Cd, Cr, Cu, Hg, Ag, $\mathrm{Zn}$ ), 2-methylnaphthalene, low molecular weight PAHs, and total PCBs were found at moderate concentrations in excess of corresponding, lower-threshold ERL values (Tables 3.3.3, 3.3.4). The most prevalent in terms of area were chromium (31\%), arsenic (8\%), 2-methylnaphthalene $(6 \%)$, cadmium $(5 \%)$, and mercury $(4 \%)$. The 2-methylnaphthalene and mercury exceedances were limited entirely to California. The mercury exceedances were all at non-sanctuary sites in California, particularly in the Los Angeles area (Fig. 3.3.8), while the 2methylnaphthalene exceedances were conspicuously grouped around the 
Chromium ERL exceedances were much more widespread, with sediments exceeding the ERL value at sites along all three states (Fig. 3.3.10). Oregon had the highest incidence: 30 of 50 stations, representing $60 \%$ of the total survey area (Tables 3.3.3, 3.3.4). The highest concentration $(296.5 \mu \mathrm{g} / \mathrm{g})$ and highest mean concentration $(129.5 \mu \mathrm{g} / \mathrm{g}$ ) also occurred off Oregon (Table 3.3.1). Chromium is naturally present in soils in the Pacific Northwest Coast range. Chromium was originally mined from black sand deposits along the Oregon coast in Coos County, and a low-grade ore was mined in the 1940's to 1950 's in Oregon and northern California, and to a lesser extent in Washington, under a federal stockpiling program (Baber et al. 1959). A report by EPA Region $X$ on the ecological condition of the estuaries of Oregon and Washington (Hayslip et al. 2006) actually excluded chromium, as well as nickel and copper, from its aggregate sediment contamination indicator. Chromium was excluded in that report because the natural concentration of this metal in the earth's crust and marine shales (100 and $90 \mu \mathrm{g} / \mathrm{g}$, respectively; Krauskopf and Bird 1995) is greater than the ERL $(81 \mu \mathrm{g} / \mathrm{g})$.

With a few exceptions, sediments within West Coast National Marine Sanctuaries (NMSs) were relatively uncontaminated (Tables 3.3.1, 3.3.3, 3.3.4; Fig. 3.3.5). The OCNMS had no chemicals in excess of ERM values and only two chemicals, chromium and silver, were found in excess of the lower-threshold ERL values (Table 3.3.2). There were only four of 30 stations in the OCNMS with such chromium exceedances, compared to 31 of 70 stations in nearby nonsanctuary waters off the coast of Washington and Oregon. Similarly, CINMS had no chemicals in excess of ERM values. Three metals (As, Cd, Cr), 2methylnaphthalene, low molecular weight PAHs, total DDT, and 4,4'-DDE were found at moderate concentrations, between corresponding ERL and ERM values, at multiple sites within the CINMS. However, total DDT, 4,4'-DDE, and chromium ERL exceedances were notably less prevalent at CINMS than in non-sanctuary waters of California (Figs. 3.3.6, 3.3.7, 3.3.10). DDT and its metabolites are well known legacy pesticides in the SCB, and the distributions seen in this survey reflect patterns seen in previous years (Schiff 2000, Schiff et al. 2006). In contrast, 2-methylnaphthalene contamination, albeit at moderately low levels (between ERL and ERM values), was much more prevalent in sediments at the CINMS compared to non-sanctuary waters off the coast of California. For example, the ERL value was exceeded at 19 of the 27 CINMS stations, compared to only 3 of 103 stations in non-sanctuary waters (Table 3.3.4, Fig. 3.3.9). Schiff et al. (2006) attribute such elevated levels of PAHs in the California region to proximity of oil production platforms and reduced degradation of the compounds under cold water conditions. However, this does not explain the higher incidence of 2-methylnaphthalene contamination specifically around CINMS relative to neighboring non-sanctuary waters in the region. 
In comparison to the present sediment quality ratings for offshore waters ( $98 \%$ of the total survey area rated as good, $<1 \%$ rated as fair, and $<1 \%$ rated as poor), estuarine habitats along the West Coast show a relatively higher incidence of sediment contamination, particularly in the moderate concentration ranges. For example, U.S. EPA (2004), based on the same contaminants and methods, found $79 \%$ of estuarine sediments along the West Coast of the U.S. in good condition, $18 \%$ in fair condition, and $3 \%$ in poor condition. While only two contaminants $\left(4,4^{\prime}-\mathrm{DDE}\right.$ and total DDT) were found in excess of ERM guideline values in the present offshore study, several contaminants were found above ERM levels in adjacent estuaries, including chromium, mercury, copper, DDT, several PAHs, and PCBs. In the present offshore survey, all stations where ERM values were exceeded (22 stations) were in California near Los Angeles. In the estuarine assessment, there were 24 stations where ERMs were exceeded, including 20 in California (majority in the San Francisco estuary and Los Angeles Harbor area) and four in Washington (three in the Puget Sound system and one in the Columbia River).

Table 3.3.2. ERM and ERL guidance values in sediments (Long et al. 1995).

\begin{tabular}{lll}
\hline Metals $(\mu \mathrm{g} / \mathrm{g})$ & ERL & ERM \\
\hline Arsenic & 8.2 & 70 \\
Cadmium & 1.2 & 9.6 \\
Chromium & 81 & 370 \\
Copper & 34 & 270 \\
Lead & 46.7 & 218 \\
Mercury & 0.15 & 0.71 \\
Nickel & 20.9 & 51.6 \\
Silver & 1 & 3.7 \\
Zinc & 150 & 410 \\
\hline Organics (ng/g) & ERL & ERM \\
\hline Acenaphthene & 16 & 500 \\
Acenaphthylene & 44 & 640 \\
Anthracene & 85.3 & 1100 \\
Fluorene & 19 & 540 \\
2-Methylnaphthalene & 70 & 670 \\
Naphthalene & 160 & 2100 \\
Phenanthrene & 240 & 1500 \\
Benzo(a)anthracene & 261 & 1600 \\
Benzo(a)pyrene & 430 & 1600 \\
Chrysene & 384 & 2800 \\
Dibenz(a,h)Anthracene & 63.4 & 260 \\
Fluoranthene & 600 & 5100 \\
Pyrene & 665 & 2600 \\
Low molecular weight PAHs & 552 & 3160 \\
High molecular weight PAHS & 1700 & 9600 \\
Total PAHs & 4020 & 44800 \\
4,4-DDE & 2.2 & 27 \\
Total DDT & 1.58 & 46.1 \\
Total PCBs & 22.7 & 180 \\
\hline & & \\
\hline & &
\end{tabular}




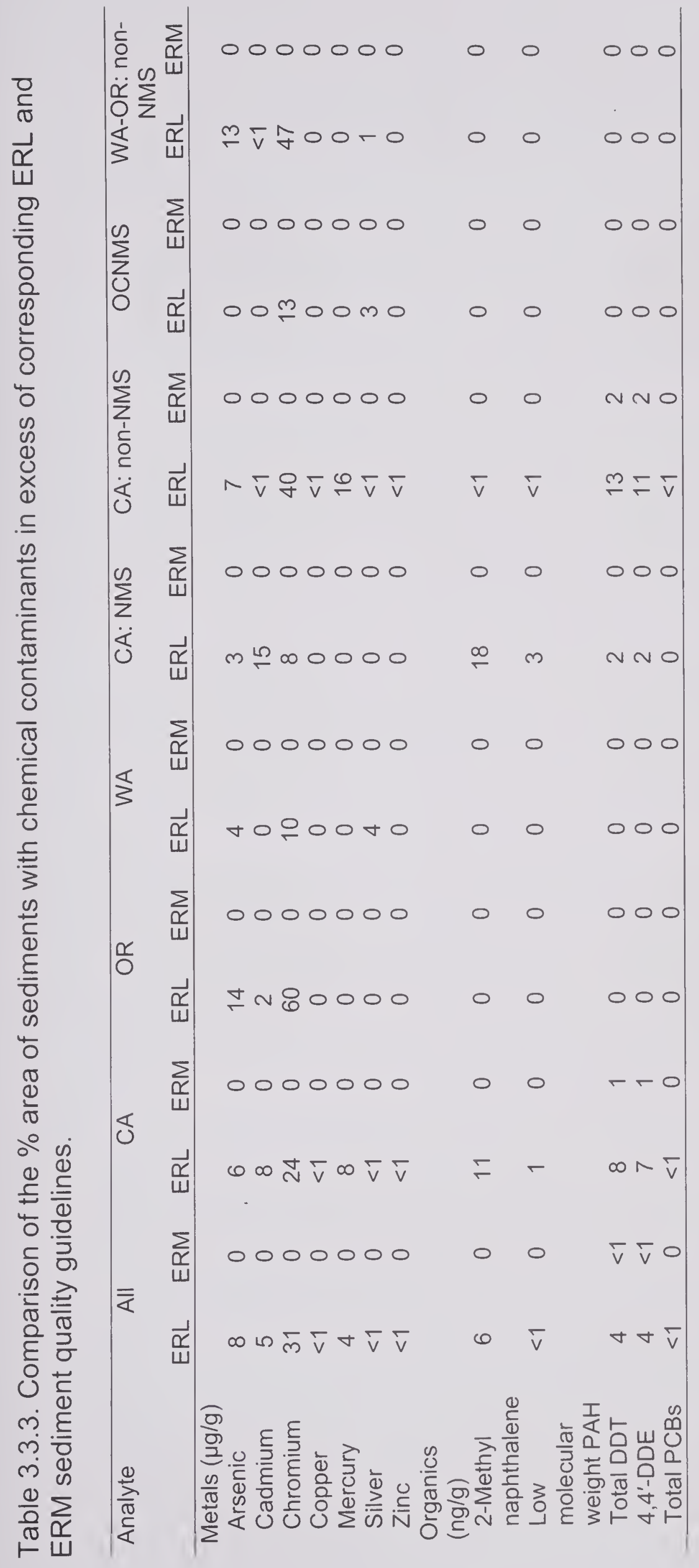




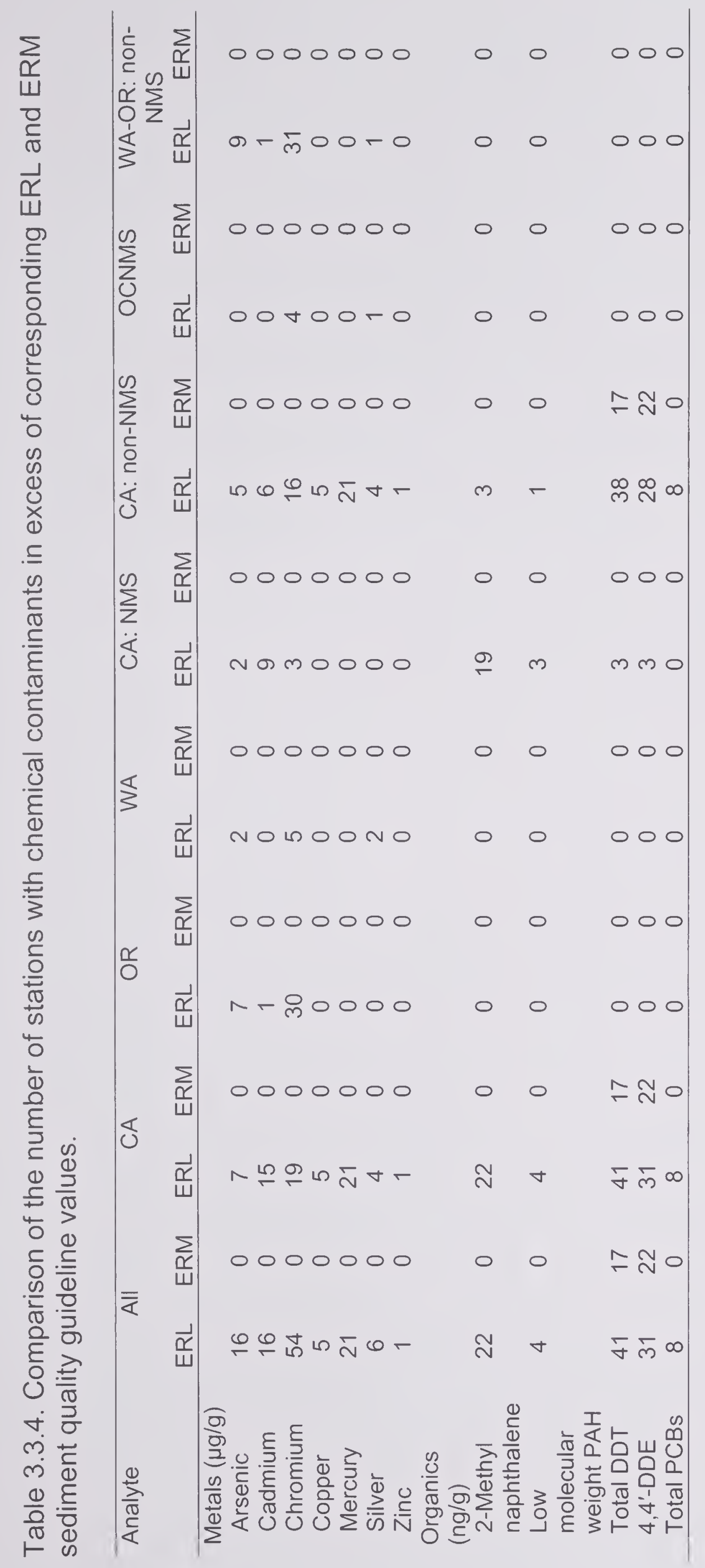




\section{Percent of Survey Area with:}

$\square$ NoERM concentrations exceeded

$\geq 5$ ERL concentrations exceeded

$\geq 1$ ERM concentration exceeded
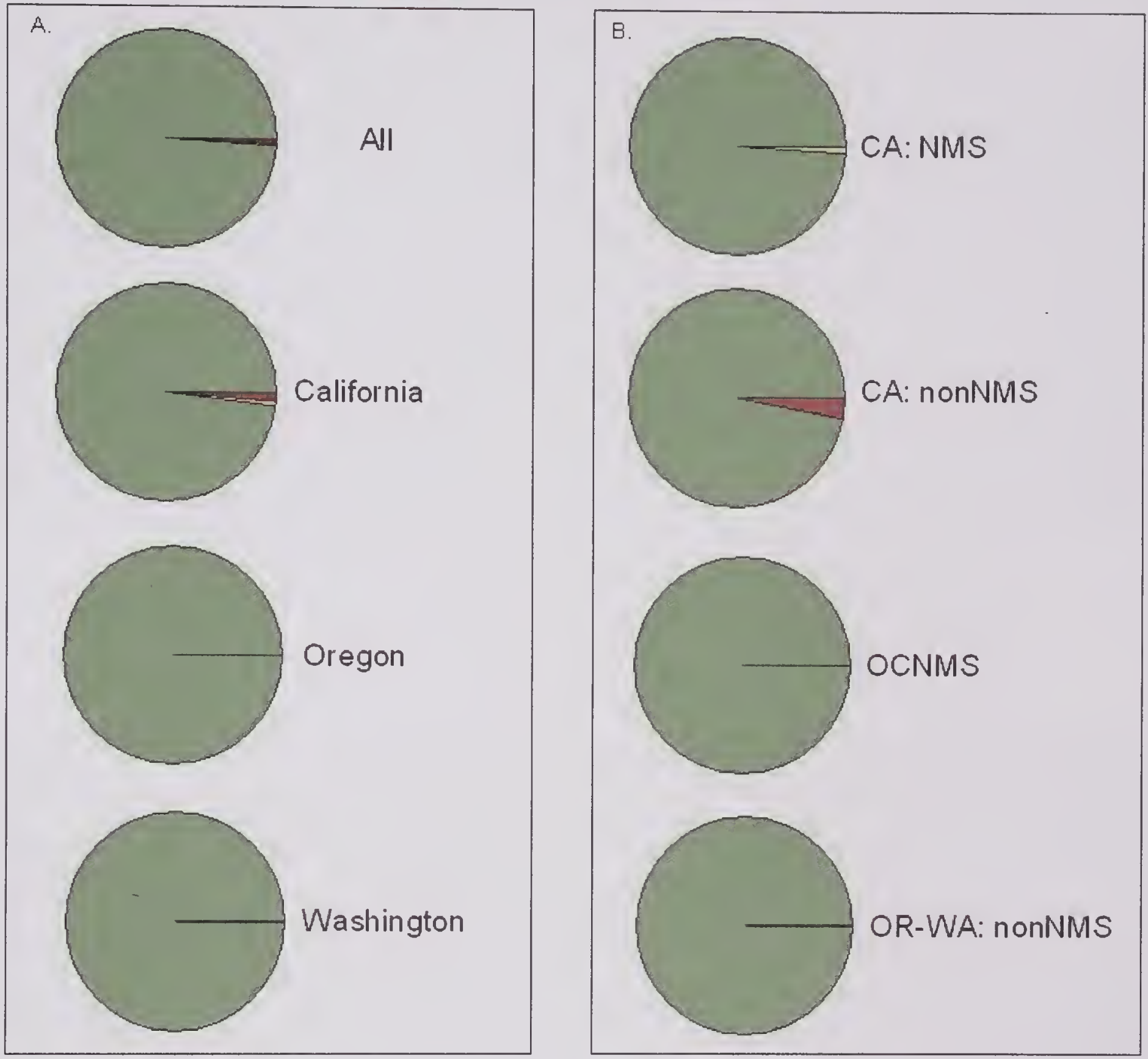

Figure 3.3.5. Comparison of the spatial extent of sediment contamination by (A) West Coast vs. individual states and (B) National Marine Sanctuary (NMS) vs. non-NMS stations. 


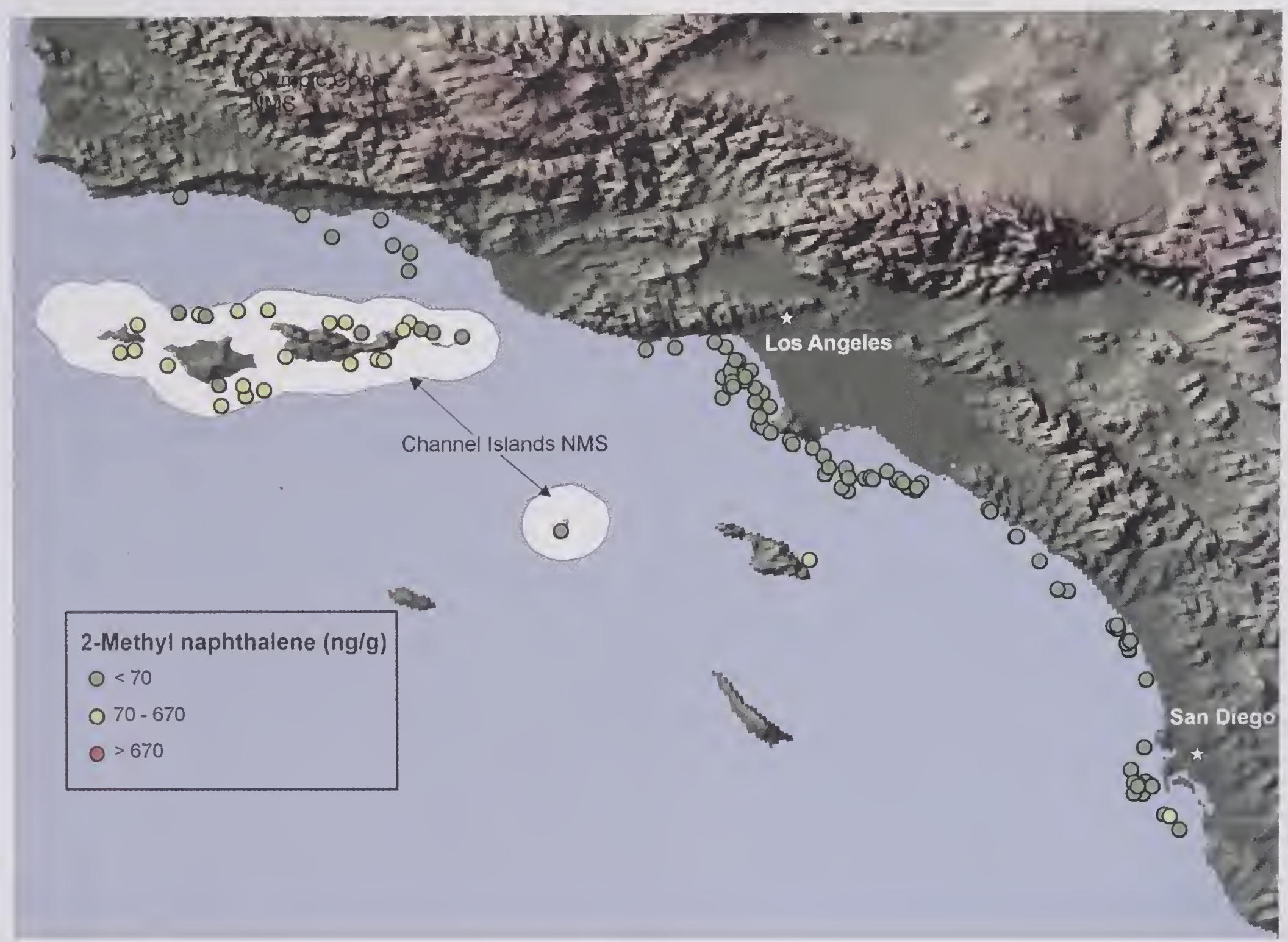

Figure 3.3.9. Distribution of 2-methylnaphthalene concentrations in sediments along the SCB relative to ERL and ERM guidelines. 


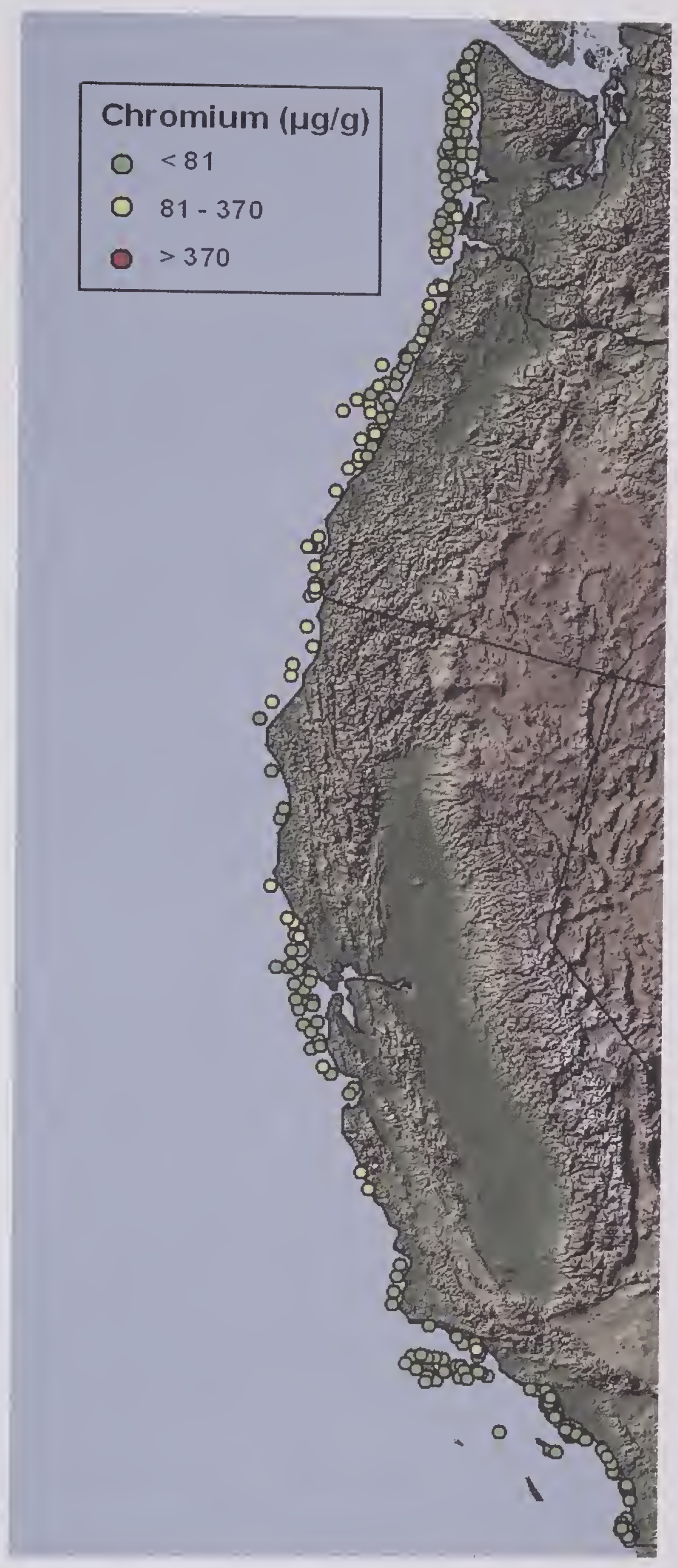

Figure 3.3.10. Distribution of chromium concentrations in sediments along the western U.S. continental shelf relative to ERL and ERM guidelines. 


\subsection{Fish Tissue Contaminants}

Concentrations of a suite of metals, PCBs, and pesticides (Table 2.3.1) were measured in whole fish collected from both the EMAP/NCA-West and FRAM groundfish surveys. All fish selected for analysis were flatfish (Pleuronectiformes) because of their commercial value and because of their potential contact with sediment-associated contaminants due to their affinity to bottom habitats. Because fish were collected from only about a third of all sites in the probabilistic EMAP/NCAWest survey, and because FRAM survey sites were not probability-based, CDFs and spatial estimates of condition could not be computed for fish-tissue contaminants. Patterns of contaminant concentrations throughout the region and the incidence of contaminant levels in excess of human-health guidelines are presented however.

Concentrations of selected contaminants in whole fish were compared with risk-based EPA advisory guidelines for recreational fishers, using non-cancer (systemic) health endpoints associated with the consumption of four 8-oz meals per month (Table 3.4.1), which is the comparison basis used in National Coastal Condition Reports (U.S. EPA 2000b, 2001, 2004, 2006). It is important to keep in mind that the guidelines used are for fish fillets, while the concentrations measured in the EMAP/NCA-West and FRAM surveys are for whole fish. Data presented here are for the parameters of interest in NCCR, including several metals, total PAH, total DDT and several other pesticides, including chlordane, dieldrin, endosulfan, endrin, heptachlor, hexachlorobenzene, lindane, mirex, and toxaphene (Table 3.4.1).

\subsubsection{EMAP}

Collection of targeted flatfish, based on hook-and-line methods, was successful at only 50 of the 147 EMAP/NCA-West stations sampled. Fish were collected from 21 stations in Washington, 20 in Oregon and nine in California. No benthic fish were collected from the SCB as part of the EMAP/NCA-West survey. Eight of the nine California samples, 13 of the 21 Washington samples, and none of the Oregon samples were collected in National Marine Sanctuaries. Species selected for analysis included Pacific sanddab (Citharichthys sordidus), speckled sanddab (Citharichthys stigmaeus), butter sole (Isopsetta isolepis), and Dover sole (Microstomus pacificus). No fish that were collected exhibited evidence of obvious pathological disorders based on visual inspections in the field. Contaminants were measured in 55 composites, including some laboratory duplicates for QA, of flatfish tissue from the 50 stations. Results are summarized in Tables 3.4.2 and 3.4.3.

Cadmium - The lower cadmium non-cancer health-risk guideline value was exceeded in at least one composite at nine stations, including six of the 20 stations where fish were collected in Oregon (OR03-0006, 0009, 0010, 0017, 0039 and 0040; Fig. 3.1.3) and three of the nine stations in California (CA03-0052, 0060 and 0064; Fig. 3.1.4). While the stations from Oregon were not in a NMS, the three stations in California were within the Monterey Bay and Gulf of Farallones NMSs. 
Tissue cadmium levels were not strongly correlated with sediment cadmium levels at corresponding stations (Fig. 3.4.1, $r^{2}=0.049$ ).

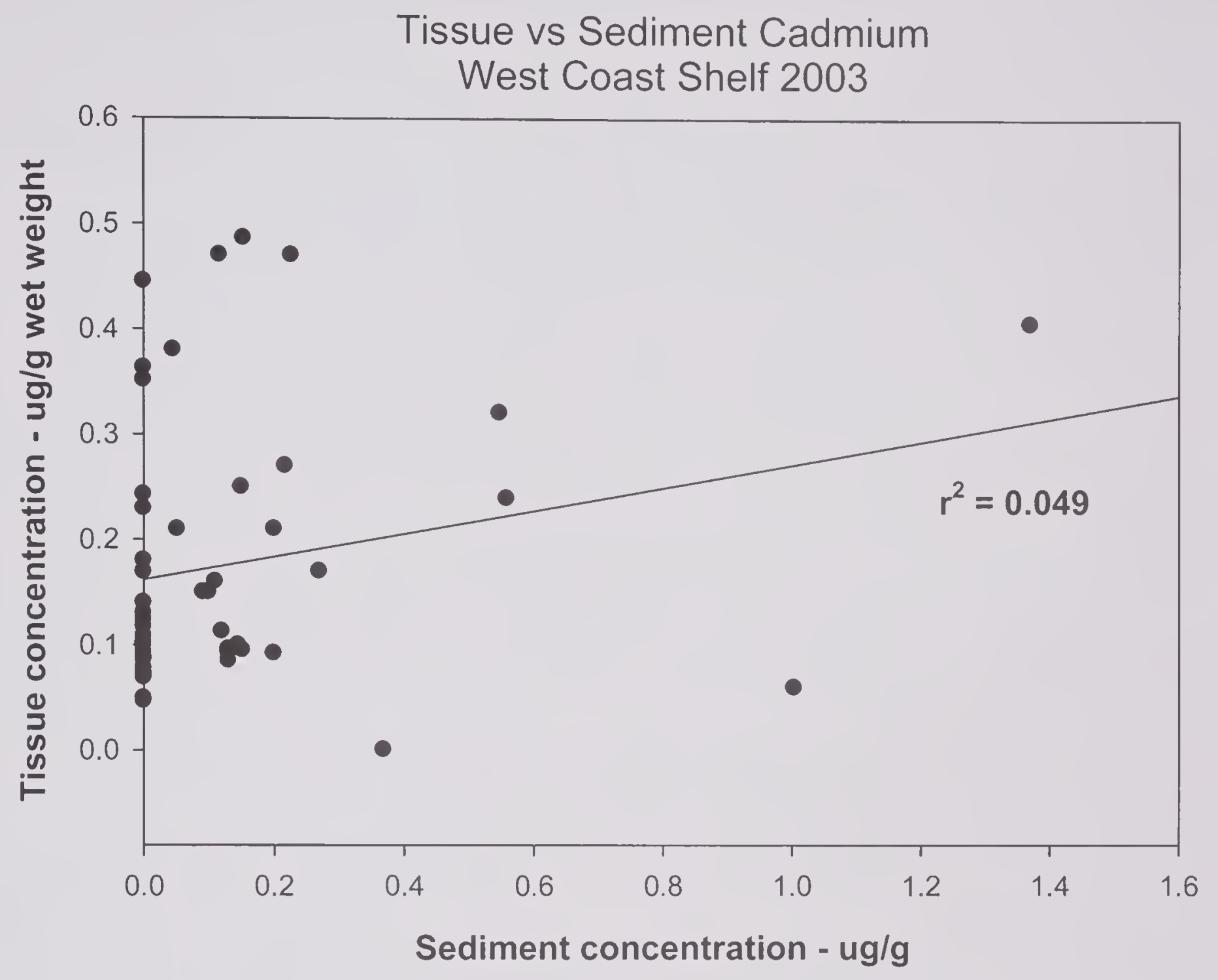

Figure 3.4.1. Tissue vs. sediment concentration of cadmium at corresponding stations from the EMAP/NCA-West 2003 shelf survey including samples from Washington, Oregon and California.

Other parameters - The lower value in the range of non-cancer health-risk guideline values for total PCB was exceeded at one of 21 stations in Washington (WA03-0086), just north of the mouth of the Columbia River (Fig. 3.1.2). This observation may have resulted from the bioaccumulation of PCB in fish from within the Columbia River, and subsequent migration out of the estuary. The health-risk guideline values for all metals other than cadmium and all pesticides measured were not exceeded in fish collected in the EMAP/NCA-West survey. Data for all stations and parameters are summarized in Table 3.4 .2 by state and in Table 3.4 .3 by NMS vs. non-NMS status. 
Table 3.4.1. Risk-based EPA advisory guidelines for recreational fishers ${ }^{a}$

\begin{tabular}{|c|c|c|}
\hline Metals $\mu \mathrm{g} / \mathrm{g}$ & Concentration Range & Health Endpoint \\
\hline Arsenic (inorganic) $)^{c}$ & $3.5-7.0$ & Non-cancer \\
\hline Cadmium & $0.35-0.70$ & Non-cancer \\
\hline Mercury (methyl) ${ }^{d}$ & $0.12-0.23$ & Non-cancer \\
\hline Selenium & $5.9-12.0$ & Non-cancer \\
\hline \multicolumn{3}{|l|}{ Organics ng/g } \\
\hline Chlordane & $590-1200$ & Non-cancer \\
\hline DDT (total) & $59-120$ & Non-cancer \\
\hline Dieldrin & $59-120$ & Non-cancer \\
\hline Endosulfan & $7000-14000$ & Non-cancer \\
\hline Endrin & $350-700$ & Non-cancer \\
\hline Heptachlor Epoxide & $15-31$ & Non-cancer \\
\hline Hexachlorobenzene & $940-1900$ & Non-cancer \\
\hline Lindane & $350-700$ & Non-cancer \\
\hline Mirex & $230-470$ & Non-cancer \\
\hline Toxaphene & $290-590$ & Non-cancer \\
\hline PCB (total) & $23-47$ & Non-cancer \\
\hline
\end{tabular}

${ }^{a}$ From U.S. EPA 2000b

${ }^{b}$ Range of concentrations associated with non-cancer health endpoint risk for consumption of four 8-oz meals per month

${ }^{c}$ Inorganic arsenic estimated as $2 \%$ of total arsenic

d. U.S. EPA $2000 \mathrm{~b}$ recommends analyzing for total mercury with the use of a conservative assumption that all mercury is present as methylmercury, and thus comparison is made to the methylmercury risk based guideline. 


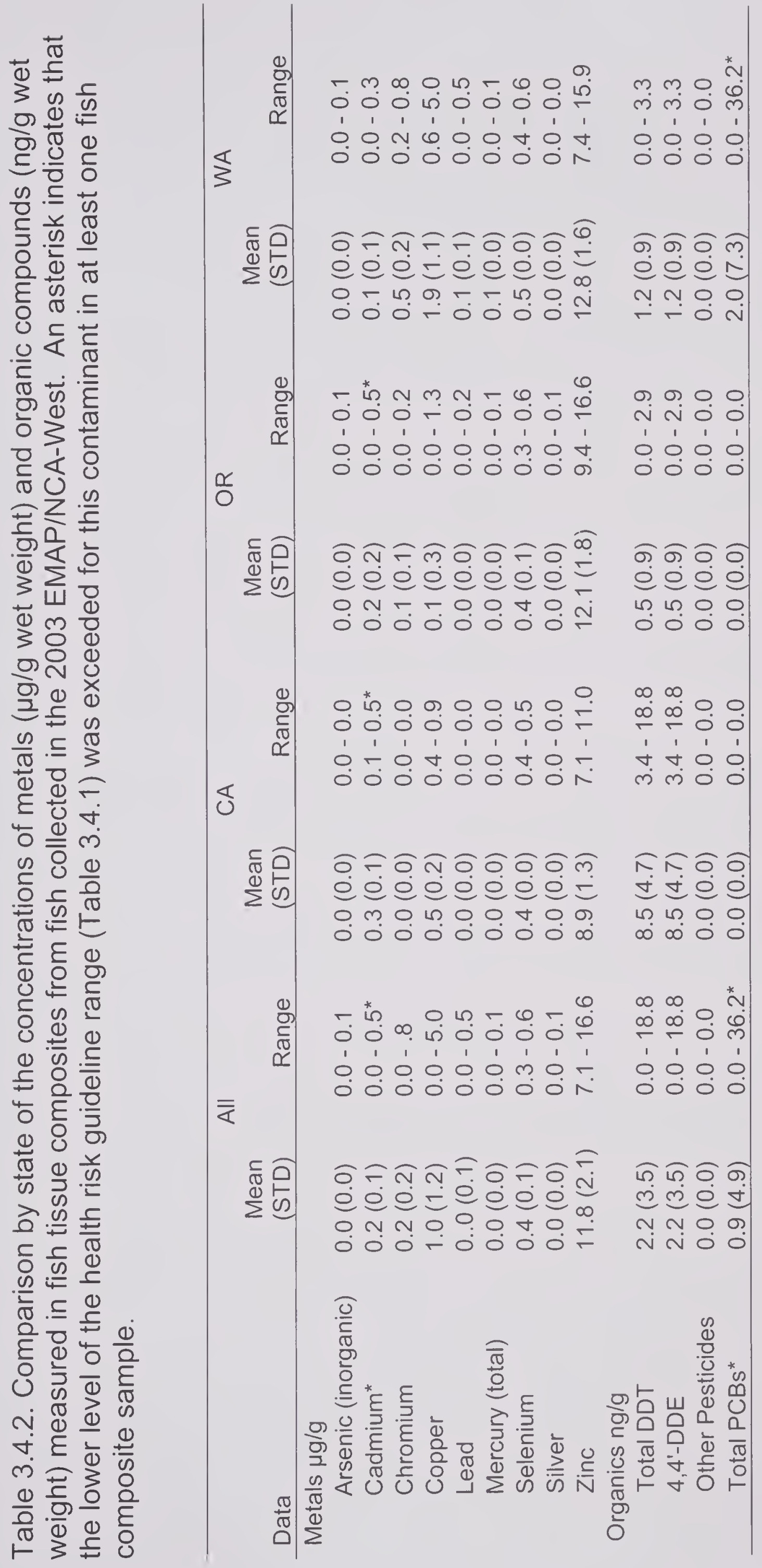

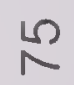




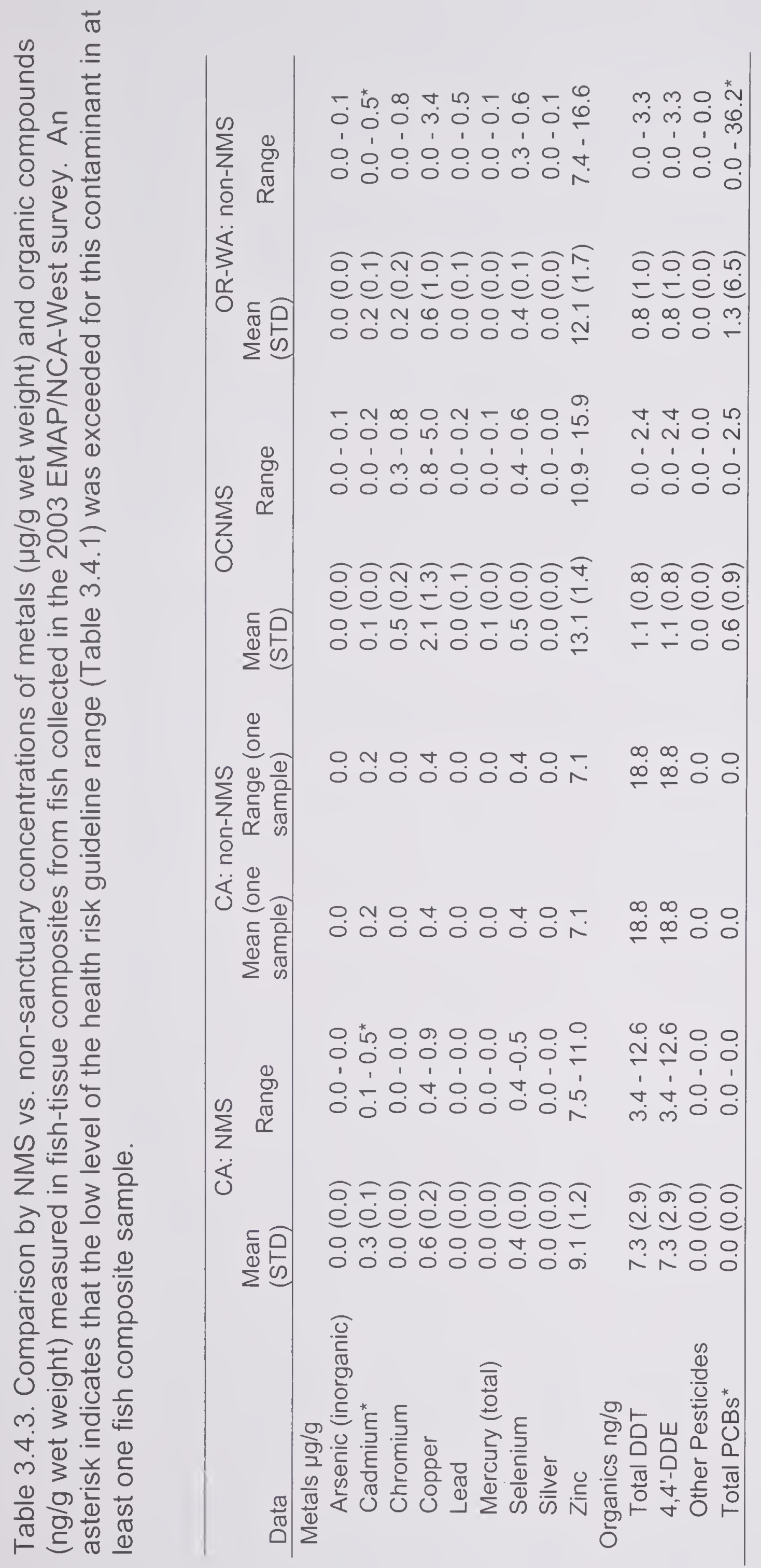




\subsubsection{FRAM Groundfish Survey}

Fish were analyzed for contaminants in 99 tissue composites from 60 stations sampled in 2003 by the Fisheries Resource Analysis and Monitoring (FRAM) Division of the Northwest Fisheries Science Center (NWFSC) of NOAA as part of their western groundfish survey program (Figs. 3.1.6-3.1.9; Appendix Table 2). Fish collected from FRAM stations that were within the EMAP/NCAWest sampling frame were transferred to EPA for subsequent analysis. Species selected for analysis included Pacific sanddab (Citharichthys sordidus), petrale sole (Eopsetta jordani), rex sole (Glyptoephalus zachirus), Dover sole (Microstomus pacificus) and English sole (Parophrys vetulus). Data for all stations and parameters are summarized in Table 3.4.4.

Cadmium - The lower end of the range of cadmium values associated with non-cancer risks was exceeded in at least one composite at nine stations coastwide, including five sites in California, mostly near San Francisco Bay (CEW03419-016, 054, and 058 in the Monterey Bay NMS; 026 in Cordell Bank NMS; and 022 not in a NMS; Fig. 3.1.9); two in Oregon (CEW03419-082 and 087 not in a NMS; Fig. 3.1.8); and two in Washington (CEW03419-112 and 116 both in the Olympic Coast NMS; Fig. 3.1.7). Fish from Station CEW03419-058, south of San Francisco Bay (Fig.3.1.9), had cadmium in excess of the upper end of the non-cancer health-risk range.

Mercury - Fish consumption has been reported to be a major source of mercury in humans. The human-health risk guideline level for mercury was not exceeded in this study, though concentrations approached that level in some composites. The mercury concentrations reported in this study are total mercury, whereas the form of mercury that may cause human-health effects is methyl mercury. However, the U.S. EPA recommends an approach where total mercury concentration is measured, and with the use of a conservative assumption that all mercury is present as methylmercury, a comparison is made to the methylmercury risk based guideline (U.S. EPA 2000b). This conservative approach is viewed as being both protective of human health and most cost effective. The presence of selenium in these fish tissue samples may reduce the health impacts of methyl mercury, as selenium sequesters mercury, making it metabolically unavailable (for a review, see Raymond and Ralston 2004).

Other parameters - The health-risk guideline values for metals (other than cadmium), PCBs, and pesticides were not exceeded in fish collected from the FRAM survey (Table 3.4.4). The maximum concentration of total DDT measured was $30.4 \mathrm{ng} / \mathrm{g}$, which is below the risk guideline. One composite sample from Washington (CEW03419-122) had an aldrin concentration of 0.64 $\mathrm{ng} / \mathrm{g}$, but the other composite from the same station had no aldrin, and aldrin was undetected in all other samples. Levels of all other pesticides were undetectable. 
Table 3.4.4. Concentrations of metals ( $\mu \mathrm{g} / \mathrm{g}$ wet weight) and organic compounds (ng/g wet weight) measured in tissue composites of fish collected from 60 stations in the 2003 FRAM survey. Frequency of detection is the number of stations (among 60) where the parameter was detected at a level above the minimum detection limit (MDL) in flatfish. An asterisk indicates that the low level of the health risk guidelines range was exceeded in at least one fish composite sample.

\begin{tabular}{lccccc}
\hline Contaminant & Mean & Maximum & Minimum & $\begin{array}{c}\text { Frequency } \\
\text { of } \\
\text { Detection }\end{array}$ & $\begin{array}{c}\text { Health Risk } \\
\text { Guideline } \\
\text { Range }\end{array}$ \\
\hline $\begin{array}{c}\text { Metals }(\mu \mathrm{g} / \mathrm{g}) \text { : } \\
\text { Inorganic }\end{array}$ & & & & & \\
$\quad$ Arsenic & 0.1 & 0.2 & 0.0 & $60 / 60$ & $3.5-7.0$ \\
Cadmium* & 0.2 & $1.5^{*}$ & 0.0 & $45 / 60$ & $0.35-0.70$ \\
Chromium & 0.2 & 1.0 & 0.0 & $34 / 60$ & - \\
Copper & 0.5 & 2.6 & 0.0 & $47 / 60$ & - \\
Lead & 0.0 & 0.1 & 0.0 & $4 / 60$ & - \\
Mercury & 0.0 & 0.1 & 0.0 & $52 / 60$ & $0.12-0.23$ \\
Selenium & 0.4 & 1.8 & 0.0 & $44 / 60$ & $5.9-12.0$ \\
Silver & 0.0 & 0.0 & 0.0 & $1 / 60$ & - \\
Zinc & 10.0 & 13.8 & 6.5 & $60 / 60$ & - \\
& & & & & \\
Organics (ng/g): & & & & & \\
Total PCB & 0.3 & 3.8 & 0.0 & $11 / 60$ & $23-47$ \\
Total DDT & 5.0 & 30.4 & 0.0 & $41 / 60$ & $59-120$ \\
4,4"-DDE & 5.0 & 30.4 & 0.0 & $41 / 60$ & - \\
Other & & & & & - \\
Pesticides* & 0.0 & 0.3 & 0.0 & $1 / 60$ & - \\
\hline
\end{tabular}

The State of Washington measured metals and organics in fillets of fish separately from the remains (whole fish minus fillets). This procedure provides some data for estimating filet levels of contaminants from measurements of contaminant levels in whole fish from California and Oregon. Cadmium levels were undetectable in all fish fillets, suggesting that the levels reported for whole fish might not be accurate for fillets, and levels of cadmium in fish fillets from fish sampled in this study might be below EPA health-risk guidance values. For other metals, the ratio of mean values in fillets to mean values in remains was variable, ranging from 0.30 to 1.35 (Table 3.4.5). Total PCBs at one station were undetectable in remains, but measured $2.8 \mathrm{ng} / \mathrm{g}$ in fillets. At other stations, the ratio of levels in fillets vs. remains averaged 0.24 . For total DDT, the ratio of levels in fillets vs. remains averaged 0.98 . 
Table 3.4.5. Ratios of concentrations of measured chemical parameters in fillets vs. remains of fish in flatfish collected in Washington for the 2003 FRAM groundfish survey.

\begin{tabular}{lccc}
\hline \multicolumn{1}{c}{ Contaminant } & Mean in Fillets & Mean in Remains & Mean of Ratios \\
\hline Metals $(\mu \mathrm{g} / \mathrm{g})$ & & & \\
Inorganic Arsenic & 0.06 & 0.07 & 0.98 \\
Cadmium & 0.00 & 0.08 & - \\
Chromium & 0.33 & 0.48 & 0.68 \\
Copper & 0.27 & 0.82 & 0.30 \\
Lead & 0.00 & 0.00 & - \\
Mercury & 0.06 & 0.04 & 1.35 \\
Nickel & 0.00 & 0.00 & - \\
Selenium & 0.29 & 0.29 & 0.94 \\
Silver & 0.00 & 0.00 & - \\
& & & \\
Organics $(\mathrm{ng} / \mathrm{g})$ & & 1.21 & 0.24 \\
$\quad$ Total PCB & 0.30 & 0.07 & 0.98 \\
$\quad$ Total DDT & 0.06 & 0.0 & - \\
$\quad$ Other Pesticides & 0.0 & & \\
\hline
\end{tabular}

\subsection{Status of Benthic Communities}

Macrobenthic infauna ( $>1 \mathrm{~mm}$ ) were sampled at a total of 256 stations throughout the study region. A single grab $\left(0.1 \mathrm{~m}^{2}\right)$ was collected at all stations except three, at which duplicates were taken, thus resulting in a total of 259 benthic grabs. The duplicate samples were averaged for the calculation of CDFs and other analysis purposes. The resulting data are used here to assess the status of benthic community characteristics (taxonomic composition, diversity, abundance and dominant species), biogeographic patterns, the incidence of nonindigenous species, and potential linkages to ecosystem stressors throughout the western U.S. continental shelf from the Strait of Juan de Fuca, WA to the Mexican border. Assessments are presented on a region-wide basis, by state (WA, Oregon, California), and by NMS vs. non-sanctuary status. The latter comparison includes California sanctuaries (Channel Islands NMS, Monterrey Bay NMS, Gulf of the Farallones NMS, and Cordell Bank NMS) vs. nonsanctuary stations in California and stations in the Olympic Coast NMS (OCNMS) vs. non-sanctuary stations in Oregon and Washington. Characteristics of the shelf benthos are also compared to those of neighbouring estuaries along the West Coast, using 1999-2000 data on estuaries from the NCA-West database (Nelson et al. 2004, 2005; U.S. EPA 2004, Hayslip et al. 2006). 


\subsubsection{Taxonomic Composition}

A total of 1,482 taxa were identified region-wide, of which 1,108 were identified to the species level. Polychaetes were the dominant taxa, both by percent abundance (59\% region-wide, Fig. 3.5.1) and percent taxa (44\% regionwide, Fig. 3.5.2, Table 3.5.1). Crustaceans and molluscs were the second and third most dominant taxa respectively, both by percent abundance $(17 \%$ crustaceans, $12 \%$ molluscs) and percent taxa (25\% crustaceans, $17 \%$ molluscs). Collectively, these three groups represented $88 \%$ of the total faunal abundance and $86 \%$ of the taxa throughout the region. Crustaceans were represented mostly by amphipods (202 identifiable taxa, $14 \%$ of the total number of taxa) followed by decapods (49 taxa, 3.3\% of total taxa) and cumaceans (39 taxa, $2.6 \%$ of total taxa) (Table 3.5.1). Molluscs were composed mostly of bivalves (116 taxa, $7.8 \%$ of total taxa) and gastropods (112 taxa, $7.5 \%$ of total taxa). High proportions of polychaete and amphipod species are also characteristic of estuaries along the West Coast, though there are notable differences in the relative proportions of other taxonomic groups (Table 3.5.2). For example, species of larval insects represented $2.9 \%$ of total taxa in the NCA-West estuarine data set, but were absent in the present shelf samples. In contrast, ophiuroids and holothurians are more specious on the shelf than in estuaries. Also, while oligochaetes as a group represent only $0.2 \%$ of the total faunal abundance on the shelf, Nelson et al. (2005) reported them as being dominant (among the 10 most abundant) members of the estuarine benthos along the West Coast.

Polychaetes, crustaceans, and molluscs dominated the benthic fauna consistently across the three states and NMS vs. non-sanctuary categories (Fig. $3.5 .1,3.5 .2$ ). Similar to the region-wide pattern, polychaetes were the most dominant, by both percent abundance and species richness, consistently across all strata. However, while crustaceans were the second-most abundant group in California (similar to the region-wide pattern), molluscs were proportionally more abundant than crustaceans in Oregon and Washington. There were no major differences in the percent composition of benthic communities between NMSs and corresponding non-sanctuary sites. However, molluscs were proportionally more abundant and specious than crustaceans at non-sanctuary sites in Oregon and Washington than at the OCNMS.

\subsubsection{Diversity}

Species richness, expressed as the number of taxa present in a $0.1-\mathrm{m}^{2}$ grab, was relatively high in these offshore shelf assemblages. A total of 1,482 taxa were identified region-wide from the 259 benthic grabs. Species richness ranged from 19 to 190 taxa/grab and averaged 79 taxa/grab (Table 3.5.3, Fig. 3.5.3). In comparison, the NCA-West estuarine data (Nelson et al. 2004, 2005; U.S. EPA 2004, Hayslip et al. 2006) show an average of 26 taxa/grab in estuaries along the West Coast (Table 3.5.3). Only five of the 256 shelf stations, 
representing about $2 \%$ of the shelf area, had $\leq 26$ taxa/grab (Fig. 3.5.4). This greater species richness was reflected over large areas of the shelf. For example, approximately $50 \%$ of the area of the shelf had species richness $\geq 67$ taxa/grab and $10 \%$ of the shelf had $\geq 110$ taxa/grab (Fig. 3.5.4, Table 3.5.3). In comparison, the corresponding CDF $50^{\text {th }}$ percentile value for estuaries was 49 taxa/grab and the $10^{\text {th }}$ percentile value was 90 taxa/grab (Table 3.5.3). Species richness along the shelf was highest off California (mean of 94 taxa/grab) and nearly equally lower in Oregon and Washington (means of 55 and 56 taxa/grab, respectively). Estuarine means by state were much lower for California (24 taxa/grab) and Oregon (11 taxa/grab) though similar for Washington (48 taxa/grab) (Table 3.5.3). Average species richness was very similar between sanctuary vs. non-sanctuary stations for both the California and Oregon/Washington regions (Fig. 3.5.3).

A more detailed examination of species richness, using quartile ranges, further confirmed a pattern of increasing species richness along the shelf with decreasing latitude (Figs. 3.5.3, 3.5.5). There were 61 stations with values in the upper quartile of all stations (i.e., values $>100$ taxa/grab). All but one of these sites (WA03-0015) were in California, most were in the SCB. A correlation analysis (SAS 2003) revealed a highly significant negative association between numbers of species and latitude (Pearson's correlation coefficient $r=-0.61, p$ $<0.0001)$. This is different from the pattern observed in estuaries. For example, the NCA-West 1999-2000 database for estuaries shows that the highest species richness among the three states was in Washington, especially in Puget Sound (Table 3.5.3; also see Partridge 2007). In fact, all estuarine stations with > 100 taxa/grab were in Washington. The high species richness reported here for shelf waters, particularly those off the California coast, is consistent with an earlier study by Hyland et al. (1991) for offshore waters of the Santa Maria Basin, which showed numbers of species (>0.5-mm size) averaging about 100 to $150 / \mathrm{grab}$ $\left(0.1 \mathrm{~m}^{2}\right)$ at comparable outer shelf/upper slope depths under $200 \mathrm{~m}$.

The high species richness, as well as a relatively even distribution of species abundances within samples, also resulted in fairly high values of the diversity index $\mathrm{H}^{\prime}$ (log base 2) for many stations across the region. Values ranged from 2.04 to 6.63/grab and averaged 5.01/grab region-wide (Table 3.5.3, Fig. 3.5.6). Approximately $50 \%$ of the shelf area had $\mathrm{H}^{\prime}$ values $\geq 4.82$, and $10 \%$ of the area had $\mathrm{H}^{\prime}$ values $\geq 5.80$ (Fig. 3.5.7). In comparison, mean diversity and the CDF $50^{\text {th }}$ percentile point for estuarine habitat along the West Coast correspond to lower $\mathrm{H}^{\prime}$ values of 2.41 and 3.84, respectively (Table 3.5.3). Mean $\mathrm{H}^{\prime}$ in the present shelf survey was highest in California (5.36) and lowest in Washington (4.27) (Fig. 3.5.7, Table 3.5.3). There were no major differences in mean $\mathrm{H}^{\prime}$ between sanctuary vs. non-sanctuary stations for both the California and Oregon/Washington regions. 
Table 3.5.1. Summary of major taxonomic groups for the west-coast shelf region wide.

\begin{tabular}{|c|c|c|}
\hline Taxonomic Group & Number identifiable taxa & $\%$ Total identifiable taxa \\
\hline Phylum Protozoa & 1 & 0.1 \\
\hline Phylum Porifera & 1 & 0.1 \\
\hline \multicolumn{3}{|l|}{ Phylum Cnidaria } \\
\hline Class Hydrozoa & 10 & 0.7 \\
\hline Class Anthozoa & 52 & 3.5 \\
\hline Phylum Platyhelminthes & 9 & 0.6 \\
\hline Phylum Nemertea & 32 & 2.2 \\
\hline Phylum Nemata & 1 & 0.1 \\
\hline Phylum Sipuncula & 10 & 0.7 \\
\hline \multicolumn{3}{|l|}{ Phylum Mollusca } \\
\hline Class Gastropoda & 112 & 7.5 \\
\hline Class Aplacophora & 10 & 0.7 \\
\hline Class Bivalvia & 116 & 7.8 \\
\hline Class Polyplacophora & 6 & 0.4 \\
\hline Class Scaphopoda & 9 & 0.6 \\
\hline Phylum Echiura & 6 & 0.4 \\
\hline \multicolumn{3}{|l|}{ Phylum Annelida } \\
\hline Class Polychaeta & 648 & 43.7 \\
\hline \multicolumn{3}{|l|}{ Class Clitellata } \\
\hline Subclass Hirudinea & 1 & 0.1 \\
\hline Subclass Oligochaeta & 1 & 0.1 \\
\hline \multicolumn{3}{|l|}{ Phylum Arthropoda } \\
\hline \multirow{2}{*}{\multicolumn{3}{|c|}{$\begin{array}{l}\text { Subphylum Crustacea } \\
\text { Class Malacostraca }\end{array}$}} \\
\hline & & \\
\hline Order Leptostraca & 3 & 0.2 \\
\hline Order Decapoda & 49 & 3.3 \\
\hline Order Mysida & 6 & 0.4 \\
\hline Order Cumacea & 39 & 2.6 \\
\hline Order Tanaidacea & 16 & 1.1 \\
\hline Order Isopoda & 43 & 2.9 \\
\hline Order Amphipoda & 202 & 13.6 \\
\hline Class Maxillopoda & 5 & 0.3 \\
\hline Class Ostracoda & 14 & 0.9 \\
\hline Subphylum Chelicerata & 7 & 0.4 \\
\hline Phylum Phoronida & 2 & 0.1 \\
\hline Phylum Ectoprocta & 1 & 0.1 \\
\hline Phylum Brachiopoda & 2 & 0.1 \\
\hline \multicolumn{3}{|l|}{ Phylum Echinodermata } \\
\hline Class Asteroidea & 4 & 0.3 \\
\hline Class Ophiuroidea & 25 & 1.7 \\
\hline Class Echinoidea & 8 & 0.5 \\
\hline Class Holothuroidea & 19 & 1.3 \\
\hline Phylum Hemichordata & 5 & 0.3 \\
\hline Phylum Chordata & 7 & 0.5 \\
\hline Total & 1482 & 100 \\
\hline
\end{tabular}


Table 3.5.2. Comparison of the proportion of taxa within major taxonomic groups on the shelf vs. West Coast estuaries. Each value is the number of species within the corresponding taxonomic group divided by the total number of species.

\begin{tabular}{lcc}
\hline Taxonomic Group & Shelf & Estuaries \\
\hline Polychaetes & $44 \%$ & $36 \%$ \\
Amphipods & $14 \%$ & $14 \%$ \\
Decapods & $3.3 \%$ & $3.4 \%$ \\
Cumaceans & $2.6 \%$ & $2.6 \%$ \\
Bivalves & $7.8 \%$ & $8.3 \%$ \\
Gastropods & $7.5 \%$ & $7.8 \%$ \\
Ophiuroids & $1.7 \%$ & $1.2 \%$ \\
Holothurians & $1.3 \%$ & $0.7 \%$ \\
Insect larvae & 0 & $2.9 \%$ \\
Total species & 1482 & 1303 \\
\# Grabs $\left(0.1 \mathrm{~m}^{2}\right.$ each) & 259 & 345 \\
\hline
\end{tabular}

* Based on 1999-2000 data from the EPA National Coastal Assessment Western Regional Component (NCA-West) database for estuaries (Nelson et al. 2004, 2005; U.S. EPA 2004; Hayslip et al. 2006). 


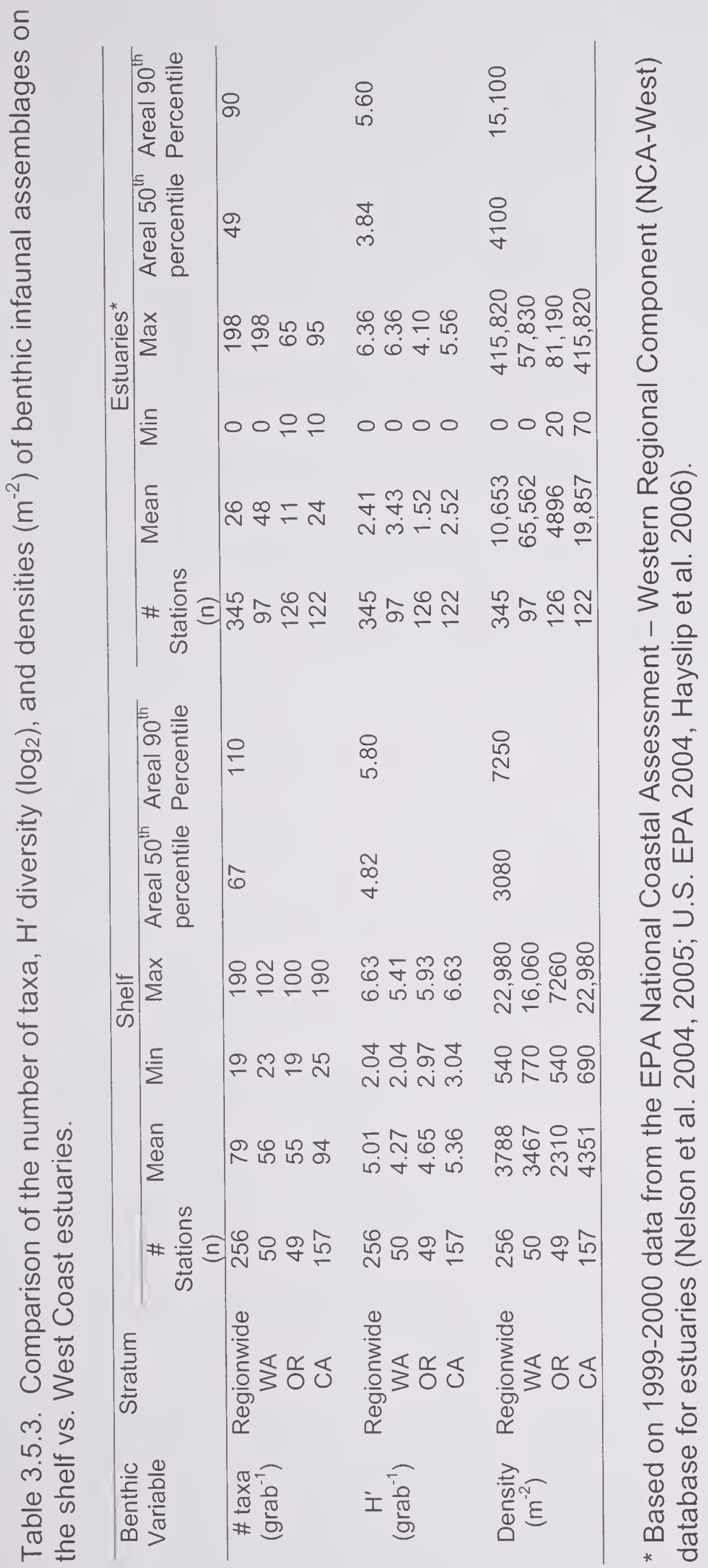


Table 3.5.4. Fifty most abundant benthic taxa in the West Coast shelf survey region wide. Average density per $\mathrm{m}^{2}$, and percent frequency of occurrence based on 256 grabs. Classification: Native $=$ native species; Crypto $=$ cryptogenic species (of uncertain origin); Indeter = indeterminate taxa (not identified to a level that would allow determination of origin).

\begin{tabular}{|c|c|c|c|c|}
\hline Taxa Name & Taxon & Classification & $\begin{array}{l}\text { Average } \\
\# / \mathrm{m}^{2}\end{array}$ & $\begin{array}{c}\% \\
\text { Frequency }\end{array}$ \\
\hline Mediomastus spp. & Polychaete & Indeter & 141.9 & 62.9 \\
\hline Axinopsida serricata & Bivalve & Native & 124.8 & 67.2 \\
\hline Magelona longicornis & Polychaete & Native & 105.3 & 23.0 \\
\hline Amphiodia urtica & Ophiuroid & Native & 87.5 & 43.4 \\
\hline Spiophanes berkeleyorum & Polychaete & Native & 86.8 & 77.0 \\
\hline Pinnixa occidentalis & Decapoda & Native & 82.0 & 27.3 \\
\hline Spiophanes bombyx & Polychaete & Native & 81.2 & 41.8 \\
\hline $\begin{array}{l}\text { Euphilomedes } \\
\text { carcharodonta }\end{array}$ & Ostracod & Native & 73.6 & 46.1 \\
\hline Spiophanes duplex & Polychaete & Native & 73.2 & 44.9 \\
\hline Prionospio jubata & Polychaete & Native & 67.2 & 71.9 \\
\hline Chloeia pinnata & Polychaete & Native & 55.0 & 40.2 \\
\hline Owenia fusiformis & Polychaete & Crypto & 48.2 & 10.9 \\
\hline Myriochele striolata & Polychaete & Native & 47.7 & 10.5 \\
\hline Galathowenia oculata & Polychaete & Crypto & 45.1 & 33.2 \\
\hline Ampelisca agassizi & Amphipod & Native & 43.4 & 30.5 \\
\hline Decamastus gracilis & Polychaete & Native & 42.0 & 46.1 \\
\hline Paraprionospio pinnata & Polychaete & Native & 39.3 & 70.7 \\
\hline Scoletoma luti & Polychaete & Native & 38.6 & 31.3 \\
\hline Euclymeninae sp. A & Polychaete & Native & 37.2 & 58.6 \\
\hline Amphiodia spp. & Ophiuroid & Indeter & 34.7 & 48.0 \\
\hline Sternaspis fossor & Polychaete & Crypto & 34.7 & 46.9 \\
\hline Rochefortia tumida & Bivalve & Native & 33.4 & 41.0 \\
\hline Euclymeninae & Polychaete & Indeter & 29.7 & 49.6 \\
\hline Lumbrineris cruzensis & Polychaete & Native & 28.6 & 45.7 \\
\hline Levinsenia gracilis & Polychaete & Crypto & 28.5 & 38.3 \\
\hline Ampelisca careyi & Amphipod & Native & 28.0 & 62.5 \\
\hline Pholoe glabra & Polychaete & Native & 26.7 & 44.9 \\
\hline Phoronida & Phoronid & Indeter & 26.7 & 28.1 \\
\hline Aphelochaeta glandaria & Polychaete & Native & 25.8 & 33.2 \\
\hline Paradiopatra parva & Polychaete & Native & 25.6 & 37.1 \\
\hline Prionospio lighti & Polychaete & Native & 25.5 & 34.4 \\
\hline Monticellina cryptica & Polychaete & Native & 23.8 & 29.3 \\
\hline Edwardsiidae & Actiniarian & Indeter & 23.6 & 10.9 \\
\hline Aricidea catherinae & Polychaete & Crypto & 23.4 & 36.3 \\
\hline $\begin{array}{l}\text { Pseudofabriciola } \\
\text { californica }\end{array}$ & Polychaete & Native & 23.2 & 2.3 \\
\hline Photis spp. & Amphipod & Indeter & 21.1 & 32.8 \\
\hline
\end{tabular}




\begin{tabular}{|c|c|c|c|c|}
\hline Taxa Name & Taxon & Classification & $\begin{array}{l}\text { Average } \\
\# / \mathrm{m}^{2}\end{array}$ & $\begin{array}{c}\% \\
\text { Frequency }\end{array}$ \\
\hline Maldane sarsi & Polychaete & Crypto & 20.8 & 40.2 \\
\hline Amphiuridae & Ophiuroid & Indeter & 20.6 & 49.2 \\
\hline Leptochelia dubia & Tanaidacea & Crypto & 19.7 & 32.4 \\
\hline Glycera nana & Polychaete & Native & 18.7 & 53.5 \\
\hline Nemertea & Nemertean & Indeter & 18.5 & 27.3 \\
\hline $\begin{array}{l}\text { Rhepoxynius } \\
\text { boreovariatus }\end{array}$ & Amphipod & Native & 17.5 & 19.1 \\
\hline Polygordius spp. & Polychaete & Indeter & 17.4 & 1.2 \\
\hline $\begin{array}{l}\text { Leitoscoloplos } \\
\text { pugettensis }\end{array}$ & Polychaete & Native & 17.0 & 32.0 \\
\hline Acila castrensis & Bivalve & Native & 16.6 & 24.2 \\
\hline Aphelochaeta monilaris & Polychaete & Native & 16.3 & 31.3 \\
\hline Scalibregma californicum & Polychaete & Native & 15.9 & 35.9 \\
\hline Fabriciinae & Polychaete & Indeter & 15.7 & 2.0 \\
\hline Ampelisca brevisimulata & Amphipod & Native & 15.4 & 34.8 \\
\hline Macoma carlottensis & Bivalve & Native & 14.8 & 21.1 \\
\hline
\end{tabular}



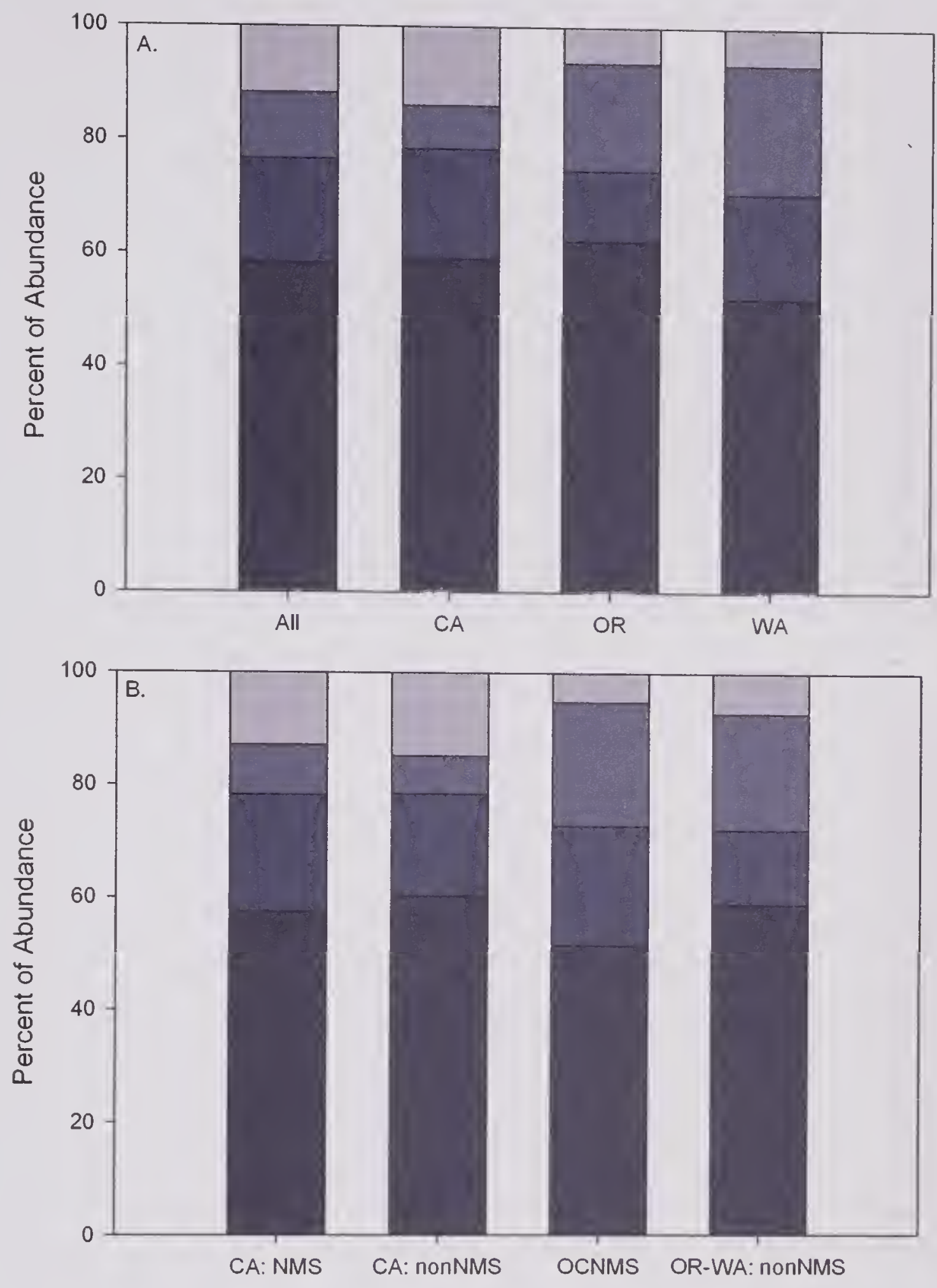

Figure 3.5.1. Comparison of percent faunal composition by abundance among (A) all, California, Oregon, and Washington sample locations, and (B) California NMS, California non-NMS, Olympic Coast NMS, and Washington-Oregon non-NMS sample locations. 

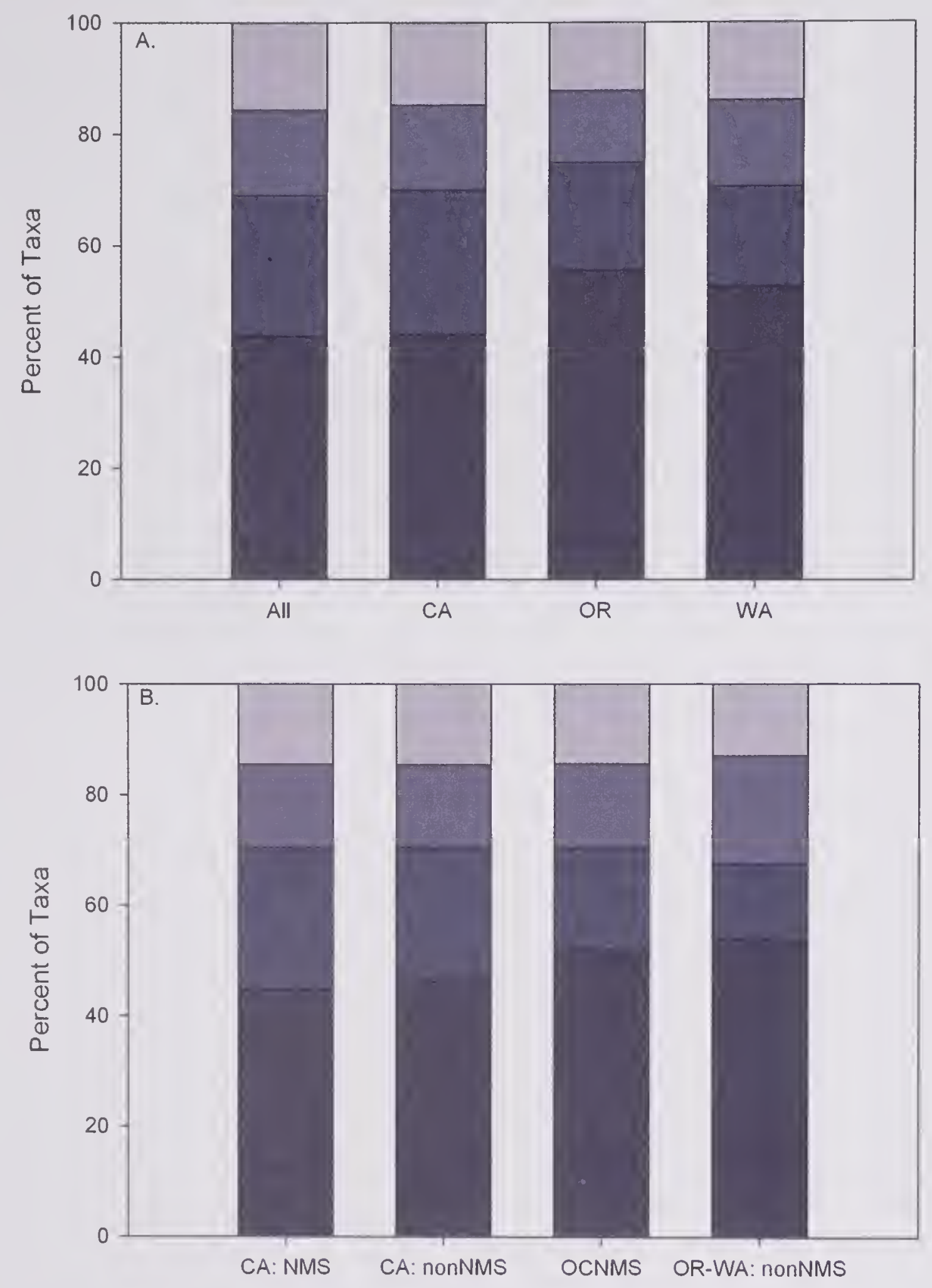

Polychaeta

Figure 3.5.2. Comparison of percent faunal composition by taxa among (A) all, California, Oregon, and Washington sample locations, and (B) California NMS, California non-NMS, Olympic Coast NMS, and Washington-Oregon non-NMS sample locations. 


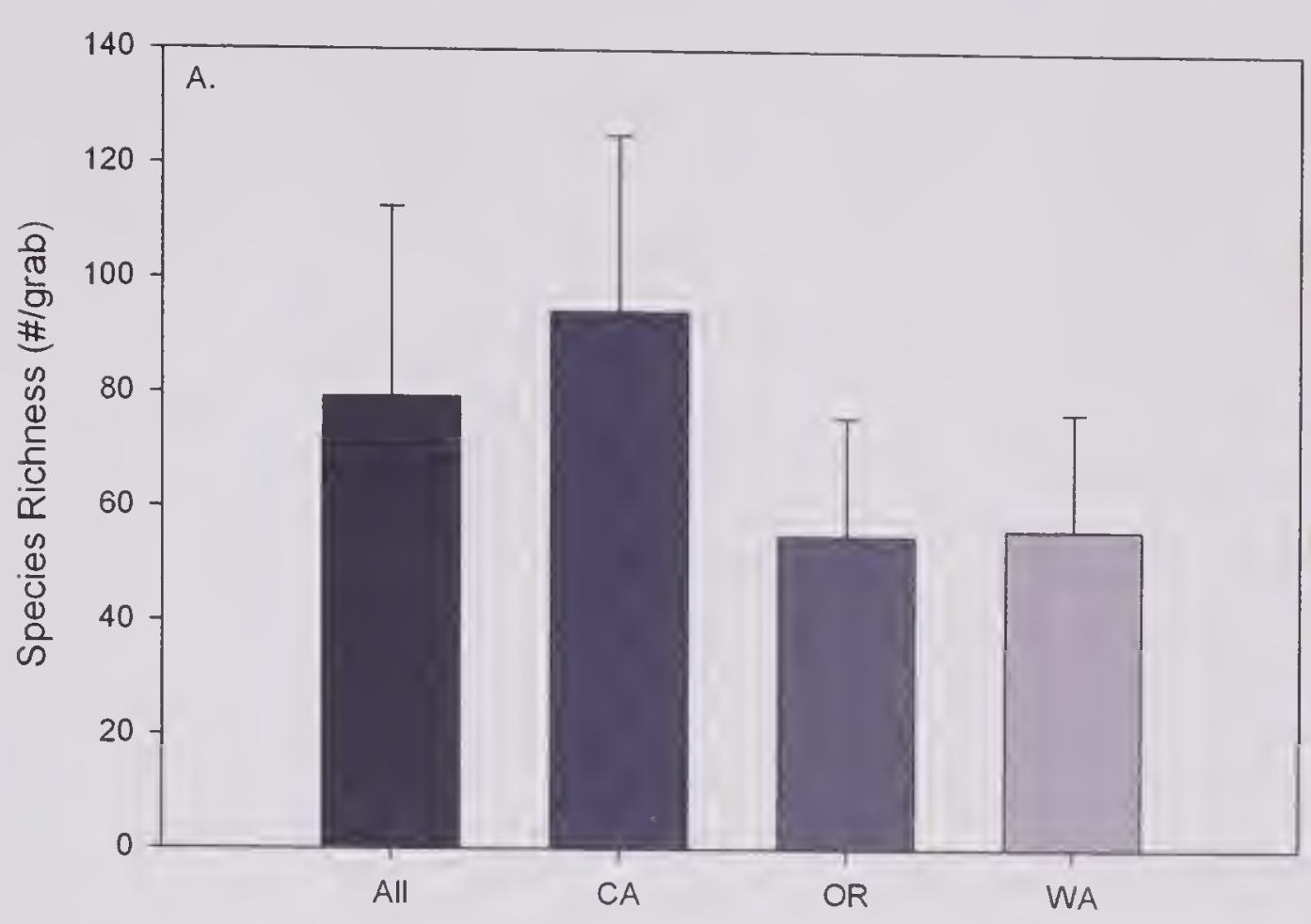

Percent of Area with Benthic Species Richness (\# species/0.1m )grab):

$\square<54$ (firstquartile)

$54-76$ (second quartile)

$\square 77-100$ (third quartile)

$>100$ (fourth quartile)

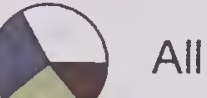

California

$\longrightarrow$ Oregon

$\rightarrow$ Washington

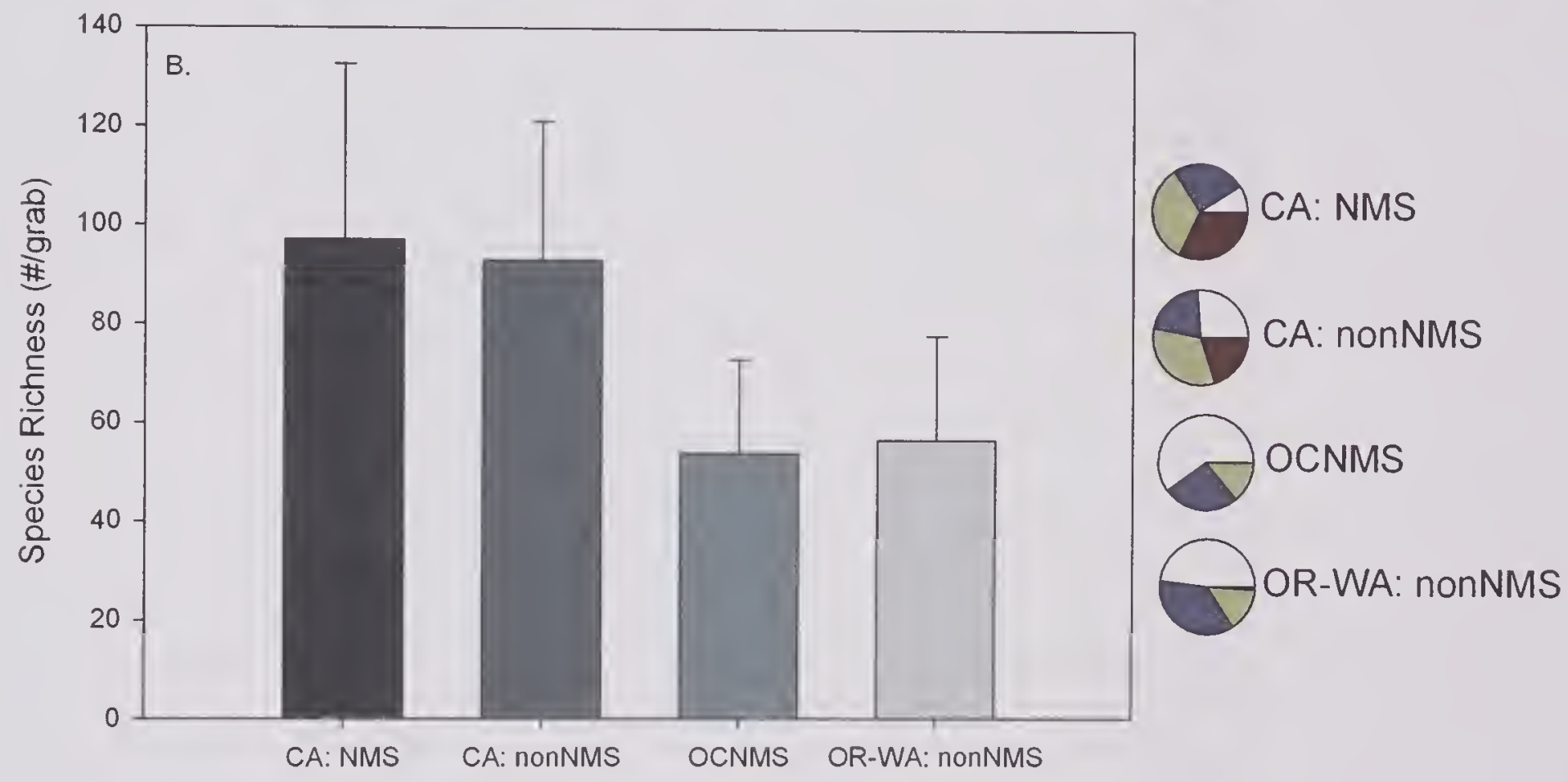

Figure 3.5.3. Comparison of benthic species richness (mean no. taxa/grab +1 $\mathrm{SD}$ ) among (A) all, California, Oregon, and Washington sample locations, and (B) California NMS, California non-NMS, Olympic Coast NMS, and Washington-Oregon non-NMS sample locations. Pie charts show quartile ranges of values. 


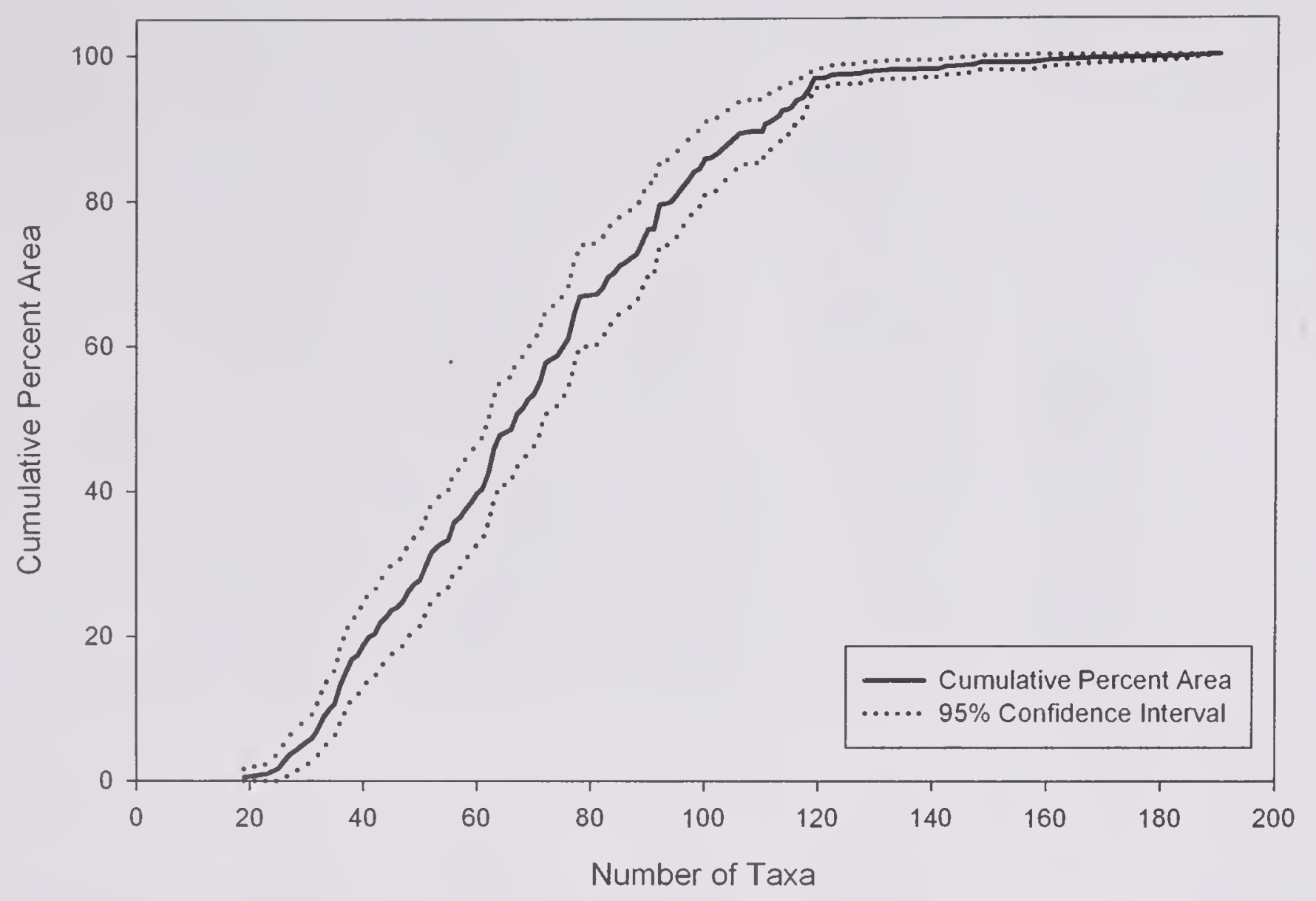

Figure 3.5.4. Percent area (and 95\% confidence interval) of overall West Coast Shelf vs. benthic species richness (\# taxa/0.1- $\mathrm{m}^{2} \mathrm{grab}$ ). 


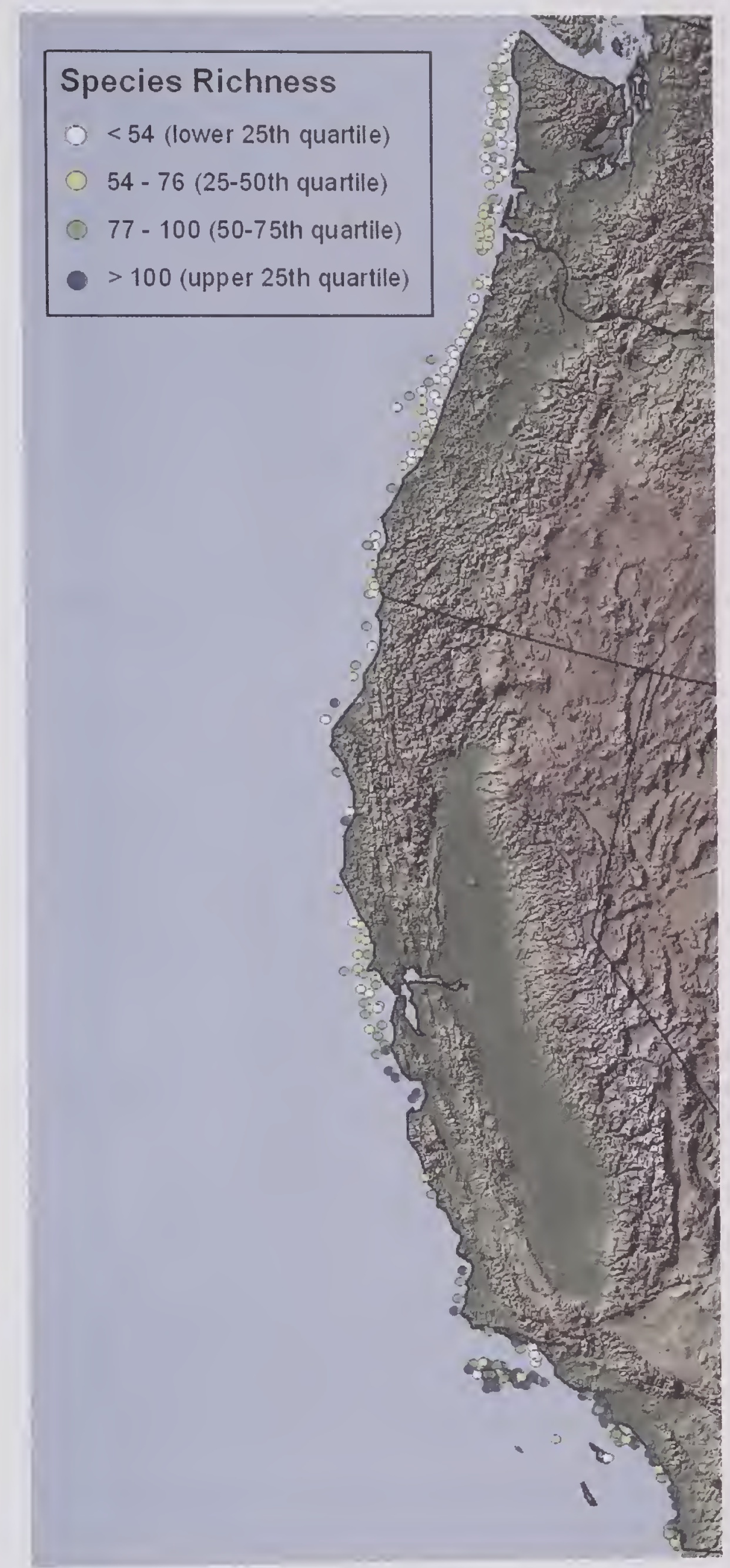

Figure 3.5.5. Map illustrating the distribution of benthic species richness (\# taxa per $0.1-\mathrm{m}^{2} \mathrm{grab}$ ) throughout the West Coast region. 


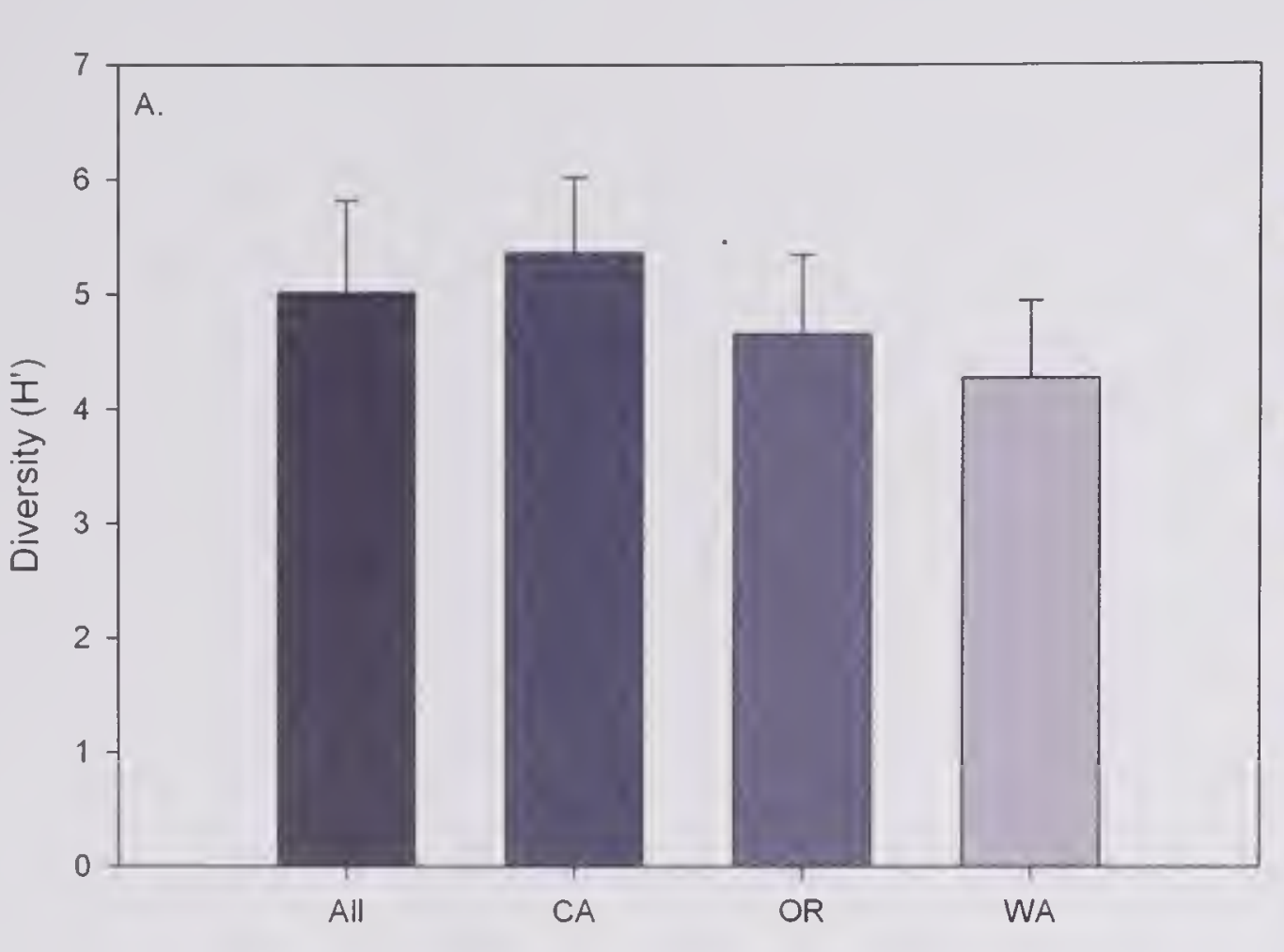

\section{Percent of Area with Benthic Diversity $\left(\mathrm{H}^{\prime}\right)$ :}

$<4.545$ (first quartile) $4.545-5.480$ ( second quartile) $5.481-5.712$ (third quartile) $>5.712$ (fourth quartile)
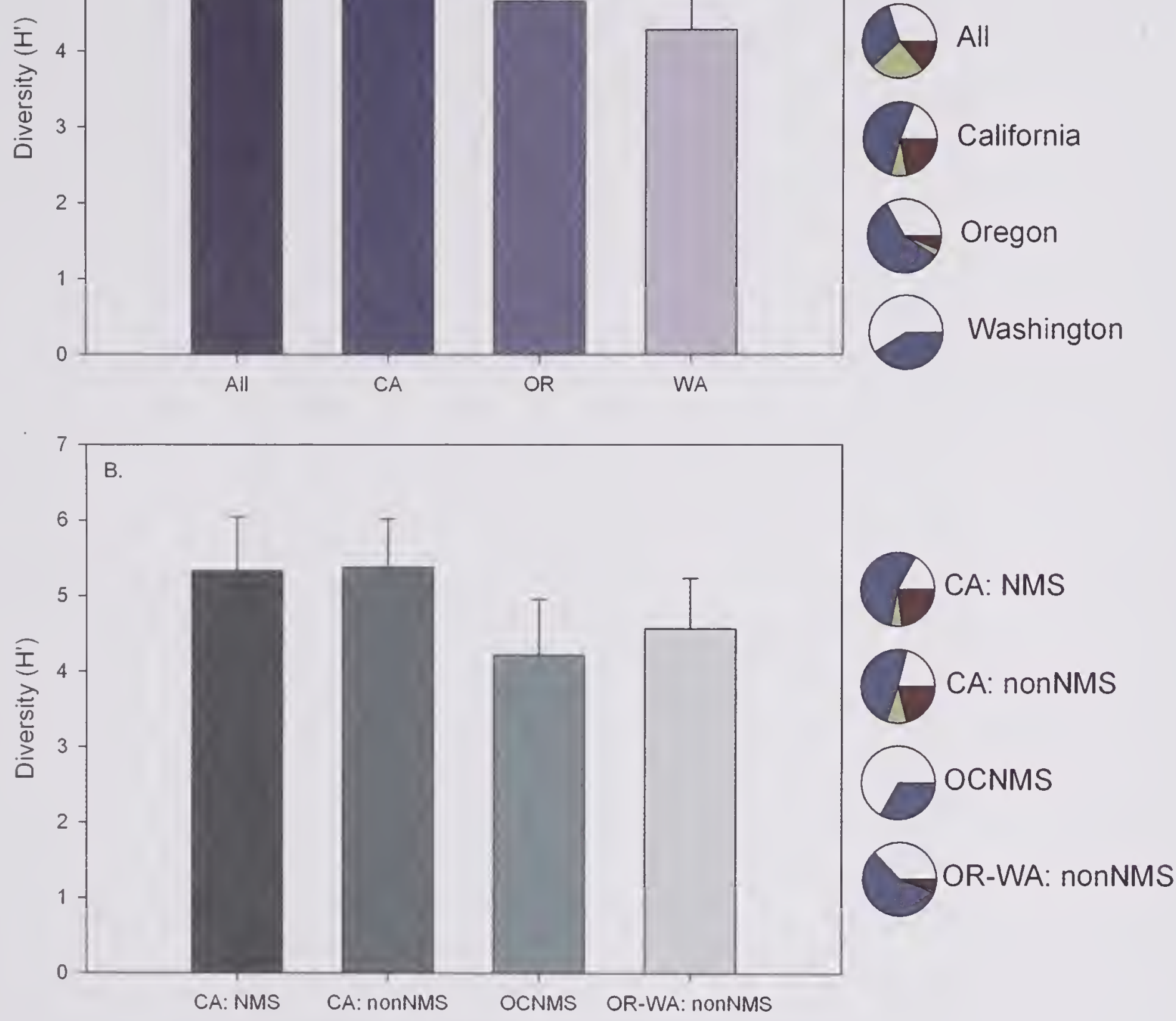

Figure 3.5.6. Comparison of benthic species diversity ( $H^{\prime}$, mean $\left.+1 S D\right)$ among (A) all, California, Oregon, and Washington sample locations, and (B) California NMS, California non-NMS, Olympic Coast NMS, and Washington-Oregon non-NMS sample locations. Pie charts show quartile ranges of values. 


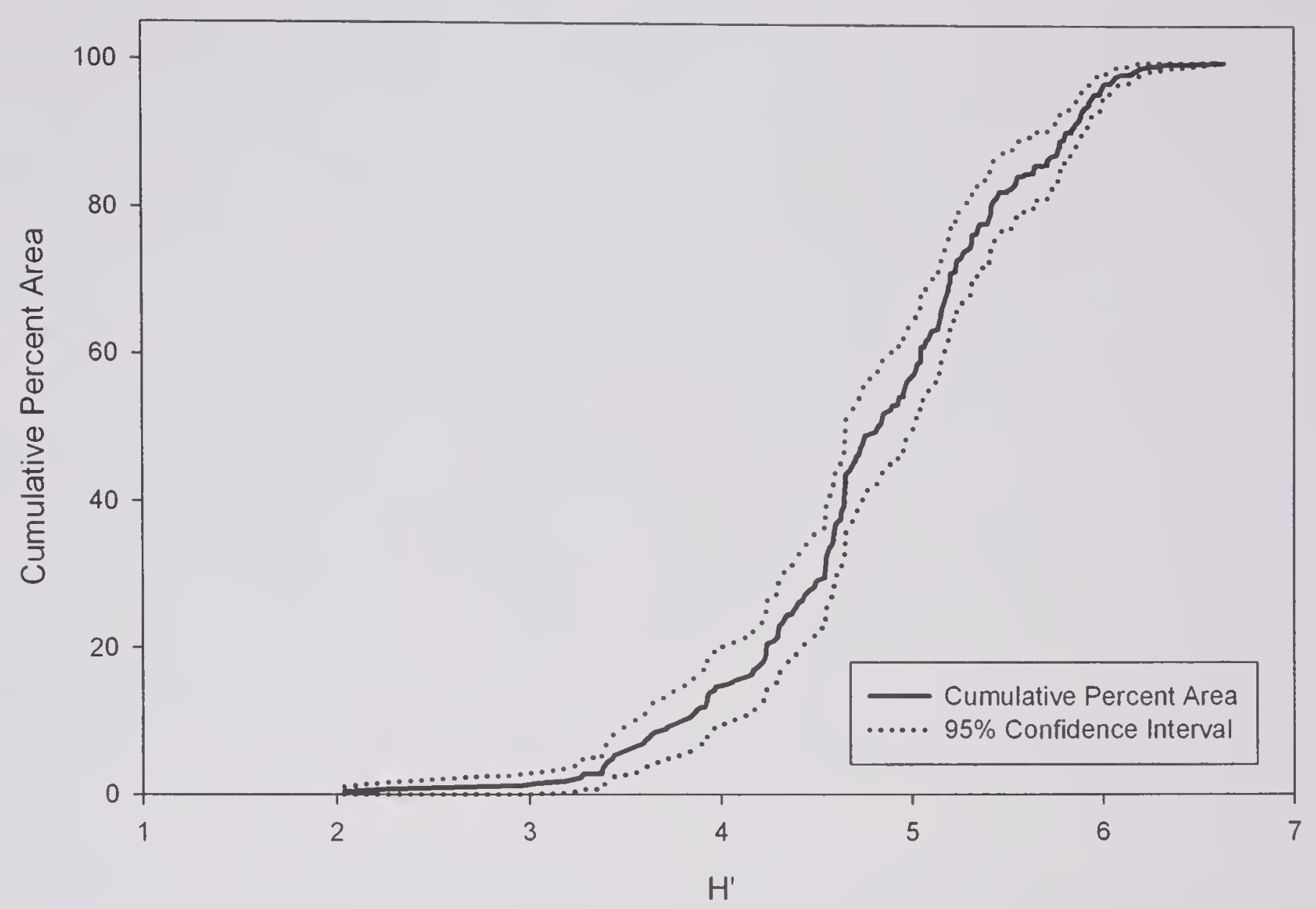

Figure 3.5.7. Percent area (and 95\% confidence interval) of overall West Coast Shelf vs. Shannon-Wiener $\mathrm{H}^{\prime}\left(\log _{2}\right)$ diversity index. 


\subsubsection{Abundance and Dominant Taxa}

A total of 99,135 individual specimens were collected across the 256 stations (259 $0.1-\mathrm{m}^{2}$ grab samples) throughout the region. Densities ranged from 540 to $22,980 \mathrm{~m}^{-2}$ and averaged $3,788 \mathrm{~m}^{-2}$ (Fig. 3.5.8, Table 3.5.3, Appendix Table 4). On a spatial basis, about $50 \%$ of the shelf area had densities $\geq 3,080$ $\mathrm{m}^{-2}$ and about $10 \%$ of the area had densities $\geq 7,250 \mathrm{~m}^{-2}$ (Fig. 3.5.9). In comparison, the NCA-West estuarine data (Nelson et al. 2004, 2005; U.S. EPA 2004; Hayslip et al. 2006) show much higher densities of benthic infauna in estuaries along the West Coast (e.g., mean of $10,653 \mathrm{~m}^{-2}$ and range of 0 to $415,820 \mathrm{~m}^{-2}$ ) (Table 3.5.3). However, the higher mean and maximum densities in the latter case are due to a greater frequency of high-density patches in these shallower estuarine systems. Spatially, while $10 \%$ of the estuarine area along the West Coast had high densities $\geq 15,100 \mathrm{~m}^{-2}, 50 \%$ of the area had lower densities $\leq 4,100 \mathrm{~m}^{-2}$, which is only moderately higher than that estimated for the corresponding percentage of shelf area $\left(3,080 \mathrm{~m}^{-2}\right)$. Densities on the shelf in excess of $10,653 \mathrm{~m}^{-2}$, the estuarine mean density, were limited to about $2 \%$ of the shelf area. Densities of benthic fauna in the present offshore survey, averaged by state, were highest in California (mean of 4,351 $\mathrm{m}^{-2}$ ) and lowest in Oregon (mean of 2,310 $\mathrm{m}^{-2}$ ) (Fig. 3.5.8, Table 3.5.3). Mean densities were slightly higher at NMS stations vs. non-sanctuary stations for both the California and Oregon/Washington regions.

The 50 most abundant taxa found in shelf waters throughout the region are listed in Table 3.5.4. The 10 most abundant members on this list include the polychaetes Mediomastus spp., Magelona longicornis, Spiophanes berkeleyorum, Spiophanes bombyx, Spiophanes duplex, and Prionospio jubata; the bivalve Axinopsida serricata; the ophiuroid Amphiodia urtica; the decapod Pinnixa occidentalis; and the ostracod Euphilomedes carcharodonta. Mediomastus spp. and A. serricata were the two most abundant taxa overall. There are clear differences between these dominant shelf fauna and those found in estuarine habitats along the West Coast. As an example, with the exception of Mediomastus spp., none of these 50 shelf species also appear on the list of dominant (10 most abundant) estuarine fauna reported by Nelson et al. (2005). The latter estuarine list (based only on 1999 data from the NCA-West database, thus excluding Puget Sound, the San Francisco estuary, and the main stem of the Columbia River) included the amphipods Americorophium spinicorne, A. salmonis, and Eogammarus confervicolus complex; oligochaetes; and the polychaetes Streblospio benedicti, Mediomastus sp, Mediomastus californiensis, Pygospio elegans, Pseudopolydora paucibranchiata, and Neanthes limnicola (Nelson et al. 2005). Thus, while estuaries have been found to be dominated by polychaetes, amphipods, and oligochaetes, the shelf environment was characterized by a broader range of taxonomic groups, including the occurrence of bivalves, ophiuroids, decapods, and ostracods as dominant members in addition to polychaetes. Another notable characteristic of these dominant shelf fauna is their relatively low densities. Average densities of the 10 most abundant 
shelf taxa ranged from 67 to $142 \mathrm{~m}^{-2}$ (Table 3.5.4). In comparison, average densities of the 10 most abundant taxa in estuaries were much higher, ranging from 197 to $5,242 \mathrm{~m}^{-2}$ (Nelson et al. 2005).

In addition to inshore-offshore differences, there were notable regional variations in the dominant offshore fauna. Though many of these fauna have broad geographic distributions throughout the region (see next section), except for the polychaete Spiophanes bombyx, the same taxa did not appear as members of the 10 most abundant taxa consistently across all three states (Table 3.5.5A). The closest similarities were between Oregon and Washington. For example, the polychaete Mediomastus spp. and ophiuroid Amphiodia urtica were the two most abundant taxa in California, while in Oregon and Washington the same two species, the polychaete Magelona longicornis and bivalve Axinopsida serricata, were the two most abundant taxa. There also was less variation between NMS vs. non-sanctuary status. For example, at least half of the 10 most abundant taxa in NMSs were also dominant in corresponding nonsanctuary waters (Table 3.5.5B). 


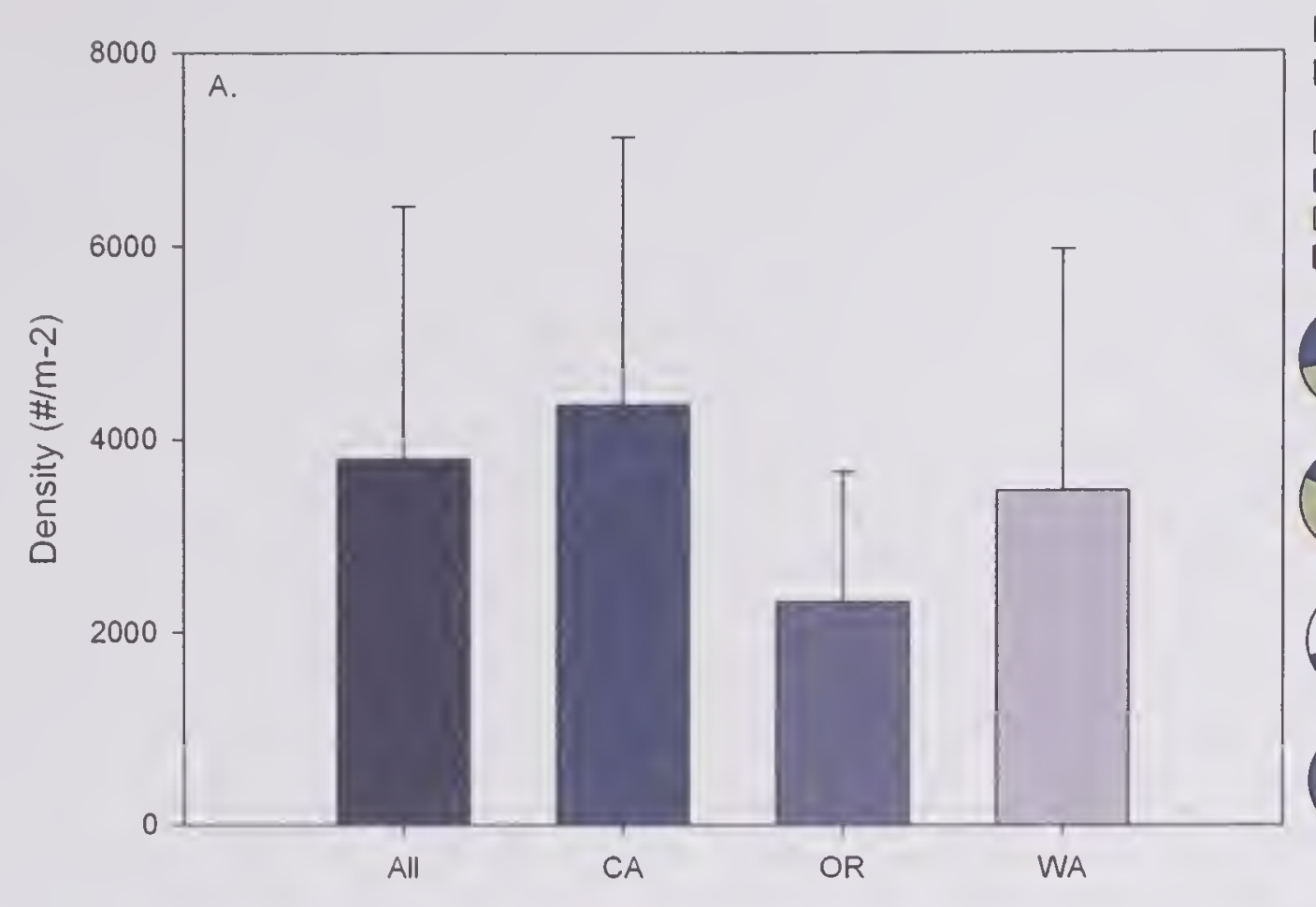

Percent of Area with Benthic Density:

$\square<2,140$ (first quartile)
$2,140-3,270$ (second quartile)

$\square 3,280-4,750$ (third quartile)

$>4,750$ (fourth quartile)

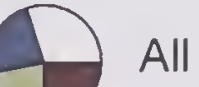

All

California

$D$ Oregon

Washington

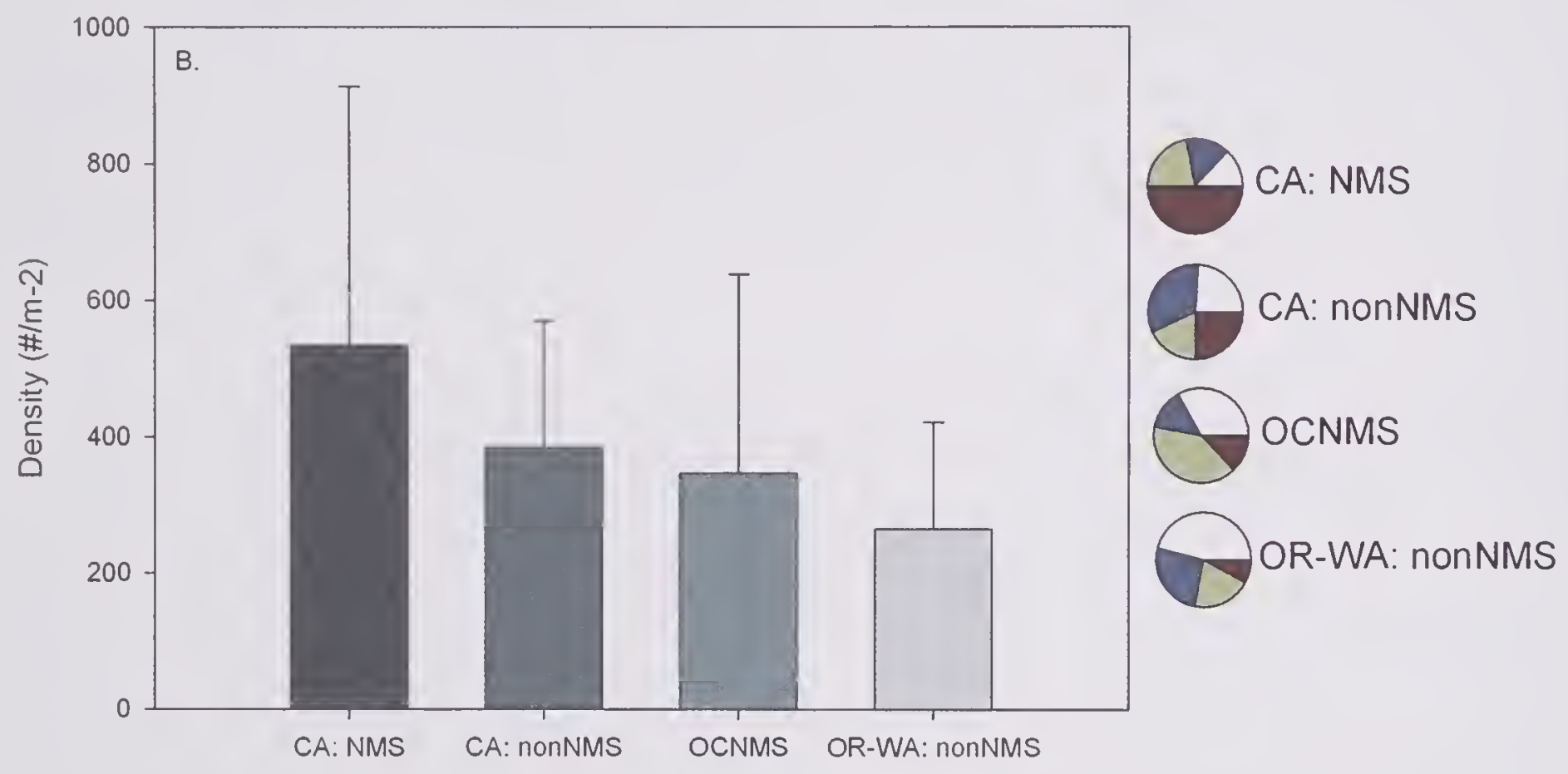

Figure 3.5.8. Comparison of benthic density (mean $+1 \mathrm{SD}$ ) among $(A)$ all, California, Oregon, and Washington sample locations, and (B) California NMS, California non-NMS, Olympic Coast NMS, and Washington-Oregon non-NMS sample locations. Pie charts show quartile ranges of values. 


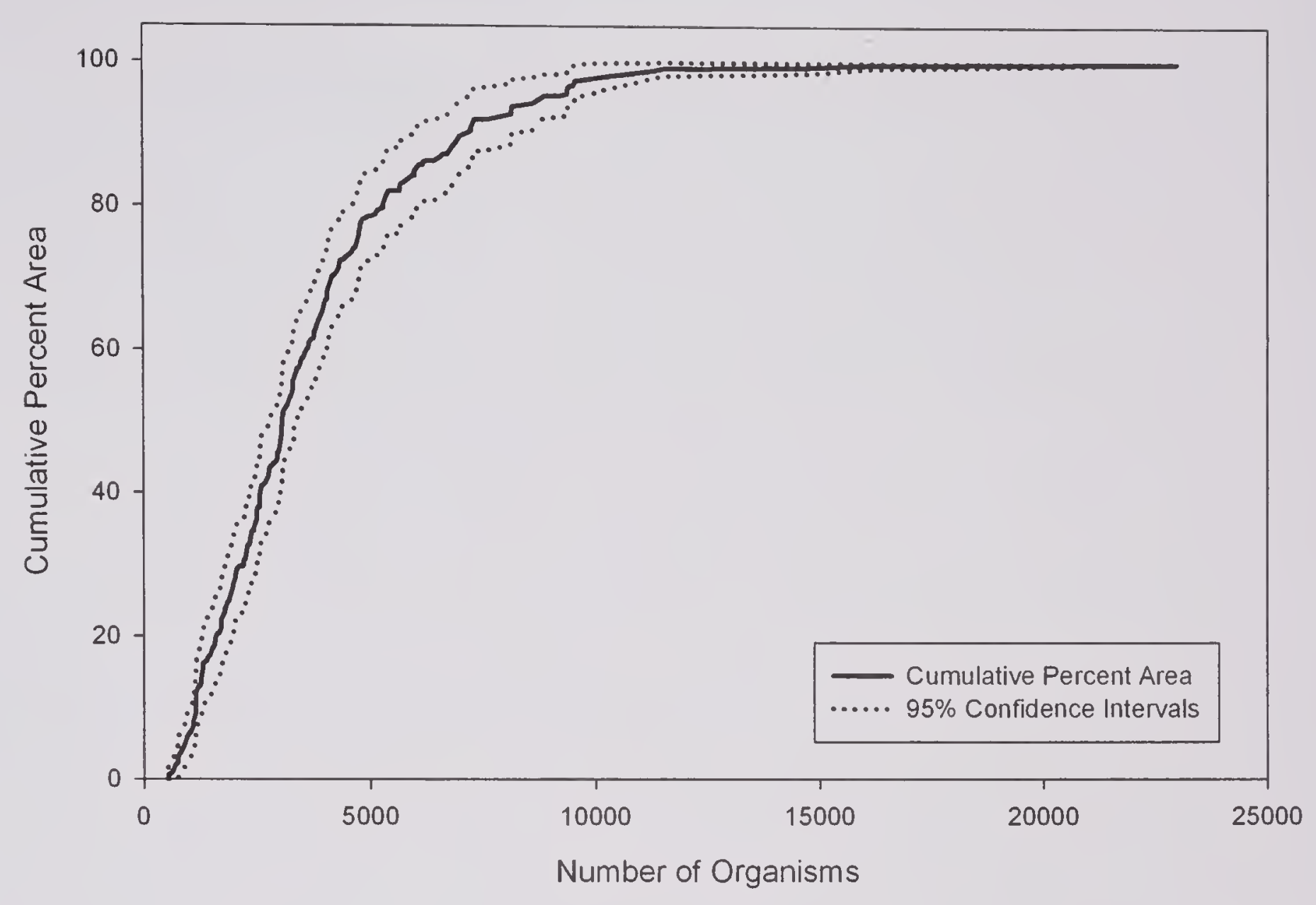

Figure 3.5.9. Percent area (and 95\% confidence interval) of overall West Coast Shelf vs. benthic abundance (number of individuals $/ \mathrm{m}^{2}$ ). 


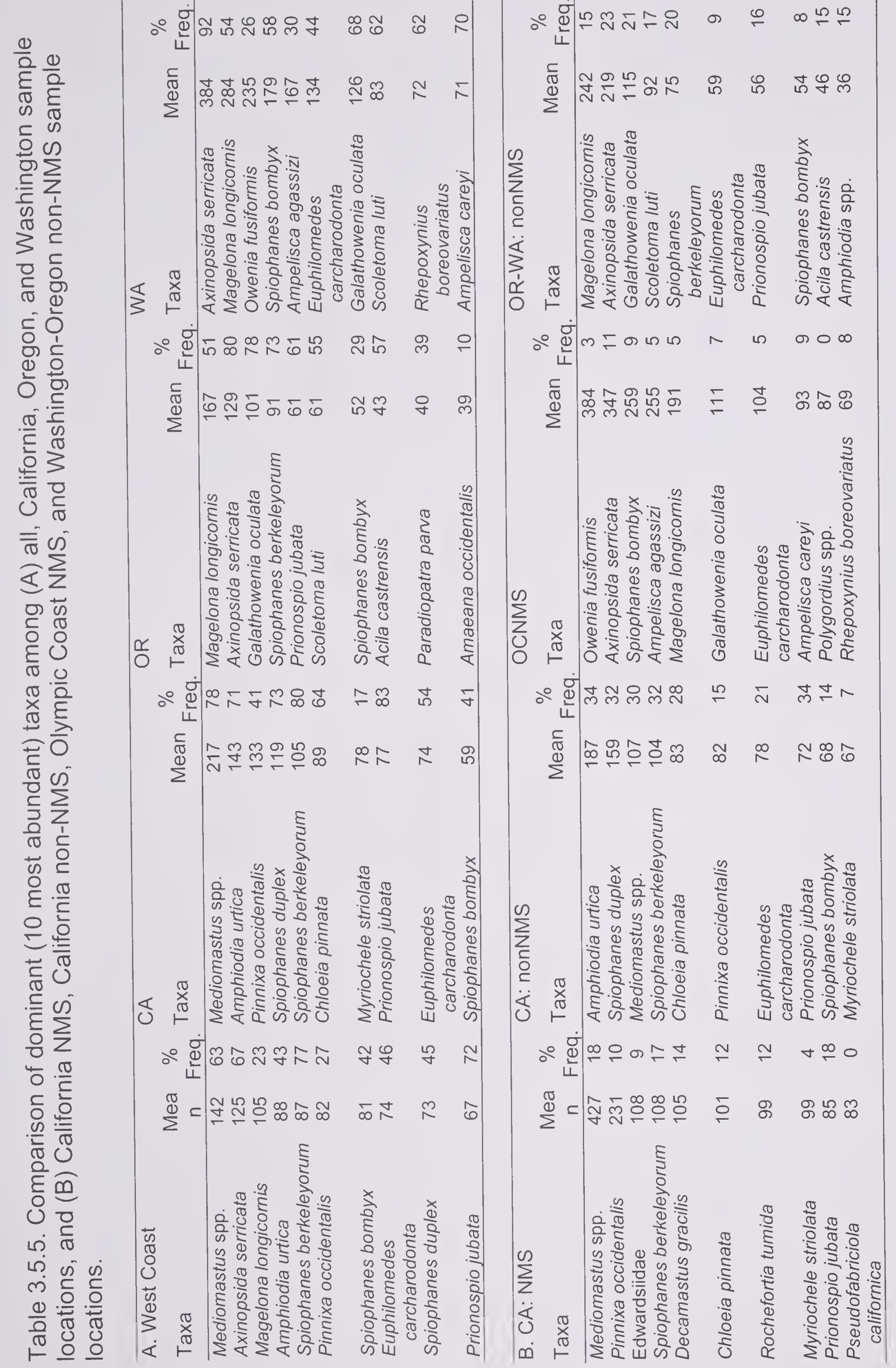




\subsubsection{Biogeographical Distributions}

The 2003 probabilistic survey is one of the few regional-scale studies of the benthos on the continental shelf of the U.S. Pacific Coast. As such, the data are well suited to addressing a number of biogeographic questions. The first question addressed is whether the shelf fauna have restricted along-coast distributions or whether they have wide latitudinal distributions. To address this question, we utilized the Marine Ecosystems of the World (MEOW) biogeographic schema recently proposed by The Nature Conservancy (Spalding et al. 2007). The MEOW scheme is hierarchical, with 12 Realms composed of 62 provinces, which in turn are composed of 232 ecoregions. Based on this scheme, we therefore evaluated the presence of species across the seven ecoregions of the Temperate Northern Pacific Realm that border the U.S. Pacific Coast (Fig. 3.5.10). These seven ecoregions include all the ecoregions of the Cold Temperate Northwest Pacific Province and the northernmost ecoregion in the Warm Temperate Northeast Pacific Province, and span from the upper half of the Baja Peninsula in Mexico to the Aleutian Islands in Alaska. Ecoregions within the Arctic Realm bordering northern Alaska are not considered, nor are the two other ecoregions of the Baja Peninsula that do not border the United States.

Appendix Table 5 summarizes the biogeographic distributions, by ecoregion, of the 39 most abundant taxa that were identified to species (from Table 3.5.4). Distributional data were derived from the present study, previous EMAP surveys including unpublished data from Alaskan surveys (Max Hober and Douglas Dasher), and the Pacific Coast Ecosystem Information System (PCEIS). PCEIS is a database synthesizing the distributions of native and nonindigenous marine/estuarine species of the Pacific Coast being developed by EPA and the USGS (Lee and Reusser 2008). Of the 39 abundant species collected along the California-Oregon-Washington shelf, almost $95 \%$ of them were found in both the SCB and Northern California ecoregions, while $87 \%$ were found in both the Oregon, Washington, Vancouver Coast and Shelf ecoregion and in the Puget Trough/ Georgia Basin ecoregion. The percentage of species occurring off the coast of Canada (North American Pacific Fijordland ecoregion) and the Gulf of Alaska drops to about $72 \%$ and $59 \%$, respectively. With 14 of the 39 species reported from the Aleutians, the percentage of the species reported declines to $36 \%$ in the most northern ecoregion of the Temperate Northern Pacific Realm.

These distributional patterns potentially could be confounded by taxonomic uncertainties. For example, seven of the species in Table 3.5.4 are classified as cryptogenic species, which are species of uncertain origin (Carlton 1996). All of these cryptogenic species occur in more than one of the MEOW provinces and at least one possible explanation for their wide distributions is that they actually represent a suite of sibling species that can not be readily distinguished morphologically. Even for natives there can be confusion about the specific identity of a species. For example, the native amphipod Ampelisca careyi may be a variant of $A$. unsocalae (Chapman 2007). To reduce this source 
of uncertainty, the analysis was repeated excluding 14 problematic species (Appendix Table 5). Removal of these problematic species reduces the percentage species overlap in all the ecoregions but did not substantially alter the general biogeographic pattern. Southern and Northern California ecoregions still had the highest percentage of species, with $92 \%$ and $88 \%$ of the species, respectively. As with the full set of species, a high percentage (>75\%) of the species were found in Puget Sound and along the coasts of Oregon and Washington, with a reduction northward up into the Gulf of Alaska and then a further reduction in the Aleutian ecoregion.

Another source of uncertainty in defining biogeographic ranges is the different levels of sampling along the coast. The SCB ecoregion has been intensively sampled (see SCAMIT 2001), as has Puget Sound. Northern California, Oregon, and Washington shelves have not been sampled as intensively, although the fauna of this section of the coast is reasonably well known (e.g., Carlton 2007). The data for northern Canada (N. American Pacific Fijordland ecoregion) were derived primarily from the dataset for the Haida Gwaii archipelago

(http://gcmd.nasa.gov/KeywordSearch/Metadata.do?Portal=caobis\&MetadataTyp $\mathrm{e}=0 \&$ KeywordPath=\&MetadataView $=$ Full\&Entryld=OBIS. Gwaii_Inv). While limited in spatial extent, this dataset includes information on more than 2,500 taxa. The Gulf of Alaska distributions were derived primarily from the EMAP 2002 survey in South-central Alaska (Saupe et al. 2005), unpublished data from the 2004 Southeast Alaska EMAP survey, and pre- and post-Exxon Valdez oil spill surveys of Prince William Sound (Hines and Ruiz 2000, Hoberg and Feder 2002). These various sources should be adequate to detect the occurrence of abundant species in most cases. In comparison, the sources for the Aleutians were more sparse and included unpublished data from the 2006-7 EMAP surveys in the Aleutians, reports on Alaskan and Canadian bivalves (Bernard 1967, Macpherson 1971, Baxter 1987), and the Global Biodiversity Information Facility (GBIF; http://data.gbif.org/). It is possible that the absence of some species from Aleutian ecoregion is result of the more limited sampling in this region.

Even with these sources of uncertainty, it can be concluded that the majority of the abundant benthic species on the California-Oregon-Washington shelf have wide latitudinal distributions along the Pacific Coast of the United States. All three of the abundant bivalves, the pinnixid crab Pinnixa occidentalis, six polychaetes, and possibly the amphipod $A$. careyi extend from Southern California into the Aleutians. Another eight species have been reported from Southern California to the Gulf of Alaska. Conversely, only the sabellid polychaete Pseudofabriciola californica was limited to a single ecoregion, while the amphipod Rhepoxynius boreovariatus and the polychaetes Myriochele striolata and possibly Monticellina cryptica have been reported from only two of the ecoregions. 
While the majority of species have wide latitudinal ranges, most species show differences in abundance among the three ecoregions within the 2003 EMAP sampling frame. The polychaete Magelona longicornis and bivalve Axinopsida serricata are examples of species with maximum densities in the northern portion of the sampling frame, the Oregon, Washington, Vancouver Shelf \& Coast ecoregion (Figs. 3.5.11, 3.5.12). The ophiuroid Amphiodia urtica is an example of a species with maximum densities in the SCB ecoregion (Fig. 3.5.13), while Pinnixa occidentalis has its maximum densities in the middle of the coast, in the Northern California ecoregion (Fig. 3.5.14).

The second question that we address is whether there is a unique shelf fauna different from that found in Puget Sound or the coastal estuaries. The Puget Sound ecoregion has a high species overlap with the shelf fauna, with $87 \%$ of the abundant species on the shelf also reported from Puget Sound (Appendix Table 5). While portions of Puget Sound are estuarine, much of Puget Sound resembles the shelf with its greater depth and high salinity, which presumably explains much of the species' overlap. Three of the five species not found in Puget Sound were not found along the Oregon-Washington coast, suggesting that they are limited to more southern latitudes in general, rather than from Puget Sound specifically. The other two abundant species (Chloeia pinnata and Paradiopatra parva) not found in Puget Sound are found in the Oregon, Washington, Vancouver Shelf \& Coast ecoregion. However, Chloeia pinnata was not found north of 44 degrees in the present survey and may not be well adapted to the most northern latitudes within the ecoregion. In contrast, Paradiopatra parva was found in the present survey up to 48 degrees latitude, suggesting that there are specific conditions within Puget Sound that limit its distribution or abundance.

Less expected was the extent of faunal overlap with the coastal estuaries. Almost $85 \%$ (33) of the most abundant shelf species have been reported at least once from the coastal estuaries of California, Oregon, or Washington exclusive of Puget Sound. Thus, it appears that the habitat requirements for many of the shelf species are sufficiently broad to allow at least colonization in estuarine ecosystems, though it is not clear whether they establish self-maintaining populations in all cases. Of the habitat requirements likely to limit shelf species from estuaries, the lower and variable salinities in estuaries are likely to be critical, if not the most critical, factors. Among the species reported from estuaries, one possibility is that they are able to colonize only the high-salinity Southern California estuaries, such as San Diego, which are euhaline (> $30 \mathrm{psu}$ ) over most of their area. Of the 33 species found in estuaries, eight (Prionospio jubata, Paradiopatra parva, Monticellina cryptica, Aricidea catherinae, Pseudofabriciola californica, Maldane sarsi, Scalibregma californicum, and Ampelisca brevisimulata) have been reported only from Southern California estuaries. In comparison to the Southern California estuaries, small estuaries in the Pacific Northwest undergo large salinity shifts both seasonally and tidally, so that species found in small estuaries are likely to have relatively broad salinity 
tolerances. Based on the 1999, 2001 and 2002 EMAP surveys (Nelson et al. $2004,2005,2007)$, as well as an EPA survey of the benthos in small estuaries (Lee et al. 2003, unpublished data), a species list of 137 species has been developed for the small estuaries of the Oregon, Washington, Vancouver Coast and Shelf ecoregion. Of the 33 abundant shelf species found in estuaries, eight (Spiophanes bombyx, Owenia fusiformis, Paraprionospio pinnata, Rochefortia tumida, Prionospio lighti, Leptochelia dubia, and Leitoscoloplos pugettensis) were found in these small estuaries.

These biogeographic patterns suggest that the abundant shelf species can be broken into three broad salinity-tolerance groups. The 14 species not found within estuaries or only within Southern California estuaries can be classified as putative stenohaline species. The eight species found within the small estuaries would have the largest relative salinity tolerances, while the remaining 11 species found in moderate and large estuaries outside of Southern California presumably would have intermediate salinity tolerances. While factors other than salinity limit species' distributions, biogeographical patterns offer an approach to generating preliminary relative salinity tolerances for a large number of species.

The present analysis draws information from both the quantitative EMAP/NCA survey and from qualitative reports of species' distributions, with each approach providing a different insight into a species' habitat requirements. Biogeographic distributions (Appendix Table 5) can be considered an indicator of species' broad tolerances while the distributional shifts in abundance (Figs. 3.5.11 - 3.5.14) can be considered an indicator of species' habitat preferences. Thus, the wide latitudinal and estuarine distributions of most species are suggestive of wide habitat tolerances among these abundant shelf species. However, the pattern of high abundance occurring in only one or two ecoregions as observed for several species (e.g., P. californica, M. longicornis, C. pinnata and $P$. occidentalis) suggests a substantially reduced preferred habitat range for this set of abundant species. Presumably, species with a more limited preferred habitat range would be relatively more susceptible to climate change than those with wide ranges. However, species' responses to sea-surface temperature increases are complex and may vary among cold-water and warm-water species (e.g., Lima et al. 2007). Nonetheless, future work on comparing species' biogeographic and preferred habitat ranges with sea-surface temperature patterns (e.g., MODIS) by ecoregion is one potential avenue to evaluating relative risk to climate change for coastal species. It is worth noting that such analyses are greatly facilitated by the continuing evolution of biological information systems at global (e.g., GBIF) and regional (e.g., PCEIS) scales. 


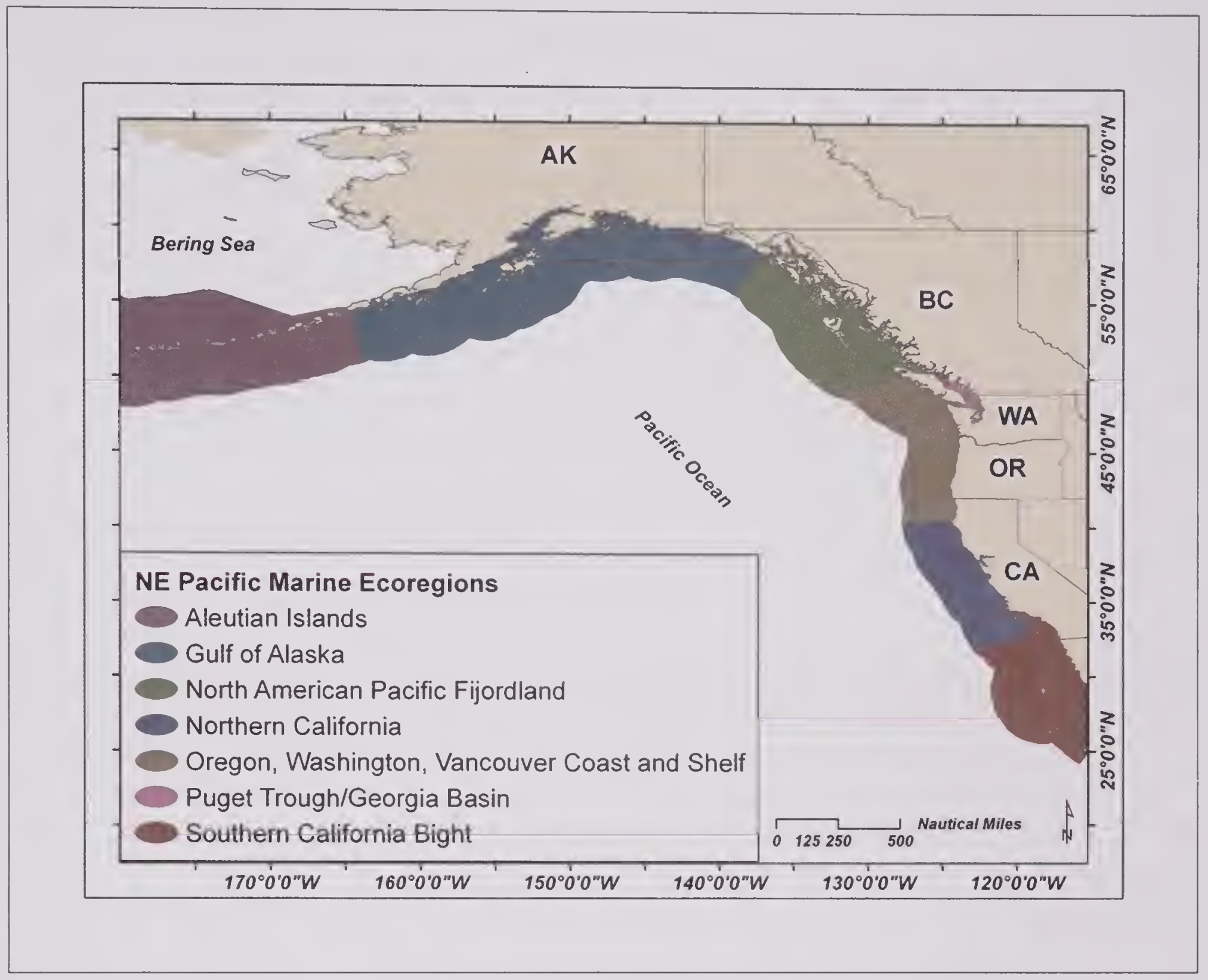

Figure 3.5.10. Marine ecoregions bordering the Pacific Coast of the United States from Southern California through the Aleutian Islands based on the MEOW biogeographic schema (Spalding et al. 2007). The ecoregions constituting the Cold Temperate Northeast Pacific Realm are the Aleutian Islands, Gulf of Alaska, North American Pacific Fijordland, Puget Trough/ Georgia Basin, Oregon, Washington, Vancouver Coast and Shelf, and Northern California. The Southern California Bight ecoregion falls in the Warm Temperate Northeast Pacific Realm. 


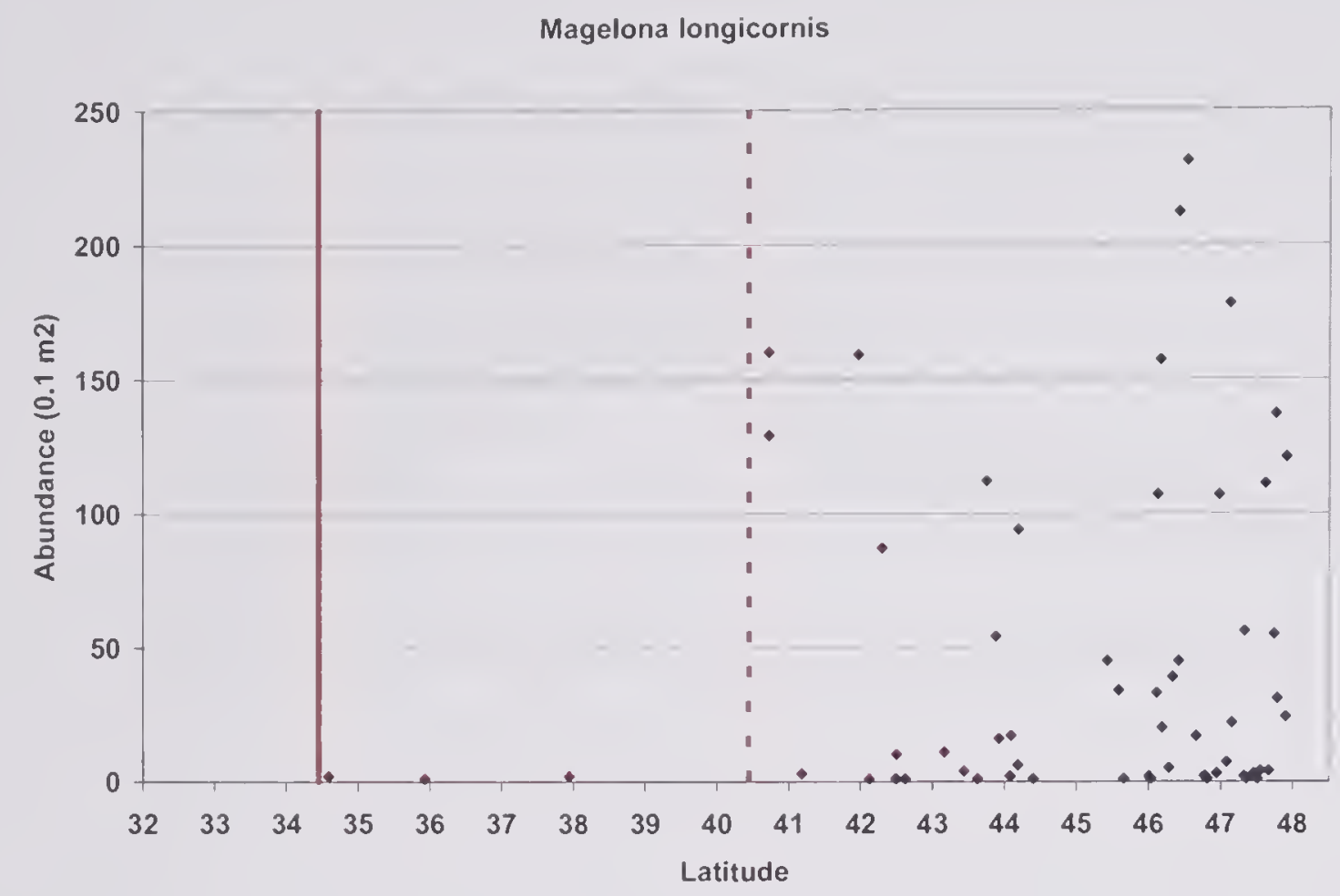

Figure 3.5.11. Latitudinal pattern of abundance of the polychaete Magelona longicornis. The solid vertical line is the boundary between the Southern California Bight ecoregion and Northern California ecoregion. The dashed line is the boundary between the Northern California ecoregion and Oregon, Washington, Vancouver Coast and Shelf ecoregion.

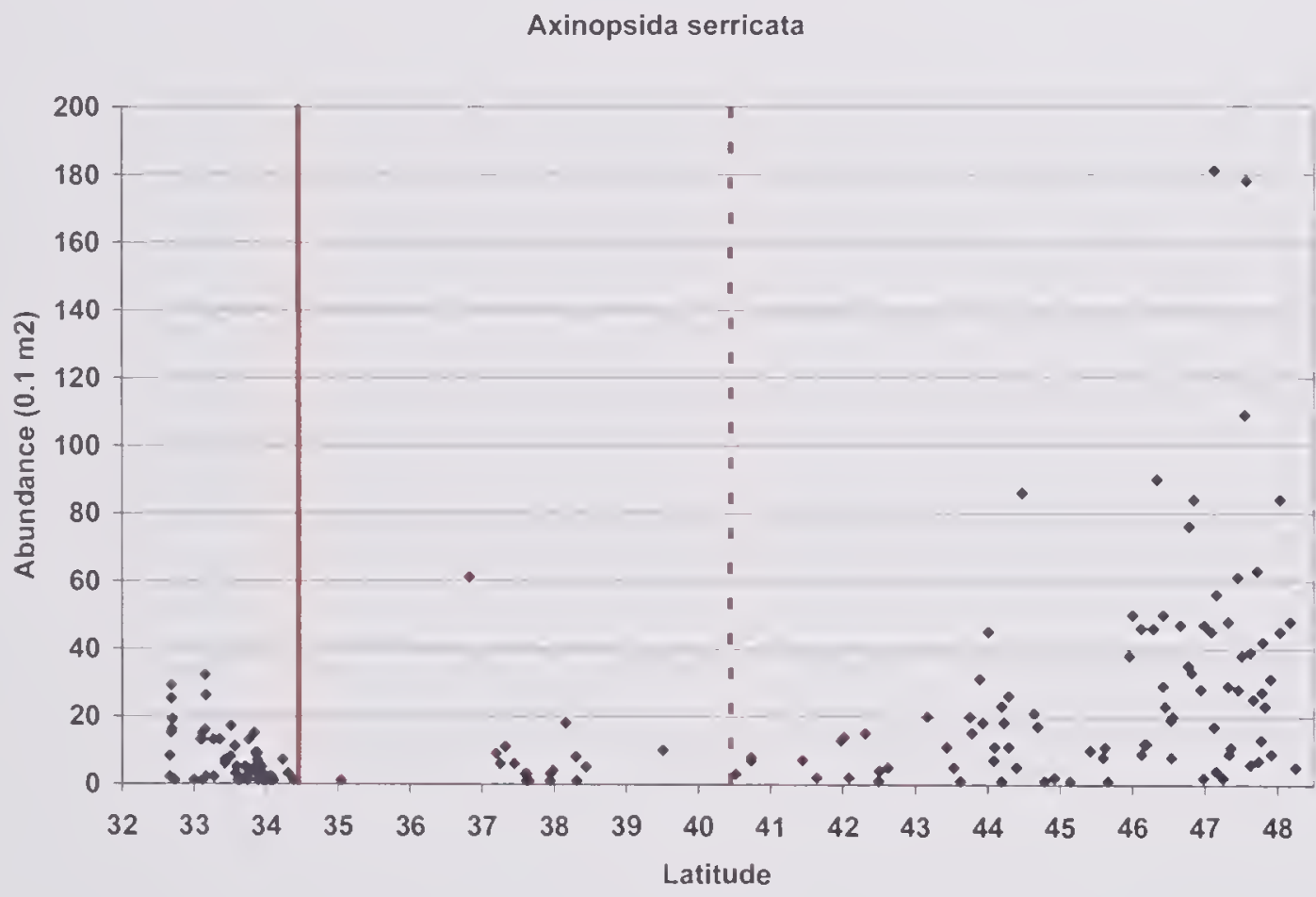

Figure 3.5.12. Latitudinal pattern of abundance of the bivalve Axinopsida serricata. The solid vertical line is the boundary between the Southern California Bight and Northern California ecoregions. The dashed line is the boundary between the Northern California and Oregon, Washington, Vancouver Coast and Shelf ecoregions. 


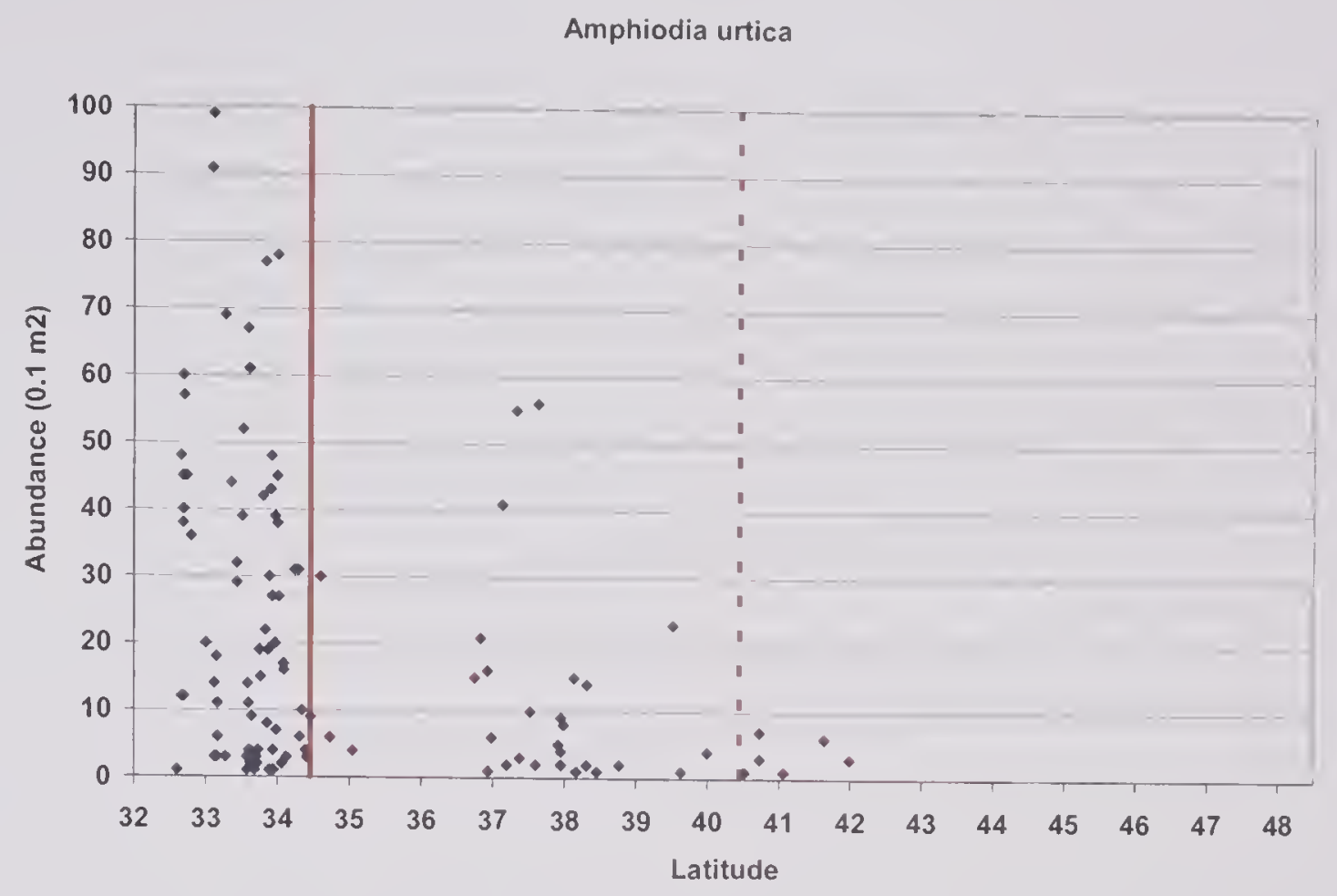

Figure 3.5.13. Latitudinal pattern of abundance of the ophiuroid Amphiodia urtica. The solid vertical line is the boundary between the Southern California Bight ecoregion and Northern California ecoregion. The dashed line is the boundary between the Northern California ecoregion and Oregon, Washington, Vancouver Coast and Shelf ecoregion.

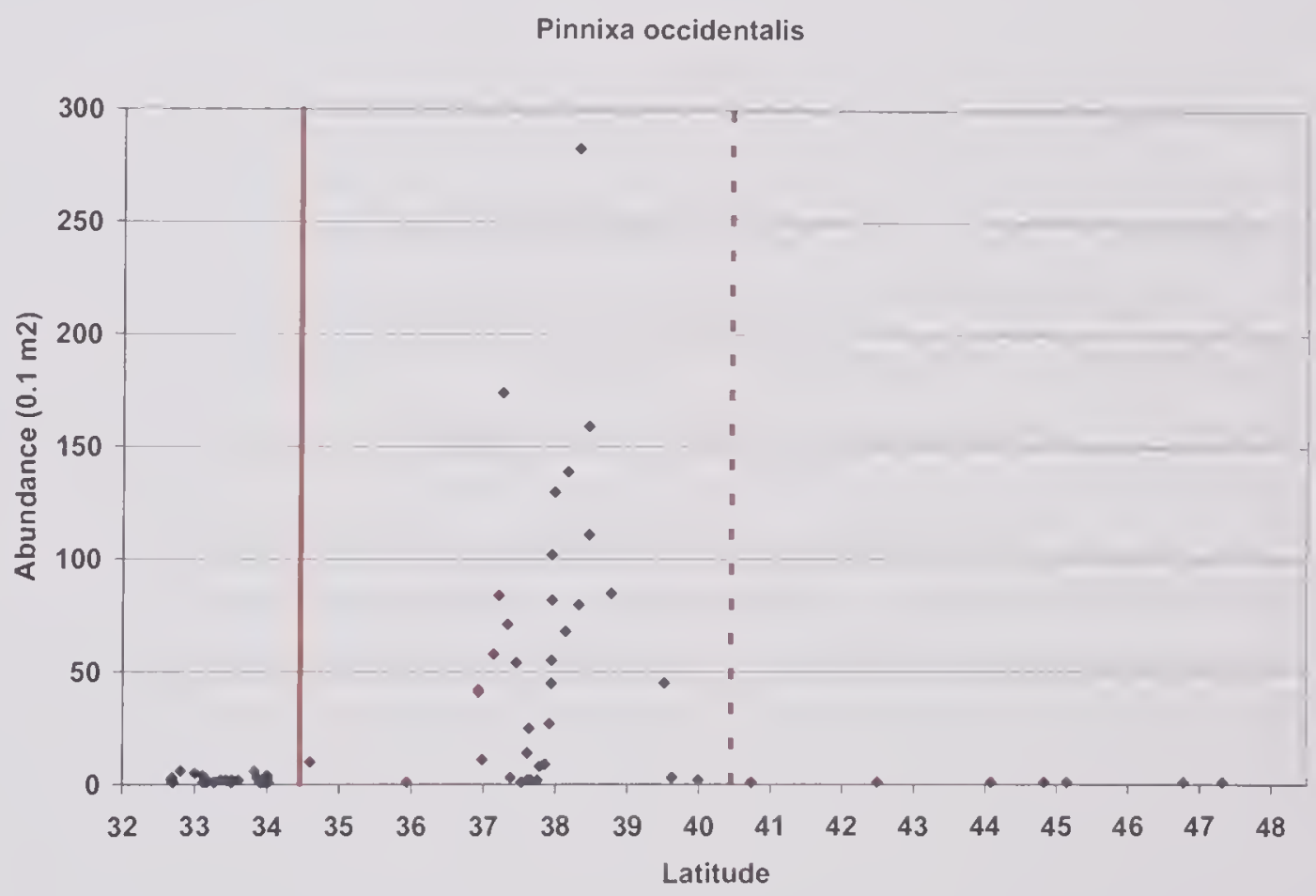

Figure 3.5.14. Latitudinal pattern of abundance of the decapod Pinnixa occidentalis. The solid vertical line is the boundary between the Southern California Bight ecoregion and Northern California ecoregion. The dashed line is the boundary between the Northern California ecoregion and Oregon, Washington, Vancouver Coast and Shelf ecoregion. 


\subsubsection{Nonindigenous Species}

Taxa were classified as native, nonindigenous, cryptogenic, indeterminate, or unclassified. Cryptogenic species are species of uncertain origin (Carlton, 1996) and may include potential introductions, sibling species, or species that have yet to be sufficiently well resolved taxonomically over their global range. Indeterminate taxa are those not identified with sufficient taxonomic resolution to classify as native, nonindigenous, or cryptogenic (Lee et al. 2003). Unclassified species are those that have yet to be analyzed sufficiently to render a final classification. The classifications used here follow the Pacific Ecosystem Information System (PCEIS), a geo-referenced database of native and nonindigenous species of the Northeast Pacific being developed by the EPA and USGS (Lee and Reusser 2008).

Of the 1,108 taxa identified to species, 13 species are currently classified as nonindigenous (Table 3.5.6), though there are uncertainties about the taxonomic resolution of several of these species. In addition, another 121 species are classified as cryptogenic and 208 species are unclassified. The taxonomic uncertainties with the putative nonindigenous species and the large number of cryptogenic and unclassified species reflect both the lack of detailed analysis of the invasion status of shelf species as well as the difficulties inherent in harmonizing taxonomy on a global scale. Thus the present analysis should be considered preliminary until additional information becomes available on the taxonomy and classification of these uncertain species.

The 13 nonindigenous species constitute only $1.2 \%$ of the taxa that were identified to species or, excluding the cryptogenic and unclassified species, $1.7 \%$ of the native species. Even with the uncertainty over the classification of some species, the number of nonindigenous species appears to be much lower on the shelf than in the estuarine ecosystems of the Pacific Coast. For example, 42 nonindigenous species were found in the probabilistic survey of tidal wetlands of the Pacific Coast (Nelson et al. 2007a), while over 200 nonindigenous species have been found in the San Francisco Estuary (Cohen and Carlton 1995). Additionally, the nonindigenous species were in low abundance. None of the nonindigenous species were included in the 50 most abundant taxa (Table 3.5.4), and combined they constituted only $0.4 \%$ of the total individuals or $0.7 \%$ of the abundance of the natives. This is in contrast to many Pacific Coast estuaries, where nonindigenous species constitute a substantial if not major portion of the total abundance (Nelson et al. 2005), and from the San Francisco Estuary in particular, where nonindigenous species are the numerical dominants in most of the benthic assemblages (Lee et al. 2003). The most abundant nonindigenous species were the spionid polychaete Laonice cirrata and the ampharetid polychaete Anobothrus gracilis, which had average abundances of 0.40 and 0.29 individuals per grab, respectively (Table 3.5.6). While neither of these species was abundant, both were moderately frequent, occurring in $23 \%$ 
and $15 \%$ of the samples. However, none of the other nonindigenous species occurred in more than $7 \%$ of the samples.

One similarity between the shelf nonindigenous species and those in coastal estuaries and Puget Sound is the predominance of non-native spionid polychaetes. Five of the 13 nonindigenous species on the shelf are spionids $(L$. cirrata, $D$. bidentata, $D$. caulleryi, $D$. quadrilobata, and $P$. paucibranchiata), while 14 nonindigenous spionids have been reported from coastal waters (Lee and Reusser 2008). However, the shelf and estuarine assemblages differ in the identity of the dominant spionid invaders. In comparison to Laonice and the Dipolydora species on the shelf, the most frequently occurring nonindigenous spionids in estuaries are Polydora cornuta, Pseudopolydora kempi, Pseudopolydora paucibranchiata and Streblospio benedicti. Although $P$. paucibranchiata was found on the shelf, it was reported from only two of the 256 samples. Another notable difference between shelf and estuarine invaders is the absence of the three most widespread estuarine invaders, the amphipods Grandidierella japonica and Monocorophium insidiosum and the bivalve Mya arenaria. Monocorophium acherusicum is also one of the most frequently occurring invaders in coastal estuaries, and though it was found on the shelf, it apparently has a very low abundance, since only a single individual was reported.

Future resolution of the taxonomy and native ranges of the shelf fauna will reduce the uncertainty in evaluating the extent of invasion along the coast. Nonetheless, this preliminary analysis indicates that the shelf benthos is substantially less invaded than estuaries along the Pacific Coast when measured either by the number of nonindigenous species or by their abundance.

Additionally, the common and widespread invaders in estuaries are either absent or in very low abundance on the shelf. The absence or low abundance of these estuarine invaders indicates that, at least to date, the offshore discharge of ballast water has not resulted in widespread invasion of the offshore benthic assemblages.

\subsubsection{Potential Linkage to Stressor Impacts}

Multi-metric benthic indices are often used as indicators of pollutioninduced degradation of the benthos (see review by Diaz et al. 2004) and have been developed for a variety of estuarine applications (Engle et al. 1994, Weisberg et al. 1997, Van Dolah et al. 1999, Llannso et al. 2002a, 2002b). A desired feature of these indices is the ability to differentiate impaired vs. unimpaired benthic condition, based on a number of key biological attributes (e.g., numbers of species, diversity, abundance, relative proportions of sensitive vs. dominant species, biomass), while attempting to take into account variations associated with natural controlling factors. While a related index has been developed for the Southern California mainland shelf (Smith et al. 2001), there is 


\begin{tabular}{|c|c|c|c|c|c|c|c|c|c|c|c|c|c|c|}
\hline 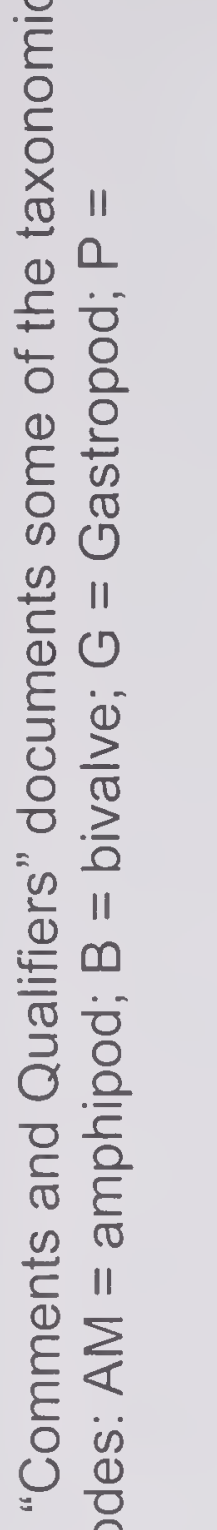 & 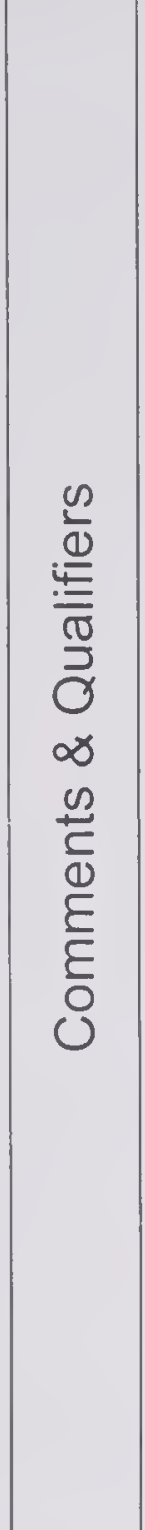 & 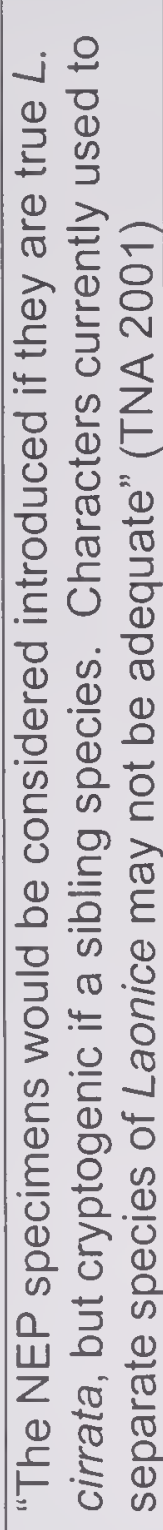 & 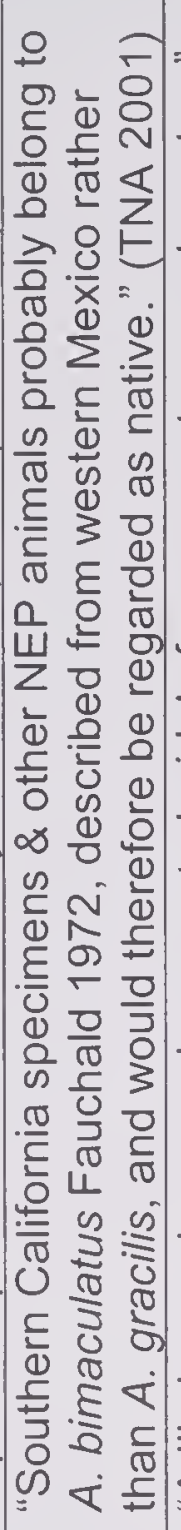 & 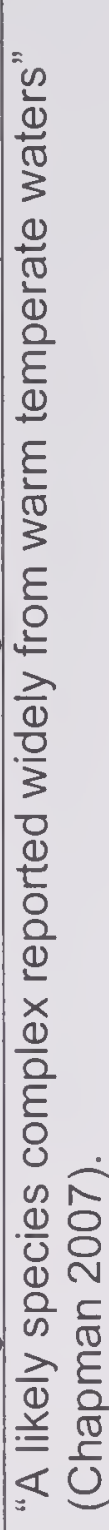 & 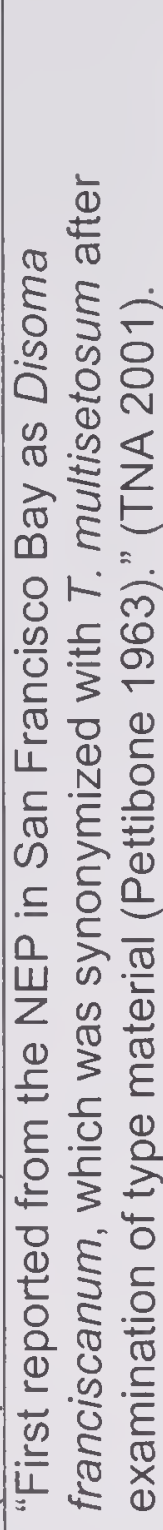 & 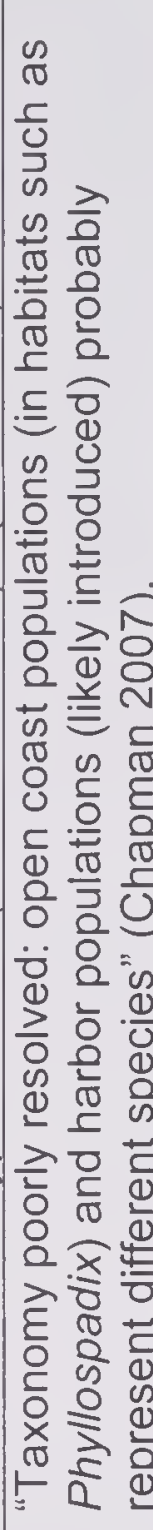 & 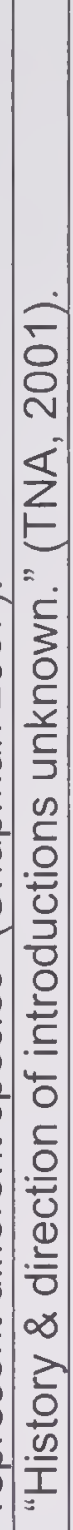 & 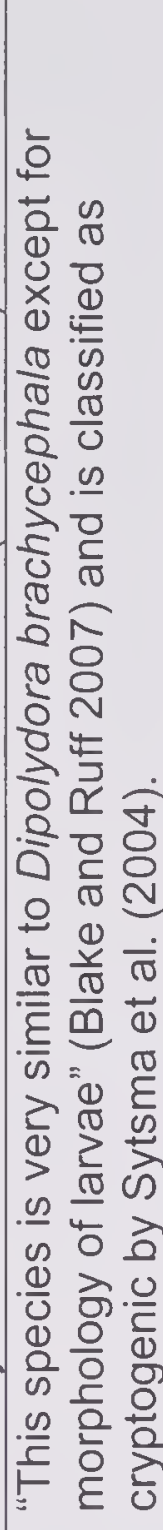 & 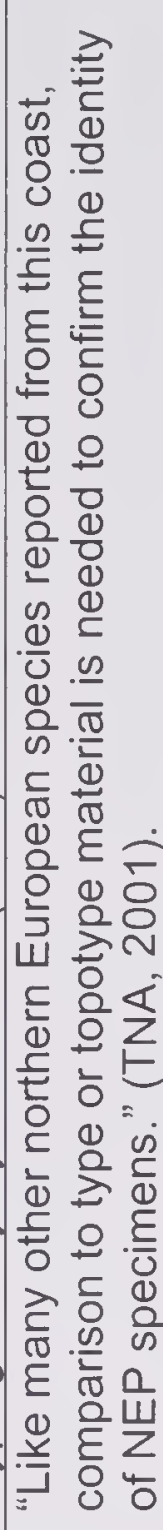 & 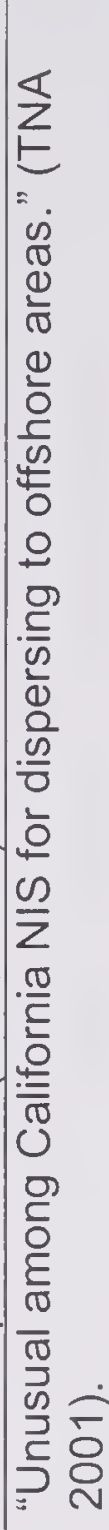 & 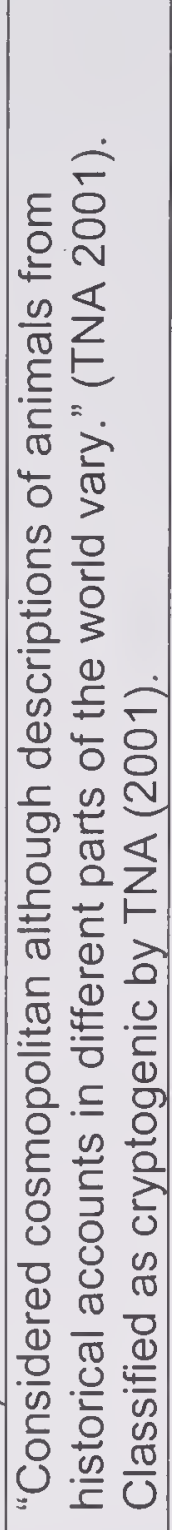 & 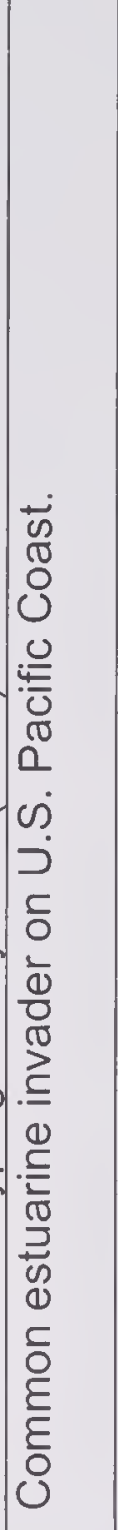 & 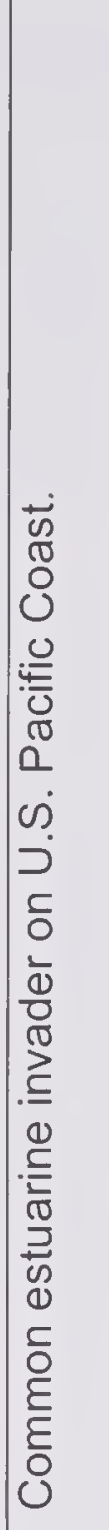 & 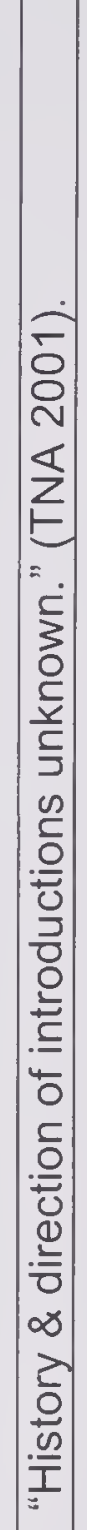 \\
\hline 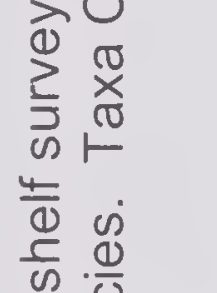 & 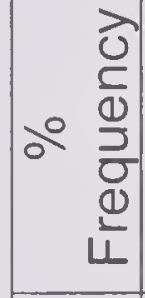 & N & is & $\hat{\sim}$ & 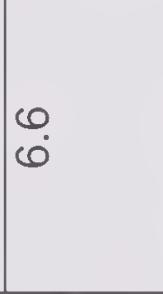 & $\stackrel{?}{\leftarrow}$ & $\begin{array}{l}\sigma \\
\dot{m}\end{array}$ & io & نما & $\stackrel{m}{\sim}$ & $\stackrel{m}{\sim}$ & $\stackrel{\infty}{\infty}$ & $\stackrel{\nabla}{\circ}$ & $\stackrel{\nabla}{\circ}$ \\
\hline 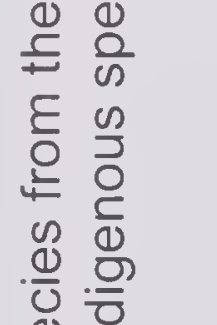 & 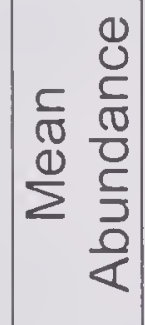 & L & 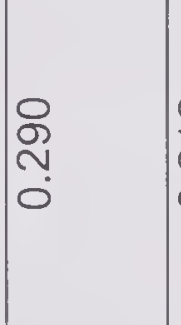 & $\frac{N}{\sim}$ & $\begin{array}{l}0 \\
0 \\
0\end{array}$ & $\frac{\infty}{2}$ & 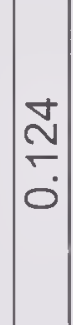 & 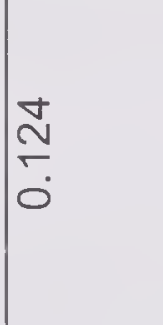 & $\begin{array}{l}\overline{1} \\
0 \\
0 \\
0\end{array}$ & $\begin{array}{l}\overline{\tilde{O}} \\
0 \\
0\end{array}$ & $\begin{array}{l}\hat{N} \\
0 \\
0 \\
0\end{array}$ & $\frac{N}{0}$ & $\begin{array}{l} \\
0 \\
0 \\
0\end{array}$ & $\begin{array}{l}\text { பे } \\
0 \\
0\end{array}$ \\
\hline 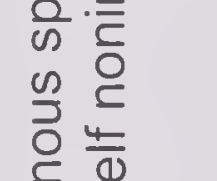 & 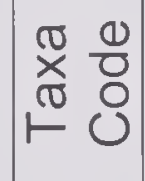 & 0 & 0 & $\sum_{<}$ & 0 & $\sum_{<}$ & 0 & 0 & 0 & 0 & 0 & 0 & $\sum_{<}$ & 0 \\
\hline 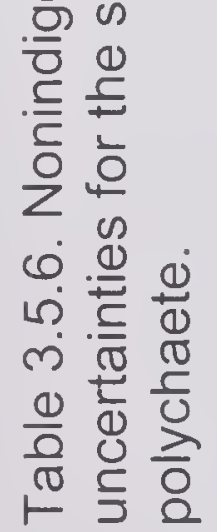 & $\begin{array}{l}\mathscr{d} \\
\frac{\mathscr{U}}{0} \\
0 \\
\stackrel{0}{0}\end{array}$ & 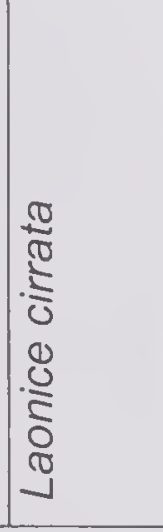 & 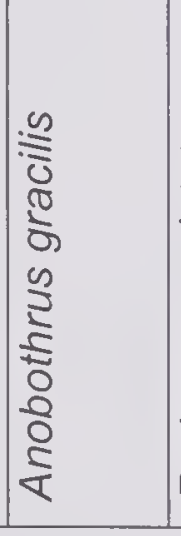 & 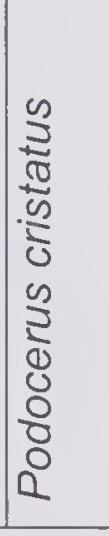 & 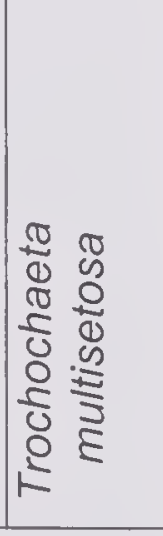 & 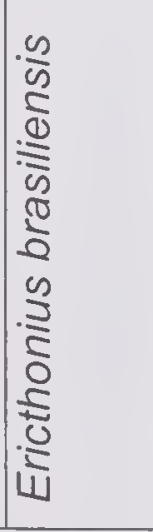 & $\mid$\begin{tabular}{|}
$\mid \frac{\pi}{\pi}$ \\
$\frac{\pi}{2}$ \\
$\frac{0}{0}$ \\
0 \\
0 \\
0 \\
0 \\
0 \\
0 \\
0 \\
0 \\
0 \\
\end{tabular} & 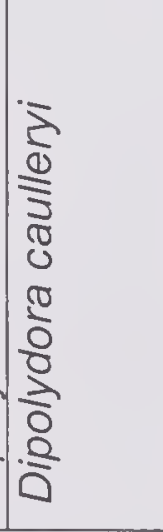 & 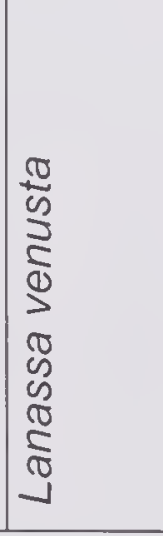 & 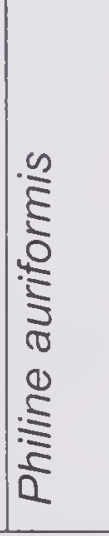 & 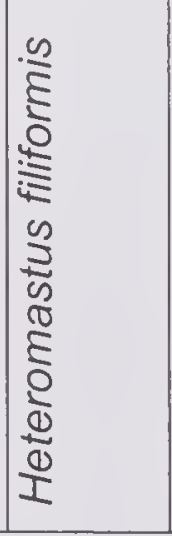 & $\begin{array}{ll}0 & \frac{\pi}{0} \\
0 & .0 \\
0 & \frac{1}{2} \\
0 & 0 \\
0 & 0 \\
0 & 0 \\
0 & 0 \\
0 & 0 \\
0 & 0 \\
0 & 0 \\
0 & 2 \\
1 & \end{array}$ & 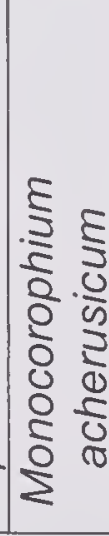 & 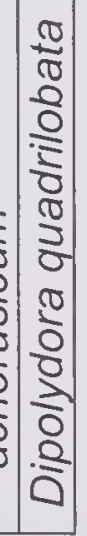 \\
\hline
\end{tabular}


currently no such index that has been developed for application in shelf waters throughout the entire West Coast.

In the absence of a benthic index, we have attempted to assess potential stressor impacts in the present study by looking for obvious linkages between reduced values of key biological attributes (numbers of taxa, diversity, and abundance) and synoptically measured indicators of poor sediment or water quality. Benthic attributes in these offshore shelf waters showed significant variations among the three states. Thus, low values of species richness, $\mathrm{H}^{\prime}$, and density were defined for the purpose of the present analysis as the lower $10^{\text {th }}$ percentile of values within each individual state. Thresholds for assessing poor sediment or water quality were defined as follows (sensu EPA 2000a for dissolved oxygen, EPA 2004 for other indicators): $\geq 5$ chemicals in excess of ERLs (from Long et al. 1995), $\geq 1$ chemical in excess of ERMs (from Long et al. 1995), TOC $>5 \%$, and DO in near-bottom water $<2.3 \mathrm{mg} / \mathrm{L}$. Appendix Table 4 provides a summary by station of each of these variables and flags those falling within the defined levels of concern.

This analysis revealed no major evidence of impaired benthic condition linked to measured stressors. There were only two stations, both in California, where low values of any of the three benthic attributes co-occurred with high sediment contamination or low DO in bottom water. One station (CA03-4039 off Los Angeles) had low benthic species richness and abundance accompanied by high sediment contamination, with eight chemicals in excess of corresponding ERL values and two in excess of ERM values. The other station (CA03-0059 north of San Francisco Bay) had low species richness and diversity accompanied by low DO. There were five other stations with DO in bottom water $<2.3 \mathrm{mg} / \mathrm{L}$; however, none of these had low values of the three benthic variables. There were two stations (CA03-4030, CA03-4417) that had TOC levels in a range $(>5 \%)$ potentially harmful to benthic fauna. A third station (CA03-4430) showed a potential concern level if the more conservative threshold of $3.6 \%$ TOC is used (Hyland et al. 2005), but low values of benthic community attributes were not observed at any of these sites. High sediment contamination was a more prevalent stressor, occurring at 23 stations (all in California), but not at any of the sites where low values of benthic attributes were observed. In fact, most of these latter stations with high sediment contamination had more than 100 species grab ${ }^{-1}$.

Such lack of concordance suggests that these offshore waters are currently in good condition, with the lower-end values of the various biological attributes representing parts of a normal reference range controlled by natural factors. Multiple linear regression was performed using full model procedures to test for the significance and direction of relationships between each of the benthic variables and various abiotic environmental factors (latitude, depth, percent fines). Data transformations were made where needed (i.e., square root for richness, $\log _{10}$ for abundance) to meet analysis assumptions including normality and homoscedasticity of residuals. Results (graphics not shown) suggested that latitude and depth had significant influences on benthic variables region-wide. All three benthic variables showed significant inverse 
relationships with latitude, i.e. with values increasing as latitude decreased $(p<0.01)$. Depth had a significant direct influence on diversity $(p<0.001)$ and a significant inverse effect on density $(p<0.01)$. None of the three benthic variables varied significantly in relation to \% fines (at $p<0.1$ ), though in general there was a tendency for muddier sediments (higher percent fines) to have lower species richness and diversity and higher densities than coarser sediments.

Alternatively, it is possible that for some of these sites the lower values of benthic variables reflect symptoms of disturbance induced by other unmeasured stressors. In efforts to be consistent with the underlying concepts and protocols of earlier EMAP and NCA programs, the indicators in this study included measures of stressors, such as chemical contaminants and symptoms of eutrophication, which are often associated with adverse biological impacts in shallower estuarine and inland ecosystems. However, there may be other sources of human-induced stress in these offshore systems that pose greater risks to living resources and which have not been adequately captured. One such activity is commercial trawling, which is a major industry in shelf waters, including NMSs, and which could have significant adverse effects on bottom habitats and benthic organisms (Jones 1992, Jennings and Kaiser 1998, Dayton et al. 1995, National Research Council 2002, Watling and Norse 1998). Future monitoring efforts in these offshore areas should include indicators of such alternative sources of disturbance. 


\subsection{Literature Cited}

Allen, M.J., T. Mikel, D. Cadien, J.E. Kalman, E.T. Jarvis, K.C. Schiff, D.W. Diehl, S.L. Moore, S. Walther, G. Deets, C. Cash, S. Watts, D.J. Pondella II, V. RacoRands, C. Thomas, R. Gartman, L. Sabin, W. Power, A.K. Groce, and J.L. Armstrong. 2007. Southern California Bight 2003 Regional Monitoring Program:

IV. Demersal Fishes and Megabenthic Invertebrates. Southern California Coastal Water Research Project. Costa Mesa, CA.

Baber, K.D., F.B. Fulkerson and N.S. Peterson. 1959. pp. 765-778. Oregon. In: Bureau of Mines/Minerals Yearbook Area Reports, 1958.

Baxter, R. 1987. Mollusks of Alaska: A listing of all mollusks, freshwater, terrestrial, and marine reported for the state of Alaska, with locations of the species types, maximum sizes, and marine depths inhabited. Shells and Sea Life. Bayside, California. $163 \mathrm{p}$.

Bay, S.M., T. Mikel, K. Schiff, S. Mathison, B. Hester, D. Young, and D. Greenstein. 2005. Southern California Bight 2003 Regional Monitoring Program: I. Sediment Toxicity. Southern California Coastal Water Research Project. Westminster, CA.

Bernard, F. 1967. Prodrome for a distributional check-list and bibliography of the recent marine mollusca of the west coast of Canada. Fisheries Research Board of Canada. Technical Report No. 2. 261 p.

Blake, J.A. and R.E. Ruff. 2007. Polychaeta. pp. 309-410, In: Carlton, J.T. (ed.) In: The Light and Smith Manual: Intertidal Invertebrates from Central California to Oregon, Fourth Edition. University of California Press, Berkeley and Los Angeles, California.

Carlton, J.T. 1996. Biological invasions and cryptogenic species. Ecology 77:16531655.

Carlton, J.T. 2007. (ed.) The Light and Smith Manual: Intertidal Invertebrates from Central California to Oregon, Fourth Edition. University of California Press, Berkeley and Los Angeles, California.

Chan, F. , J. A. Barth, J. Lubchenco, A. Kirincich, H. Weeks, W. T. Peterson, B. A. Menge. 2008. Emergence of anoxia in the California Current Large Marine Ecosystem. Science 319:920.

Chapman, J.W. 2007. Gammaridea. pp. 545-618, In: Carlton, J.T. (ed.), The Light and Smith Manual: Intertidal Invertebrates from Central California to Oregon, Fourth Edition. University of California Press, Berkeley and Los Angeles, California.

Cohen, A. and J.T. Carlton. 1995. Nonindigenous aquatic species in a United States estuary: A case study of the biological invasions of the San Francisco Bay and Delta. Report for the National Sea Grant College Program, DT and the U.S. Fish and Wildlife Service, Washington, D.C. Report No. PB 96-166525.

Cooksey, C. L. 2003. Cruise Report, NOAA Ship McARTHUR II Cruise AR-03-01-NC (June 1 - 26, 2003). EMAP Summer 03 Survey of Ecological Conditions of the Western U.S. Continental Shelf. Internal Report. NOAA, NOS, National Centers for Coastal Ocean Science, Center for Coastal Environmental Health and Biomolecular Research, 219 Fort Johnson Road, Charleston, South Carolina, 29412. 
Dayton, P.K., S.F. Thrush, M.T. Agardy, and R.J. Hofman. 1995. Environmental effects of marine fishing. Aquatic Conservation: Marine and Freshwater Ecosystems 5: 205-232.

Diaz, R.J., M. Solan, and R.M. Valente. 2004. A review of approaches for classifying benthic habitats and evaluating habitat quality. Journal of Environmental Management 73:165-181.

Diaz-Ramos, S., D.L. Stevens, Jr., and A.R. Olsen. 1996. EMAP Statistics Methods Manual. EPA/620/R-96/002. Corvallis, OR: U.S. Environmental Protection Agency, Office of Research and Development, National Health and Environmental Effects Research Laboratory.

Engle, V. D., J. K. Summers, and G.R. Gaston. 1994. A benthic index of environmental condition of Gulf of Mexico estuaries. Estuaries 17: 372-384.

Fauchald, K. and G.F. Jones. 1978. Variation in community structure of shelf, slope and basin macrofaunal communities of the Southern California Bight. Chapter 19, Year II benthic study. Report submitted by Science Applications, Inc. to Bureau of Land Management, Pacific OCS Office, Los Angeles, CA under Contract No. AA551-CT6-40.

Geider, R. J. and J. La Roche. 2002. Redfield revisited: variability of C:N:P in marine microalgae and its biochemical basis. European Journal of Phycology 37:1-17.

Grantham, B.A., F. Chan, K.J. Nielsen, D.S. Fox, J.A. Barth, A. Huyer, J. Lubchenco, and B. A. Menge. 2004. Upwelling-driven nearshore hypoxia signals ecosystem and oceanographic changes in the northeast Pacific. Nature 429:749-754.

Hayslip, G., L. Edmond, V. Partridge, W. Nelson, H. Lee, F. Cole, J. Lamberson, and L. Caton. 2006. Ecological Condition of the Estuaries of Oregon and Washington.

EPA 910-R-06-001. U.S. Environmental Protection Agency, Office of Environmental Assessment, Region 10, Seattle, Washington.

Hines, A.H., and G.M. Ruiz. 2000. Biological invasions of cold-water coastal ecosystems: Ballast-mediated introductions in Port Valdez/Prince William Sound, Alaska. Prince William Sound Regional Advisory Board, Valdez, AK. Available online at http://www.pwsrcac.org/docs/d0018502.pdf.

Hoberg, M. and H. Feder. 2002. The macrobenthos of sites within Prince William Sound, Alaska, prior to the Exxon Valdez oil spill. International Review of Hydrobiology 87:25-45.

Hyland, J. L., T.J. Herrlinger, T.R. Snoots, A.H. Ringwood, R.F. Van Dolah, C.T. Hackney, G.A. Nelson, J.S. Rosen, and S.A. Kokkinakis. 1996. Environmental Quality of Estuaries of the Carolinian Province: 1994. Annual Statistical Summary for the 1994 EMAP- Estuaries Demonstration Project in the Carolinian Province. NOAA Technical Memorandum NOS ORCA 97. NOAA/NOS, Office of Ocean Resources Conservation and Assessment, Silver Spring, MD. 102 p.

Hyland, J., E. Baptiste, J. Campbell, J. Kennedy, R. Kropp, and S. Williams. 1991. Macroinfaunal communities of the Santa Maria Basin on the California outer continental shelf and slope. Marine Ecology Progress Series 78:147-161.

Hyland, J., L. Balthis, I. Karakassis, P. Magni, A. Petrov, J. Shine, O. Vestergaard, and R. Warwick. 2005. Organic carbon content of sediments as an indicator of stress in the marine benthos. Marine Ecology Progress Series 295:91-103. 
Jennings, S. and M.J. Kaiser. 1998. The effects of fishing on marine ecosystems. Advances in Marine Biology 34:201-352.

Jones, G.F. 1969. The benthic macrofauna of the mainland shelf of southern California. Allan Hancock Monographs in Marine Biology 4: 1-219.

Jones, J.B. 1992. Environmental impact of trawling on the seabed: a review. New Zealand Journal of Marine and Freshwater Research 26:59-67.

Krauskopf, K.B. and D.K. Bird. 1995. Introduction to Geochemistry. $3^{\text {rd }}$ edition. Appendix IV, Average Abundance of Elements in the Earth's Crust, Continental Crust, in Three Common Rocks, and in Seawater. New York: McGraw-Hill.

Lauenstein, G.G. and A.Y. Cantillo (eds.). 1993. Sampling and analytical methods of the National Status and Trends Program National Benthic Surveillance and Mussel Watch Projects 1984-1992: Comprehensive descriptions of trace organic analytical methods, Volume IV NOAA Technical Memorandum NOS ORCA 71, Silver Spring, MD. 182 pp.

Lauenstein, G.G., E.A. Crecelius, and A.Y. Cantillo. 2000. Baseline metal concentrations of the U.S. West Coast and their use in evaluating sediment contamination. Presented at $21 \mathrm{st}$ Ann. Soc. Environ. Toxicology and Chemistry meeting, November 12 - 15, 2000, Nashville Tennessee.

Lee II, H. and D.A. Reusser. with contributions from M.Ranelletti, R. Nehmer, K. Welch, and L. Hillmann. 2008. Pacific Coast Ecosystem Information System (PCEIS) V. 2.0. U.S. EPA and USGS (Microsoft Access 2003 database).

Lee II, H., B. Thompson, and S. Lowe. 2003. Estuarine and scalar patterns of invasion in the soft-bottom benthic communities of the San Francisco Estuary. Biological Invasions 5:85-102.

Lee II, H., W.G. Nelson, J.O. Lamberson, and D.A. Reusser. 2003. Regional assessment of the invasive macrobenthos in the small West Coast estuaries. $p$. $81 \mathrm{In}$ : Third International Conference on Marine Bioinvasions, Abstract Book. La Jolla, California, March 16-19. $134 \mathrm{p}$.

Levin, P.S., M.J. Fogarty, G.C. Matlock, and M. Ernst. 2008. Integrated ecosystem assessments. U.S. Department of Commerce, NOAA Tech. Memo. NMFSNWFSC-92, $20 \mathrm{pp}$.

Lima, F.P., P.A. Ribeiro, N. Queiroz, S.J. Hawkins, and A.M. Santos. 2007. Do distributional shifts of northern and southern species of algae match the warming pattern? Global Change Biology 13:2592-2604.

Llanso, R.J., L.C. Scott, D.M. Dauer, J.L. Hyland, and D.E. Russell. 2002a. An estuarine benthic index of biotic integrity for the Mid-Atlantic region of the United States. I.

Classification of assemblages and habitat definition. Estuaries 25:1219-1230.

Llansó, R.J., L.C. Scott, J.L. Hyland, D.M. Dauer, D.E. Russell, and F.W. Kutz. 2002. An estuarine benthic index of biological integrity for the Mid Atlantic region of the United States. II. Index development. Estuaries 25:1231-1242.

Long, E.R., D.D. MacDonald, S.L. Smith, and F.D. Callander. 1995. Incidence of adverse biological effects within ranges of chemical concentrations in marine and estuarine sediments. Environmental Management 19:81-97.

Long, E.R., J. Hameedi, A. Robertson, M. Dutch, S. Aasen, K. Welch, S. Magoon, R. Carr, T. Johnson, J. Biedenbach, K. Scott, C. Mueller, and J. Anderson. 2000. 
Sediment Quality in Puget Sound. Year 2 - Central Puget Sound. National Oceanic and Atmospheric Administration, National Ocean Service, Silver Spring, MD. NOS NCCOS CCMA Technical Memo No. 147. Washington State Department of Ecology, Olympia, WA, Publication No. 00-03-055. 353 p. Macpherson, E. 1971. The Marine Molluscs of Arctic Canada. National Museum of

Natural Sciences. Publications in Biological Oceanography No. 3. 149 p.

Marine Ecosystems and Management. 2007. Experts describe challenges facing marine EBM (multiple related short papers included). Marine Ecosystems Management 1: $1-8$.

Murawski, S.A. 2007. Ten myths concerning ecosystem approaches to marine resource management. Marine Pollution 31:681-690.

Murawski, S. and E. Menashes. 2007. What is an integrated ecosystem assessment?

Presentation at March 27-28, 2007 meeting on "An Integrated, Ecosystem-based Approach to Regional Ocean Management: Creating a Policy-Relevant Science Vision for Ecosystem-based Management in the Gulf of Maine," University of New Hampshire.

http://www.gulfofmaine.org/ebm/meeting2007/presentations/noaa_murawski_file s/noaa_murawski.ppt.

National Research Council. 2002. Effects of trawling and dredging on seafloor habitat.

National Academy Press, Washington D.C. 126 p.

Nelson, W.G., H. Lee II, J.O. Lamberson, V. Engle, L. Harwell and L.M. Smith. 2004. Condition of Estuaries of Western United States for 1999: A Statistical Summary. Office of Research and Development, National Health and Environmental Effects Research Laboratory, EPA/620/R-04/200. 132 p.

Nelson, W.G., H. Lee II, and J.O. Lamberson. 2005. Ecological Condition of the Estuaries of California for 1999: A Statistical Summary. Office of Research and Development, National Health and Environmental Effects Research Laboratory. EPA/620/R-05/004. 128 p.

Nelson, W.G., H. Lee II, J.O. Lamberson, F.A. Cole, C. Weilhoefer, and P.J. Clinton. 2007a. The Condition of Tidal Wetlands of Washington, Oregon, and California 2002. Office of Research and Development, National Health and Environmental Effects Research Laboratory. $84 \mathrm{p}$.

Nelson, W.G., R. Brock, H. Lee II, J.O. Lamberson and F. Cole. 2007b. Condition of Estuaries and Bays of Hawaii for 2002: A Statistical Summary. Technical Report. Office of Research and Development, National Health and Environmental Effects Research Laboratory, EPA/620-R-07/001. 134 p.

Nezlin, N.P., P.M. DiGiacomo, S.B. Weisberg, D.W. Diehl, J.A. Warrick, J. Mengel, B.H. Jones, K.M. Reifel, S.C. Johnson, J.C. OhImann, L. Washburn, and E.J. Terrill. 2007. Southern California Bight 2003 Monitoring Program: V. Water Quality. Southern California Coastal Water Research Project, Costa Mesa, CA.

NMSP (National Marine Sanctuaries Program). 2004. A monitoring framework for the National Marine Sanctuary System. U.S. Department of Commerce, National Oceanic and Atmospheric Administration, National Ocean Service, National Marine Sanctuary Program, Silver Spring, MD. 22p. 
NOAA 2007. Integrated Ecosystem Assessment. White paper, November 2007. NOAA IEA Priority Area Task Team. http://wwwocean.tamu.edu/GCOOS/Office/documents/Nov2007/04b.pdf. 7 p.

Partridge, V. 2007. Condition of coastal waters of Washington State, 2000-2003. A statistical summary. Publication No. 07-03-051. Environmental Assessment Program, Washington State Department of Ecology, Olympia, WA. 251 p.

Ranasinghe, J.A., A.M. Barnett, K. Schiff, D.E. Montagne, C. Brantley, C. Beegan, D.B. Cadien, C. Cash, G.B. Deets, D.R. Diener, T.K. Mikel, R.W. Smith, R.G. Velarde, S.D. Watts, and S.B. Weisberg. 2007. Southern California Bight 2003 Regional Monitoring Program: III. Benthic Macrofauna. Southern California Coastal Water Research Project. Costa Mesa, CA.

Raymond, L.J. and N.V.C. Ralston. 2004. Mercury: selenium interactions and health implications. Seychelles Medical and Dental Journal, Special Issue, 7:72-77. Available at: http://www.seychelles.net/smdj/SECIIIC.pdf

SAS Institute Inc. 2004. SAS OnlineDoc® 9.1.3. Cary, North Carolina: SAS Institute Inc. Saupe, S.M., J. Gendron, and D. Dasher. 2005. The Condition of Southcentral Alaska Coastal Bays and Estuaries. A Statistical Summary for the National Coastal Assessment Program. Alaska Department of Environmental Conservation.

SCAMIT, 2001. A taxonomic listing of soft bottom macro- and megainvertebrates from infaunal \& epibenthic monitoring programs in the Southern California Bight. Edition 4. Prepared by Southern California Association of Marine Invertebrate Taxonomists, San Pedro, California. Available at http://www.scamit.org/edition_four_information.htm.

Schiff, K. 2000. Sediment chemistry on the mainland shelf of the Southern California Bight. Marine Pollution Bulletin 40:267-276.

Schiff, K., K. Maruya and K. Christensen. 2006. Southern California Bight 2003 Regional Monitoring Program: II. Sediment Chemistry. Southern California Coastal Water Research Project. Westminster, CA.

Smith, R.W., M. Bergen, S.B. Weisberg, D. Cadien, A. Dalkey, D. Montagne, J.K. Stull, and R.G. Velarde. 2001. Benthic response index for assessing infaunal communities on the southern California mainland shelf. Ecological Applications 11:1073-1087

Spalding, M.D. H.E. Fox, G.R. Allen, N. Davidson, Z. A. Ferdaña, M. Finlayson, B.S. Halpern, M. A. Jorge, A. Lombana, S.A. Lourie, K.D. Martin, E. Mcmanus, J. Molnar, C.A. Recchia, and J. Robertson. 2007. Marine ecoregions of the world: A bioregionalization of coastal and shelf areas. Bioscience 57:573-583.

Strobel, C. J., H. W. Buffum, S.J. Benyi, E.A. Petrocelli, D.R. Reifsteck, and D.J. Keith. 1995. Statistical summary: EMAP - Estuaries Virginian Province - 1990 to 1993. U.S. EPA National Health and Environmental Effects Research Laboratory, Atlantic Ecology Division, Narragansett, R.I. EPA/620/R-94/026. 72 p. plus Appendices A-C.

Summers, J.K., J.M. Macauley, P.T. Heitmuller, V.D. Engle, A.M. Adams, and G.T. Brooks. 1993. Annual Statistical Summary: EMAP-Estuaries Louisianian Province -1991. U.S. Environmental Protection Agency, Office of Research and 
Development, Environmental Research Laboratory, Gulf Breeze, FL. EPA/600/R93/001. 101 p. plus Appendices A-C.

Sytsma M., J. Cordell, J. Chapman, R.C. Draheim. 2004. Lower Columbia River Aquatic Nonindigenous Species Survey 2001-2004 Final Technical Report: (Appendices). Prepared for the United States Coast Guard and United States Fish and Wildlife Service. 164 p.

T N \& Associates, Inc. 2001. Compiling Lists of Nonindigenous Species (NIS) from the West Coast of the Unites States, Excluding San Francisco Bay. Report on EMAP 1999 species submitted to National Center for Environmental Assessment/ORD/EPA, Washington, D.C. 81 pages and spreadsheet. (available from PCEB/EPA).

U.S. EPA. 1994. Environmental Monitoring and Assessment Program (EMAP):

Laboratory Methods Manual - Estuaries, Volume 1: Biological and Physical Analyses. Office of Research and Development, Environmental Monitoring and Systems Laboratory, Cincinnati, OH. EPA/600/4-91/024. 321-324.

U.S. EPA (U.S. Environmental Protection Agency). 2000a. Ambient Aquatic Life Water Quality Criteria for Dissolved Oxygen (Saltwater): Cape Cod to Cape Hatteras. EPA-822-R-00-012. Office of Water and Office of Research and Development, Washington, DC. 49p. Available at:

http://www.epa.gov/waterscience/standards/dissolved/docriteria.pdf

U.S. EPA (U.S. Environmental Protection Agency). 2000b. Guidance for Assessing

Chemical Contaminant Data for Use in Fish Advisories, Volume 2: Risk

Assessment and Fish Consumption Limits. EPA-823-B-00-008. U.S.

Environmental Protection Agency, Office of Water, Washington, DC. 383 p. Available at:

http://www.epa.gov/region6/6pd/qa/qadevtools/mod4references/supplemental/vol ume2.pdf

U.S. EPA (U.S. Environmental Protection Agency). 2001. National Coastal Condition

Report. EPA-620/R-01/005. Office of Research and Development and Office of Water, Washington, DC. 204 p. Available at:

http://www.epa.gov/owow/oceans/nccr/downloads.html

U.S. EPA (U.S. Environmental Protection Agency). 2004. National Coastal Condition

Report II. EPA-620/R-03/002. U.S. Environmental Protection Agency, Office of

Research and Development and Office of Water, Washington, D.C. 286 p.

Available at: http://www.epa.gov/nccr/2005/downloads.html

U.S. EPA (U.S. Environmental Protection Agency). 2006. National Estuary Program Coastal Condition Report. EPA-842/B-06/001. U.S. Environmental Protection Agency, Office of Water, Washington, D.C. 445 p. Available at: http://www.epa.gov/owow/oceans/nepccr/index.html

U.S. EPA/WED Unpublished Data. EPA National Coastal Assessment Western

Regional Component (NCA-West) 1999-2000 database for estuaries. EPA Western Ecology Division (EPA/WED), National Health and Environmental Effects Research Laboratory, U.S. Environmental Protection Agency, Newport, OR 32561. 
Van Dolah, R. F., J. L. Hyland, A. F. Holland, J. S. Rosen, and T. R. Snoots. 1999. A benthic index of biological integrity for assessing habitat quality in estuaries of the southeastern USA. Marine Environmental Research 48: 269-283.

Weisberg, S.B., J.A. Ranasinghe, D.M. Dauer, L.C. Schaffner, R.J. Diaz, and J.B. Frithsen. 1997. An estuarine benthic index of biotic integrity (B-IBI) for Chesapeake Bay. Estuaries 20:149-158.

Watling, L. and E.A. Norse. 1998. Disturbance of the seabed by mobile fishing gear: A comparison with forest clear-cutting. Conservation Biolology 12: 1180-1197.

Wilson, S. and V. Partridge. 2007. Condition of Outer Coastal Estuaries of Washington State, 1999. A Statistical Summary. Publication No. 07-03-012. Washington State Department of Ecology, Olympia, WA. 249 p. 


\subsection{Appendix Tables}

Appendix Table 1. Sampling coordinates for the 2003 West Coast Shelf Assessment. The "Frame $\mathrm{km}^{2}$ " represents the total area within a multi-density category. The weighting factor for computing CDFs is obtained by dividing the multi-density category area by the number of samples for a given parameter obtained in that category (see section 2.6).

\begin{tabular}{|c|c|c|c|c|c|c|}
\hline $\begin{array}{c}\text { EMAP } \\
\text { Station ID }\end{array}$ & $\begin{array}{l}\text { Sample } \\
\text { Depth }\end{array}$ & Date & Latitude & Longitude & $\begin{array}{c}\text { Multi-density } \\
\text { Category }\end{array}$ & $\begin{array}{c}\text { Frame } \\
\mathrm{km}^{2}\end{array}$ \\
\hline CA03-0001 & 106 & $10 / 16 / 2003$ & 33.362 & -118.307 & CA-Other & 6311.78 \\
\hline CA03-0007 & 70 & $6 / 25 / 2003$ & 38.158 & -123.056 & CA-NMS & 5863.69 \\
\hline CA03-0008 & 64.3 & $6 / 24 / 2003$ & 37.248 & -122.495 & CA-NMS & 5863.69 \\
\hline CA03-0012 & 40 & $6 / 26 / 2003$ & 37.651 & -122.711 & CA-NMS & 5863.69 \\
\hline CA03-0019 & 110 & $6 / 18 / 2003$ & 39.990 & -124.158 & CA-Other & 6311.78 \\
\hline CA03-0024 & 68 & $6 / 25 / 2003$ & 37.598 & -122.827 & CA-NMS & 5863.69 \\
\hline CA03-0027 & 84 & $6 / 19 / 2003$ & 38.444 & -123.258 & CA-Other & 6311.78 \\
\hline CA03-0028 & 94 & $6 / 25 / 2003$ & 37.946 & -123.145 & CA-NMS & 5863.69 \\
\hline CA03-0032 & 56 & $6 / 22 / 2003$ & 34.908 & -120.737 & CA-Other & 6311.78 \\
\hline CA03-0035 & 81 & $6 / 18 / 2003$ & 39.510 & -123.840 & CA-Other & 6311.78 \\
\hline CA03-0039 & 90 & $6 / 19 / 2003$ & 38.311 & -123.206 & CA-Other & 6311.78 \\
\hline CA03-0040 & 93 & $6 / 20 / 2003$ & 37.373 & -122.753 & CA-NMS & 5863.69 \\
\hline CA03-0043 & 78 & $6 / 14 / 2003$ & 40.728 & -124.445 & CA-Other & 6311.78 \\
\hline CA03-0044 & 61 & $6 / 25 / 2003$ & 37.943 & -123.028 & CA-NMS & 5863.69 \\
\hline CA03-0048 & 62 & $6 / 22 / 2003$ & 34.590 & -120.719 & CA-Other & 6311.78 \\
\hline CA03-0051 & 63 & $6 / 14 / 2003$ & 41.636 & -124.319 & CA-Other & 6311.78 \\
\hline CA03-0052 & 104 & $6 / 25 / 2003$ & 37.908 & -123.310 & CA-NMS & 5863.69 \\
\hline CA03-0056 & 95 & $6 / 21 / 2003$ & 37.524 & -122.874 & CA-NMS & 5863.69 \\
\hline CA03-0059 & 103 & $6 / 19 / 2003$ & 38.465 & -123.350 & CA-Other & 6311.78 \\
\hline CA03-0060 & 80 & $6 / 24 / 2003$ & 36.823 & -121.903 & CA-NMS & 5863.69 \\
\hline CA03-0064 & 50 & $6 / 22 / 2003$ & 35.783 & -121.375 & CA-NMS & 5863.69 \\
\hline CA03-0071 & 75 & $6 / 25 / 2003$ & 38.303 & -123.124 & CA-Other & 6311.78 \\
\hline CA03-0072 & 89 & $6 / 20 / 2003$ & 37.317 & -122.628 & CA-NMS & 5863.69 \\
\hline CA03-0075 & 69 & $6 / 15 / 2003$ & 40.515 & -124.521 & CA-Other & 6311.78 \\
\hline CA03-0076 & 54 & $6 / 25 / 2003$ & 37.749 & -122.877 & CA-NMS & 5863.69 \\
\hline CA03-0083 & 32.7 & $6 / 14 / 2003$ & 41.442 & -124.149 & CA-Other & 6311.78 \\
\hline CA03-0088 & 46 & $6 / 24 / 2003$ & 37.611 & -122.714 & CA-NMS & 5863.69 \\
\hline CA03-0091 & 115 & $6 / 19 / 2003$ & 38.765 & -123.702 & CA-Other & 6311.78 \\
\hline CA03-0092 & 89 & $6 / 20 / 2003$ & 36.924 & -122.236 & CA-NMS & 5863.69 \\
\hline CA03-0096 & 55 & $6 / 22 / 2003$ & 35.042 & -120.740 & CA-Other & 6311.78 \\
\hline CA03-0099 & 65 & $6 / 18 / 2003$ & 39.621 & -123.828 & CA-Other & 6311.78 \\
\hline CA03-0104 & 61.5 & $6 / 24 / 2003$ & 37.444 & -122.598 & CA-NMS & 5863.69 \\
\hline CA03-0112 & 61 & $6 / 22 / 2003$ & 34.725 & -120.730 & CA-Other & 6311.78 \\
\hline CA03-0116 & 89 & $6 / 21 / 2003$ & 37.623 & -122.933 & CA-NMS & 5863.69 \\
\hline CA03-0123 & 40.4 & $6 / 25 / 2003$ & 37.927 & -122.836 & CA-NMS & 5863.69 \\
\hline CA03-0124 & 104 & $6 / 20 / 2003$ & 37.128 & -122.577 & CA-NMS & 5863.69 \\
\hline CA03-0128 & 85 & $6 / 22 / 2003$ & 35.933 & -121.516 & CA-NMS & 5863.69 \\
\hline CA03-0135 & 94 & $6 / 25 / 2003$ & 38.128 & -123.180 & CA-NMS & 5863.69 \\
\hline CA03-0136 & 112 & $6 / 20 / 2003$ & 36.980 & -122.347 & CA-NMS & 5863.69 \\
\hline
\end{tabular}




\begin{tabular}{|c|c|c|c|c|c|c|}
\hline $\begin{array}{c}\text { EMAP } \\
\text { Station ID }\end{array}$ & $\begin{array}{l}\text { Sample } \\
\text { Depth }\end{array}$ & Date & Latitude & Longitude & $\begin{array}{l}\text { Multi-density } \\
\text { Category }\end{array}$ & $\begin{array}{l}\text { Frame } \\
\mathrm{km}^{2}\end{array}$ \\
\hline CA03-0139 & 75 & $6 / 14 / 2003$ & 41.974 & -124.405 & CA-Other & 6311.78 \\
\hline CA03-0140 & 49.6 & $6 / 25 / 2003$ & 37.853 & -122.825 & CA-NMS & 5863.69 \\
\hline CA03-0147 & 123 & $6 / 14 / 2003$ & 41.184 & -124.319 & CA-Other & 6311.78 \\
\hline CA03-0157 & 85 & $6 / 25 / 2003$ & 37.980 & -123.133 & CA-NMS & 5863.69 \\
\hline CA03-0158 & 53 & $6 / 24 / 2003$ & 37.194 & -122.457 & CA-NMS & 5863.69 \\
\hline CA03-0194 & 69 & $6 / 21 / 2003$ & 37.777 & -123.010 & CA-NMS & 5863.69 \\
\hline CA03-0210 & 102 & $6 / 24 / 2003$ & 36.748 & -121.939 & CA-NMS & 5863.69 \\
\hline CA03-0289 & 102 & $6 / 14 / 2003$ & 41.058 & -124.301 & CA-Other & 6311.78 \\
\hline CA03-4001 & 34 & $7 / 21 / 2003$ & 32.550 & -117.200 & SPME-S & 488.75 \\
\hline CA03-4007 & 60 & $7 / 21 / 2003$ & 33.860 & -118.448 & SPME-C & 385.46 \\
\hline CA03-4013 & 73 & $7 / 22 / 2003$ & 32.695 & -117.302 & Large POTW Outfalls & 163.22 \\
\hline CA03-4016 & 87 & $7 / 24 / 2003$ & 34.334 & -119.742 & SPME-N & 949.7 \\
\hline CA03-4020 & 83 & $8 / 18 / 2003$ & 34.231 & -119.512 & SPME-N & 949.7 \\
\hline CA03-4022 & 35 & $7 / 21 / 2003$ & 33.928 & -118.483 & SPME-C & 385.46 \\
\hline CA03-4027 & 43 & $8 / 19 / 2003$ & 33.621 & -118.195 & SPME-C & 385.46 \\
\hline CA03-4028 & 101 & $8 / 15 / 2003$ & 34.116 & -119.936 & Channel Islands NMS & 2160.8 \\
\hline CA03-4030 & 75 & $7 / 21 / 2003$ & 34.034 & -119.351 & Channel Islands NMS & 2160.8 \\
\hline CA03-4031 & 42 & $7 / 24 / 2003$ & 33.512 & -117.771 & Small POTW Outfalls & 25.81 \\
\hline CA03-4036 & 71 & $8 / 18 / 2003$ & 34.284 & -119.507 & SPME-N & 949.7 \\
\hline CA03-4037 & 48 & $7 / 23 / 2003$ & 32.796 & -117.305 & SPME-S & 488.75 \\
\hline $\mathrm{CA03-4038}$ & 59 & $7 / 23 / 2003$ & 33.998 & -118.709 & SPME-C & 385.46 \\
\hline CA03-4039 & 131 & $8 / 20 / 2003$ & 33.767 & -118.460 & Large POTW Outfalls & 163.22 \\
\hline CA03-4041 & 56 & $8 / 6 / 2003$ & 33.153 & -117.387 & Small POTW Outfalls & 25.81 \\
\hline CA03-4042 & 70 & $7 / 29 / 2003$ & 33.568 & -117.990 & Large POTW Outfalls & 163.22 \\
\hline CA03-4043 & 28 & $8 / 19 / 2003$ & 33.695 & -118.296 & Large POTW Outfalls & 163.22 \\
\hline CA03-4046 & 57 & $7 / 22 / 2003$ & 33.935 & -118.539 & Large POTW Outfalls & 163.22 \\
\hline CA03-4049 & 72 & $8 / 5 / 2003$ & 33.088 & -117.351 & SPME-S & 488.75 \\
\hline CA03-4052 & 92 & $7 / 21 / 2003$ & 34.076 & -119.748 & Channel Islands NMS & 2160.8 \\
\hline CA03-4071 & 72 & $8 / 20 / 2003$ & 33.759 & -118.446 & Large POTW Outfalls & 163.22 \\
\hline CA03-4074 & 38 & $7 / 29 / 2003$ & 33.598 & -118.046 & Large POTW Outfalls & 163.22 \\
\hline CA03-4078 & 57 & $7 / 22 / 2003$ & 33.922 & 519 & Large POTW Outfalls & 163.22 \\
\hline CA03-4080 & 36.5 & $7 / 25 / 2003$ & 34.384 & -119.596 & SPME-N & 949.7 \\
\hline CA03-4081 & 63 & $8 / 7 / 2003$ & 33.266 & -117.534 & SPME-S & 488.75 \\
\hline CA03-4087 & 93 & $7 / 21 / 2003$ & 33.835 & -118.470 & SPME-C & 385.46 \\
\hline CA03-4090 & 80 & $7 / 21 / 2003$ & 33.848 & -118.568 & SPME-C & 385.46 \\
\hline CA03-4096 & 79 & $8 / 7 / 2003$ & 33.270 & -117.565 & SPME-S & 488.75 \\
\hline CA03-4099 & 72 & $8 / 18 / 2003$ & 34.307 & -119.558 & SPME-N & 949.7 \\
\hline CA03-4101 & 38 & $7 / 23 / 2003$ & 33.998 & -118.559 & SPME-C & 385.46 \\
\hline CA03-4102 & 42 & $8 / 20 / 2003$ & 33.721 & -118.365 & Large POTW Outfalls & 163.22 \\
\hline CA03-4109 & 42 & $7 / 22 / 2003$ & 33.959 & -118.520 & Large POTW Outfalls & 163.22 \\
\hline CA03-4113 & 41 & $7 / 29 / 2003$ & 33.590 & -117.971 & SPME-S & 488.75 \\
\hline CA03-4115 & 92 & $7 / 21 / 2003$ & 34.078 & -119.701 & Channel Islands NMS & 2160.8 \\
\hline CA03-4120 & 86 & $7 / 22 / 2003$ & 32.658 & -117.309 & Large POTW Outfalls & 163.22 \\
\hline CA03-4122 & 48 & $8 / 19 / 2003$ & 33.604 & -118.140 & SPME-C & 385.46 \\
\hline CA03-4123 & 56.5 & $7 / 30 / 2003$ & 34.454 & -120.198 & SPME-N & 949.7 \\
\hline CA03-4126 & 50 & $9 / 3 / 2003$ & 33.354 & -117.619 & SPME-S & 488.75 \\
\hline CA03-4134 & 78 & $8 / 21 / 2003$ & 33.820 & -118.427 & SPME-C & 385.46 \\
\hline
\end{tabular}




\begin{tabular}{|c|c|c|c|c|c|c|}
\hline $\begin{array}{c}\text { EMAP } \\
\text { Station ID }\end{array}$ & $\begin{array}{l}\text { Sample } \\
\text { Depth }\end{array}$ & Date & Latitude & Longitude & $\begin{array}{l}\text { Multi-density } \\
\text { Category }\end{array}$ & $\begin{array}{c}\text { Frame } \\
\mathrm{km}^{2}\end{array}$ \\
\hline CA03-4137 & 57 & $7 / 29 / 2003$ & 33.577 & -118.012 & Large POTW Outfalls & 163.22 \\
\hline CA03-4150 & 60 & $7 / 21 / 2003$ & 33.877 & -118.470 & SPME-C & 385.46 \\
\hline CA03-4152 & 98 & $8 / 5 / 2003$ & 33.115 & -117.357 & Small POTW Outfalls & 25.81 \\
\hline CA03-4154 & 34 & $7 / 23 / 2003$ & 33.625 & -118.075 & SPME-C & 385.46 \\
\hline CA03-4155 & 101 & $8 / 15 / 2003$ & 34.102 & -120.142 & Channel Islands NMS & 2160.8 \\
\hline CA03-4159 & 71 & $8 / 21 / 2003$ & 33.994 & -120.337 & Channel Islands NMS & 2160.8 \\
\hline CA03-4163 & 134 & $7 / 21 / 2003$ & 34.078 & -119.510 & Channel Islands NMS & 2160.8 \\
\hline CA03-4164 & 100 & $7 / 25 / 2003$ & 32.730 & -117.345 & SPME-S & 488.75 \\
\hline CA03-4165 & 34 & $7 / 23 / 2003$ & 34.014 & -118.592 & SPME-C & 385.46 \\
\hline CA03-4166 & 67 & $8 / 20 / 20,03$ & 33.708 & -118.357 & Large POTW Outfalls & 163.22 \\
\hline CA03-4171 & 78 & $7 / 22 / 2003$ & 33.856 & -120.002 & Channel Islands NMS & 2160.8 \\
\hline CA03-4172 & 45 & $7 / 21 / 2003$ & 32.595 & -117.245 & SPME-S & 488.75 \\
\hline CA03-4173 & 121 & $7 / 22 / 2003$ & 33.908 & -118.567 & SPME-C & 385.46 \\
\hline CA03-4183 & 35.1 & $7 / 29 / 2003$ & 34.400 & -119.830 & Small POTW Outfalls & 25.81 \\
\hline CA03-4184 & 92 & $7 / 25 / 2003$ & 32.688 & -117.324 & Large POTW Outfalls & 163.22 \\
\hline CA03-4185 & 48 & $7 / 31 / 2003$ & 33.992 & -118.798 & SPME-C & 385.46 \\
\hline CA03-4186 & 111 & $8 / 19 / 2003$ & 33.567 & -118.191 & SPME-C & 385.46 \\
\hline CA03-4197 & 65 & $8 / 21 / 2003$ & 33.790 & -118.456 & SPME-C & 385.46 \\
\hline CA03-4199 & 56 & $8 / 6 / 2003$ & 33.159 & -117.398 & Small POTW Outfalls & 25.81 \\
\hline CA03-4204 & 65 & $7 / 22 / 2003$ & 33.928 & -118.543 & Large POTW Outfalls & 163.22 \\
\hline CA03-4215 & 50 & $8 / 19 / 2003$ & 33.607 & -118.125 & SPME-C & 385.46 \\
\hline CA03-4219 & 41.5 & $9 / 3 / 2003$ & 33.428 & -117.690 & Small POTW Outfalls & 25.81 \\
\hline CA03-4226 & 56 & $7 / 21 / 2003$ & 33.898 & -118.501 & Large POTW Outfalls & 163.22 \\
\hline CA03-4227 & 74 & $8 / 5 / 2003$ & 33.107 & -117.357 & Small POTW Outfalls & 25.81 \\
\hline CA03-4229 & 34 & $8 / 18 / 2003$ & 33.672 & -118.265 & SPME-C & 385.46 \\
\hline CA03-4230 & 56 & $7 / 22 / 2003$ & 33.887 & -120.010 & Channel Islands NMS & 2160.8 \\
\hline CA03-4236 & 32 & $7 / 29 / 2003$ & 33.603 & -118.036 & Large POTW Outfalls & 163.22 \\
\hline CA03-4238 & 82 & $7 / 22 / 2003$ & 33.966 & -119.605 & Channel Islands NMS & 2160.8 \\
\hline CA03-4239 & 57 & $7 / 22 / 2003$ & 32.682 & -117.282 & Large POTW Outfalls & 163.22 \\
\hline CA03-4243 & 58 & $7 / 22 / 2003$ & 32.679 & -117.282 & Large POTW Outfalls & 163.22 \\
\hline CA03-4245 & 84 & $8 / 19 / 2003$ & 33.577 & -118.210 & SPME-C & 385.46 \\
\hline CA03-4251 & 40 & $7 / 21 / 2003$ & 32.590 & -117.228 & SPME-S & 488.75 \\
\hline CA03-4255 & 125 & $7 / 22 / 2003$ & 32.659 & -117.336 & SPME-S & 488.75 \\
\hline CA03-4260 & 40 & $7 / 29 / 2003$ & 33.592 & -118.027 & Large POTW Outfalls & 163.22 \\
\hline CA03-4270 & 52 & $7 / 21 / 2003$ & 33.910 & -118.499 & Large POTW Outfalls & 163.22 \\
\hline CA03-4271 & 64 & $7 / 22 / 2003$ & 33.878 & -118.545 & Large POTW Outfalls & 163.22 \\
\hline CA03-4273 & 40 & $8 / 5 / 2003$ & 33.115 & -117.348 & Small POTW Outfalls & 25.81 \\
\hline CA03-4274 & 33 & $8 / 20 / 2003$ & 33.636 & -118.198 & SPME-C & 385.46 \\
\hline CA03-4278 & 41 & $7 / 24 / 2003$ & 33.503 & -117.765 & Small POTW Outfalls & 25.81 \\
\hline CA03-4288 & 48 & $8 / 6 / 2003$ & 33.152 & -117.383 & Small POTW Outfalls & 25.81 \\
\hline CA03-4291 & 82 & $7 / 22 / 2003$ & 33.874 & -119.948 & Channel Islands NMS & 2160.8 \\
\hline CA03-4293 & 62 & $7 / 22 / 2003$ & 33.897 & -118.540 & Large POTW Outfalls & 163.22 \\
\hline CA03-4302 & 119 & $7 / 25 / 2003$ & 32.691 & -117.336 & Large POTW Outfalls & 163.22 \\
\hline CA03-4303 & 46 & $8 / 20 / 2003$ & 33.606 & -118.190 & SPME-C & 385.46 \\
\hline CA03-4313 & 41 & $8 / 20 / 2003$ & 33.743 & -118.424 & Large POTW Outfalls & 163.22 \\
\hline CA03-4315 & 28 & $8 / 6 / 2003$ & 33.162 & -117.386 & Small POTW Outfalls & 25.81 \\
\hline CA03-4317 & 63 & $8 / 18 / 2003$ & 33.617 & -118.260 & SPME-C & 385.46 \\
\hline
\end{tabular}




\begin{tabular}{|c|c|c|c|c|c|c|}
\hline $\begin{array}{c}\text { EMAP } \\
\text { Station ID }\end{array}$ & $\begin{array}{l}\text { Sample } \\
\text { Depth }\end{array}$ & Date & Latitude & Longitude & $\begin{array}{c}\text { Multi-density } \\
\text { Category }\end{array}$ & $\begin{array}{c}\text { Frame } \\
\mathrm{km}^{2}\end{array}$ \\
\hline CA03-4324 & 64 & $7 / 22 / 2003$ & 33.953 & -119.687 & Channel Islands NMS & 2160.8 \\
\hline CA03-4329 & 64 & $8 / 19 / 2003$ & 33.602 & -118.117 & SPME-C & 385.46 \\
\hline CA03-4330 & 110 & $8 / 15 / 2003$ & 34.113 & -120.025 & Channel Islands NMS & 2160.8 \\
\hline CA03-4333 & 37.6 & $9 / 3 / 2003$ & 33.428 & -117.686 & Small POTW Outfalls & 25.81 \\
\hline CA03-4334 & 51 & $8 / 21 / 2003$ & 34.071 & -120.328 & Channel Islands NMS & 2160.8 \\
\hline CA03-4339 & 51 & $7 / 22 / 2003$ & 33.881 & -118.535 & Large POTW Outfalls & 163.22 \\
\hline $\mathrm{CA03-4343}$ & 51 & $8 / 20 / 2003$ & 33.637 & -118.248 & SPME-C & 385.46 \\
\hline CA03-4346 & 48 & $7 / 23 / 2003$ & 33.960 & -118.529 & Large POTW Outfalls & 163.22 \\
\hline CA03-4350 & 56 & $7 / 29 / 2003$ & 33.575 & -117.985 & Large POTW Outfalls & 163.22 \\
\hline CA03-4352 & 78 & $7 / 21 / 2003$ & 34.054 & -119.528 & Channel Islands NMS & 2160.8 \\
\hline CA03-4357 & 92 & $7 / 22 / 2003$ & 32.680 & -117.324 & Large POTW Outfalls & 163.22 \\
\hline CA03-4365 & 41.5 & $8 / 4 / 2003$ & 32.999 & -117.301 & Small POTW Outfalls & 25.81 \\
\hline CA03-4377 & 46 & $7 / 22 / 2003$ & 33.890 & -120.082 & Channel Islands NMS & 2160.8 \\
\hline CA03-4380 & 95 & $8 / 21 / 2003$ & 33.988 & -120.380 & Channel Islands NMS & 2160.8 \\
\hline CA03-4389 & 100 & $8 / 19 / 2003$ & 33.450 & -119.053 & Channel Islands NMS & 2160.8 \\
\hline CA03-4390 & 52 & $8 / 21 / 2003$ & 33.950 & -120.237 & Channel Islands NMS & 2160.8 \\
\hline $\mathrm{CA03-4396}$ & 99 & $8 / 18 / 2003$ & 34.097 & -120.123 & Channel Islands NMS & 2160.8 \\
\hline CA03-4411 & 84 & $8 / 22 / 2003$ & 34.046 & -119.439 & Channel Islands NMS & 2160.8 \\
\hline CA03-4417 & 119 & $8 / 19 / 2003$ & 33.827 & -120.076 & Channel Islands NMS & 2160.8 \\
\hline CA03-4425 & 100 & $8 / 22 / 2003$ & 34.108 & -120.205 & Channel Islands NMS & 2160.8 \\
\hline $\mathrm{CA03-4427}$ & 85 & $8 / 23 / 2003$ & 34.047 & -119.655 & Channel Islands NMS & 2160.8 \\
\hline CA03-4430 & 83 & $8 / 28 / 2003$ & 34.057 & -119.475 & Channel Islands NMS & 2160.8 \\
\hline CA03-4435 & 63 & $8 / 27 / 2003$ & 33.976 & -119.881 & Channel Islands NMS & 2160.8 \\
\hline CA03-4444 & 100 & $8 / 28 / 2003$ & 33.963 & -119.586 & Channel Islands NMS & 2160.8 \\
\hline OR03-0001 & 50 & $6 / 13 / 2003$ & 42.503 & -124.539 & OR-ALL & 7994.69 \\
\hline OR03-0002 & 108 & $6 / 6 / 2003$ & 45.959 & -124.244 & OR-ALL & 7994.69 \\
\hline OR03-0003 & 102 & $6 / 11 / 2003$ & 44.193 & -124.485 & OR-ALL & 7994.69 \\
\hline OR03-0004 & 101 & $6 / 10 / 2003$ & 44.819 & -124.237 & OR-ALL & 7994.69 \\
\hline OR03-0005 & 47 & $6 / 14 / 2003$ & 42.010 & -124.354 & OR-ALL & 7994.69 \\
\hline OR03-0006 & 54 & $6 / 12 / 2003$ & 44.014 & -124.212 & OR-ALL & 7994.69 \\
\hline OR03-0007 & 119 & $6 / 11 / 2003$ & 43.787 & -124.437 & OR-ALL & 7994.69 \\
\hline OR03-0008 & 82 & $6 / 6 / 2003$ & 45.658 & -124.112 & OR-ALL & 7994.69 \\
\hline OR03-0009 & 70 & $6 / 10 / 2003$ & 44.590 & -124.253 & OR-ALL & 7994.69 \\
\hline OR03-0010 & 91 & $6 / 11 / 2003$ & 44.034 & -124.812 & OR-ALL & 7994.69 \\
\hline OR03-0011 & 64 & $6 / 13 / 2003$ & 42.119 & -124.400 & OR-ALL & 7994.69 \\
\hline OR03-0012 & 100 & $6 / 12 / 2003$ & 43.525 & -124.364 & OR-ALL & 7994.69 \\
\hline OR03-0013 & 84 & $6 / 6 / 2003$ & 46.123 & -124.214 & OR-ALL & 7994.69 \\
\hline OR03-0014 & 64 & $6 / 10 / 2003$ & 44.460 & -124.351 & OR-ALL & 7994.69 \\
\hline OR03-0015 & 77 & $6 / 9 / 2003$ & 45.044 & -124.104 & OR-ALL & 7994.69 \\
\hline OR03-0016 & 112 & $6 / 8 / 2003$ & 45.421 & -124.154 & OR-ALL & 7994.69 \\
\hline OR03-0017 & 80 & $6 / 9 / 2003$ & 45.270 & -124.088 & OR-ALL & 7994.69 \\
\hline OR03-0018 & 123 & $6 / 10 / 2003$ & 44.639 & -124.513 & OR-ALL & 7994.69 \\
\hline OR03-0019 & 93 & $6 / 10 / 2003$ & 44.294 & -124.517 & OR-ALL & 7994.69 \\
\hline OR03-0020 & 76 & $6 / 13 / 2003$ & 42.302 & -124.477 & OR-ALL & 7994.69 \\
\hline OR03-0021 & 120 & $6 / 6 / 2003$ & 46.003 & -124.304 & OR-ALL & 7994.69 \\
\hline OR03-0022 & 76 & $6 / 12 / 2003$ & 43.164 & -124.540 & OR-ALL & 7994.69 \\
\hline OR03-0023 & 92 & $6 / 13 / 2003$ & 42.496 & -124.620 & OR-ALL & 7994.69 \\
\hline
\end{tabular}




\begin{tabular}{|c|c|c|c|c|c|c|}
\hline $\begin{array}{c}\text { EMAP } \\
\text { Station ID }\end{array}$ & $\begin{array}{l}\text { Sample } \\
\text { Depth }\end{array}$ & Date & Latitude & Longitude & $\begin{array}{l}\text { Multi-density } \\
\text { Category }\end{array}$ & $\begin{array}{l}\text { Frame } \\
\mathrm{km}^{2}\end{array}$ \\
\hline OR03-0024 & 110 & $6 / 6 / 2003$ & 46.118 & -124.351 & OR-ALL & 7994.69 \\
\hline OR03-0025 & 57 & $6 / 10 / 2003$ & 44.471 & -124.212 & OR-ALL & 7994.69 \\
\hline OR03-0026 & 93 & $6 / 9 / 2003$ & 44.922 & -124.165 & OR-ALL & 7994.69 \\
\hline OR03-0027 & 102 & $6 / 12 / 2003$ & 43.935 & -124.310 & OR-ALL & 7994.69 \\
\hline OR03-0028 & 79 & $6 / 12 / 2003$ & 43.754 & -124.252 & OR-ALL & 7994.69 \\
\hline OR03-0029 & 52 & $6 / 6 / 2003$ & 45.622 & -124.011 & OR-ALL & 7994.69 \\
\hline OR03-0030 & 64 & $6 / 10 / 2003$ & 44.686 & -124.185 & OR-ALL & 7994.69 \\
\hline OR03-0031 & 74.7 & $6 / 11 / 2003$ & 44.296 & -124.307 & OR-ALL & 7994.69 \\
\hline OR03-0032 & 54 & $6 / 13 / 2003$ & 42.078 & -124.376 & OR-ALL & 7994.69 \\
\hline OR03-0033 & 107 & $6 / 12 / 2003$ & 43.598 & -124.381 & OR-ALL & 7994.69 \\
\hline OR03-0034 & 116 & $6 / 6 / 2003$ & 46.190 & -124.389 & OR-ALL & 7994.69 \\
\hline OR03-0035 & 118 & $6 / 10 / 2003$ & 44.402 & -124.449 & OR-ALL & 7994.69 \\
\hline OR03-0036 & 115 & $6 / 11 / 2003$ & 44.189 & -124.676 & OR-ALL & 7994.69 \\
\hline OR03-0037 & 106 & $6 / 6 / 2003$ & 45.591 & -124.161 & OR-ALL & 7994.69 \\
\hline OR03-0038 & 76 & $6 / 9 / 2003$ & 45.138 & -124.090 & OR-ALL & 7994.69 \\
\hline OR03-0039 & 73 & $6 / 11 / 2003$ & 44.080 & -124.257 & OR-ALL & 7994.69 \\
\hline OR03-0040 & 112 & $6 / 11 / 2003$ & 44.095 & -124.426 & OR-ALL & 7994.69 \\
\hline OR03-0041 & 92 & $6 / 13 / 2003$ & 42.622 & -124.567 & OR-ALL & 7994.69 \\
\hline OR03-0042 & 88 & $6 / 6 / 2003$ & 46.030 & -124.192 & OR-ALL & 7994.69 \\
\hline OR03-0043 & 106 & $6 / 12 / 2003$ & 43.436 & -124.466 & OR-ALL & 7994.69 \\
\hline OR03-0044 & 100 & $6 / 13 / 2003$ & 42.489 & -124.652 & OR-ALL & 7994.69 \\
\hline OR03-0045 & 81 & $6 / 6 / 2003$ & 46.164 & -124.228 & OR-ALL & 7994.69 \\
\hline OR03-0046 & 57 & $6 / 11 / 2003$ & 44.224 & -124.215 & OR-ALL & 7994.69 \\
\hline OR03-0047 & 64 & $6 / 10 / 2003$ & 44.782 & -124.191 & OR-ALL & 7994.69 \\
\hline OR03-0048 & 95 & $6 / 12 / 2003$ & 43.885 & -124.279 & OR-ALL & 7994.69 \\
\hline OR03-0049 & 69 & $6 / 12 / 2003$ & 43.624 & -124.266 & OR-ALL & 7994.69 \\
\hline OR03-0050 & 54 & $6 / 6 / 2003$ & 45.655 & -124.024 & OR-ALL & 7994.69 \\
\hline WA03-0001 & 28 & $6 / 2 / 2003$ & 47.823 & -124.645 & Olympic Coast & 3097.99 \\
\hline WA03-0002 & 75 & $6 / 4 / 2003$ & 46.977 & -124.509 & WA-Other & 2551.6 \\
\hline WA03-0003 & 60 & $6 / 3 / 2003$ & 47.554 & -124.642 & Olympic Coast & 3097.99 \\
\hline WA03-0004 & 88 & 6/5/2003 & 46.665 & -124.428 & WA-Other & 2551.6 \\
\hline WA03-0005 & 46 & $6 / 3 / 2003$ & 47.313 & -124.494 & Olympic Coast & 3097.99 \\
\hline WA03-0006 & 60 & $6 / 2 / 2003$ & 48.039 & -124.883 & Olympic Coast & 3097.99 \\
\hline WA03-0007 & 54 & $6 / 4 / 2003$ & 47.128 & -124.441 & WA-Other & 2551.6 \\
\hline WA03-0008 & 116 & $6 / 3 / 2003$ & 47.325 & -124.717 & Olympic Coast & 3097.99 \\
\hline WA03-0009 & 104 & $6 / 4 / 2003$ & 47.086 & -124.702 & WA-Other & 2551.6 \\
\hline WA03-0010 & 61 & $6 / 5 / 2003$ & 46.285 & -124.244 & WA-Other & 2551.6 \\
\hline WA03-0011 & 30.6 & $6 / 2 / 2003$ & 48.073 & -124.797 & Olympic Coast & 3097.99 \\
\hline WA03-0012 & 91 & $6 / 2 / 2003$ & 47.909 & -124.908 & Olympic Coast & 3097.99 \\
\hline WA03-0013 & 55 & $6 / 3 / 2003$ & 47.246 & -124.505 & Olympic Coast & 3097.99 \\
\hline WA03-0014 & 32 & $6 / 2 / 2003$ & 48.297 & -124.766 & Olympic Coast & 3097.99 \\
\hline WA03-0015 & 64 & $6 / 5 / 2003$ & 46.426 & -124.293 & WA-Other & 2551.6 \\
\hline WA03-0017 & 30 & $6 / 3 / 2003$ & 47.623 & -124.543 & Olympic Coast & 3097.99 \\
\hline WA03-0018 & 57 & $6 / 5 / 2003$ & 46.549 & -124.267 & WA-Other & 2551.6 \\
\hline WA03-0019 & 52 & $6 / 3 / 2003$ & 47.354 & -124.533 & Olympic Coast & 3097.99 \\
\hline WA03-0020 & 60 & $6 / 4 / 2003$ & 46.782 & -124.344 & WA-Other & 2551.6 \\
\hline WA03-0021 & 91 & $6 / 3 / 2003$ & 47.737 & -124.828 & Olympic Coast & 3097.99 \\
\hline
\end{tabular}




\begin{tabular}{|c|c|c|c|c|c|c|}
\hline $\begin{array}{c}\text { EMAP } \\
\text { Station ID }\end{array}$ & $\begin{array}{c}\text { Sample } \\
\text { Depth }\end{array}$ & Date & Latitude & Longitude & $\begin{array}{c}\text { Multi-density } \\
\text { Category }\end{array}$ & $\begin{array}{c}\text { Frame } \\
\mathrm{km}^{2}\end{array}$ \\
\hline WA03-0022 & 65 & $6 / 2 / 2003$ & 47.780 & -124.753 & Olympic Coast & 3097.99 \\
\hline WA03-0023 & 100 & $6 / 5 / 2003$ & 46.814 & -124.551 & WA-Other & 2551.6 \\
\hline WA03-0024 & 31 & $6 / 2 / 2003$ & 48.253 & -124.815 & Olympic Coast & 3097.99 \\
\hline WA03-0025 & 39 & $6 / 4 / 2003$ & 46.844 & -124.242 & WA-Other & 2551.6 \\
\hline WA03-0026 & 110 & $6 / 3 / 2003$ & 47.458 & -124.754 & Olympic Coast & 3097.99 \\
\hline WA03-0027 & 54 & $6 / 2 / 2003$ & 47.717 & -124.685 & Olympic Coast & 3097.99 \\
\hline WA03-0029 & 44 & $6 / 3 / 2003$ & 47.457 & -124.558 & Olympic Coast & 3097.99 \\
\hline WA03-0030 & 107 & $6 / 4 / 2003$ & 46.948 & -124.641 & WA-Other & 2551.6 \\
\hline WA03-0031 & 54 & $6 / 5 / 2003$ & 46.528 & -124.263 & WA-Other & 2551.6 \\
\hline WA03-0032 & 118 & $6 / 3 / 2003$ & 47.665 & -124.907 & Olympic Coast & 3097.99 \\
\hline WA03-0033 & 106 & $6 / 2 / 2003$ & 47.899 & -124.965 & Olympic Coast & 3097.99 \\
\hline WA03-0034 & 89 & $6 / 4 / 2003$ & 47.127 & -124.645 & WA-Other & 2551.6 \\
\hline WA03-0035 & 103 & $6 / 4 / 2003$ & 47.161 & -124.693 & Olympic Coast & 3097.99 \\
\hline WA03-0037 & 98 & $6 / 5 / 2003$ & 46.418 & -124.409 & WA-Other & 2551.6 \\
\hline WA03-0038 & 47.3 & $6 / 2 / 2003$ & 48.030 & -124.843 & Olympic Coast & 3097.99 \\
\hline WA03-0039 & 82 & $6 / 3 / 2003$ & 47.623 & -124.754 & Olympic Coast & 3097.99 \\
\hline WA03-0041 & 81 & $6 / 3 / 2003$ & 47.331 & -124.617 & Olympic Coast & 3097.99 \\
\hline WA03-0042 & 48 & $6 / 4 / 2003$ & 46.934 & -124.359 & WA-Other & 2551.6 \\
\hline WA03-0043 & 102 & $6 / 2 / 2003$ & 47.795 & -124.896 & Olympic Coast & 3097.99 \\
\hline WA03-0044 & 67 & $6 / 2 / 2003$ & 47.827 & -124.788 & Olympic Coast & 3097.99 \\
\hline WA03-0046 & 53 & $6 / 2 / 2003$ & 48.177 & -124.878 & Olympic Coast & 3097.99 \\
\hline WA03-0047 & 61 & $6 / 4 / 2003$ & 46.769 & -124.345 & WA-Other & 2551.6 \\
\hline WA03-0048 & 113 & $6 / 3 / 2003$ & 47.504 & -124.795 & Olympic Coast & 3097.99 \\
\hline WA03-0051 & 94 & $6 / 2 / 2003$ & 47.773 & -124.841 & Olympic Coast & 3097.99 \\
\hline WA03-0053 & 45 & $6 / 3 / 2003$ & 47.565 & -124.598 & Olympic Coast & 3097.99 \\
\hline WA03-0060 & 29 & $6 / 5 / 2003$ & 46.447 & -124.177 & WA-Other & 2551.6 \\
\hline WA03-0068 & 28 & $6 / 4 / 2003$ & 47.152 & -124.289 & Olympic Coast & 3097.99 \\
\hline WA03-0070 & 50 & $6 / 4 / 2003$ & 46.989 & -124.488 & WA-Other & 2551.6 \\
\hline WA03-0081 & 108 & $6 / 5 / 2003$ & 46.339 & -124.395 & WA-Other & 2551.6 \\
\hline WA03-0086 & 71 & $6 / 5 / 2003$ & 46.532 & -124.331 & WA-Other & 2551.6 \\
\hline
\end{tabular}


Appendix Table 2. Sampling coordinates for the 2003 FRAM Groundfish Survey stations from which fish were analyzed for tissue contaminants by EPA.

\begin{tabular}{|c|c|c|c|c|c|c|}
\hline $\begin{array}{c}\text { EMAP } \\
\text { Station ID }\end{array}$ & State & $\begin{array}{l}\text { Sample } \\
\text { Depth }\end{array}$ & Date & Latitude & Longitude & $\begin{array}{l}\text { National Marine } \\
\text { Sanctuary }\end{array}$ \\
\hline CEW03419-001 & $\mathrm{CA}$ & 96 & $10 / 7 / 2003$ & 39.248020 & -123.835800 & no \\
\hline CEW03419-003 & CA & 36 & $7 / 31 / 2003$ & 36.808020 & -121.820760 & Monterey Bay \\
\hline CEW03419-004 & $\mathrm{CA}$ & 59 & $7 / 29 / 2003$ & 37.795140 & -122.882400 & Gulf of the Farallones \\
\hline CEW03419-006 & CA & 62 & $7 / 19 / 2003$ & 41.604140 & -124.294740 & no \\
\hline CEW03419-008 & CA & 102 & $7 / 27 / 2003$ & 39.548520 & -123.856450 & no \\
\hline CEW03419-016 & $\mathrm{CA}$ & 91 & $10 / 9 / 2003$ & 37.211350 & -122.560360 & Monterey Bay \\
\hline CEW03419-017 & CA & 116 & $10 / 8 / 2003$ & 38.767360 & -123.705910 & no \\
\hline CEW03419-018 & $\mathrm{CA}$ & 93 & $8 / 2 / 2003$ & 35.507480 & -121.133150 & no \\
\hline CEW03419-019 & CA & 83 & $7 / 19 / 2003$ & 41.470380 & -124.316410 & no \\
\hline CEW03419-022 & CA & 97 & $10 / 16 / 2003$ & 34.668990 & -120.791560 & no \\
\hline CEW03419-023 & CA & 68 & $8 / 7 / 2003$ & 34.526280 & -120.644900 & no \\
\hline CEW03419-026 & CA & 106 & $7 / 29 / 2003$ & 38.007320 & -123.195850 & Cordell Bank \\
\hline CEW03419-030 & $\mathrm{CA}$ & 61 & $7 / 31 / 2003$ & 37.161140 & -122.437850 & Monterey Bay \\
\hline CEW03419-031 & CA & 51 & $8 / 7 / 2003$ & 34.757170 & -120.692350 & no \\
\hline CEW03419-032 & CA & 94 & $7 / 21 / 2003$ & 41.323850 & -124.295010 & no \\
\hline CEW03419-036 & CA & 84 & $8 / 6 / 2003$ & 34.965570 & -120.773340 & no \\
\hline CEW03419-043 & CA & 73 & $7 / 28 / 2003$ & 39.170940 & -123.791370 & no \\
\hline CEW03419-044 & CA & 47 & $8 / 6 / 2003$ & 34.733340 & -120.681540 & no \\
\hline CEW03419-045 & CA & 80 & $9 / 29 / 2003$ & 41.364890 & -124.265620 & no \\
\hline CEW03419-047 & CA & 56 & $10 / 16 / 2003$ & 35.089980 & -120.752310 & no \\
\hline CEW03419-048 & CA & 72 & $9 / 28 / 2003$ & 41.569970 & -124.313020 & no \\
\hline CEW03419-054 & CA & 117 & $10 / 10 / 2003$ & 37.064480 & -122.512150 & Monterey Bay \\
\hline CEW03419-058 & CA & 100 & $7 / 31 / 2003$ & 37.152230 & -122.563930 & Monterey Bay \\
\hline CEW03419-059 & CA & 83 & $8 / 2 / 2003$ & 35.501100 & -121.111680 & no \\
\hline CEW03419-060 & CA & 64 & $7 / 30 / 2003$ & 37.377030 & -122.551340 & Monterey Bay \\
\hline CEW03419-071 & CA & 69 & $10 / 11 / 2003$ & 35.728440 & -121.376240 & Monterey Bay \\
\hline CEW03419-079 & OR & 110 & $9 / 24 / 2003$ & 42.991690 & -124.628400 & no \\
\hline CEW03419-082 & OR & 82 & $9 / 16 / 2003$ & 44.335710 & -124.390000 & no \\
\hline CEW03419-084 & OR & 103 & $9 / 16 / 2003$ & 44.697040 & -124.420680 & no \\
\hline CEW03419-085 & OR & 70 & $7 / 9 / 2003$ & 44.925250 & -124.126530 & no \\
\hline CEW03419-087 & OR & 95 & $9 / 17 / 2003$ & 44.107350 & -124.360670 & no \\
\hline CEW03419-089 & OR & 97 & $7 / 9 / 2003$ & 44.881670 & -124.185170 & no \\
\hline CEW03419-091 & OR & 99 & $9 / 16 / 2003$ & 43.937380 & -124.288410 & no \\
\hline CEW03419-092 & OR & 60 & $7 / 9 / 2003$ & 44.208650 & -124.210820 & no \\
\hline CEW03419-096 & OR & 64 & $9 / 24 / 2003$ & 42.801400 & -124.644780 & no \\
\hline CEW03419-097 & OR & 115 & $7 / 11 / 2003$ & 43.546480 & -124.408680 & no \\
\hline CEW03419-098 & OR & 92 & $7 / 6 / 2003$ & 45.922470 & -124.159120 & no \\
\hline CEW03419-099 & OR & 81 & $7 / 10 / 2003$ & 44.187780 & -124.303200 & no \\
\hline CEW03419-100 & WA & 115 & $6 / 29 / 2003$ & 48.126430 & -124.957210 & Olympic Coast \\
\hline CEW03419-103 & WA & 65 & $6 / 29 / 2003$ & 47.995030 & -124.879080 & Olympic Coast \\
\hline CEW03419-104 & WA & 99 & $9 / 3 / 2003$ & 47.728780 & -124.853600 & Olympic Coast \\
\hline CEW03419-105 & WA & 65 & $9 / 6 / 2003$ & 48.160750 & -124.895050 & Olympic Coast \\
\hline CEW03419-108 & WA & 115 & $7 / 1 / 2003$ & 47.256030 & -124.712740 & Olympic Coast \\
\hline
\end{tabular}




\begin{tabular}{ccccccl}
\hline $\begin{array}{c}\text { EMAP } \\
\text { Station ID }\end{array}$ & State & $\begin{array}{c}\text { Sample } \\
\text { Depth }\end{array}$ & Date & Latitude & Longitude & Sanctuary \\
\hline CEW03419-109 & WA & 80 & $7 / 1 / 2003$ & 46.394080 & -124.324500 & no \\
CEW03419-110 & WA & 69 & $6 / 30 / 2003$ & 47.719490 & -124.736600 & Olympic Coast \\
CEW03419-112 & WA & 89 & $7 / 1 / 2003$ & 47.225690 & -124.629530 & Olympic Coast \\
CEW03419-113 & WA & 97 & $6 / 29 / 2003$ & 47.906270 & -124.914910 & Olympic Coast \\
CEW03419-114 & WA & 108 & $6 / 30 / 2003$ & 47.775640 & -124.910230 & Olympic Coast \\
CEW03419-115 & WA & 99 & $9 / 7 / 2003$ & 47.751500 & -124.861750 & Olympic Coast \\
CEW03419-116 & WA & 65 & $9 / 6 / 2003$ & 48.016830 & -124.890230 & Olympic Coast \\
CEW03419-118 & WA & 88 & $9 / 8 / 2003$ & 46.583160 & -124.400940 & no \\
CEW03419-119 & WA & 84 & $6 / 29 / 2003$ & 48.186830 & -124.918710 & Olympic Coast \\
CEW03419-120 & WA & 99 & $9 / 6 / 2003$ & 47.997830 & -124.957630 & Olympic Coast \\
CEW03419-121 & WA & 106 & $6 / 25 / 2003$ & 47.602070 & -124.815620 & Olympic Coast \\
CEW03419-122 & WA & 57 & $7 / 1 / 2003$ & 47.023160 & -124.432590 & no \\
CEW03419-125 & WA & 107 & $9 / 7 / 2003$ & 47.653430 & -124.854420 & Olympic Coast \\
CEW03419-126 & WA & 111 & $9 / 6 / 2003$ & 47.862850 & -124.959860 & Olympic Coast \\
CEW03419-127 & WA & 88 & $9 / 6 / 2003$ & 48.145470 & -124.921600 & Olympic Coast \\
CEW03419-904 & OR & 87 & $7 / 9 / 2003$ & 44.642220 & -124.429540 & no \\
CEW03419-931 & OR & 96 & $7 / 10 / 2003$ & 44.350900 & -124.600980 & no \\
\hline
\end{tabular}


Appendix Table 3a. Summary for Washington data of performance with regard to QC criteria for analysis of reference materials, matrix spike recoveries, and relative percent difference or coefficient of variation (RPD, CV) of replicates. SRM = Standard Reference Material, CRM = Certified Reference Material, LCM = Laboratory Control Material, NA = not applicable, none $=$ this $\mathrm{QC}$ material was not analyzed or QC activity not done. Those values in red are averages failing DQO, borderline average values, or a significantly reduced number of analytes were reported.

Washington 2003

\begin{tabular}{|c|c|c|c|}
\hline \multicolumn{2}{|c|}{$\begin{array}{c}\text { Reference Materials } \\
\text { average recovery within: } \\
\pm 30 \% \text { organics and } \\
\pm 20 \% \text { metals } \\
\text { of true value*; } 70 \% \text { of } \\
\text { individuals within } \pm 35 \% \\
\text { of true value** }\end{array}$} & \multirow{2}{*}{$\begin{array}{c}\text { Matrix } \\
\text { spikes } \\
\\
\\
\\
\\
\text { recovery } \\
\text { DQO of } \\
50 \%- \\
120 \% \\
\text { met? }\end{array}$} & \multirow{2}{*}{$\begin{array}{l}\text { RPDs and } \\
\text { CVs } \\
\text { of Matrix } \\
\text { spikes and } \\
\text { Reference } \\
\text { Materials } \\
\\
\text { met DQO of } \\
\text { average } \\
<30 \% ?\end{array}$} \\
\hline DQO met? & $\begin{array}{l}\text { If no, } \\
\text { average \% } \\
\text { different } \\
\text { from true } \\
\text { value } \\
\text { (\# analytes } \\
\text { reported) } \\
\end{array}$ & & \\
\hline $\begin{array}{l}\text { no* no** } \\
\text { NIST } 1941 \\
\end{array}$ & $\begin{array}{c}44 \% * 59 \% * * \\
(22)\end{array}$ & $\begin{array}{l}\text { yes } \\
(22)\end{array}$ & yes \\
\hline NA & NA & NA & NA \\
\hline
\end{tabular}

PAHs (22)

\begin{tabular}{|l|l} 
Sediment & NIST \\
\hline Tissue & \\
\hline
\end{tabular}

\begin{tabular}{r|l|c|c|}
\cline { 2 - 4 } $\begin{array}{r}\text { Metals } \\
\text { (tissues by }\end{array}$ & Sediment (15) & $\begin{array}{c}\text { yes* yes** } \\
\text { NIST 2711 }\end{array}$ & 29.8 \\
\cline { 2 - 4 } GPL lab) & Tissue (13) & $\begin{array}{c}\text { yes } \\
\text { sniked cod }\end{array}$ \\
\cline { 2 - 4 }
\end{tabular}

$29.8 \% * 80 \% *$ 
Appendix Table 3b. Summary for Oregon data of performance with regard to QC criteria for analysis of reference materials, matrix spike recoveries, and relative percent difference or coefficient of variation (RPD, CV) of replicates. SRM = Standard Reference Material, CRM = Certified Reference Material, LCM = Laboratory Control Material, NA = not applicable, none $=$ this $\mathrm{QC}$ material was not analyzed or QC activity not done. Those values in red are averages failing $D Q O$, borderline average values, or a significantly reduced number of analytes were reported.

\section{Oregon 2003}

\begin{tabular}{|c|c|c|c|c|c|}
\hline \multirow[b]{2}{*}{ Analytes (\#) } & \multirow[b]{2}{*}{ Matrix } & \multicolumn{2}{|c|}{$\begin{array}{c} \pm 30 \% \text { organics and } \\
\pm 20 \% \text { metals } \\
\text { of true value* } ; 70 \% \text { of } \\
\text { individuals within } \pm 35 \% \\
\text { of true value** }\end{array}$} & \multirow{2}{*}{$\begin{array}{l}\text { Matrix } \\
\text { spikes } \\
\\
\\
\\
\text { recovery } \\
\text { DQO of } \\
50 \%- \\
120 \% \\
\text { met? }\end{array}$} & \multirow{2}{*}{$\begin{array}{l}\text { of Matrix } \\
\text { spikes and } \\
\text { Reference } \\
\text { Materials } \\
\\
\text { met DQO of } \\
\text { average } \\
<30 \% ?\end{array}$} \\
\hline & & $\begin{array}{l}\text { DQO } \\
\text { met? }\end{array}$ & $\begin{array}{c}\text { If no, } \\
\text { average \% } \\
\text { different from } \\
\text { true value } \\
\text { (\# analytes } \\
\text { reported) }\end{array}$ & & \\
\hline \multirow[t]{2}{*}{ PAHs (22) } & Sediment & $\begin{array}{l}\text { no* no** } \\
\text { NIST } 1944\end{array}$ & $\begin{array}{c}40 \% 42 \% \\
\text { (19) }\end{array}$ & $\begin{array}{l}\text { yes } \\
(22)\end{array}$ & yes \\
\hline & Tissue & NA & NA & NA & NA \\
\hline \multirow{2}{*}{ Metals } & Sediment (15) & $\begin{array}{c}\text { yes } \\
\text { MESS-2 }\end{array}$ & (11) & $\begin{array}{l}\text { yes } \\
\text { (15) }\end{array}$ & yes \\
\hline & Tissue (13) & $\begin{array}{c}\text { yes } \\
\text { NIST } 2976\end{array}$ & $(10)$ & none & yes \\
\hline \multirow{2}{*}{ PCBs (21) } & Sediment & $\begin{array}{l}\text { no* no** } \\
\text { NIST } 1944\end{array}$ & $\begin{array}{c}115 \% 16 \% \\
(19)\end{array}$ & $\begin{array}{l}\text { yes } \\
(18)\end{array}$ & $\begin{array}{c}\text { yes* } \\
* 1944=37 \%\end{array}$ \\
\hline & Tissue & $\begin{array}{c}\text { no* no** } \\
\text { CARP-2 }\end{array}$ & $\begin{array}{c}58 \% 18 \% \\
(17)\end{array}$ & yes & yes \\
\hline \multirow[b]{2}{*}{ Pesticides (20) } & Sediment & $\begin{array}{l}\text { no* no** } \\
\text { NIST } 1944\end{array}$ & $\begin{array}{c}90 \% 47 \% \\
1944 \& \text { MS/MSD } \\
(8,11)\end{array}$ & $\begin{array}{l}\text { yes } \\
(19)\end{array}$ & yes \\
\hline & Tissue & $\begin{array}{c}\text { no* no** } \\
\text { CARP-2 }\end{array}$ & $\begin{array}{c}36 \% \quad 40 \% \\
\text { CARP \& MS/MSD } \\
(6,12)\end{array}$ & yes & yes \\
\hline
\end{tabular}


Appendix Table 3c. Summary for California data of performance with regard to QC criteria for analysis of reference materials, matrix spike recoveries, and relative percent difference or coefficient of variation (RPD, CV) of replicates. SRM = Standard Reference Material, CRM = Certified Reference Material, LCM = Laboratory Control Material, NA = not applicable, none $=$ this $\mathrm{QC}$ material was not analyzed or QC activity not done. Those values in red are averages failing DQO, borderline average values, or a significantly reduced number of analytes were reported.

\section{California 2003}

Analytes (\#)

Matrix

Reference Materials
average recovery within: $\pm 30 \%$ organics and $\pm 20 \%$ metals

of true value*; $70 \%$ of individuals within $\pm 35 \%$ of true value**

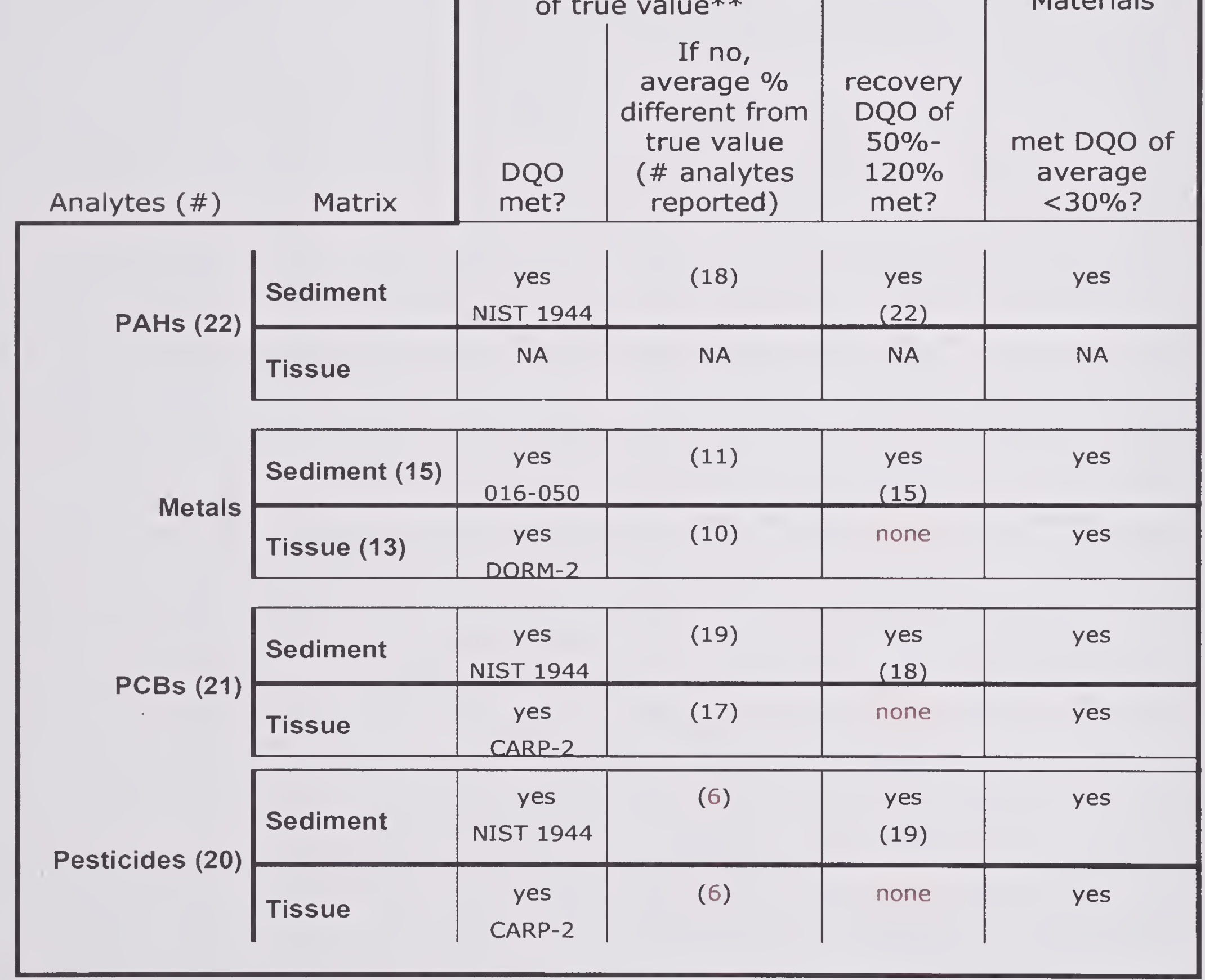


Appendix Table 4. Summary by station of key benthic variables and corresponding sediment and water-quality indicators. Bolded values indicate: Low species richness (lower $10^{\text {th }}$ percentile of values for corresponding state), Low densities (lower $10^{\text {th }}$ percentile of values for corresponding state), Low H' (lower $10^{\text {th }}$ percentile of values for corresponding state), $\geq 5$ chemicals in excess of ERLs, $\geq$ 1 chemical in excess of ERMs, TOC $>5 \%$, DO in near-bottom water $<2.3 \mathrm{mg} / \mathrm{L}$.

\begin{tabular}{|c|c|c|c|c|c|c|c|c|}
\hline Station & $\begin{array}{c}\text { Mean No. } \\
\text { Taxa per } \\
\text { Grab } \\
\left(0.1 \mathrm{~m}^{2}\right)\end{array}$ & $\begin{array}{c}\text { Mean } \\
\text { Density } \\
(\text { all } \\
\left.\text { fauna } / \mathrm{m}^{2}\right)\end{array}$ & $\begin{array}{c}\text { Mean } \mathrm{H}^{\prime} \\
\text { per } \\
\text { Grab } \\
\left(0.1 \mathrm{~m}^{2}\right)\end{array}$ & $\begin{array}{l}\text { No. } \\
\text { Chemicals } \\
>\text { ERL }\end{array}$ & $\begin{array}{l}\text { No. } \\
\text { Chemicals } \\
>\text { ERM }\end{array}$ & $\begin{array}{c}\text { TOC } \\
(\%)\end{array}$ & $\begin{array}{c}\mathrm{DO} \\
(\mathrm{mg} / \mathrm{L})\end{array}$ & $\begin{array}{c}\text { Silt+Clay } \\
(\%)\end{array}$ \\
\hline CA03-0001 & 51 & 1160 & 5.146 & 1 & 0 & 1.501 & 4.27 & 22.819 \\
\hline CA03-0007 & 77 & 6930 & 4.744 & 0 & 0 & 0.75 & 3.62 & 90.1 \\
\hline CA03-0008 & 77 & 10340 & 4.59 & 0 & 0 & 0.61 & 2.84 & 81.58 \\
\hline CA03-0012 & 56 & 3240 & 4.544 & 0 & 0 & 0.24 & 2.95 & 24.95 \\
\hline CA03-0019 & 96 & 4350 & 5.555 & $\dot{0}$ & 0 & 0.64 & 2.45 & 37.78 \\
\hline CA03-0024 & 75 & 4600 & 5.177 & 1 & 0 & 0.45 & 2.31 & 46.48 \\
\hline CA03-0027 & 67 & 4810 & 4.238 & 2 & 0 & 1.58 & & 89.18 \\
\hline CA03-0028 & 72 & 4780 & 4.652 & 1 & 0 & 1.11 & 2.16 & 73.06 \\
\hline CA03-0032 & 78 & 3030 & 5.417 & 0 & 0 & 0.23 & 6.1 & 6.24 \\
\hline CA03-0035 & 116 & 7330 & 5.77 & 0 & 0 & 1.25 & 3.06 & 60.42 \\
\hline CA03-0039 & 58 & 2380 & 4.304 & 1 & 0 & 0.96 & & 70.8 \\
\hline CA03-0040 & 68 & 3790 & 5.074 & 0 & 0 & 0.32 & 2.49 & 7.39 \\
\hline CA03-0043 & 110.5 & 6845 & 5.317 & 1 & 0 & 0.69 & 4.61 & 74.82 \\
\hline CA03-0044 & 90 & 6610 & 5.155 & 0 & 0 & 0.49 & 3.54 & 27.895 \\
\hline CA03-0048 & 118 & 8880 & 5.643 & 0 & 0 & 0.68 & 3.77 & 57.48 \\
\hline CA03-0051 & 77 & 3080 & 5.236 & 1 & 0 & 0.29 & 2.08 & 51.45 \\
\hline CA03-0052 & 77 & 2510 & 5.545 & 0 & 0 & 0.36 & 2.64 & 5.34 \\
\hline CA03-0056 & 97 & 5690 & 5.202 & 0 & 0 & 0.37 & 2.24 & 9.42 \\
\hline CA03-0059 & 48 & 2610 & 3.651 & 2 & 0 & 1.16 & 2.24 & 64.59 \\
\hline CA03-0060 & 113 & 6010 & 5.776 & 0 & 0 & 0.36 & 2.45 & 30.15 \\
\hline CA03-0064 & 82 & 5350 & 5.271 & 1 & 0 & 0.53 & 4.23 & 6.32 \\
\hline CA03-0071 & 62 & 5960 & 3.538 & 1 & 0 & 1.22 & 2.87 & 88.16 \\
\hline CA03-0072 & 100 & 9390 & 4.822 & 1 & 0 & 0.59 & 2.71 & 39.15 \\
\hline CA03-0075 & 40 & 1320 & 4.63 & 0 & 0 & 0.35 & 4.8 & 6.03 \\
\hline CA03-0076 & 25 & 690 & 3.788 & 0 & 0 & 0.26 & 3.4 & 1.24 \\
\hline CA03-0083 & 34 & 1720 & 3.877 & 1 & 0 & 0.23 & 2.81 & 3.07 \\
\hline CA03-0088 & 52 & 1800 & 4.751 & 0 & 0 & 0.26 & 2.79 & 30.27 \\
\hline CA03-0091 & 64 & 3060 & 4.654 & 1 & 0 & 1.08 & & 61.53 \\
\hline CA03-0092 & 113.5 & 8140 & 5.188 & 1 & 0 & 0.82 & 3.03 & 53.145 \\
\hline CA03-0096 & 105 & 4740 & 6.006 & 0 & 0 & 0.5 & 4.51 & 39.46 \\
\hline CA03-0099 & 36 & 1150 & 4.551 & 0 & 0 & 0.32 & 3.11 & 4.26 \\
\hline CA03-0104 & 78 & 6110 & 4.645 & 0 & 0 & 0.28 & 2.38 & 9.75 \\
\hline CA03-0112 & 92 & 4130 & 5.409 & 0 & 0 & 0.46 & 2.68 & 47.39 \\
\hline CA03-0116 & 85 & 7010 & 4.335 & 1 & 0 & 0.66 & 2.34 & 46.12 \\
\hline CA03-0123 & 60 & 4000 & 4.593 & 0 & 0 & 0.52 & 4.41 & 33.52 \\
\hline CA03-0124 & 90 & 4330 & 5.169 & 0 & 0 & 0.43 & 2.61 & 24.44 \\
\hline CA03-0128 & 71 & 3070 & 5.107 & 1 & 0 & 0.46 & 2.86 & 5.42 \\
\hline CA03-0135 & 66 & 4080 & 4.409 & 0 & 0 & 1.02 & 3.68 & 93.98 \\
\hline
\end{tabular}




\begin{tabular}{|c|c|c|c|c|c|c|c|c|}
\hline Station & $\begin{array}{c}\text { Mean No. } \\
\text { Taxa per } \\
\text { Grab } \\
\left(0.1 \mathrm{~m}^{2}\right)\end{array}$ & $\begin{array}{c}\text { Mean } \\
\text { Density } \\
(\text { all } \\
\left.\text { fauna } / \mathrm{m}^{2}\right)\end{array}$ & $\begin{array}{c}\text { Mean } \mathrm{H}^{\prime} \\
\text { per } \\
\text { Grab } \\
\left(0.1 \mathrm{~m}^{2}\right) \\
\end{array}$ & $\begin{array}{l}\text { No. } \\
\text { Chemicals } \\
>\text { ERL }\end{array}$ & $\begin{array}{c}\text { No. } \\
\text { Chemicals } \\
>\text { ERM }\end{array}$ & $\begin{array}{c}\text { TOC } \\
(\%)\end{array}$ & $\begin{array}{c}\mathrm{DO} \\
(\mathrm{mg} / \mathrm{L})\end{array}$ & $\begin{array}{c}\text { Silt+Clay } \\
(\%)\end{array}$ \\
\hline CA03-0136 & 119 & 9560 & 5.347 & 2 & 0 & 0.61 & & 22.82 \\
\hline CA03-0139 & 92 & 8160 & 5.045 & 1 & 0 & 0.66 & 3.62 & 56.73 \\
\hline CA03-0140 & 78 & 3920 & 5.43 & 0 & 0 & 0.41 & 2.46 & 17.16 \\
\hline CA03-0147 & 90 & 2580 & 5.809 & 1 & 0 & 1.24 & & 98.71 \\
\hline CA03-0157 & 76 & 5420 & 4.731 & 0 & 0 & 1.14 & 2.77 & 87.13 \\
\hline CA03-0158 & 103 & 7250 & 5.315 & 0 & 0 & 0.48 & 3.12 & 35.38 \\
\hline CA03-0194 & 32 & 1130 & 4.468 & 0 & 0 & 0.19 & 2.55 & 2.29 \\
\hline CA03-0210 & 106 & 11230 & 4.233 & 0 & 0 & 0.75 & 2.45 & 43.94 \\
\hline CA03-0289 & 63 & 2300 & 5.047 & 1 & 0 & 1.11 & 3.62 & 98.16 \\
\hline CA03-4001 & 79 & 2500 & 5.341 & 0 & 0 & 0.107 & & 22.4505 \\
\hline CA03-4007 & 99 & 3640 & 5.711 & 3 & 2 & 0.55 & 6.3 & 35.45 \\
\hline CA03-4013 & 73 & 5010 & 3.378 & 0 & 0 & 0.735 & & 60.046 \\
\hline CA03-4016 & 88 & 2470 & 5.895 & 2 & 0 & 0.512 & & 48.08 \\
\hline CA03-4020 & 49 & 1890 & 4.646 & 3 & 0 & 1.366 & & 80.31 \\
\hline CA03-4022 & 114 & 4170 & 5.989 & 3 & 1 & 0.477 & 6.44 & 40.92 \\
\hline CA03-4027 & 68 & 1960 & 5.398 & 2 & 0 & 0.234 & 6.31 & 13.7 \\
\hline CA03-4028 & 147 & 5160 & 6.187 & 2 & 0 & 0.814 & & 41.606 \\
\hline CA03-4030 & 148 & 11520 & 5.929 & 0 & 0 & 7.645 & & \\
\hline CA03-4031 & 106 & 4870 & 5.469 & 2 & 0 & 0.676 & & 72.83 \\
\hline CA03-4036 & 37 & 1290 & 4.168 & 3 & 0 & 1.429 & & 95.85 \\
\hline CA03-4037 & 119 & 3480 & 5.911 & 0 & 0 & 0.458 & 6.74 & 36.532 \\
\hline CA03-4038 & 81 & 3190 & 4.941 & 2 & 1 & 1.031 & 5.96 & 75.44 \\
\hline CA03-4039 & 56 & 1530 & 5.194 & 8 & 2 & 1.248 & & 63.52 \\
\hline CA03-4041 & 87 & 2960 & 5.308 & 0 & 0 & 0.983 & & 67.402 \\
\hline CA03-4042 & 93 & 2340 & 5.598 & 1 & 0 & 0.24 & & 13.659 \\
\hline CA03-4043 & 124 & 6000 & 6.04 & 2 & 2 & 0.525 & & 33.31 \\
\hline CA03-4046 & 92 & 2700 & 5.943 & 2 & 0 & 0.396 & & 19.66 \\
\hline CA03-4049 & 87 & 3670 & 5.069 & 0 & 0 & 0.677 & 6.42 & 64.102 \\
\hline CA03-4052 & 122 & 4700 & 6.052 & 3 & 0 & 1.553 & & 62.77 \\
\hline CA03-4071 & 92 & 3260 & 5.752 & 7 & 2 & 1.042 & & 60.34 \\
\hline CA03-4074 & 128 & 5000 & 5.942 & 2 & 0 & 0.25 & & 22.345 \\
\hline CA03-4078 & 127 & 4650 & 5.898 & 3 & 1 & 0.789 & & 48.7 \\
\hline CA03-4080 & 50 & 1270 & 4.967 & 2 & 0 & 1.211 & & 91.64 \\
\hline CA03-4081 & 81 & 2950 & 5.137 & 2 & 0 & 0.694 & & 66.235 \\
\hline CA03-4087 & 122 & 5310 & 5.686 & 2 & 2 & 0.754 & 5.68 & 28.83 \\
\hline CA03-4090 & 102 & 2490 & 6.155 & 5 & 2 & 0.842 & 5.75 & 24.52 \\
\hline CA03-4096 & 100 & 2780 & 6.065 & 0 & 0 & 0.395 & & 37.483 \\
\hline CA03-4099 & 33 & 830 & 4.545 & 2 & 0 & 1.485 & & 95.26 \\
\hline CA03-4101 & 123 & 5430 & 5.784 & 2 & 0 & 0.739 & 6.36 & 53 \\
\hline CA03-4102 & 67 & 2990 & 5.063 & 7 & 2 & 1.288 & & 75.16 \\
\hline CA03-4109 & 102 & 4610 & 5.48 & 3 & 1 & 0.566 & & 47.37 \\
\hline CA03-4113 & 92 & 3810 & 5.23 & 2 & 0 & 0.444 & & 44.132 \\
\hline CA03-4115 & 117 & 5280 & 5.881 & 1 & 0 & 2.33 & & 48.064 \\
\hline CA03-4120 & 59 & 1460 & 4.651 & 0 & 0 & 0.583 & & 56.207 \\
\hline CA03-4122 & 93 & 4860 & 5.249 & 3 & 0 & 0.244 & & 19.88 \\
\hline CA03-4123 & 98 & 3660 & 5.855 & 0 & 0 & 0.747 & & 48.87 \\
\hline
\end{tabular}




\begin{tabular}{|c|c|c|c|c|c|c|c|c|}
\hline Station & $\begin{array}{c}\text { Mean No. } \\
\text { Taxa per } \\
\text { Grab } \\
\left(0.1 \mathrm{~m}^{2}\right)\end{array}$ & $\begin{array}{c}\text { Mean } \\
\text { Density } \\
(\text { all } \\
\left.\text { fauna } / \mathrm{m}^{2}\right) \\
\end{array}$ & $\begin{array}{c}\text { Mean } H^{\prime} \\
\text { per } \\
\text { Grab } \\
\left(0.1 \mathrm{~m}^{2}\right)\end{array}$ & $\begin{array}{l}\text { No. } \\
\text { Chemicals } \\
>\text { ERL }\end{array}$ & $\begin{array}{l}\text { No. } \\
\text { Chemicals } \\
>\text { ERM }\end{array}$ & $\begin{array}{c}\text { TOC } \\
(\%) \\
\end{array}$ & $\begin{array}{c}\mathrm{DO} \\
(\mathrm{mg} / \mathrm{L})\end{array}$ & $\begin{array}{c}\text { Silt+Clay } \\
(\%)\end{array}$ \\
\hline CA03-4126 & 72 & 2490 & 5.207 & 2 & 0 & 0.631 & & 61.187 \\
\hline CA03-4134 & 100 & 3830 & 5.813 & 4 & 2 & 0.957 & 6.1 & 59.31 \\
\hline CA03-4137 & 83 & 4000 & 4.915 & 2 & 0 & 0.361 & & 17.2325 \\
\hline CA03-4150 & 141 & 5220 & 6.152 & 3 & 2 & 0.674 & & 44.54 \\
\hline CA03-4152 & 75 & 2300 & 5.499 & 0 & 0 & 0.955 & & 65.227 \\
\hline CA03-4154 & 55 & 2560 & 4.369 & 0 & 0 & 0.056 & & 2.38 \\
\hline CA03-4155 & 86 & 2020 & 5.888 & 1 & 0 & 2.148 & & 67.266 \\
\hline CA03-4159 & 167 & 5190 & 6.633 & 1 & 0 & 1.231 & & 47.279 \\
\hline CA03-4163 & 160 & 9380 & 5.905 & 2 & 0 & 2.424 & & 26.774 \\
\hline CA03-4164 & 86 & 3650 & 5.043 & 0 & 0 & 0.57 & & 50.64 \\
\hline CA03-4165 & 123 & 4830 & 5.964 & 2 & 0 & 0.58 & 6.11 & 52.58 \\
\hline CA03-4166 & 75 & 3240 & 5.087 & 9 & 2 & 1.769 & & 70.51 \\
\hline CA03-4171 & 119 & 4460 & 5.957 & 1 & 0 & 2.009 & & 14.222 \\
\hline CA03-4172 & 83 & 1900 & 5.746 & 0 & 0 & 0.275 & & 22.048 \\
\hline CA03-4173 & 121 & 3580 & 6.154 & 2 & 0 & 1.748 & 5.81 & 15.669 \\
\hline CA03-4183 & 126 & 6370 & 5.776 & 0 & 0 & 0.828 & & 35.63 \\
\hline CA03-4184 & 91 & 3130 & 5.307 & 0 & 0 & 0.55 & & 51.884 \\
\hline CA03-4185 & 137 & 6260 & 5.774 & 2 & 0 & 0.461 & 6.71 & 32.14 \\
\hline CA03-4186 & 83 & 2630 & 5.514 & 2 & 0 & 0.253 & & 14.07 \\
\hline CA03-4197 & 111 & 3920 & 5.738 & 4 & 2 & 0.844 & 6.51 & 59.33 \\
\hline CA03-4199 & 67 & 1810 & 5.203 & 0 & 0 & 1.082 & & 66.9835 \\
\hline CA03-4204 & 113 & 4430 & 5.636 & 6 & 2 & 1.075 & & 33.35 \\
\hline $\mathrm{CA03-4215}$ & 102 & 3970 & 5.619 & 2 & 0 & 0.28 & & 22.18 \\
\hline CA03-4219 & 86 & 2420 & 5.671 & 2 & 0 & 0.674 & & 75.375 \\
\hline CA03-4226 & 110 & 4150 & 5.711 & 3 & 2 & 0.695 & & 53.42 \\
\hline $\mathrm{CA03-4227}$ & 118 & 5430 & 5.644 & 0 & 0 & 0.675 & & 66.426 \\
\hline CA03-4229 & 105 & 6190 & 4.415 & 2 & 0 & 0.129 & & 3.429 \\
\hline CA03-4230 & 183 & 22980 & 5.137 & 2 & 0 & 1.348 & & 20.574 \\
\hline CA03-4236 & 121 & 4440 & 6.148 & 1 & 0 & 0.195 & & 14.713 \\
\hline CA03-4238 & 128 & 5140 & 5.989 & 5 & 0 & 2.911 & & 21.9545 \\
\hline CA03-4239 & 94 & 3800 & 5.062 & 1 & 0 & 0.551 & & 50.313 \\
\hline CA03-4243 & 101 & 5670 & 4.235 & 0 & 0 & 0.646 & & 50.126 \\
\hline CA03-4245 & 97 & 3030 & 5.781 & 2 & 0 & 0.459 & & 21.85 \\
\hline CA03-4251 & 58 & 1300 & 4.926 & 2 & 0 & 0.185 & & 9.026 \\
\hline CA03-4255 & 97 & 2240 & 6.195 & 0 & 0 & 0.554 & & 44.777 \\
\hline CA03-4260 & 98 & 2750 & 5.903 & 1 & 0 & 0.315 & & 26.375 \\
\hline CA03-4270 & 135 & 5740 & 5.963 & 3 & 2 & 0.782 & & 56.62 \\
\hline CA03-4271 & 85 & 2440 & 5.434 & 2 & 2 & 0.68 & & 21.421 \\
\hline CA03-4273 & 157 & 6730 & 6.279 & 0 & 0 & 0.483 & & 41.356 \\
\hline $\mathrm{CA03-4274}$ & 157 & 9180 & 6.016 & 2 & 0 & 0.308 & & 11.738 \\
\hline CA03-4278 & 150 & 7590 & 6.025 & 2 & 0 & 0.857 & & 57.061 \\
\hline CÁ03-4288 & 75 & 1830 & 5.519 & 0 & 0 & 0.991 & & 65.298 \\
\hline CA03-4291 & 142 & 6640 & 6.07 & 1 & 0 & 0.487 & & 21.254 \\
\hline CA03-4293 & 91 & 2430 & 5.918 & 2 & 0 & 0.256 & & 8.181 \\
\hline CA03-4302 & 85 & 2190 & 5.933 & 0 & 0 & 0.497 & & 39.883 \\
\hline CA03-4303 & 87 & 3390 & 5.321 & 2 & 0 & 0.206 & & 12.89 \\
\hline
\end{tabular}




\begin{tabular}{|c|c|c|c|c|c|c|c|c|}
\hline Station & $\begin{array}{c}\text { Mean No. } \\
\text { Taxa per } \\
\text { Grab } \\
\left(0.1 \mathrm{~m}^{2}\right)\end{array}$ & $\begin{array}{c}\text { Mean } \\
\text { Density } \\
(\text { all } \\
\left.\text { fauna } / \mathrm{m}^{2}\right)\end{array}$ & $\begin{array}{c}\text { Mean } H^{\prime} \\
\text { per } \\
\text { Grab } \\
\left(0.1 \mathrm{~m}^{2}\right)\end{array}$ & $\begin{array}{c}\text { No. } \\
\text { Chemicals } \\
>\text { ERL }\end{array}$ & $\begin{array}{l}\text { No. } \\
\text { Chemicals } \\
>\text { ERM }\end{array}$ & $\begin{array}{l}\text { TOC } \\
(\%)\end{array}$ & $\begin{array}{c}\mathrm{DO} \\
(\mathrm{mg} / \mathrm{L})\end{array}$ & $\begin{array}{c}\text { Silt+Clay } \\
(\%)\end{array}$ \\
\hline CA03-4313 & 128 & 6420 & 5.837 & 4 & 2 & 0.756 & & 43.87 \\
\hline CA03-4315 & 156 & 6290 & 6.406 & 0 & 0 & 1.769 & & 49.581 \\
\hline CA03-4317 & 66 & 1660 & 5.418 & 2 & 0 & 0.33 & & 20.93 \\
\hline CA03-4324 & 119 & 4150 & 5.837 & 2 & 0 & 0.796 & & 24.258 \\
\hline CA03-4329 & 76 & 3070 & 4.955 & 2 & 0 & 0.449 & & 32.15 \\
\hline CA03-4330 & 95 & 2210 & 6.096 & 1 & 0 & 1.297 & & 33.141 \\
\hline CA03-4333 & 116 & 4070 & 5.755 & 2 & 0 & 0.51 & & 63.165 \\
\hline CA03-4334 & 94 & 2900 & 5.941 & 1 & 0 & & & \\
\hline CA03-4339 & 86 & 9520 & 3.915 & 2 & 0 & 2.394 & & 8.316 \\
\hline CA03-4343 & 99 & 3760 & 5.761 & 2 & 2 & 0.44 & & 29.41 \\
\hline CA03-4346 & 117 & 5030 & 5.696 & 3 & 1 & 0.649 & & 50.48 \\
\hline CA03-4350 & 126 & 4620 & 5.798 & 1 & 0 & 0.363 & & 21.786 \\
\hline CA03-4352 & 132 & 5370 & 6.057 & 2 & 0 & 0.454 & & 17.034 \\
\hline CA03-4357 & 93 & 3440 & 5.579 & 0 & 0 & 0.457 & & 46.811 \\
\hline CA03-4365 & 133 & 5670 & 5.856 & 0 & 0 & 0.467 & & 44.477 \\
\hline CA03-4377 & 190 & 14820 & 6.328 & 0 & 0 & 0.564 & & 16.386 \\
\hline CA03-4380 & 119 & 3180 & 6.249 & 1 & 0 & 0.84 & & 46.422 \\
\hline CA03-4389 & 69 & 1560 & 5.26 & 0 & 0 & 2.771 & & 12.8425 \\
\hline CA03-4390 & 52 & 3160 & 3.039 & 2 & 0 & 0.283 & & 11.899 \\
\hline CA03-4396 & 113 & 3200 & 6.166 & 0 & 0 & 1.696 & & 59.782 \\
\hline CA03-4411 & 56 & 1530 & 5.087 & 2 & 0 & 0.552 & & 21.035 \\
\hline CA03-4417 & 105 & 2720 & 5.949 & 1 & 0 & 6.036 & & 7.198 \\
\hline $\mathrm{CA03-4425}$ & 61 & 1300 & 5.502 & 0 & 0 & 2.248 & & 62.78 \\
\hline $\mathrm{CA03-4427}$ & 64 & 1840 & 5.152 & 1 & 0 & 0.891 & & 44.4 \\
\hline CA03-4430 & 108 & 3970 & 5.594 & 0 & 0 & 4.176 & & 14.4555 \\
\hline CA03-4435 & 95 & 2940 & 5.888 & 1 & 0 & 0.455 & & 47.115 \\
\hline CA03-4444 & 115 & 3640 & 5.856 & 4 & 0 & 2.193 & & 20.98 \\
\hline OR03-0001 & 32 & 640 & 4.646 & 1 & 0 & 0.15 & 3.58 & 3.4 \\
\hline OR03-0002 & 83 & 2960 & 5.231 & 1 & 0 & 0.49 & & 17.4 \\
\hline OR03-0003 & 63 & 3030 & 4.436 & 1 & 0 & 0.38 & 2.27 & 18.1 \\
\hline OR03-0004 & 33 & 1490 & 3.38 & 0 & 0 & 0.16 & 2.41 & 2.9 \\
\hline OR03-0005 & 31 & 1060 & 4.296 & 1 & 0 & 0.15 & 3.98 & 4.633333 \\
\hline OR03-0006 & 30 & 1090 & 3.607 & 0 & 0 & 0.055 & 2.81 & 1.1 \\
\hline OR03-0007 & 60 & 2100 & 5.195 & 1 & 0 & 0.7 & 2.71 & 33.6 \\
\hline OR03-0008 & 53 & 1140 & 5.155 & 1 & 0 & 0.18 & & 3 \\
\hline OR03-0009 & 26 & 1160 & 3.924 & 0 & 0 & 0.085 & 2.56 & 1.1 \\
\hline OR03-0011 & 63 & 2030 & 5.01 & 1 & 0 & 0.35 & 3.78 & 14.2 \\
\hline OR03-0012 & 51 & 2300 & 4.242 & 1 & 0 & 0.76 & 2.57 & 39 \\
\hline OR03-0013 & 69 & 4170 & 4.81 & 0 & 0 & 0.39 & & 10.1 \\
\hline OR03-0014 & 38 & 950 & 4.556 & 1 & 0 & 0.1 & 2.78 & 1.5 \\
\hline OR03-0015 & 64 & 4080 & 4.626 & 1 & 0 & 0.12 & 2.6 & 2.5 \\
\hline OR03-0016 & 47 & 1590 & 4.38 & 1 & 0 & 0.34 & & 6.3 \\
\hline OR03-0017 & 37 & 540 & 5.023 & 0 & 0 & 0.15 & & 2.4 \\
\hline OR03-0018 & 100 & 7260 & 4.492 & 2 & 0 & 1.1 & & 26.8 \\
\hline OR03-0019 & 33 & 1250 & 4.222 & 0 & 0 & 0.15 & & 2.7 \\
\hline OR03-0020 & 71 & 3310 & 4.897 & 1 & 0 & 0.615 & 3.44 & 22.9 \\
\hline
\end{tabular}




\begin{tabular}{|c|c|c|c|c|c|c|c|c|}
\hline Station & $\begin{array}{c}\text { Mean No. } \\
\text { Taxa per } \\
\text { Grab } \\
\left(0.1 \mathrm{~m}^{2}\right)\end{array}$ & $\begin{array}{c}\text { Mean } \\
\text { Density } \\
(\text { all } \\
\left.\text { fauna } / \mathrm{m}^{2}\right) \\
\end{array}$ & $\begin{array}{c}\text { Mean } \mathrm{H}^{\prime} \\
\text { per } \\
\text { Grab } \\
\left(0.1 \mathrm{~m}^{2}\right)\end{array}$ & $\begin{array}{l}\text { No. } \\
\text { Chemicals } \\
>\text { ERL }\end{array}$ & $\begin{array}{l}\text { No. } \\
\text { Chemicals } \\
>\text { ERM }\end{array}$ & $\begin{array}{c}\text { TOC } \\
(\%)\end{array}$ & $\begin{array}{c}\mathrm{DO} \\
(\mathrm{mg} / \mathrm{L})\end{array}$ & $\begin{array}{c}\text { Silt+Clay } \\
(\%)\end{array}$ \\
\hline OR03-0021 & 62 & 2050 & 4.847 & 1 & 0 & 0.95 & & 33.2 \\
\hline OR03-0022 & 98 & 4270 & 5.88 & 2 & 0 & 0.6 & 2.76 & 26.8 \\
\hline OR03-0023 & 92 & 3320 & 5.93 & 1 & 0 & 0.55 & 2.82 & 29.3 \\
\hline OR03-0024 & 69 & 2780 & 4.973 & 0 & 0 & 0.345 & & 12.55 \\
\hline OR03-0025 & 35 & 2510 & 3.405 & 0 & 0 & 0.082 & 2.59 & 0.9 \\
\hline OR03-0026 & 45 & 1180 & 4.957 & 0 & 0 & 0.15 & & 2.6 \\
\hline OR03-0027 & 57 & 1980 & 4.931 & 1 & 0 & 1.1 & 2.62 & 37.5 \\
\hline OR03-0028 & 76 & 5320 & 4.651 & 0 & 0 & 0.57 & & 14.2 \\
\hline OR03-0029 & 45 & 1620 & 4.6 & 1 & 0 & 0.084 & & 2 \\
\hline OR03-0030 & 36 & 1960 & 3.839 & 0 & 0 & 0.089 & & 1.55 \\
\hline OR03-0031 & 39 & 760 & 4.696 & 0 & 0 & 0.053 & 2.65 & 1.1 \\
\hline OR03-0032 & 56 & 3390 & 3.592 & 1 & 0 & 0.34 & 4.37 & 12.2 \\
\hline OR03-0033 & 38 & 1000 & 4.685 & 1 & 0 & 1.4 & 2.63 & 49.9 \\
\hline OR03-0034 & 67 & 2010 & 5.302 & 0 & 0 & 0.31 & & 10.3 \\
\hline OR03-0035 & 92 & 3090 & 5.451 & 2 & 0 & 0.76 & & 12.4 \\
\hline OR03-0036 & 90 & 2770 & 5.731 & 2 & 0 & 0.81 & & 20.9 \\
\hline OR03-0037 & 62 & 2750 & 4.845 & 1 & 0 & 0.34 & & 7.7 \\
\hline OR03-0038 & 43 & 900 & 5.027 & 0 & 0 & 0.13 & 2.36 & 2.4 \\
\hline OR03-0039 & 36 & 920 & 4.584 & 0 & 0 & 0.088 & 2.69 & 2 \\
\hline OR03-0040 & 56 & 1700 & 5.203 & 2 & 0 & 0.54 & 2.55 & 27.1 \\
\hline OR03-0041 & 43 & 1760 & 4.647 & 1 & 0 & 0.83 & 3.55 & 49.8 \\
\hline OR03-0042 & 63 & 1580 & 5.356 & 1 & 0 & 0.18 & & 5.2 \\
\hline OR03-0043 & 73 & 1930 & 5.462 & 1 & 0 & 0.5 & 2.58 & 19.3 \\
\hline OR03-0044 & 83 & 2380 & 5.712 & 1 & 0 & 0.45 & 2.47 & 20.6 \\
\hline OR03-0045 & 72 & 4770 & 4.324 & 0 & 0 & 0.29 & & 9.1 \\
\hline OR03-0046 & 28 & 2970 & 3.28 & 1 & 0 & 0.038 & 2.43 & 1.2 \\
\hline OR03-0047 & 19 & 750 & 2.967 & 1 & 0 & 0.039 & & 1.1 \\
\hline OR03-0048 & 59 & 3130 & 4.889 & 1 & 0 & 1.1 & 2.72 & 41.3 \\
\hline OR03-0049 & 54 & 2220 & 4.675 & 0 & 0 & 0.43 & 3.28 & 13.2 \\
\hline OR03-0050 & 27 & 3290 & 3.433 & 1 & 0 & 0.087 & & 2.3 \\
\hline WA03-0001 & 47 & 3550 & 4.132 & 0 & 0 & 0.1 & 4.99 & 3.600487 \\
\hline WA03-0002 & 84 & 4850 & 4.987 & 1 & 0 & 0.335 & 3.47 & 17.02132 \\
\hline WA03-0003 & 55 & 3830 & 3.942 & 0 & 0 & 0.16 & 4.52 & 4.34159 \\
\hline WA03-0004 & 67 & 2570 & 5.016 & 0 & 0 & 1.17 & 2.28 & 42.75506 \\
\hline WA03-0005 & 35 & 1410 & 4.032 & 0 & 0 & 0 & 3.28 & 0.751084 \\
\hline WA03-0006 & 53 & 2440 & 4.592 & 0 & 0 & 0.11 & & 2.447882 \\
\hline WA03-0007 & 44 & 3610 & 3.266 & 1 & 0 & 0 & 3.18 & 1.873989 \\
\hline WA03-0008 & 40 & 1710 & 4.057 & 1 & 0 & 1.3 & 2.78 & 65.2519 \\
\hline WA03-0009 & 61 & 2250 & 4.707 & 0 & 0 & 1.3 & 3.1 & 55.69044 \\
\hline WA03-0010 & 72 & 3710 & 4.933 & 0 & 0 & 0.7 & 3.13 & 19.71789 \\
\hline WA03-0011 & 38 & 3970 & 3.194 & 0 & 0 & 0.12 & 5.68 & 5.568328 \\
\hline WA03-0012 & 71 & 3400 & 4.276 & 0 & 0 & 0.21 & 6.72 & 8.584751 \\
\hline WA03-0013 & 26 & 3850 & 2.037 & 0 & 0 & 0 & 3.27 & 2.59643 \\
\hline WA03-0014 & 30 & 1110 & 4.207 & 0 & 0 & 0.16 & 5.13 & 2.053567 \\
\hline WA03-0015 & 102 & 8620 & 4.723 & 0 & 0 & 0.9 & 2.98 & 25.03443 \\
\hline WA03-0017 & 70 & 9440 & 3.895 & 1 & 0 & 0 & 4.67 & 1.869526 \\
\hline
\end{tabular}




\begin{tabular}{|c|c|c|c|c|c|c|c|c|}
\hline Station & $\begin{array}{c}\text { Mean No. } \\
\text { Taxa per } \\
\text { Grab } \\
\left(0.1 \mathrm{~m}^{2}\right)\end{array}$ & $\begin{array}{c}\text { Mean } \\
\text { Density } \\
(\text { all } \\
\left.\text { fauna } / \mathrm{m}^{2}\right)\end{array}$ & $\begin{array}{c}\text { Mean } H^{\prime} \\
\text { per } \\
\text { Grab } \\
\left(0.1 \mathrm{~m}^{2}\right)\end{array}$ & $\begin{array}{c}\text { No. } \\
\text { Chemicals } \\
>\text { ERL }\end{array}$ & $\begin{array}{c}\text { No. } \\
\text { Chemicals } \\
>\text { ERM }\end{array}$ & $\begin{array}{c}\text { TOC } \\
(\%) \\
\end{array}$ & $\begin{array}{c}\mathrm{DO} \\
(\mathrm{mg} / \mathrm{L})\end{array}$ & $\begin{array}{c}\text { Silt+Clay } \\
(\%)\end{array}$ \\
\hline WA03-0018 & 52 & 4000 & 4.49 & 0 & 0 & 0.33 & 2.58 & 25.94177 \\
\hline WA03-0019 & 46 & 1930 & 4.543 & 0 & 0 & 0 & 3.19 & 1.618769 \\
\hline WA03-0020 & 41 & 3070 & 3.969 & 0 & 0 & 0.24 & 2.9 & 17.6921 \\
\hline WA03-0021 & 75 & 2520 & 5.093 & 0 & 0 & 0.27 & 3.79 & 17.65717 \\
\hline WA03-0022 & 37 & 1780 & 3.966 & 1 & 0 & 0.14 & 4.46 & 4.703177 \\
\hline WA03-0023 & 27 & 1270 & 3.387 & 0 & 0 & 1.4 & 2.45 & 57.00271 \\
\hline WA03-0024 & 30 & 860 & 3.929 & 0 & 0 & 0.13 & 6.45 & 6.431472 \\
\hline WA03-0025 & 43 & 2580 & 4.085 & 0 & 0 & 0.16 & 3.11 & 7.842778 \\
\hline WA03-0026 & 38 & 1430 & 4.347 & 0 & 0 & 1.032 & 2.56 & 58.13735 \\
\hline WA03-0027 & 37 & 2480 & 3.723 & 1 & 0 & 0.14 & 4.28 & 5.368892 \\
\hline WA03-0029 & 44 & 3350 & 4.39 & 0 & 0 & 0 & 5.08 & 0.513504 \\
\hline WA03-0030 & 36 & 1110 & 4.19 & 0 & 0 & 1.32 & 2.97 & 55.00728 \\
\hline WA03-0031 & 72 & 4040 & 4.598 & 0 & 0 & 0.29 & 2.49 & 20.57284 \\
\hline WA03-0032 & 48 & 1510 & 4.854 & 0 & 0 & 1.05 & 3.67 & 60.30199 \\
\hline WA03-0033 & 70 & 3870 & 4.836 & 0 & 0 & 0.52 & 7.28 & 39.08816 \\
\hline WA03-0034 & 90 & 4650 & 4.569 & 0 & 0 & 0.39 & 3.14 & 20.18086 \\
\hline WA03-0035 & 59 & 2400 & 4.563 & 0 & 0 & 1.17 & 2.99 & 53.20249 \\
\hline WA03-0037 & 72 & 2680 & 5.191 & 0 & 0 & 0.54 & 2.31 & 16.90976 \\
\hline WA03-0038 & 52 & 3300 & 3.929 & 0 & 0 & 0.11 & 6.65 & 4.727134 \\
\hline WA03-0039 & 85 & 3500 & 4.757 & 0 & 0 & 0.19 & 8.28 & 7.7529 \\
\hline WA03-0041 & 87 & 3560 & 5.412 & 0 & 0 & 0.27 & 2.89 & 11.44192 \\
\hline WA03-0042 & 23 & 770 & 3.712 & 1 & 0 & 0 & 3.86 & 1.199462 \\
\hline WA03-0043 & 63 & 3320 & 4.707 & 0 & 0 & 0.61 & & 48.8409 \\
\hline WA03-0044 & 83 & 3480 & 5.202 & 0 & 0 & 0.19 & 3.96 & 6.183616 \\
\hline WA03-0046 & 51 & 1830 & 4.507 & 0 & 0 & 0.13 & 6.91 & 4.115209 \\
\hline WA03-0047 & 56 & 3780 & 4.43 & 0 & 0 & 0.25 & 3.02 & 19.79299 \\
\hline WA03-0048 & 41 & 1390 & 4.164 & 0 & 0 & 1.01 & 2.62 & 61.43117 \\
\hline WA03-0051 & 99 & 4970 & 4.961 & 0 & 0 & 0.38 & 3.63 & 28.98603 \\
\hline WA03-0053 & 63 & 5700 & 3.931 & 1 & 0 & 0.1 & 4.67 & 2.172309 \\
\hline WA03-0060 & 49 & 3470 & 4.297 & 1 & 0 & 0 & 4.45 & 6.915079 \\
\hline WA03-0068 & 41 & 16060 & 2.25 & 0 & 0 & 0.13 & 3.53 & 4.089049 \\
\hline WA03-0070 & 42 & 2850 & 3.44 & 0 & 0 & 0 & 3.66 & 0.650744 \\
\hline WA03-0081 & 74 & 3340 & 4.649 & 0 & 0 & 0.74 & 2.56 & 21.87764 \\
\hline WA03-0086 & 95 & 6200 & 4.545 & 0 & 0 & 0.73 & 2.58 & 25.80202 \\
\hline
\end{tabular}




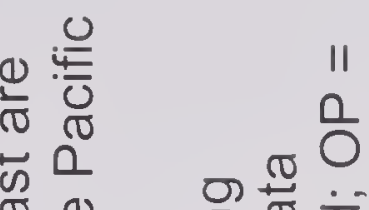

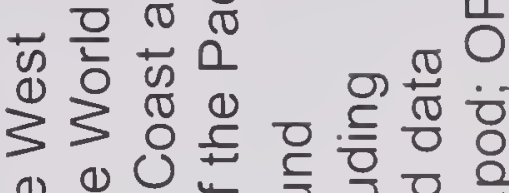

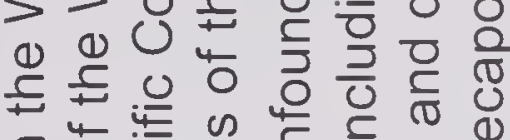
$\subseteq 40$. क थ ब हो ब 응 की क西 $0 \times 1$

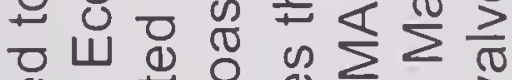

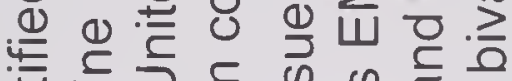
航

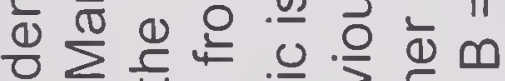
त 0 O

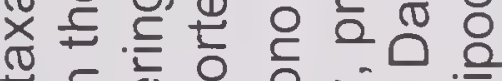

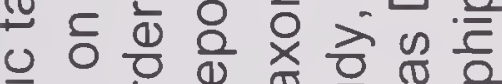
힝헤

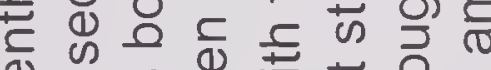

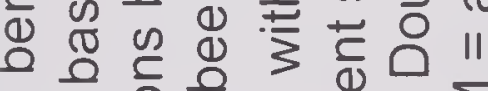
다응 0 o

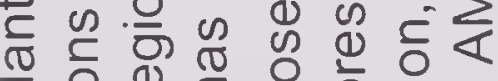
응 今.

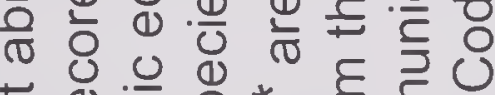

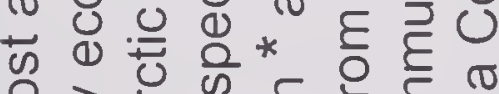

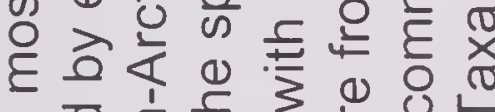

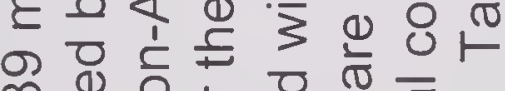

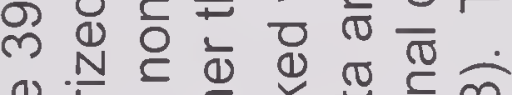

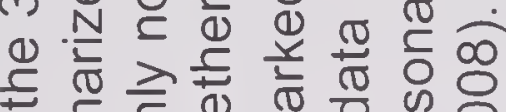

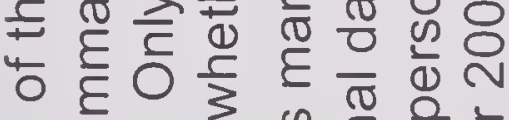

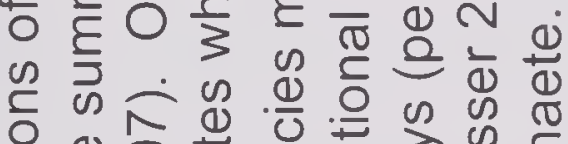

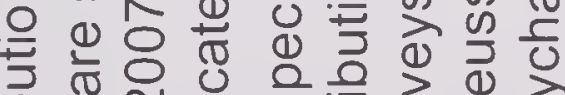

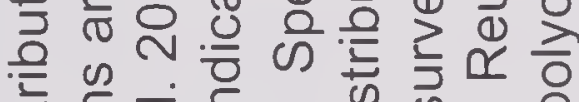
는 㕸. 음 으의.

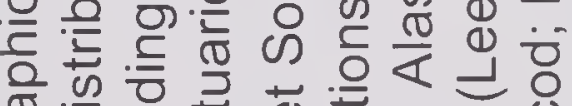
西

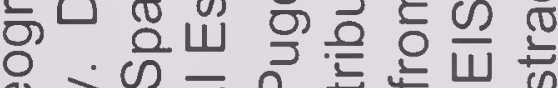
o 일

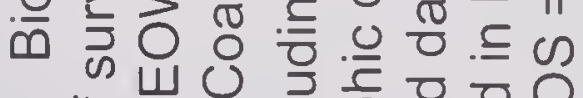

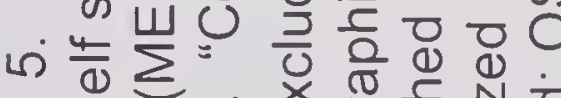
势 का

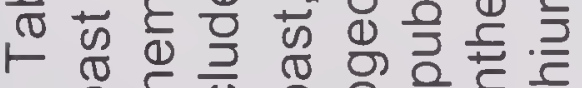

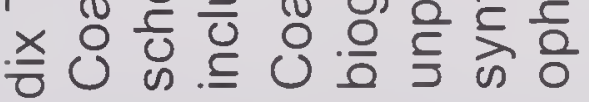
递

\begin{tabular}{|c|c|c|c|c|c|c|c|c|c|c|c|}
\hline 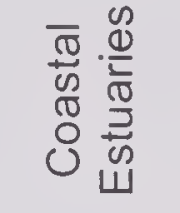 & $\stackrel{\infty}{>}$ & $\stackrel{\infty}{\succ}$ & $\stackrel{0}{\mathbf{z}}$ & $\stackrel{\infty}{\nu}$ & $\stackrel{\infty}{\nu}$ & $\underbrace{\infty}$ & $\stackrel{\infty}{\circlearrowright}$ & $\stackrel{\infty}{\nu}$ & $\stackrel{\infty}{\nu}$ & 20 & $\stackrel{\mathscr{D}}{>}^{\mathbb{N}}$ \\
\hline 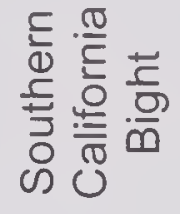 & $\stackrel{\mathscr{0}}{\succ}$ & $\stackrel{\infty}{\nu}$ & $\mid \begin{array}{c}\infty \\
\stackrel{\infty}{\succ}\end{array}$ & $\stackrel{\infty}{>}$ & 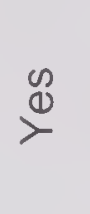 & $\stackrel{\infty}{\succ}$ & $\stackrel{\infty}{\nu}$ & $\stackrel{\infty}{\nu}$ & $\stackrel{\mathscr{D}}{\nu}$ & $\left|\begin{array}{c}\mathscr{D} \\
\succ\end{array}\right|$ & $\stackrel{\circ}{z}$ \\
\hline 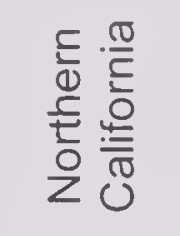 & $\stackrel{\infty}{\stackrel{\infty}{\nu}^{-}}$ & $\stackrel{\mathbb{D}}{\succ}$ & $\mid \begin{array}{l}\mathscr{D} \\
\stackrel{\succ}{\succ}\end{array}$ & $\stackrel{\infty}{>}$ & $\stackrel{\infty}{\stackrel{\infty}{\nu}}$ & $\stackrel{\infty}{\nu}$ & $\stackrel{\infty}{\nu}$ & $\stackrel{\infty}{\nu}^{\infty}$ & $\stackrel{\infty}{\nu}^{\infty}$ & $\left|\begin{array}{c}\mathscr{D} \\
\searrow\end{array}\right|$ & $\stackrel{\mathbb{D}}{\nu}$ \\
\hline
\end{tabular}

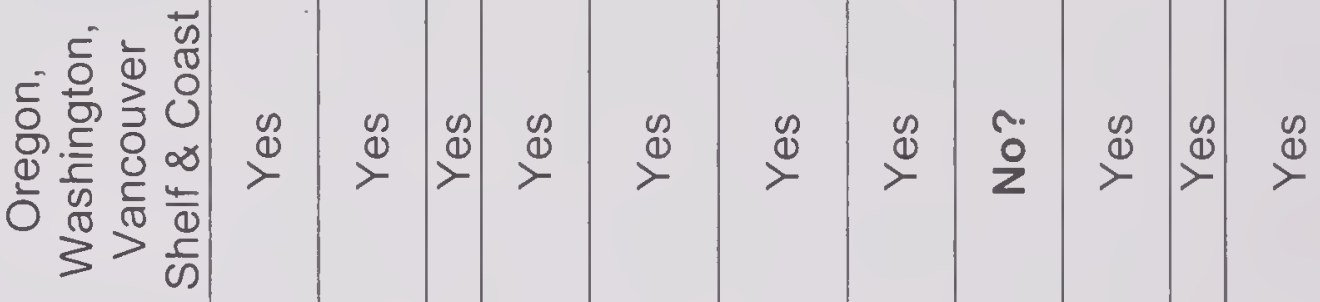

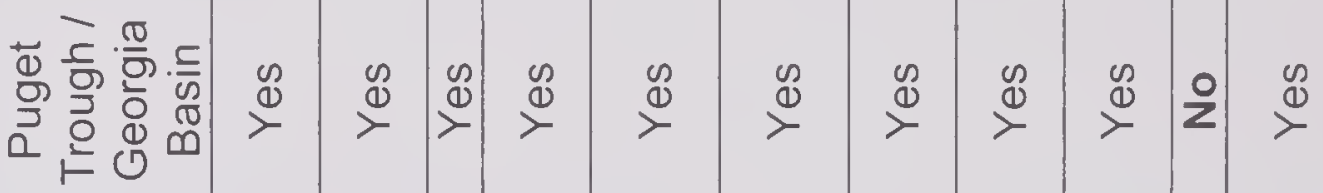

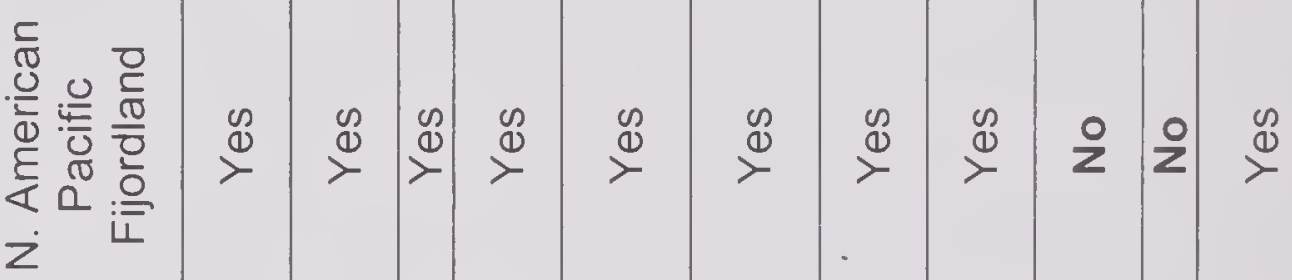

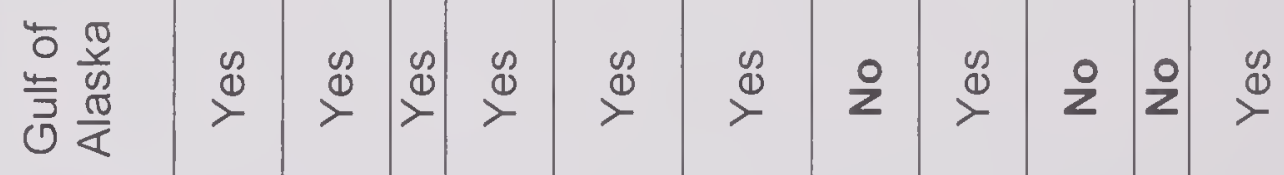

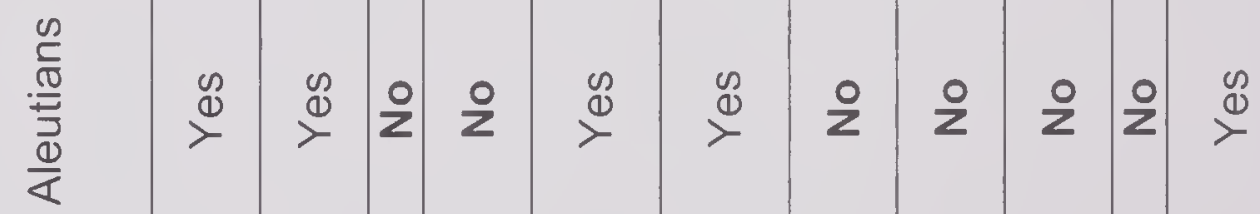

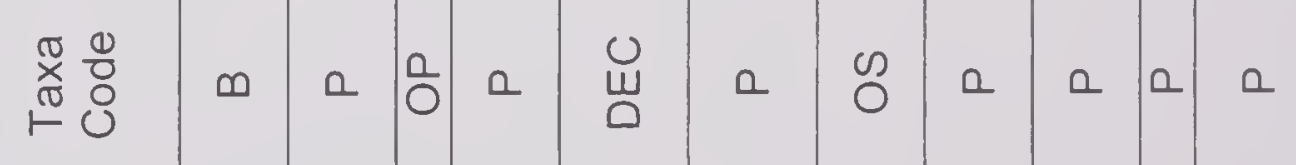

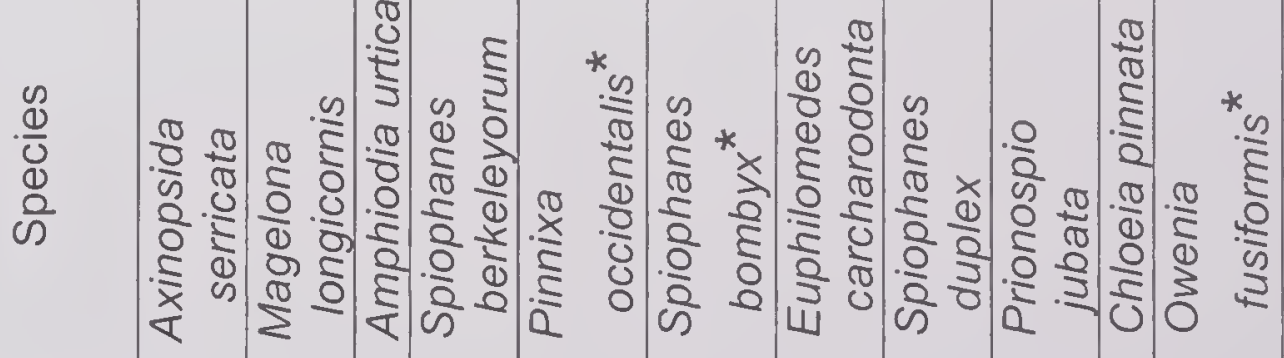




\begin{tabular}{|c|c|c|c|c|c|c|c|c|c|c|c|c|c|c|c|c|c|}
\hline 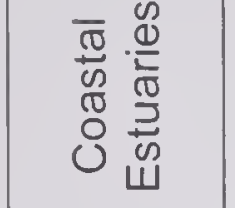 & 울 & $\stackrel{\mathscr{U}}{\searrow}$ & $\stackrel{\mathscr{J}}{\check{\nu}}$ & $\stackrel{\mathscr{d}}{\check{\nu}}$ & $\stackrel{\mathscr{J}}{\check{\nu}}$ & $\stackrel{\mathscr{D}}{\stackrel{D}{\succ}}$ & $\stackrel{\mathscr{C}}{\supset}$ & $\stackrel{\mathscr{D}}{\supset}$ & 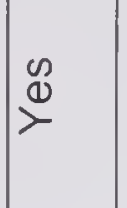 & $\stackrel{\mathscr{D}}{\nu}$ & $\stackrel{\mathbb{N}}{\nu}$ & o̊. & $\stackrel{\mathscr{\infty}}{\nu}$ & $\stackrel{\mathscr{D}}{\succ}$ & $\stackrel{\mathscr{d}}{\check{\nu}}$ & 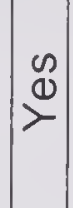 & $\stackrel{\mathscr{D}}{\supset}$ \\
\hline 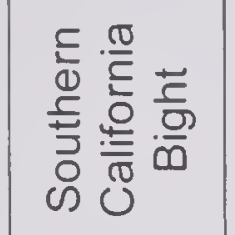 & $\stackrel{\infty}{\stackrel{\infty}{\nu}}$ & $\stackrel{\mathscr{J}}{\succ}$ & $\stackrel{\mathscr{N}}{\nu}$ & $\stackrel{\infty}{\mathcal{D}}$ & $\stackrel{\mathscr{D}}{\nu}$ & 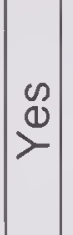 & 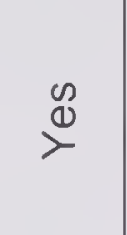 & $\stackrel{\mathbb{D}}{\supset}$ & $\stackrel{\infty}{\stackrel{\infty}{\perp}}$ & $\stackrel{\mathscr{d}}{\check{\nu}}$ & $\stackrel{\mathscr{J}}{\nu}$ & $\stackrel{\mathscr{2}}{\check{\nu}}$ & $\stackrel{\mathscr{D}}{\succ}$ & $\stackrel{\mathscr{J}}{\supset}$ & $\stackrel{\infty}{\infty}$ & $\begin{array}{c}\infty \\
\mathbb{d} \\
\nu\end{array}$ & $\stackrel{\infty}{\stackrel{\infty}{\nu}}$ \\
\hline 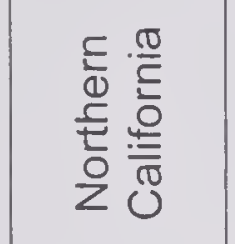 & $\stackrel{\mathbb{d}}{>}$ & $\stackrel{\mathscr{d}}{\nu}$ & $\stackrel{\mathscr{J}}{\supset}$ & $\stackrel{\mathscr{d}}{\check{\nu}}$ & $\stackrel{\mathscr{J}}{\nu}$ & $\stackrel{\mathscr{D}}{\searrow}$ & $\stackrel{\infty}{\stackrel{\infty}{\nu}}$ & $\stackrel{\mathscr{D}}{\supset}$ & 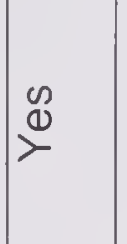 & $\stackrel{\mathscr{D}}{>}$ & $\stackrel{\infty}{\infty}$ & $\stackrel{\infty}{\nu}$ & $\begin{array}{l}\mathscr{D} \\
\stackrel{\infty}{\nu}\end{array}$ & $\stackrel{\mathscr{d}}{\check{\infty}}$ & $\stackrel{\mathbb{N}}{\supset}$ & $\begin{array}{l}\infty \\
\mathbb{2} \\
\nu\end{array}$ & $\underset{\nu}{\mathscr{D}}$ \\
\hline 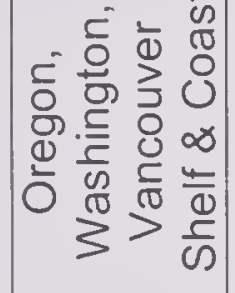 & 운 & $\stackrel{\infty}{\infty}$ & $\stackrel{\mathscr{N}}{\stackrel{\infty}{2}}$ & $\stackrel{\infty}{\infty}$ & $\stackrel{\mathscr{D}}{\nu}$ & $\left|\begin{array}{c}0 \\
\infty \\
>\end{array}\right|$ & $\stackrel{\mathscr{N}}{\nu}$ & $\stackrel{\mathbb{N}}{\nu}$ & $\stackrel{\infty}{\infty}$ & $\stackrel{\mathscr{N}}{\mathcal{\infty}}$ & $\stackrel{\mathbb{N}}{\nu}$ & $\stackrel{\Perp}{\perp}$ & $\mid \begin{array}{l}\mathscr{D} \\
\searrow\end{array}$ & $\stackrel{\mathscr{D}}{\nu}$ & $\stackrel{\infty}{\infty}$ & 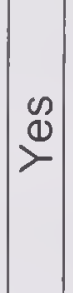 & 울 \\
\hline 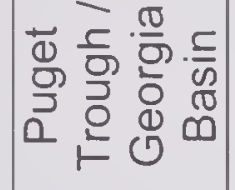 & 운 & $\stackrel{\infty}{\infty}$ & $\stackrel{\mathscr{U}}{\check{\nu}}$ & $\stackrel{\mathscr{N}}{\nu}$ & $\stackrel{\mathscr{N}}{>}$ & $\mid \begin{array}{c}0 \\
\infty \\
>\end{array}$ & $\stackrel{\mathscr{C}}{\check{\nu}}$ & $\stackrel{\infty}{\infty}$ & $\stackrel{\infty}{\infty}$ & $\stackrel{\mathscr{D}}{2}$ & $\stackrel{\mathscr{C}}{\check{\nu}}$ & $\stackrel{\Perp}{2}$ & $\stackrel{\mathscr{N}}{\stackrel{\infty}{2}}$ & $\stackrel{\mathscr{D}}{\check{\nu}}$ & 울 & $\mid \begin{array}{c}0 \\
\mathbb{1} \\
>\end{array}$ & i \\
\hline 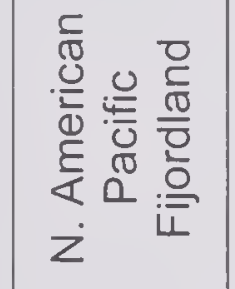 & 운 & $\stackrel{\infty}{\infty}$ & $\stackrel{\infty}{\infty}$ & $\stackrel{\mathbb{D}}{\nu}$ & $\stackrel{\infty}{\infty}$ & $\begin{array}{c}0 \\
\infty \\
\nu\end{array}$ & $\stackrel{\mathbb{d}}{\nu}$ & $\stackrel{\infty}{\infty}$ & $\stackrel{\mathscr{N}}{\mathcal{1}}$ & 울 & $\stackrel{\mathscr{D}}{>}$ & $\stackrel{\mathscr{d}}{\check{x}}$ & $\left|\begin{array}{l}\infty \\
\mathbb{D} \\
>\end{array}\right|$ & 울 & 운 & $\left|\begin{array}{l}0 \\
1 \\
>\end{array}\right|$ & 운 \\
\hline 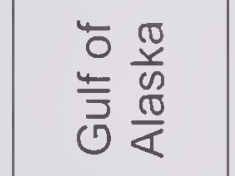 & ㅇ & $\stackrel{\mathbb{N}}{\nu}$ & $\underset{\mathcal{D}}{\mathscr{O}}$ & 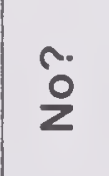 & i & i & i & $\underset{\nu}{\mathbb{N}}$ & $\stackrel{\mathscr{d}}{\stackrel{1}{2}}$ & 운 & $\stackrel{\mathscr{N}}{>}$ & $\stackrel{\mathscr{d}}{>}$ & 之o & 운 & 운 & $\mid \begin{array}{c}0 \\
\stackrel{2}{二}\end{array}$ & $\stackrel{\ddot{w}}{\stackrel{\tilde{D}}{\nu}}$ \\
\hline 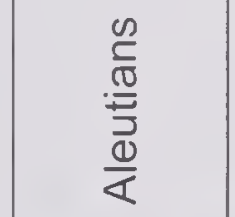 & z & $\stackrel{\mathscr{d}}{>}$ & 운 & $\stackrel{\mathscr{D}}{\succ}$ & 운 & 20 & z & z & $\stackrel{\mathscr{N}}{\underset{\nu}{2}}$ & 운 & 운 & $\stackrel{\infty}{2}$ & 之) & 운 & 운 & 20 & 운 \\
\hline 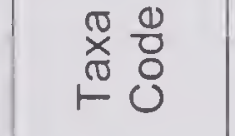 & a & Q & $\varangle$ & ‥ & a. & 0 & 0 & 0 & $\infty$ & 0 & 0 & $\sum_{<}$ & 0 & a & a & $0 \mid$ & a. \\
\hline 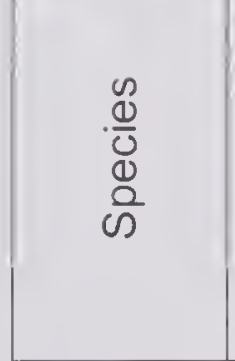 & 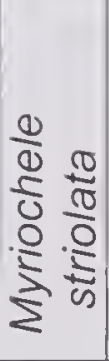 & 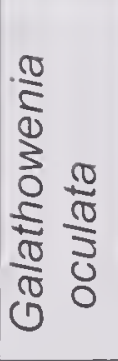 & 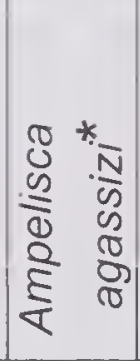 & 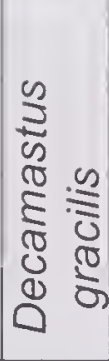 & 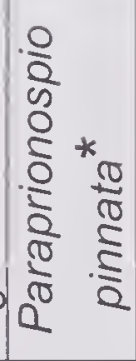 & \begin{tabular}{|l}
1 \\
5 \\
0 \\
0 \\
5 \\
0 \\
0 \\
0 \\
0 \\
5
\end{tabular} & 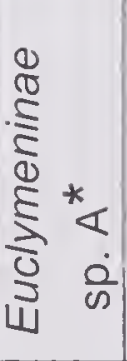 & 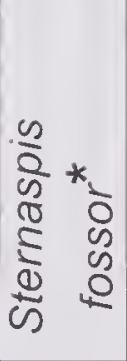 & 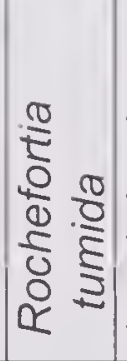 & 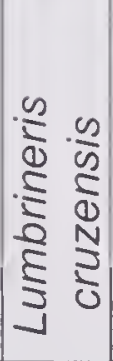 & 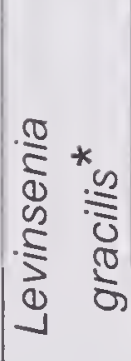 & 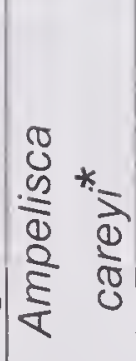 & $\mid \begin{array}{l}* \\
0 \\
\frac{0}{0} \\
\frac{\pi}{0} \\
0 \\
0 \\
0 \\
0 \\
\frac{0}{2}\end{array}$ & $\begin{array}{l}\frac{1}{2} \\
\frac{\pi}{2} \\
\frac{\pi}{2} \\
\frac{\pi}{2} \\
\frac{\pi}{2} \\
\frac{\pi}{2} \\
\frac{\pi}{2} \\
\frac{\pi}{2}\end{array}$ & 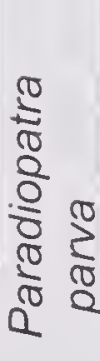 & $\begin{array}{l}0 \\
0 \\
0 \\
0 \\
0 \\
0 \\
0 \\
0 \\
0 \\
0 \\
0 \\
0 \\
0\end{array}$ & 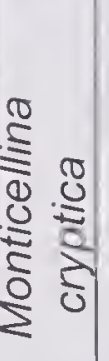 \\
\hline
\end{tabular}




\begin{tabular}{|c|c|c|c|c|c|c|c|c|c|c|c|c|c|}
\hline 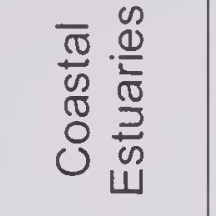 & $\stackrel{\infty}{\infty}$ & $\stackrel{\mathscr{\infty}}{\succ}$ & $\stackrel{\infty}{\infty}$ & $\stackrel{\infty}{\infty}$ & $\stackrel{\infty}{\infty}$ & 운 & $\stackrel{\mathscr{J}}{\succ}$ & 20 & $\stackrel{\infty}{\succ}$ & $\stackrel{\mathscr{\infty}}{\succ}$ & $\stackrel{\mathbb{D}}{>}$ & mె & $\stackrel{\infty}{-}$ \\
\hline 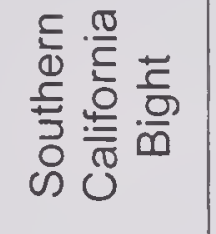 & $\stackrel{\mathscr{1}}{\succ}$ & $\stackrel{\mathscr{D}}{\nu}$ & $\stackrel{\infty}{\infty}$ & $\stackrel{\mathscr{1}}{\succ}$ & $\stackrel{\infty}{\stackrel{\infty}{\swarrow}}$ & i & $\stackrel{\infty}{\infty}$ & $\stackrel{0}{\infty}$ & $\stackrel{\infty}{\varnothing}$ & $\stackrel{\infty}{>}$ & $\stackrel{\mathscr{1}}{>}$ & $\hat{m}$ & N \\
\hline 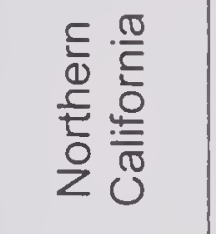 & $\stackrel{\infty}{\varnothing}$ & 운 & $\stackrel{\infty}{0}$ & $\stackrel{\mathscr{D}}{\supset}$ & $\stackrel{\infty}{\infty}$ & 울 & 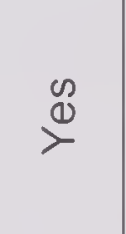 & $\mid \begin{array}{l}0 \\
0 \\
>\end{array}$ & $\stackrel{\infty}{\infty}$ & $\stackrel{\infty}{\perp}$ & $\stackrel{\infty}{2}$ & $\hat{m}$ & $\bar{v}$ \\
\hline 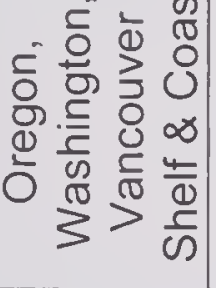 & i & 운 & $\stackrel{\infty}{\infty}$ & $\stackrel{\infty}{\infty}$ & $\stackrel{\mathscr{d}}{\succ}$ & $\stackrel{\infty}{\infty}$ & $\stackrel{\mathscr{d}}{\succ}$ & $\mid \begin{array}{l}0 \\
0 \\
>\end{array}$ & $\stackrel{\mathscr{D}}{\check{\nu}}$ & $\stackrel{\infty}{\infty}$ & $\stackrel{\infty}{\infty}$ & ले & $\stackrel{\sigma}{-}$ \\
\hline 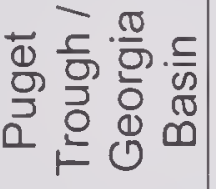 & $\stackrel{\mathscr{1}}{>}$ & z & $\stackrel{\infty}{0}$ & $\stackrel{\mathscr{U}}{\circlearrowright}$ & $\stackrel{\infty}{\stackrel{\infty}{\succ}}$ & $\stackrel{\infty}{\infty}$ & $\stackrel{\mathscr{d}}{>}$ & $\stackrel{\infty}{\infty}$ & $\stackrel{\infty}{\infty}$ & $\stackrel{\mathscr{d}}{\stackrel{1}{\succ}}$ & $\stackrel{\mathscr{J}}{\nu}$ & ले & $\stackrel{\infty}{-}$ \\
\hline 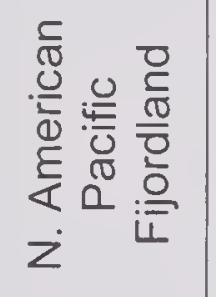 & 울 & $\stackrel{0}{z}$ & $\stackrel{\infty}{\infty}$ & $\stackrel{\mathscr{D}}{2}$ & $\stackrel{\infty}{\stackrel{\infty}{\succ}}$ & 운 & $\stackrel{\infty}{\infty}$ & $\stackrel{\substack{\infty \\
\searrow}}{>}$ & $\stackrel{\mathbb{N}}{\mathbb{2}}$ & ô & $\stackrel{\infty}{\infty}$ & $\stackrel{\infty}{\sim}$ & $\stackrel{m}{\longrightarrow}$ \\
\hline $\begin{array}{l}40 \\
0 \frac{1}{0} \\
\frac{1}{5} \\
0 \frac{0}{6}\end{array}$ & 우 & z & $\stackrel{\mathscr{N}}{\mathcal{D}}$ & $\stackrel{\mathscr{J}}{\circlearrowright}$ & $\stackrel{\mathscr{d}}{\check{D}}$ & z & 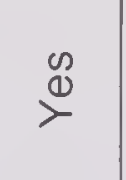 & $\left|\begin{array}{c}0 \\
0 \\
>\end{array}\right|$ & i & $\stackrel{\infty}{\infty}$ & $\stackrel{\infty}{\infty}$ & $\stackrel{\sim}{\sim}$ & $\stackrel{N}{\sim}$ \\
\hline $\begin{array}{l}\frac{0}{.} \\
\frac{.0}{5} \\
\frac{0}{2} \\
\frac{0}{4}\end{array}$ & z & z & $\stackrel{\mathscr{d}}{2}$ & 울 & $\stackrel{\infty}{2}$ & 울 & 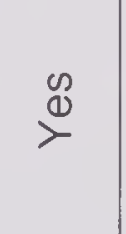 & $\mid \begin{array}{c}0 \\
\mathbb{2} \\
>\end{array}$ & 운 & $\stackrel{\mathscr{D}}{>}$ & 운 & 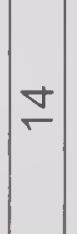 & $\lambda$ \\
\hline 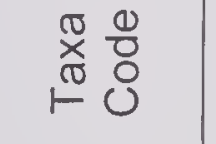 & 0 & 0 & 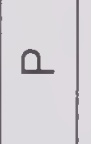 & 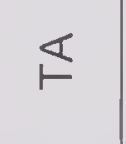 & 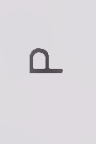 & $\sum_{<}$ & Q & $\infty$ & Q & 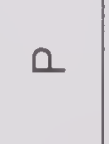 & $\sum_{\alpha}$ & लి & $\stackrel{\nabla}{\sim}$ \\
\hline 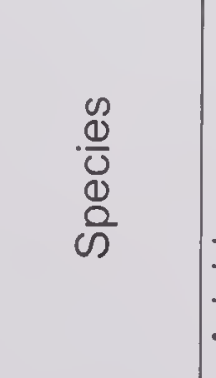 & 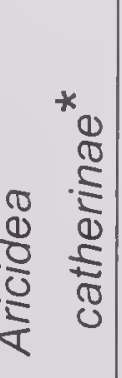 & 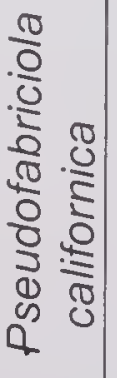 & 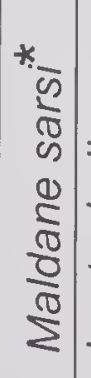 & 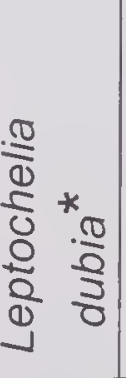 & 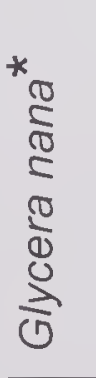 & 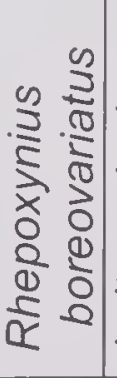 & 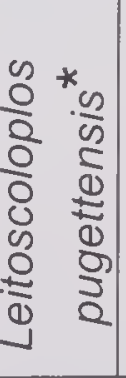 & 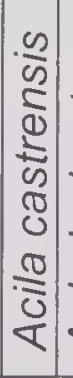 & 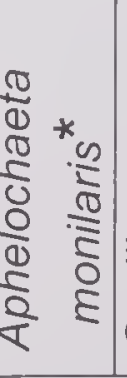 & 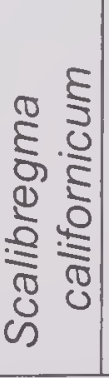 & 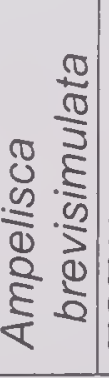 & $\underset{1}{2}$ & 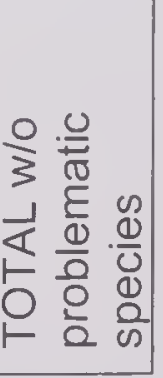 \\
\hline
\end{tabular}





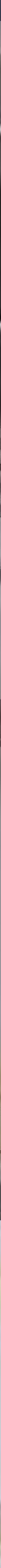

\section{\&EPA}

United States

Environmental Protection

Agency

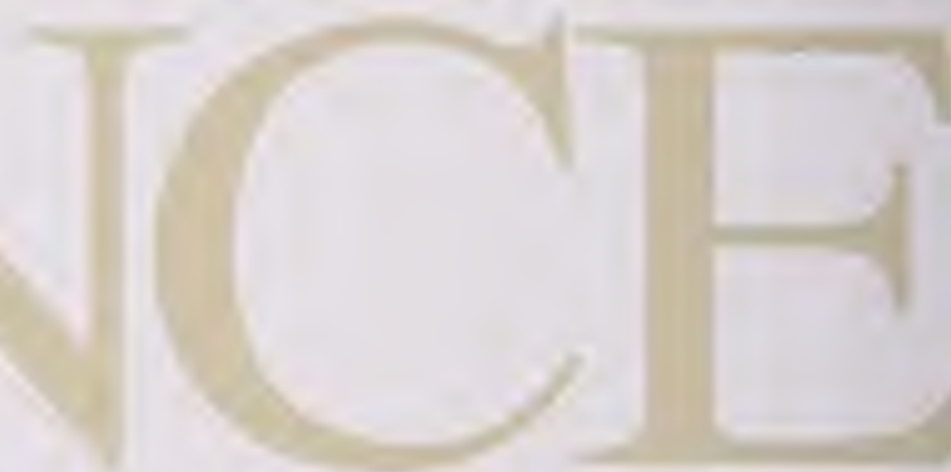

\section{PRESORTED STANDARD POSTAGE \& FEES PAID EPA \\ PERMIT NO. G-35}

Office of Research and Development (8101R)

Washington, DC 20460

Official Business

Penalty for Private Use

$\$ 300$ 